\title{
Model Based Enterprise / Technical Data Package Summit Report
}

Joshua Lubell

Kenway Chen

John Horst

Simon Frechette

Paul Huang

http://dx.doi.org/10.6028/NIST.TN.1753

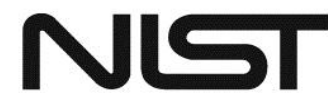

National Institute of Standards and Technology U.S. Department of Commerce 


\title{
Model Based Enterprise / Technical Data Package Summit Report
}

\author{
Joshua Lubell \\ Kenway Chen \\ Simon Frechette \\ Systems Integration Division \\ Engineering Laboratory \\ John Horst \\ Intelligent Systems Division \\ Engineering Laboratory \\ Paul Huang \\ United States Army Research Laboratory \\ http://dx.doi.org/10.6028/NIST.TN.1753
}

August 2012

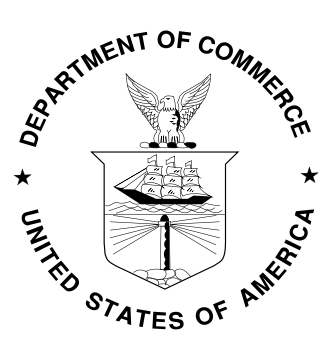

U.S. Department of Commerce

Rebecca M. Blank, Acting Secretary

National Institute of Standards and Technology Patrick D. Gallagher, Under Secretary of Commerce for Standards and Technology and Director 
Certain commercial entities, equipment, or materials may be identified in this document in order to describe an experimental procedure or concept adequately. Such identification is not intended to imply recommendation or endorsement by the National Institute of Standards and Technology, nor is it intended to imply that the entities, materials, or equipment are necessarily the best available for the purpose.

National Institute of Standards and Technology Technical Note 1753 Natl. Inst. Stand. Technol. Tech. Note 1753, 111 pages (August, 2012) http://dx.doi.org/10.6028/NISTTN.1753

CODEN: NTNOEF 


\begin{abstract}
This report summarizes the presentations, discussions and recommendations from the ModelBased Enterprise Summit held at the National Institute of Standards and Technology in December of 2011. The purpose of the Summit was to identify challenges, research, implementation issues, and lessons learned in manufacturing and quality assurance where a digital three-dimensional (3D) model of the product serves as the authoritative information source for all activities in the product's lifecycle. The report includes an overview of modelbased engineering, technical challenges, summaries of the presentations given at the workshop, and conclusions that emerged from the presentations and discussions.
\end{abstract}

\title{
Acknowledgment
}

We wish to acknowledge the individuals who organized and participated in the Model Based Engineering / Technical Data Package Summit - particularly those who presented to the group as a whole, many of whom provided comments and suggestions on an earlier draft of this document. We would like to acknowledge Richard Neal, whose meeting notes were invaluable in writing the presentation summaries in this report, and Roy Whittenburg for his thorough review of this document.

\section{Keywords}

Model-based, manufacturing, quality, MBE, MBD, technical data package 


\section{Introduction}

The National Institute of Standards and Technology (NIST) Engineering Laboratory and the Office of the Secretary of Defense (OSD) hosted the third annual Model-based Enterprise and Technical Data Package ${ }^{1}$ (MBE/TDP) Summit from December 12 through December 15, 2011, at NIST. Over 150 participants from industry and government met to share the latest technological developments and best practices for model-based engineering (MBE) ${ }^{2}$, and to continue work on a new version of the MIL-STD-31000 Technical Data Package (TDP) standard [1] to include requirements for 3D models. The Department of Defense (DoD) Engineering Drawing and Modeling Working Group is responsible for updating MIL-STD-31000 to support delivery of model-based technical data for defense systems. Table 1 lists the organizations that attended the Summit.

The Summit consisted of a series of technical presentations focusing on different aspects of model-based engineering. The summit included separate working group meetings devoted to revising MIL-STD-31000 and related DoD standards. This report is concerned with the technical presentations and technical discussions related to MBE. The results and materials from the MIL standards working group meetings are not included in this report.

Section 1 of the report provides a brief introduction. Section 2 describes the main concepts of $\mathrm{MBE}$ and its advantages for manufacturing. Section 3 highlights technical challenges to adopting MBE in manufacturing. Section 4 summarizes each of the technical presentations. Conclusions and recommendations are in Section 5. The appendix contains a table of acronyms used in the report, agenda, and all presentations approved for public distribution. ${ }^{3}$

\footnotetext{
${ }^{1}$ The Technical Data Package (TDP) is the collection of all product data needed to manufacture and maintain the product.

${ }^{2}$ Model-based "Enterprise" and Model-based "Engineering" are often treated as interchangeable terms. For the purposes of this document, we define the terms as follows.

- $\quad$ Model-Based Engineering - an approach to product development, manufacturing, and lifecycle support that uses a digital model to drive all engineering activities.

- $\quad$ Model-Based Enterprise - an organization that uses model-based engineering.

${ }^{3}$ Those not included were not approved as of the publication of this Technical Note.
} 
Table 1. Organizations participating in the Summit

\begin{tabular}{|c|c|}
\hline ACIT & Action Engineering \\
\hline Aerospace Industries Association (AIA) & Anark Corporation \\
\hline $\begin{array}{l}\text { South Carolina Research Authority } \\
\text { (SCRA) }\end{array}$ & Autodesk, Inc. \\
\hline Automation Alley & $\begin{array}{l}\text { B\&W Y-12, LLC National Security } \\
\text { Complex }\end{array}$ \\
\hline BAE Systems & Bell Helicopter Textron \\
\hline Boeing Company & CT Core Technologies \\
\hline Dassault Systemes & Decision / Analysis Partners \\
\hline Defense Logistics Agency & GE Energy \\
\hline Honeywell & ICF International \\
\hline Imagecom, Inc. & ITI TranscenData \\
\hline Jacobs Engineering & Jotne North America Inc. \\
\hline L-3 Combat Propulsion Systems & LMI Government Consulting \\
\hline Lockheed Martin Missiles \& Fire Control & Lucrum Group \\
\hline Metrosage LLC & Mitutoyo America Corporation \\
\hline $\begin{array}{l}\text { National Institute of Standards and } \\
\text { Technology }\end{array}$ & Nextec Applications Inc. \\
\hline Northrop Grumman Technical Services & OSD Manufacturing Technology \\
\hline Peerless Technologies Corporation & Pratt \& Whitney \\
\hline PTC & Raytheon Company \\
\hline RECON Services/Army & Renaissance Services, Inc. \\
\hline Renishaw PLC & Rolls-Royce North America \\
\hline Sandia National Laboratories & Siemens PLM Software Inc. \\
\hline Spatial Integrated Systems, Inc. & TSR Optima \\
\hline U.S. Air Force & U.S. Air Force Research Laboratory \\
\hline $\begin{array}{l}\text { U.S. Air Force Warner Robins Air } \\
\text { Logistics Center (WR-ALC) }\end{array}$ & $\begin{array}{l}\text { U.S. Army Armament Research, } \\
\text { Development and Engineering Center } \\
\text { (ARDEC) }\end{array}$ \\
\hline $\begin{array}{l}\text { U.S. Army Materiel Command Logistics } \\
\text { Support Activity (USAMC LOGSA) }\end{array}$ & $\begin{array}{l}\text { U.S. Army Research, Development and } \\
\text { Engineering Command (RDECOM) }\end{array}$ \\
\hline U.S. Army Research Laboratory & $\begin{array}{l}\text { U.S. Army Tank Automotive Research, } \\
\text { Development and Engineering Center } \\
\text { (TARDEC) }\end{array}$ \\
\hline U.S. Coast Guard & U.S. Marine Corps \\
\hline $\begin{array}{l}\text { U.S. Naval Air Systems Command } \\
\text { (NAVAIR) }\end{array}$ & $\begin{array}{l}\text { U.S. Naval Facilities Expeditionary } \\
\text { Logistics Center (NFELC) }\end{array}$ \\
\hline $\begin{array}{l}\text { U.S. Naval Sea Systems Command } \\
\text { (NAVSEA) }\end{array}$ & \\
\hline
\end{tabular}




\section{Model-Based Engineering}

Until recently, most engineering and manufacturing activities relied on hardcopy and/or digital documents (including 2D drawings) to convey engineering data and to drive manufacturing processes. With the advent of new manufacturing data format standards and more powerful engineering software, it is now possible to perform all engineering functions using data models. The model-based engineering (MBE) approach uses these models rather than documents as the data source for all engineering activities throughout the product life cycle. The core MBE tenet is that models are used to drive all aspects of the product lifecycle and that data is created once and reused by all downstream data consumers.

A model is a representation or idealization of the structure, behavior, operation, or other characteristics of a real-world system. A model is used to convey design information, simulate real world behavior, or specify a process. Engineers use models to convey product definition or otherwise define a product's form, fit and function. In MBE, models can be applicable to a wide range of domains (systems, software, electronics, mechanics, human behavior, logistics, and manufacturing). Models can be either computational or descriptive. Computational models are meant for computer interpretation and have a machine-readable format and syntax. Descriptive models are human interpretable and meant for human consumption (symbolic representation and presentation). Core to MBE is the integration of descriptive models with computational models. Computer aided design (CAD) models used in manufacturing are a good example. Early CAD models were meant only for human viewing. Today, CAD models can be directly interpreted by other engineering software applications. A variety of standard interchange formats now exist to enable application-to-application transfer of engineering data.

In the context of manufacturing, model data drives production and quality processes. A product model used in manufacturing is a container not only of the nominal geometry, but also of any additional information needed for production and support. This additional data, known as Product Manufacturing Information (PMI), may include geometric dimensions and tolerances (GD\&T), material specifications, component lists, process specifications, and inspection requirements.

Two critical factors give MBE significant advantages over drawing-based or document-based engineering: 1) computer interpretability and 2) data associativity. The primary reason to use a data model in engineering and manufacturing is that a model can be processed directly by engineering software applications. In a document-based environment, humans must interpret the engineering documents and then enter the information into the specific user interface of each engineering application. Whether it is finite element analysis (FEA) or computer aided manufacturing (CAM), each application creates its own internal model. In the past, the only access to this model was through the application's user interface (keyboard and screen). With 
MBE, the applications read and write the models directly. This results in fewer errors and a drastic reduction in processing time.

Data associativity is critical to model integrity. Data association within and between documents is very difficult to maintain. Tolerances, material specifications, surface finish, hardness, and other information must be associated with specific features in the model. In analysis models, for example, boundary conditions are associated with the point at which they act. In assembly models, components must be associated with and oriented toward mating components. Data associativity is critical for model interpretation by software applications and is built-in to the model representation formats and data exchange standards.

Quintana et al. [2] define a product's Model-Based Definition (MBD) as a dataset containing the model's precise 3D geometry and annotations. The annotations specify manufacturing and life cycle support data and may include notes and lists. The model comprises a complete definition of the product, without relying on supplemental documents such as $2 \mathrm{D}$ drawings. 2D drawings are not needed when annotations are associated with objects in the model and can be viewed with the model.

Not only do humans have to be able to understand the model, but software applications have to "understand" the model as well. Quintana outlines requirements for engineering models.

- CAD systems must be able to manipulate, import, and export 3D solid models.

- CAM software must be able to define and validate machine-readable instructions for making the model, and must document the process definition.

- Computer Aided Engineering (CAE) software must be able to validate and optimize the product definition.

- Product Lifecycle Management (PLM) software must be able to control access and manage change of the various models and documents associated with the product.

- Applications such as Enterprise Resource Planning and Manufacturing Execution Systems need to extract raw material and component information from product models.

The key to achieve interoperability across software applications is open standards, i.e., those developed by consensus either within a standards development organization or a consortium of stakeholders. No single software tool can perform all of the engineering tasks needed to design and manufacture a product. No single software product can do it all well. Users will mix and match software products according to their business objectives. Standards define an agreed-upon syntax and semantics of 3D modeling constructs and annotation so that users can understand one another's models. Standards for representing, exchanging, and determining the fidelity of PMI are of particular importance because PMI (includes GD\&T annotations) is essential to manufacturing. Driven by industry, standards are adopted nationally and internationally, positively affecting interoperability across software applications. 
Open standards are vital for MBE. Unlike industry standards, where the underlying technology is neither open nor democratically managed, no single company can exert an inordinate amount of control over the intellectual property in an open standard.[3] As a result, a company whose product model is based on open standards is less likely to find itself in a situation where it must rely on a competitor's software in order to "understand" the model or, even worse, support a product whose digital model was created using software and computer hardware that is no longer available. Avoiding the latter scenario is of particular concern for companies such as aerospace manufacturers whose products have lifecycles measured in decades - far longer than the typical lifetime of a CAD software application or computer operating system. 


\section{Benefits, Opportunities, and Challenges}

MBE yields significant benefits to manufacturers and their customers. MBE has been shown to substantially improve productivity and reduce manufacturing costs. A study by the Aberdeen Group documented significant time and cost savings when model-based techniques are compared to conventional engineering practices.[4] Another study found MBE methods result in time savings of a factor of three for first-article product development and a factor of four for engineering change management.[5]

Model-based engineering increases the potential value of archived product data. As mentioned in Section 2, MBE enables Product Manufacturing Information (PMI) including Geometric Dimensions and Tolerances (GD\&T), annotations, and notes to be integrated with the product's digital 3D representation. Incorporating PMI into the model eliminates the need for 2D drawings and other supporting documents. MBE can also improve the accuracy of GD\&T annotations by enabling the association of GD\&T semantics with features in a 3D model of a part. Software tools can detect inconsistencies between the GD\&T and the part geometry. New PMI standards for dimensioning and tolerancing make this possible. As Bill Tandler states in his presentation (4.11.4), emerging standards and technologies have the potential to prevent useless and costly "decoration" of models.

Scott Lucero, OSD, states (4.7), MBE facilitates "cross-domain coupling," i.e., integration across a complex system spanning more than one engineering discipline. Cross-domain coupling results in benefits such as improved integration of modeling and simulation, which in turn can lower product development costs.

Recent technical and standards developments now make the vision of MBE possible for even the smallest manufacturers. Developments include the implementation of 3D PMI (e.g., GD\&T) standards in CAD software, and the availability of low-cost software using new formats for viewing - and potentially exchanging - models. The result is a dramatic lowering of the cost of MBE, particularly for small businesses. For example, a 3D CAD model with GD\&T annotations and other supporting information can now be exported to the 3D Portable Document Format (3D PDF).[6] A 3D PDF file can, in turn, be viewed with the Adobe Reader, free software that is a standard application on most computers.

As discussed in Section 2, an open standards-based approach provides many advantages to achieve interoperability between the applications creating and accessing model-based engineering data. Still needed are new standards for the syntax and semantics of PMI symbols, standards for the exchange of annotated 3D model data between systems, and standards for lowcost, efficient formats such as 3D PDF used for collaboration with partners and customers. Key to the success of standards is effective deployment and risk reduction. Test methods for 
validating that software applications correctly produce and interpret model data are an essential component of standards development.

Validation testing is a multi-faceted, multiple-stage process. Not only must CAD systems correctly implement dimensioning and tolerancing standards, but CAD systems must also be able to exchange data with other CAD systems using standard formats. In addition, translators must correctly export data to low-cost, collaborative formats. Finally, software for viewing and manipulating the formats must correctly interpret the model. 


\section{Workshop Presentation Summaries}

This section contains subsections summarizing each technical presentation. Subsection titles are presentation titles. Italicized text following the subsection title identifies the presenter and organization represented. Summary text for the most part paraphrases the actual ideas communicated by the presenter. An exception is Bill Tandler's summary (4.11.4, second paragraph), where we describe a real-time demonstration.

The Summit included two special sessions, each containing a group of presentations sharing a common theme. The first, a session on quality control and quality assurance (4.11), was organized by John Horst of NIST's Intelligent Systems Division, Engineering Laboratory, who was responsible for choosing and inviting the speakers. The second special session, a series of CAD vendor demonstrations, was organized by Rich Eckenrode of RECON Services.

\subsection{OSD MBE / TDP Summit Objectives}

Paul Huang, US Army Research Laboratory

The Department of Defense (DoD) Engineering Drawing and Modeling Working Group (DEDMWG) provides technical coordination and policy guidance on weapon systems data for acquisition, product design, analysis, simulation, manufacturing, provisioning and other product lifecycle management functions. The DEDMWG works in concert with the Joint Defense Manufacturing Technology Panel and DoD's Advanced Manufacturing Enterprise subpanel. A major emphasis of the DEDMWG is to reduce costs by creating synergy across the community utilizing work that has been done and avoiding "reinventing the wheel" in moving toward a model-based enterprise. DEDMWG team members and collaborators include:

- OSD Manufacturing Technology (ManTech)

- Armed services (Army, Air Force, Navy/Marine Corps)

- Defense Logistics Agency

- Standards organizations such as the American Society of Mechanical Engineers (ASME) and the Aerospace Industries Association

- Government agencies including NIST, Department of Energy (DoE), and National Aeronautics and Space Administration (NASA)

The scope of the DEDMWG includes standardization of technical data information requirements for computer-aided design, engineering, manufacturing, data repository, data archival and retrieval tools, and related applications for total product lifecycle management. Current ManTech-funded activities where DEDMWG is playing a leadership role include definition and validation of certified 3D models, use of 3D models across supply chains, reuse of 3D technical data package (TDP) in technical publications, and revision of MIL-STD-31000. Key DEDMWG accomplishments to date include: 
- Conversion of the MIL-DTL-31000C Detail Specification [7] to MIL-STD-31000

- Improving synergy between ASME Y14.41 Digital Product Definition Data Practice standard [8] and the Aerospace Industries Association's NAS3500 standard [9]

- Refinement of annotations and delivery of schemas and validation guidebook into MILSTD-31000

- Over 60 subject matter experts participating in the revision to MIL-STD-31000

The MBE Summit supports the DEDMWG goals of encouraging cross-agency and industry/government partnerships and discouraging duplication of efforts. The purpose of the Summit for OSD is to communicate the state of the art, key research challenges, and to share lessons learned and best practices.

\subsection{NIST Engineering Laboratory Manufacturing Programs Overview} Vijay Srinivasan, Alkan Donmez, Mike Shneier, Fred Proctor, and Simon Frechette National Institute of Standards and Technology

The Engineering Laboratory manufacturing program vision is to be the source for measurement science and critical technical contributions underpinning standards used by the U.S. manufacturing industry. Consistent with this vision, the Engineering Laboratory conducts research to help advance standards and technology enabling U.S. manufacturers to compete more effectively. The Engineering Laboratory has five manufacturing research programs: Smart Manufacturing Processes and Equipment, Next Generation Robotics and Automation, Smart Manufacturing Controls, Systems Integration for Manufacturing and Construction Applications, and Sustainable Manufacturing.

The Smart Manufacturing Processes and Equipment Program's objective is to advance measurement science enabling rapid and cost-effective production of innovative, complex products through advanced manufacturing processes and equipment. There are three thrust areas in the program: metal-based additive manufacturing, smart machining, and micro- and nanomanufacturing. The metal-based additive manufacturing thrust addresses the need to understand, identify, and reduce uncertainties in metal powder characteristics coupled with uncertainties in the advanced manufacturing process and equipment that lead to uncertainties in the final product. The smart machining thrust addresses the need to integrate modeling and simulation with realtime measurements to optimize processes and equipment. The micro- and nano-manufacturing thrust addresses the need to improve the quality and yield of micro- and nano-scale products through new measurement methods for improved process control.

The Next Generation Robotics and Automation Program's objective is to advance measurement science to increase the safety, versatility, autonomy, and rapid re-tasking of intelligent robots and automation technologies for smart manufacturing and cyber-physical systems applications. There are four thrust areas in the program: sensing and perception, manipulation, mobility, and autonomy. Sensing and perception enables next-generation robots to collaborate with humans in 
unstructured environments. Manipulation enables robotic dexterity essential for agile manufacturing operations and a greater breadth of applications through Robotic Industries Association (RIA) or ASTM standards for measuring performance. Mobility aims at allowing manufacturing vehicles to operate safely and more effectively in the same workspace as humans through the development of industrial vehicle safety standards. Finally, autonomy enables creation of agile and reconfigurable robots that are easily tasked to perform new manufacturing operations through standards and measurement tools for intelligent planning and modeling.

The Smart Manufacturing Controls Program objective is to advance measurement science enabling real-time monitoring, control, and performance optimization of smart manufacturing systems in the factory. There are three thrust areas in the program: factory networks, information modeling and testing, and performance measurement and optimization. The factory network thrust aims at enabling cost savings and ease of integration for networked equipment and sensors by developing performance and conformance tests for data exchange and cyber security standards through the Institute of Electrical and Electronics Engineers (IEEE) and International Society of Automation (ISA). The information modeling and testing thrust aims at enabling seamless information exchange throughout production activities by developing validation and conformance tests for information exchange standards through ISO and the Dimensional Measurement Standards Consortium (DMSC). The performance measurement and optimization thrust aims at enabling optimization of manufacturing across the shop floor by developing standards for measuring key performance indicators through the Association for Manufacturing Technology (AMT).

The Systems Integration for Manufacturing and Construction Applications Program's objective is to develop and deploy measurement science for integration of engineering information systems used in complex manufacturing and construction networks to improve product and process performance by 2016. The program addresses industry's struggle to digitize manufacturing and thus achieve the level of integration needed to make substantial breakthroughs in manufacturing productivity, quality, and agility. The two major program thrusts are Model-based Engineering and Service-based Manufacturing. The Model-based Engineering thrust's objectives are to conduct research and deliver technical results to enable the transition from document-based data to model-based data, support new manufacturing processes and quality improvement, and enable end-to-end integration from systems engineering to manufacturing. The Service-based Manufacturing thrust's objectives are to develop service-oriented architectures for manufacturing, and to create supply chain service models that enable SMEs to participate in manufacturing supply chains.

The Sustainable Manufacturing Program's objective is to develop and deploy advances in measurement science to enable improvements in resource (energy, material) efficiency and waste reduction across manufacturing processes and product assembly by 2016 . The program addresses the industry's need for well-defined sustainability metrics and a measurement science-based 
methodology to compose those metrics across global supply chains within manageable uncertainty. The two major program thrusts are Methodologies for Characterizing Sustainable Processes and Resources and Integration Infrastructure for Sustainable Manufacturing. The Methodologies for Characterizing Sustainable Processes thrust aims to define sustainability metrics of unit and assembly processes and use those metrics in life-cycle predictions and decisions. The Integration Infrastructure for Sustainable Manufacturing thrust aims to develop a sustainability testbed based on real manufacturing scenarios.

\subsection{NASA Integrated Model-Centric Architecture}

Paul Gill, NASA

The NASA Integrated Model-Centric Architecture is based on the general model-centric vision of advancing from a document-centric engineering practice to one in which structural, behavioral, and simulation-based models representing the technical designs are integrated throughout the lifecycle.

There are several problems to be solved, including:

- Lack of affordability of projects and activities

- Mission complexity growing faster than the ability to manage it

- Inability to share models in a collaborative environment

- Ineffective testing and too many design reviews

- Lack of early problem identification

- Necessity of searching for needed data

- Necessity of integrating pieces as opposed to total model solutions

- Data model quality uncertainty

Moving to a model-driven environment with integration and simulation capability will help resolve many of the issues listed above. NASA has developed three use cases to illustrate the benefits of deploying the model-centric vision. The first scenario is a change in requirements late in the development cycle where a fully model-centric program would enable the tracing of effect of a change across all aspects of the product. The second scenario is an in-flight anomaly, where a model-centric architecture would allow immediate definition of data and information needed to address the problem and locations of spare parts and needed materials. The third scenario involves the deluge of development data where the volume of data is huge, and a model-centric architecture would accommodate that requirement.

The means of establishing a model-centric environment comes in two parts. The first is the establishment of Communities of Practice $(\mathrm{CoP})$ in several areas including model-based systems engineering, product data and lifecycle management, models and simulations, and computer aided design. The CoP mission goes beyond communication and discussion to include the deployment of model-centric toolsets. Seven teams have been established to address various 
aspects of the challenge. They are Benchmarking, Foundations, Current Architecture, Concept of Operations (ConOps), Communications Plan, Pilots, and Workforce Capabilities.

The second part is the development of a three-phase roadmap to guide the model-centric activities. The first phase is preparation, which involves establishing a common vision and developing strategic and implementation plans. The second phase is implementation, which involves developing standards and policies for new capabilities and developing a standard suite of modeling tools and technologies. The third phase is sustaining and improving, which involves establishing an operational model-centric infrastructure and a mature model-based development methodology.

Key benefits that NASA envisions from moving to a model-centric culture include enhanced affordability, increased collaboration, earlier identification of problems, and quicker diagnoses and solutions. Early results are already having an impact.

\subsection{Affordable Readiness through Model-Based Enterprise}

Shelley Diedrich, U.S. Coast Guard

A new goal for the Coast Guard is affordable readiness through a model-based enterprise. Coast Guard equipment is aging. Much equipment is at least 40 years old and no longer has data for sustainment and maintenance. The access to needed data for maintaining equipment is becoming an important issue.

The Coast Guard defines logistics as "all the activities associated with developing, acquiring, sustaining, and eventually retiring the components of capability, including people, systems and information." This definition of logistics includes mission requirements and regulation requirements needed to support assets. This view of logistics is different from the more limited view of logistics in certain circles.

The Coast Guard vision includes:

- Affordable readiness

- Spiral MBE implementation

- Standard Coast Guard processes

- Integrated modular architecture

- A configuration-based business model

- Baseline management

The three elements of the vision are a standard product model, standard business model, and single information technology system. The approach to achieving the vision involves developing systems engineering for business model management and leveraging of government and industry best practices. A roadmap was created to outline the strategy plan for achieving the vision. Every 
organization within the Coast Guard must be transformed to embrace and implement the MBE solution.

Several risks have been identified and need to be addressed. These risks include lack of a comprehensive ISO 10303 (also known as "STEP" - the Standard for the Exchange of Product Model Data) [10] pilot, limited STEP expertise, competing standards and limited ability to sustain them, and revisions to STEP standards making the end state a moving target.

\subsection{Model-based Engineering / Manufacturing Review from Y-12 National Security Complex}

Donna Bennett, National Nuclear Security Administration

Y-12 is a manufacturing facility whose mission includes sustaining a safe nuclear arsenal, processing highly enriched uranium, and preventing nuclear proliferation and nuclear terrorism. B\&W Y-12 operates it for the National Nuclear Security Administration (NNSA). Y-12 plays a vital role in DOE's Nuclear Security Enterprise. It has four core areas of research and development: defense programs, transformation, complementary work, and basic science.

Y-12 focuses on the link between design and manufacturing by emphasizing model-based engineering and manufacturing, which includes the use of 3D models for defining refurbished stockpile product, supporting certification, and integrating design, engineering, and manufacturing activities throughout the lifecycle. The model-based engineering and manufacturing concepts are applied during design, analysis/simulation, manufacturing, inspection, and packaging.

Y-12 has model-based activities in four areas: packaging of materials, life-extension programs, the integrated glove box program, and the uranium processing facility. Packaging of materials involves designing a product and testing it for requirement fulfillment (e.g., designing a container and then dropping it to analyze the impact result). Life-extension programs develop business rules around MBE needs and requirements, and complete process planning using workin-process models. The integrated glove box program uses virtual process planning to identify problems in fixture design and allows for corrections of these problems before any builds. The uranium processing facility involves conceptual and ergonomic design with the intent of identifying and resolving problems early in the design process.

The Y-12 Complex collaborates with other Department of Energy sites and federal agencies as well as universities and private industry. The Plant Directed Research, Development, and Demonstration Program supports innovative or high-risk design and manufacturing concepts and technologies with potentially high payoff for the Nuclear Security Enterprise.

\subsection{Model-Based Enterprise Impact on Organizational Behavior}

James DeLaPorte, NexTec 
Organizations have a large inertia, and change is difficult. It is analogical to Newton's law of motion stating, "A body in motion tends to stay in motion unless acted on by an outside force." The model-based enterprise (MBE) is an outside force that can drive change.

People in an organization tend to establish and to reinforce "normal" behavior. MBE is a fundamental shift to 3D from 2D for all major organizations, which is a major perturbation from the normal behavior. The impacts are felt in engineering, operations, quality, service and support, information technology, and finance and contracts. All of these business units are required to adapt, which means there is a need to rebuild the organization to support the use of $3 \mathrm{D}$, to update training and instructions, and to manage new applications and processes.

In order to achieve MBE and organizational behavior transformation, four elements are needed: (1) empowerment of leaders at all levels, (2) adaptation to changing roles and responsibilities, (3) trust and encouragement, and (4) active pursuit of conflict resolution. People will follow the new behaviors defined by the organizational leaders. Keeping people involved and informed will increase the individual commitment to the new norms. This commitment will stabilize and sustain the new organizations. The new organizational behavior will be much more dynamic and flexible.

\subsection{Engineered Resilient Systems}

Scott Lucero, Office of the Secretary of Defense

Engineered Resilient Systems (ERS) is one of the seven Department of Defense (DoD) Science and Technology priorities. ERS was established to guide FY13-17 defense investments across DoD services and agencies. Although ERS is a systems engineering approach, it goes far beyond process. New technologies, applied across a broad community, are imperative in addressing the changing requirements. New tools help engineers and users understand interactions, identify implications, and manage consequences. This scenario of operations points to an ability to automatically evaluate many options, understand all implications, respond to requirements, propagate tradeoffs, and adapt through a continuous learning process.

A ten-year technology and science roadmap is currently under development. Four technology enablers have been identified. These are:

- System representation and modeling - capturing physical and logical structures, behavior, interactions with the environment and other systems

- Characterizing changing operational contexts - directly capturing operational data, deeper understanding of warfighter needs and operational impacts of alternatives

- Cross-domain coupling-- better interchange between incommensurate models, resolving temporal, multi-scale, multi-physics issues

- Collaborative design and decision support - well-informed decision support among many stakeholders. 
Research will develop the tools and technologies to enhance engineering productivity, resulting in resilient systems that are effective in a wide range of situations, readily adaptable through reconfiguration or replacement, with graceful degradation. The goals for success of the roadmap include adaptable design, faster and more efficient engineering iterations, and decisions informed by mission needs.

\subsection{The National Digital Engineering and Manufacturing Consortium Dennis Thompson, South Carolina Research Authority}

The National Digital Engineering and Manufacturing Consortium (NDEMC) is a public-private partnership that is part of the President's Advanced Manufacturing initiative. The goal of the NDEMC is to provide high performance computing capability for the small manufacturing community. The consortium is providing Software-as-a-Service access to high performance software and to the hardware on which it runs with an emphasis on modeling and simulation capabilities.

There are two major thrust areas: 1) specialized consulting or training in modeling, simulation, and analysis provided by teams of experts, and 2) on-line manufacturing support systems. NDEMC stresses shared solutions. The goal is to provide tools that can serve a broader community, not just satisfy very specific needs of a highly specialized application. The program is focused across the product lifecycle. The benefits are realized by the original equipment manufacturers, software providers, SMEs, and by the U.S. government.

Seven projects have been launched, and 30 to 40 projects are planned to be launched. A catalog of 143 software tools is being developed and will be accessible by SMEs through the NDEMC portal.

\subsection{Department of Defense (DoD) MBE Program Reviews}

\subsubsection{Navy Digital Product Model}

Ben Kassel, Naval Surface Warfare Center, Carderock Division

The Digital Product Model will be the authoritative source of data for the entire ship's lifecycle. ${ }^{4}$ NAVSEA (Naval Sea Systems Command) is pursuing a two-level approach. At the first level, the ship design is a collection of parts with the model supporting the management of the collection. At the second level, there is an additional layer of information required to manage and

\footnotetext{
${ }^{4}$ A memo signed by the Chief Engineer and Deputy Commander, Naval Systems Engineering Directorate - SHIP DESIGN AND ANALYSIS TOOLS GOALS, Ser 05T/015, Naval Sea Systems Command, Washington D.C., Sep 292010 -"NAVSEA is committed to creating and maintaining LEAPS models for every major ship class in the U.S. Navy to enhance lifecycle support and incident response. A future goal is for NAVSEA to maintain a LEAPS model for every ship in the fleet." LEAPS (Leading Edge Architecture for Prototyping Systems) is NAVSEA's product model repository implementation.
} 
support the product from the as-designed and as-built derived models of the product. The Navy believes that the STEP Product life cycle support standard (ISO 10303-239) [11] has emerged as a useful mechanism to define product structure, the relationship between objects, and configuration management, and that the STEP Core data for automotive mechanical design processes standard (ISO 10303-214) [12] is a relatively mature mechanism for managing product data. Contracts with the ship builder will specify that the contractor supply Data Exchange Specifications (DEXs) based on the ISO 10303-239 information model supporting the interpretation of data. In the future, the Navy will provide standard DEXs and will specify compliance with those DEXs in all contracts.

\subsubsection{Air Force Technical Data Objectives}

Brench Boden, United States Air Force

The Air Force program Expeditionary Logistics for the $21^{\text {st }}$ Century focuses on the transformation of supply chain activities. It addresses major issues including data rights, data availability, and acquisition strategy. A ManTech opportunity is seen in PLM integration and new methodologies for managing product technical data. Interoperability is a major opportunity area. Studies show the lack of interoperability costs billions of dollars per year.[13] The Air Force ManTech program is developing a strategic vision and technical thrusts. The four focus areas are:

- Moving manufacturing left (i.e., developing technologies enabling early consideration of manufacturing requirements during design)

- Cradle-to-cradle digital thread

- Responsive integrated supply base

- Factory of the future

The cradle-to-cradle digital thread is particularly important to the TDP/MBE activities.

\subsubsection{Army Research Objectives for MBE}

Andy Davis, US Army Research Development and Engineering Command

The Army has identified three goals in achieving a model-based enterprise:

- Fully integrated manufacturing enterprise to support weapons systems development

- Digital thread connectivity from prototype to production

- Establishment and implementation of best practices and standards for product data use

The Army is addressing challenges including lack of resources, competition from industry, political interests, and institutional issues. Current investments include the Net-centric MBE project (\$ 8.9 million over 4 years) and Accelerated and Adaptive Army Fabrication Enterprise 
(\$9.2 million over 4 years). The latter is a major activity focused on establishing an organic capability within the army to pilot and demonstrate an advanced model-based enterprise.

\subsubsection{Defense Logistics Agency Objectives for MBE}

Rick Norton, Defense Logistics Agency (DLA)

There are three active MBE projects within DLA named Charter 1, 2, and 3. Charter 1 is an A-10 jet aircraft TDP exchange pilot. Charter 2 involves a contracting TDP within an MBE environment. Charter 3 addresses supply chain activities. The Charter 1 project is a partnership with the Air Force and Boeing that addresses parts provisioning using 3D model data. The objective is to modernize the means of exchanging data. Charter 2 will begin with an in-depth study of the present state of practice and emerging best practices in the model-based enterprise. The study will include benchmarking supporting gap and trend analysis, and business case analysis. Charter 2 will deliver a model-based enterprise/product lifecycle management technology discovery and investment strategy for DLA. In summary, Charter 1 defines what needs to be done in developing new MBE tools. Charter 2 determines what needs to happen to drive contract deliverables within an MBE. Charter 3 will make MBE happen within the supply chain.

\subsection{Industry and ManTech Interaction Success}

\section{David Baum, Raytheon}

Raytheon has four mission areas in addressing a technology-driven growth strategy:

- Sensing, which expands beyond traditional Radio Frequency/Electrical-Optical to new growth focus areas, including multi-mission areas.

- Command, Control, Communication, and Intelligence), which broadens market presence in communications, networking and knowledge management.

- Effects (military actions or outcome), which leverages kinetic energy-based expertise into Electronic Warfare, directed energy and cyber markets.

- Mission support, engineering services, and training.

The objective is to identify and establish common product data management (PDM) systems, engineering documentation standards, and process asset libraries. Technology-readiness level and manufacture-readiness level should be defined in each lifecycle phase.

Raytheon's capability development timeline is as follows:

- 2011: model-based definition - complete an enterprise MBD specification,

- 2012: model-based manufacturing - establish global supplier communication and deploy CAD model derivatives,

- 2013: model-based engineering and lifecycle support - implement virtual verification and requirement allocations/derivations. 
Raytheon leverages the Customer/Supplier Interoperability (CSI) ManTech program (see 4.13). The vision of CSI is a flexible, configurable, standard-based system that automates common tasks associated with customer supplier interoperability. Specific leveraging of the ManTech work includes:

- Working with industry partners PTC and ITI TranscenData to validate conversions of CAD file formats,

- Developing a standard MBD schema with start parts ${ }^{5}$ and PDM attributes,

- Developing MBD model qualifications and workflows prioritized by modeling defect causes,

- Using ITI's model comparison software to identify model changes during the change management process.

\subsection{Special Session: MBE for Quality Control / Quality Assurance}

\section{John Horst, National Institute of Standards and Technology}

The summit included a mini-session on MBE for quality control and quality assurance. Several leading US quality measurement experts presented their perspectives on the potential offered by a model-based approach to performing quality measurement. The presentations shared as a common theme the improvement of the quality measurement process, i.e., making it more efficient, less error prone, and more cost effective. They also touched on improving the integration of the quality measurement process into the entire manufacturing enterprise particularly that part of the enterprise focusing on product design, quality management, and production. A model-based quality measurement process promises huge benefits, but also presents huge challenges. A key challenge is intelligent use of model data.

\subsubsection{Product Tolerance Representation: Critical Requirements for Product Definition and Metrology Interoperability}

\section{Curtis Brown, Honeywell Federal Manufacturing \& Technology}

Full semantic product tolerance representation in digital information models is a critical requirement for cost-effective and efficient manufacturing, where "full semantic" means that no information in the digital model is mere "decoration," but contains the complete and rich association between geometry, feature definitions, tolerance frames, datum definitions, etc.

Current standard model-based product representations define nominal shapes only, and unfortunately, one cannot manufacture nominally shaped parts. Parts that fit and function are

\footnotetext{
${ }^{5}$ A "start part" is used to speed up the initial creation of a CAD model for a part, drawing, or assembly. Start parts can help to encourage common modeling practices throughout an organization. Start parts are analogous to the document templates often used with office suite applications to facilitate creation of reports, spreadsheets, or slide presentations.
} 
manufactured via 2D drawings and, to a lesser degree, via proprietary 3D models. Product tolerance representation that is correct, complete, unambiguous, and verified is essential for the successful exchange of product models for next generation automated applications and the return on investment promised by MBE. There is currently no model-based CAD system with the level of robustness to adequately represent and transfer product tolerance.

A fully semantic product definition must include:

- Solid models augmented with product tolerance.

- "Tolerance features," i.e., geometric features with tolerance frame attached, as is defined in GD\&T standards like ASME Y14.5.[14]

- Correct tolerances automatically inferred per ASME Y14.5 and company standards.

- Part functional tolerance definitions that are checked, validated, and scored.

- The ability to exchange tolerance definition with other product definitions.

- A published application programming interface suite for extending tolerance analysis, integration with existing software applications, and supporting downstream activities like manufacturing and measurement.

Downstream machining and inspection processes require tolerance information. Therefore, product data standards such as STEP Managed Model Based 3D Engineering [15] [16], process data standards such as STEP Numerical Controllers [17], and the Dimensional Metrology Standards Consortium's (DMSC) Quality Information Framework (QIF) ${ }^{6}$ all support representation and exchange of tolerance semantics. GD\&T validation tools are needed to ensure the correctness of the tolerance information being exchanged.

\subsubsection{MBE for Dimensional Quality within a Heterogeneous Supply Base Nick Orchard and Ron Snyder, Rolls-Royce}

There is a proliferation of incompatible CAD, PDM, PLM, and CAM software environments. Rolls-Royce wants one single integrated environment. In the current Rolls-Royce PLM environment, even though geometry can be linked between models, the system does not allow users to link PMI, a capability that is essential to achieve the "paperless office." In terms of CAD models, one important question to ask is whether one size could fit all? For example, if the analysis department doesn't like including blends and radii in the CAD Model but CAM programmers and quality engineers do, then the answer is no.

An "inflated CAD model" is a concept where the CAD model has elements useful to downstream processes. Such processes include analysis, machining, and inspection - particularly

\footnotetext{
${ }^{6}$ http://www.qifstandards.org
} 
3D inspection (i.e., using non-contact optical systems). For point cloud data, there are concerns about how to determine the validity of the results, how to determine the correct point density, how to qualify optical measurement systems based on an optical based inspection standard, and whether there is an optical based inspection standard.

\subsubsection{Improving First Article Inspection in a Model-Based Environment Ray Admire, Lockheed Martin}

First-Article Inspection (FAI) in a model-based environment, compliant with industry information standards (such as ISO STEP, Aerospace First Article Inspection [18], and the Dimensional Measurement Standards Consortium's Quality Information Framework), will deliver substantial benefits to manufacturers and their customers.

Challenges and risk to product quality in the supply chain include the uncertainty of experienced talent, the supplier value stream, fixed price contracts, technical challenges in achieving quality targets, vicissitudes in the national and international economy, uncertain performance of lower tier suppliers, changes in government policy, changes in trade regulations, and increasing Government Industry Data Exchange Program notifications.

Characteristic Accountability \& Verification (CAV) is a process ensuring that all critical and major characteristics are defined and accounted for in the product technical data package. CAV also ensures that manufacturing and quality plans include controls adequate for conformance of these characteristics.

FAI can be improved in a model-based environment. However, a barrier to model-based FAI is that CAD data (including GD\&T) does not flow seamlessly to downstream processes when components are not from the same vendor. The GD\&T is not fully associated to critical characteristic features. This is because CAD vendors do not use standards, the standards are incomplete, end users do not enforce standards compliance, and there are no formal tools or methods for verifying $\mathrm{CAD}$ vendor compliance to the standards.

Top inspection process definition issues are:

- Lack of comprehensive non-shape information available from the product - including CAD tolerance data, material properties, and optical properties.

- Lack of a standard mechanism to capture and exchange knowledge - including methods, practices, resources, and rules.

As a result, costly rework is required at each step in the inspection process: planning, programming, results generation, and analysis.

The importance of FAI is that it reassures the customer or supplier that lower tier suppliers are compliant to all specified design characteristics (dimensional, material, etc.). The QIF model and 
schema (from the DMSC) holds promise for facilitating successful FAIs. A pilot demo involving joint efforts of NIST and Lockheed Martin is planned for demonstrating the joint benefits from FAI and QIF.

\subsubsection{The Key to Intelligent GD\&T}

\section{Bill Tandler, MultiMetrics}

MBD is absolutely essential for ensuring the intelligent application of GD\&T, since the concepts and symbolic language of GD\&T are so complex that few individuals have the time, skill or interest to master them. This lack of mastery leads to improperly defined GD\&T, which further leads to most GD\&T being merely "decorative" and therefore, useless or even dangerous. MBD holds promise for automating precise application of GD\&T to part geometry and features to enable correct execution of precision tasks such as tolerance stack-up analysis, manufacturing process management, coordinate metrology, and assembly.

Tandler presented a live example of the problems with a "decorative" GD\&T application on a part not satisfying fit and function requirements, versus a correct GD\&T definition satisfying fit and function. He described an experiment demonstrating this process. In concert with an unnamed "3D metrology" vendor, Tandler was able to encode the geometry and features of the same part, associate ASME Y14.5 standards-compliant and requirements-satisfying GD\&T with the critical features on the part, and exchange this information with the 3D metrology vendor's software. The vendor's software then produced measurement results sufficient for analysis on fit and function.

Prerequisites to achieving the goal of model-based definitions that produce parts that assemble and function as required include:

- Significantly improving the ergonomics of MBD technology to encourage its use.

- Refining and solidifying the concepts, tools, rules, processes and best practices of GD\&T to enable large-scale automation of the "encoding" and "decoding" processes.

- Largely automating the GD\&T "encoding" process in the 3D CAD environment using the refinements referenced in the previous bullet.

- Fully automating the GD\&T "decoding" process in the 3D CAD environment to graphically illustrate the impact of the "code" during the "encoding" processes.

- Largely automating the tolerance stack-up analysis process in the 3D CAD environment and providing intelligent feedback to enable iterative refinement of the GD\&T code.

\subsubsection{D Technical Data Package Validation Demonstration}

Roy Whittenburg, Universal Technical Resource Services, Inc.

The 3D technical data package validation demonstration provides an illustration in which a model is built and then broken down into segments, each segment having its own validation point. The approach focuses on defining what needs to be validated and then working with the 
industry to fill any technology gaps. Since DoD is inherently 2D and drawing based, there is a fundamental distrust of 3D data. Verification and validation is needed to gain this trust.

The objective of the project is to provide a process to verify and validate whether the data quality of the 3D TDP is sufficient for manufacturing. A team that consists of DoD service representatives, vendors, and subject matter experts executes the project.

The demonstration of the 3D technical data package validation process is provided in three steps: design model creation, product lifecycle management (PLM) check-in, and derivative model creation. The demonstration intentionally selects different tools for each section of the demonstration. The demonstration evaluates the model, determines issues causing deviations between the model and its derivatives, and offers assistance in resolving the issues. The issues are highlighted in the model and in the reports related to those models. The validation is not limited to parts, but also operates on assemblies.

In the demonstration, a model is created, initial validation is conducted, and the model is checked into the PLM system to enable sharing. An additional series of checks are executed to assure that the model has reached certain levels of model maturity and usability. If the model passes the checks, it is then available to be shared with others in either a released or unreleased state. After the model is checked in, derivatives (translations) are created. The derivatives must be validated, just like the original. In addition to the kinds of checking performed on the original model, derivative models must also be checked for deviations from the original.

\subsection{The 3D PDF Consortium}

Jim Merry, Tetra4D

A 3D PDF document is any PDF document that contains CAD data in Universal 3D (U3D) [19] or Product Representation Compact (PRC) [6] formats. Adobe no longer supports translation of CAD data to PRC or U3D. They are still supporting insertion of U3D and PRC to create 3D PDFs in their Acrobat Professional product. Although Adobe's Reader software will continue to support viewing of 3D PDF, partners have been chosen to continue the development and support of the CAD to 3D PDF conversion technology. Tech Soft 3D has taken on development and maintenance of the software toolkit for PRC-based CAD translator development, and is now leading the PRC ISO standardization effort. Tetra 4D is now the sole distributor of the 3D PDF conversion technology for the Adobe Acrobat platform and provides a plug-in enabling the latest version of Acrobat Professional to generate 3D PDF documents from multiple 3D formats from the mechanical CAD, architecture, engineering and construction, and digital content creation domains. ProSTEP AG now provides a server-level capability integrating 3D PDF generation in business processes and enterprise systems. Recent versions of Adobe Reader will read 3D PDFs, providing ubiquitous access to CAD model information. 
While PDF is commonly perceived primarily as a presentation mechanism, PDF supports other functionalities relevant to the MBE environment such as information protection mechanisms and digital rights management. The ability for Adobe Reader users to interact with the 3D model via forms is another important capability. Support for digital signatures is important for document workflows requiring approval and/or certification for information authentication assurance.

The 3D PDF Consortium is a newly formed non-profit organization comprised of users, software developers, and solution providers whose goal is to accelerate 3D PDF standardization, implementation, and industry adoption. The consortium intends to achieve this goal through demonstration, communication, and evangelism. The consortium's website is http://www.3dpdfconsortium.org.

\subsection{Engineering Software Provider Session}

Rich Eckenrode, RECON Services, moderated a session consisting of CAD vendor demonstrations of new capabilities supporting MBE. Table 2 shows the vendors represented in the session, software products demonstrated, and the people who gave the presentations.

Table 2. CAD vendor demonstrations.

\begin{tabular}{|l|l|l|}
\hline Vendor & Software Product & Presenter(s) \\
\hline Dassault Systèmes & CATIA & Bob Brown and Israel Flores \\
\hline PTC & Creo & Mark Nielson \\
\hline Siemens & NX & Dennis Keating \\
\hline Siemens & Solid Edge & Ricky Black \\
\hline Dassault Systèmes & SolidWorks & Craig Therrien \\
\hline
\end{tabular}

\subsection{Reducing New Product Introduction Time and Cost through More Effective Collaboration}

John Gray, ITI TranscenData

Interoperability costs can easily add up. No manufacturer has an "explicit" interoperability budget. The Customer Supplier Interoperability (CSI) program is a solution to reduce interoperability costs.

The cost of interoperability is the summation of many small things that add to a significant dollar amount. For example, a forty-year program can have up to four million interoperability issues, costing in excess of $\$ 1$ billion over the program's lifetime. Extrapolation of existing studies point to the fact that the lack of interoperability is a $\$ 2$ billion per year problem for DoD. CSI sought to understand the interoperability issues and prototype some solutions. The steps in the CSI approach included review (data contract language), analyze (failures), prioritize (opportunities), identify (most value actions), and demonstrate (solutions in pilots). 
The CSI vision involves a flexible and configurable standards-based system in which common tasks associated with Customer-Supplier Interoperability are automated. A model for effective interoperability was established and applied using a toolkit configured with tools from multiple technology suppliers. Prototypes of automated solutions have been demonstrated. To support the value proposition for CSI, a higher fidelity study of cost savings for the F-35 combat aircraft was undertaken. The potential savings for the F-35 program were conservatively estimated at $\$ 140$ million over the life of the program.

The CSI program is now initiating four new activities. These are:

- Draw-to-PMI - automating merging of 2D GD\&T into a 3D model, producing associative 3D PMI facilitating manufacturers migrating to a model based design methodology in new projects.

- Critical Problem Resolution Process - detecting and resolving model issues in design for manufacturability.

- 3D PMI Translation - translating associative 3D models and 3D PMI between dissimilar CAD environments with either BREP or Features.

- 3D ECO (Engineering Change Order) Documentation - documenting model changes in a 3D PDF format that improves communication between different organizations in an enterprise. 


\section{Conclusions}

The December 2011 MBE/TDP Summit brought together a collection of stakeholders representing a wide variety of organizations spanning both the public and private sectors. Speakers included program managers, quality measurement experts, researchers, and solution providers. Conclusions and recommendations that emerged from the Summit are summarized in the following.

\subsection{MBE is a key driver of affordability}

Cost and affordability was a high priority for many organizations represented at the Summit. For instance, Paul Gill (4.3) pointed out that one of NASA's major problems is the lack of affordability of projects and activities. Other speakers agreed that implementing MBE can lead to cost savings and provided promising progress and results. Donna Bennett (4.5) highlighted a cost savings of $\$ 535 \mathrm{~K}$ that resulted from using virtual testing instead of physical testing for packaging in the Y-12 program. Brench Boden from the Air Force (4.9.2) highlighted several studies substantiating the cost of the lack of interoperability in billions of dollars per year. In summary, the consensus is that cost control is crucial and the use of a model-centric architecture leads to increasing affordability.

\subsection{MBE reduces errors}

Current practices for communicating and accurately implementing changes in product requirements are inefficient. Such practices still depend on email, phone communication, and manual entry and reentry of data, creating opportunities for errors. These errors lead to delays and additional costs. John Gray (4.13) presented a demonstration scenario of interactions between an airframe manufacturer and mechanical equipment provider in the F-35 program. In his scenario, human interaction was required on numerous occasions to complete processes such as translating data into STEP, checking models for compliance issues, and verifying that the translated file is correct.

Implementation of MBE will increase the efficiency in dealing with changing requirements, especially during later development cycle stages. A fully model-centric software application could trace the effect of that change through many viewpoints. In an example use case from NASA (4.3) illustrating the use of such an application, a changing requirement resulted in successful identification of the affected mission segment, functions, and parts. David Baum also stressed (4.10) that one of the benefits of MBE is the reduction of time to implement changes in systems by enabling design reuse and configuration management. Successful change management and design reuse shows that MBE increases efficiency in processing change in design requirements. 


\subsection{MBE enables effective data reuse across the entire system lifecycle}

Many presenters emphasized the ability to communicate and manage product data across the lifecycle. Paul Gill (4.3) stressed the ideal of a reusable model-driven environment with integration and simulation capability applicable to every activity and extending across the product lifecycle. Gill said that product data and lifecycle management are key to establishing a model-centric environment. Dennis Thompson (4.8) stated that the National Digital Engineering and Manufacturing Consortium (NDEMC) is focused on providing tools serving a broad community across the product lifecycle. Ben Kassel (4.9.1) emphasized that a goal for the Navy is the use of the digital product model as the authoritative source for the entire ship's lifecycle. Gill's, Thompson's and Kassel's presentations indicate a growing consensus that while it is important to achieve a model-centric environment and incorporating technical data into 3D models, it is also equally important that this environment and the data contained in the models are easily accessible and usable during the entire product lifecycle.

\subsection{We need new research to achieve true model-based quality control}

Software implementations of 3D geometry and PMI, both proprietary and standards-based, are increasingly addressing information modeling requirements for automating downstream quality control and quality assurance (QC/QA) processes. The presence of QC/QA domain experts at the Summit (4.11) addressed the need to integrate manufacturing with QC/QA. The experts' presentations articulated a shared commitment to improve the quality measurement process by making it more efficient, less error prone, and more cost effective. The development of new research areas in test methods, measurement methods, and standards is the key to improve product and process performance for manufacturing.

One key requirement for achieving these improvements is to fully incorporate GD\&T data with CAD models and allow these data to flow seamlessly to downstream processes. Currently, GD\&T data is often not associated with individual features of the part, making it impossible to automate inspection process programming. If GD\&T information is expressed as individual lines and arcs in a CAD model or as notes on a drawing, it is not available to automated computer processes that can use it.

Another key area of need is to develop methods to verify and validate that the data quality of the 3D technical data package is sufficient for manufacturing. As Roy Whittenburg pointed in his presentation (4.11.5), there is a lack of trust in the data quality of 3D TDPs because current DoD practices are inherently $2 \mathrm{D}$ and drawing based, and there is no method of verifying the quality of the 3D data received. Hence, development of test methods for 3D TDPs is an area that needs more research.

\subsection{We need new open standards to achieve the full potential of MBE}

As the industry continues to make progress in implementing MBE, it is crucial that common conventions be agreed upon and that best practices are codified. Bill Tandler (4.11.4) argued that 
the full value of MBE and GD\&T will not be realized until the standards that support MBD and GD\&T are improved. He stated that GD\&T almost fulfills its promise, but with great difficulty. Other speakers outlined and discussed the approach that their organizations are undertaking in developing new standards for MBE. David Baum (4.10) said that Raytheon is developing a standard MBD schema with start parts and PDM attributes. Ray Admire (4.11.3) mentioned that Lockheed Martin is working with other organizations to achieve agreement and common understanding of metrology issues to enable standardization and best practices.

Curtis Brown (4.11.1) stated that modern product definition systems can "successfully deliver the representation and exchange of nominal shapes." However, "no one can manufacture nominally shaped parts." The use of PMI enables semantic and accurate specification of product tolerances. As Brown pointed out, correct, complete, unambiguous, and verified tolerance definitions are the critical enabler for realizing successful representation of product models such that they can be consumed by next generation automation applications. Ron Snyder and Nick Orchard (4.11.2) also agreed that the move to PMI provides a pathway to a better modeling environment because this migration enables a participatory engagement in which manufacturing challenges are addressed in the design configuration. 


\section{References}

[1] MIL-STD-31000, Department of Defense Standard Practice: Technical Data Packages (TDP) (05 NOV 2009) [Superseding MIL-DTL-31000C].

[2] Virgilio Quintana, Louis Rivest, Robert Pellerin, Frédérick Venne, Fawzi Kheddouci, Will Model-based Definition replace engineering drawings throughout the product lifecycle? A global perspective from aerospace industry, Computers in Industry, Volume 61, Issue 5, June 2010, Pages 497-508, ISSN 0166-3615, 10.1016/j.compind.2010.01.005.

[3] Russell S. Peak, Joshua Lubell, Vijay Srinivasan, and Stephen C. Waterbury. "STEP, XML, and UML: Complementary Technologies.” J. Comput. Inf. Sci. Eng. 4, 379 (2004).

DOI:10.1115/1.1818683

[4] Aberdeen Group. The Transition from 2D Drafting to 3D Modeling Benchmark Report Improving Engineering Efficiency. September 2006.

[5] Boehm B, ed. Systems 2020 Strategic Initiative. DoD Systems Engineering Research Center Final Technical Report SERC-2010-TR-009, August 29, 2010. Online at http://www.dtic.mil/cgi-bin/GetTRDoc?AD=ADA545210 (accessed July 26, 2012).

[6] ISO/DIS 14739-1.2. Document management - 3D use of Product Representation Compact (PRC) format - Part 1: PRC 10001.

[7] MIL-DTL-31000C, Detail Specification: Technical Data Packages (9 July 2004) [Superseding MIL-DTL-31000B].

[8] ASME Y14.41 Digital Product Definition Practices. New York: The American Society of Mechanical Engineers. New York, NY. 2012.

[9] Aerospace Industries Association. NAS3500. Revision/Edition: 08. Date: 11/00/08. Technical Data Package: Composition, Communication, and Application.

[10] STEP Application Handbook: ISO 10303 (Version 3 ed.), North Charleston, SC: SCRA, 30 June 2006. Online at http://www.uspro.org/documents/STEP_application_hdbk_63006_BF.pdf

[11] ISO 10303-239:2005. Industrial automation systems and integration - Product data representation and exchange - Part 239: Application protocol: Product life cycle support.

[12] ISO 10303-214:2010. Industrial automation systems and integration - Product data representation and exchange - Part 214: Application protocol: Core data for automotive mechanical design processes. 
[13] National Institute of Standards and Technology. Planning Report 02-5. Economic Impact Assessment of the International Standard for the Exchange of Product Model Data (STEP) in Transportation Equipment Industries. December 2002. Online at http://www.nist.gov/director/planning/upload/report02-5.pdf

[14] ASME Y14.5 Dimensioning and Tolerancing. New York: The American Society of Mechanical Engineers. New York, NY. 2009.

[15] Aerospace and Defence Industries Association of Europe, Aerospace Industries Association (US), PDES, Inc., ProSTEP iViP. Development of a Convergent Modular STEP Application Protocol Based on AP 203 and AP 214: STEP AP 242 - Managed Model Based 3D Engineering. Version 1.0. 2009-11-05.

[16] ISO/CD 10303-242. Industrial automation systems and integration - Product data representation and exchange - Part 242: Application protocol: Managed Model-based 3D Engineering. Stage 30.99 (2012-05-15).

[17] ISO 10303-238:2007. Industrial automation systems and integration - Product data representation and exchange - Part 238: Application protocol: Application interpreted model for computerized numerical controllers.

[18] SAE International. AS9102A. Aerospace First Article Inspection Requirement. 2004-0113.

[19] Ecma International. Standard ECMA-363. Universal 3D File Format. 4th Edition. June 2007. 


\section{Appendix 1: Table of Acronyms}

\begin{tabular}{|l|l|}
\hline Acronym & Expansion \\
\hline \hline AMT & Association for Manufacturing Technology \\
\hline ASME & American Society of Mechanical Engineers \\
\hline ASTM & American Society for Testing and Materials \\
\hline CoP & Communities of Practice \\
\hline CAD & Computer Aided Drawing \\
\hline CAE & Computer Aided Engineering \\
\hline CAM & Computer Aided Manufacturing \\
\hline CAV & Characteristic Accountability \& Verification \\
\hline CSI & Customer/Supplier Interoperability \\
\hline DoD & Department of Defense \\
\hline DEDMWG & Department of Defense Engineering Drawing and Modeling Working \\
& Group \\
\hline DEX & Data Exchange Specification \\
\hline DLA & Defense Logistics Agency \\
\hline DMSC & Dimensional Measurement Standards Consortium \\
\hline DOE & Department of Energy \\
\hline ECO & Engineering Change Order \\
\hline \hline ERS & Engineered Resilient Systems \\
\hline FAI & First Article Inspection \\
\hline FEA & Finite Element Analysis \\
\hline GD\&T & Geometric Dimensions and Tolerances \\
\hline \hline IEEE & Institute of Electrical and Electronics Engineers \\
\hline ISA & International Society of Automation \\
\hline ISO & International Organization for Standardization \\
\hline LEAPS & Leading Edge Architecture for Prototyping Systems \\
\hline ManTech & Manufacturing Technology \\
\hline MBD & Model Based Definition \\
\hline MBE & Model Based Enterprise/Engineering \\
\hline NASA & National Aeronautics and Space Administration \\
\hline NAVSEA & Naval Sea Systems Command \\
\hline NDEMC & National Digital Engineering and Manufacturing Consortium \\
\hline NIST & National Institute of Standards and Technology \\
\hline NNSA & National Nuclear Security Administration \\
\hline OSD & Office of the Secretary of Defense \\
\hline PDF & Portable Document Format \\
\hline PDM & Product Data Management \\
\hline PLM & Product Lifecycle Management \\
\hline PMI & Product Manufacturing Information \\
\hline PRC & Product Representation Compact \\
\hline
\end{tabular}




\begin{tabular}{|l|l|}
\hline QC/QA & Quality Control / Quality Assurance \\
\hline \hline QIF & Quality Information Framework \\
\hline \hline RIA & Robotic Industries Association \\
\hline \hline SCRA & South Carolina Research Authority \\
\hline SME & Small or Medium Enterprise \\
\hline STEP & Standard for the Exchange of Product Model Data \\
\hline TDP & Technical Data Package \\
\hline U3D & Universal 3D \\
\hline
\end{tabular}




\section{Appendix 2: Final Agenda and Presentation Materials}

The following pages contain:

1. The final MBE/TDP Summit agenda

2. Presentation materials from all Summit speakers who gave NIST permission to distribute their slides.

In order to minimize page count, each page of presentation materials contains six slides. In some cases, we deleted slides determined to be content-free (e.g., "Thank you" and "Any questions?" slides) and slides that were partial builds of other slides (useful for "animating" presentations but not of much value in a printed hard copy).

With the exception of presentations given by NIST staff (e.g., 4.2), inclusion in this Appendix implies neither endorsement nor approval by the National Institute of Standards and Technology. 
MBE/TDP Summit

NIST, Gaithersburg, MD

Green Auditorium

12 Dec. 2011

\begin{tabular}{|c|c|c|}
\hline Time & Topic & Speaker(s) \\
\hline $0730-0830$ & Registration & \\
\hline 0830-0840 & Introductions and Admin & $\begin{array}{l}\text { Simon Frechette, NIST \& Paul } \\
\text { Huang, ARL }\end{array}$ \\
\hline 0840-0900 & Opening Remarks & $\begin{array}{l}\text { Dr. Harary, NIST \& Ms. Radcliff, } \\
\text { OSD ManTech }\end{array}$ \\
\hline 0900-0930 & OSD MBE/TDP Summit Objectives & Paul Huang/Simon Frechette \\
\hline 0930-1010 & $\begin{array}{l}\text { NIST Engineering Laboratory } \\
\text { Manufacturing Programs Overview }\end{array}$ & $\begin{array}{l}\text { Vijay Srinivasan, Simon Frechette, } \\
\text { Fred Proctor, Alkan Donmez, Mike } \\
\text { Shneier, NIST }\end{array}$ \\
\hline $1010-1030$ & Break & \\
\hline $1030-1110$ & $\begin{array}{l}\text { NASA Integrated Model-centric } \\
\text { Architecture }\end{array}$ & Paul Gill, NASA \\
\hline $1110-1150$ & $\begin{array}{l}\text { Integrated Data Management Strategy in } \\
\text { support of MBE life cycle management }\end{array}$ & Shelley Detrich, USGC \\
\hline $1150-1230$ & $\begin{array}{l}\text { Model Based Engineering/Manufacturing } \\
\text { Review from Y-12 }\end{array}$ & Donna Bennet, NNSA \\
\hline $1230-1330$ & Lunch Break & \\
\hline $1330-1400$ & $\begin{array}{l}\text { MBE Implementation at Enterprise Level } \\
\text { Requirements }\end{array}$ & James Delaporte, NexTec \\
\hline $1400-1430$ & Engineering Resilient System & Scott Lucero, OSD \\
\hline $1430-1510$ & EDA Overview & Dennis Thompson, ATI \\
\hline $1510-1530$ & Break & \\
\hline $1530-1730$ & DoD Program reviews & \\
\hline $30 \mathrm{~min}$ & Navy & Ben Kassel, NAVSEA \\
\hline $30 \mathrm{~min}$ & Air Force & Brench Boden, AFRL \\
\hline $30 \mathrm{~min}$ & DLA & Ric Norton, DLA-LIS \\
\hline $30 \mathrm{~min}$ & Army & Andrew Davis, RDECOM \\
\hline 1730 & Wrap-up & All \\
\hline
\end{tabular}


MBE/TDP Summit

NIST, Gaithersburg, MD

Green Auditorium

13 Dec. 2011

\begin{tabular}{|c|c|c|}
\hline Time & Topic & Speaker(s) \\
\hline $0730-0830$ & Registration & \\
\hline $0830-0840$ & Opening Remarks & Paul Huang/Simon Frechette \\
\hline 0840-0920 & Industry and ManTech Interaction success & David Baum, Raytheon \\
\hline 0920-0930 & MBE for QC/QA & John Horst, NIST \\
\hline 0930-1010 & $\begin{array}{l}\text { Critical Product Tolerance } \\
\text { Representation Requirements for } \\
\text { MBD and Metrology Interoperability }\end{array}$ & Curtis Brown, DoE/KCP \\
\hline $1010-1030$ & Break & \\
\hline $1030-1110$ & $\begin{array}{l}\text { MBD for Dimensional Quality within } \\
\text { a Heterogeneous Supply Base }\end{array}$ & Ron Snyder, Rolls Royce \\
\hline $1110-1150$ & $\begin{array}{l}\text { Improving First Article Inspection in a } \\
\text { Model-Based Environment }\end{array}$ & Ray Admire, Lockheed Martin \\
\hline $1150-1230$ & MBE - Enabler of Intelligent GD\&T & Bill Tandler, MultiMetrics \\
\hline $1230-1330$ & Lunch Break & \\
\hline \multirow[t]{2}{*}{$1330-1400$} & TDP Validation & Roy Whittenburg, UTRC \\
\hline & Vendor Session - MBD/MBE Capabilities & $\begin{array}{l}\text { Rich Eckenrode, Army-Support } \\
\text { CTR }\end{array}$ \\
\hline $1400-1430$ & Dassault Systemes & Bob Brown, Michael Melton \\
\hline $1430-1500$ & PTC & Mark Nielson \\
\hline $1500-1515$ & Break & \\
\hline $1515-1545$ & Siemens & Dennis Keating \\
\hline $1545-1615$ & SolidEdge & Ricky Black \\
\hline $1615-1645$ & SolidWorks & Craig Therrien \\
\hline $1645-1715$ & 3D PDF Consortium & Jim Merry \\
\hline \multirow[t]{2}{*}{$1715-1730$} & Wrap-up discussion & ALL \\
\hline & Q \& A session for vendors & \\
\hline
\end{tabular}




\section{MBE/TDP Summit}

NIST, Gaithersburg, MD

Green Auditorium

14 Dec. 2011 MIL-STD-31000 \& 973

\begin{tabular}{|c|c|c|}
\hline Time & Topic & Speaker(s) \\
\hline 0730-0830 & Registration & \\
\hline $0830-0845$ & Intro and Admin & Paul Huang/Simon Frechette \\
\hline 0845-0935 & MIL-STD-31000 Working Group Updates & \\
\hline $10 \mathrm{~min}$. & Acquisition WG & Gary Sunderland/Hank Oakes \\
\hline $10 \mathrm{~min}$. & Data Content WG & Ric Norton/Gordon Ney \\
\hline $10 \mathrm{~min}$. & Data Delievery WG & Roy Whittenburg/Paul Huang \\
\hline $10 \mathrm{~min}$. & Nomenclature & Simon Frechette \\
\hline $10 \mathrm{~min}$. & Manufacturing WG & Fred Proctor/Rich Eckenrode \\
\hline 0935-1030 & Review of 31000 & Ric Norton/Paul Huang \\
\hline $1030-1045$ & Break & \\
\hline $1045-1130$ & Review of 31000 & Ric Norton/Paul Huang \\
\hline $1130-1200$ & Customer Supplier Interoperability & John Gray, ITI \\
\hline $1200-1230$ & $\begin{array}{l}\text { Update on PowerLOG-J PLCS Adapter \& } \\
\text { PLCS Implementor Form }\end{array}$ & Scott Motquin, LOGSA \\
\hline $1230-1330$ & Lunch Break & \\
\hline $1330-1400$ & $\begin{array}{l}\text { Joint Service Product Data Requirement } \\
\text { Detrmination }\end{array}$ & John Campbell, ARDEC \\
\hline $1400-1500$ & MIL-STD-31000 Review of Appendices & Simon/Roy \\
\hline $1500-1520$ & Break & \\
\hline $1520-1700$ & MIL-STD-31000 Review of Appendices & Simon/Roy \\
\hline
\end{tabular}




\section{MBE/TDP Summit}

NIST, Gaithersburg, MD

Gaithersburg Hilton

15 Dec. $2011 \quad$ MIL-STD-31000 \& 973

\begin{tabular}{|l|l|l|}
\hline Time & Topic & Speaker(s) \\
\hline $0800-1045$ & MIL-STD-31000 WG breakout sessions & All \\
\hline $1045-1100$ & Break & Ric/Paul \\
\hline $1100-1230$ & Wrap-up and closing remarks & \\
\hline $1230-1330$ & Lunch Break & Paul Huang/Robert Morris \\
\hline $1330-1600$ & $\begin{array}{l}\text { AIA NAS3500 \& 31000 WG joint } \\
\text { discussion }\end{array}$ & Paul/Simon/Robert \\
\hline $1600-1630$ & Wrap-up and closing remarks & \\
\hline
\end{tabular}

http://www.nist.gov/el/msid/tdpsummit_2011.cfm 
- Overview of DEDMWG History

Dom

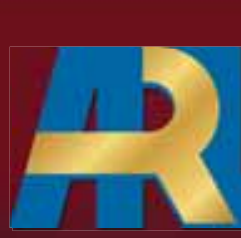

TECHNOLOGY DRIVEN. WARFIGHTER FOCUSED.

DEDMWG and MIL-STD-31000 Overview and Status of Model Based Definition Efforts

Paul Huang, U.S. Army Research Laboratory

28 Nov. 2011
- DEDMWG relationship within DoD/ManTech Community

- Scope \& Objectives

- Current Relevant Projects

- Accomplishments

- Summary and Gaps

- Questions

\section{(7) तैDECOM}

November 2008 .

$>$ DoD Engineering Drawing and Modeling Working Group (DEDMWG) established by the Services and DoD in 2008 to establish a Community of Interest for sharing and leveraging ideas, tools, processes, and to be a unified voice within DoD and to Industry Standard Groups.

> Membership includes all the Services, Coast Guard, DoD and Industry partners. A Workspace is located at the Acquisition Community Connection (ACC).

First task taken on was the update to MIL-DTL-31000C, which is being converted to a MIL STD. Also looking to update associated Data Item Descriptions (DIDs) Accomplished Nov 2009.

> Charter has been endorsed by OSD ManTech Director 29 June 2010

> Held multiple workshop/summits with SME from all services, NIST, NASA, USCG, Industry, Academia participants. The last meeting was in July 2011 with next meeting on 14-15 Dec.2011.

TECHNOLOGY DRIVEN. WARFIGHTER FOCUSED.

\section{(7) HUTECOM Leverage Between JDMTP,} AME Subpanel \& DEDMWG

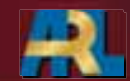

Defens

Manufacturing

Enterprise

Defense Tech Data Standards Enterprise (System Design, Production,

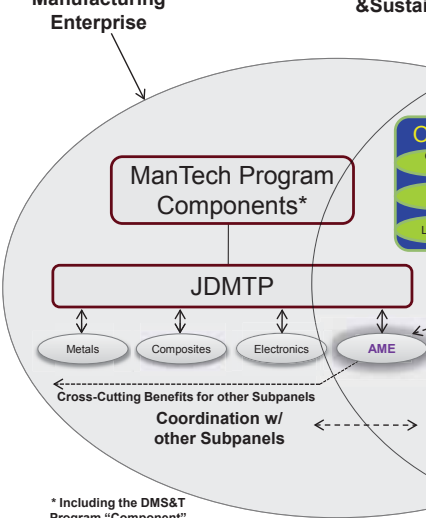

Approved for public release: Distribution unlimited

\section{3 निIIECOM \\ Scope and Objectives}

I. Scope:

DoD Engineering Drawing and Modeling Working Group (DEDMWG) is chartered to lead efforts for technical coordination and policy guidance on weapon systems technical data for acquisition, product design, analysis, simulation, manufacturing, provisioning and other product lifecycle management functions within a Model Based Enterprise (MBE). This includes offering guidance on technical data requirements for computer-aided design, engineering, manufacturing, data repository, data archival/retrieval tools, and related applications for total product lifecycle management.

II. Goals \& Objectives:

Establish a group of respected subject matter experts (SMEs) across the DoD technical acquisition communities.

Work with DoD organizations to establish requirements for acquisition defined in the scope. Investigate state of the art tools and technologies.

Revise current DoD specifications, standards, handbooks and other documents to incorporate requirements and guidance for (acquisition and management of) state-of-the-art modelbased technical data.

Partner with government and non-government organizations that develop specifications and standards that are suitable for DoD Acquisition Programs to ensure DoD requirements are being met.

Work with domestic and international partners to access technology and tools to allow the DoD community to effectively perform life cycle support activities related to technical data, and define the terminology and definitions for this activity.

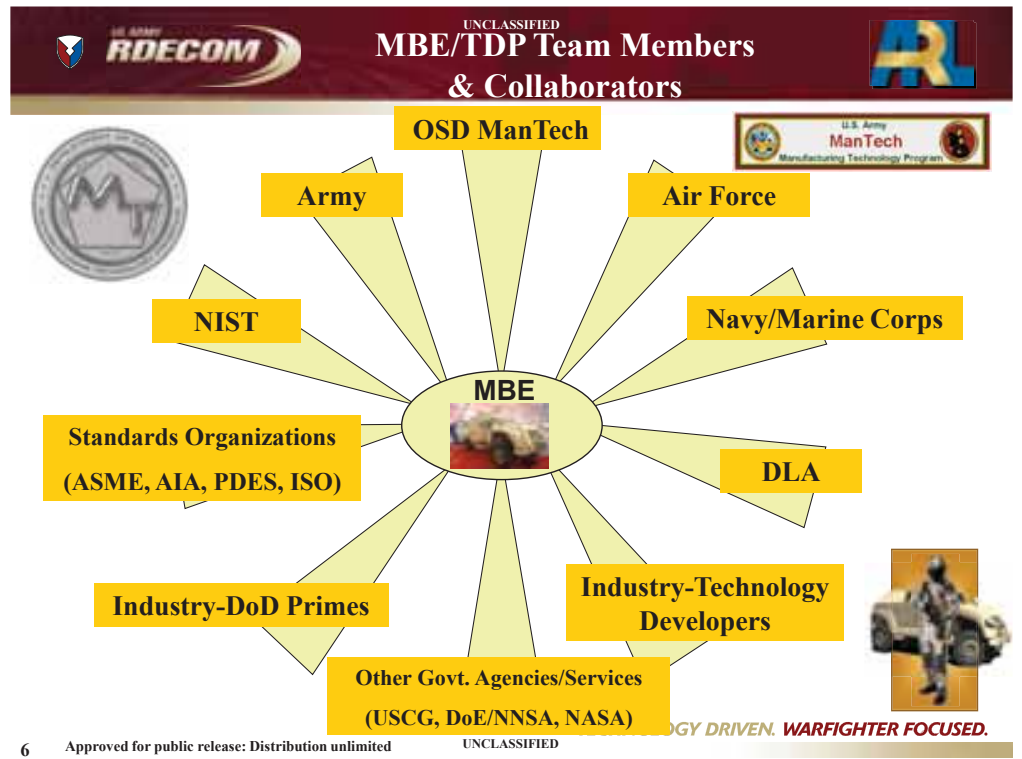



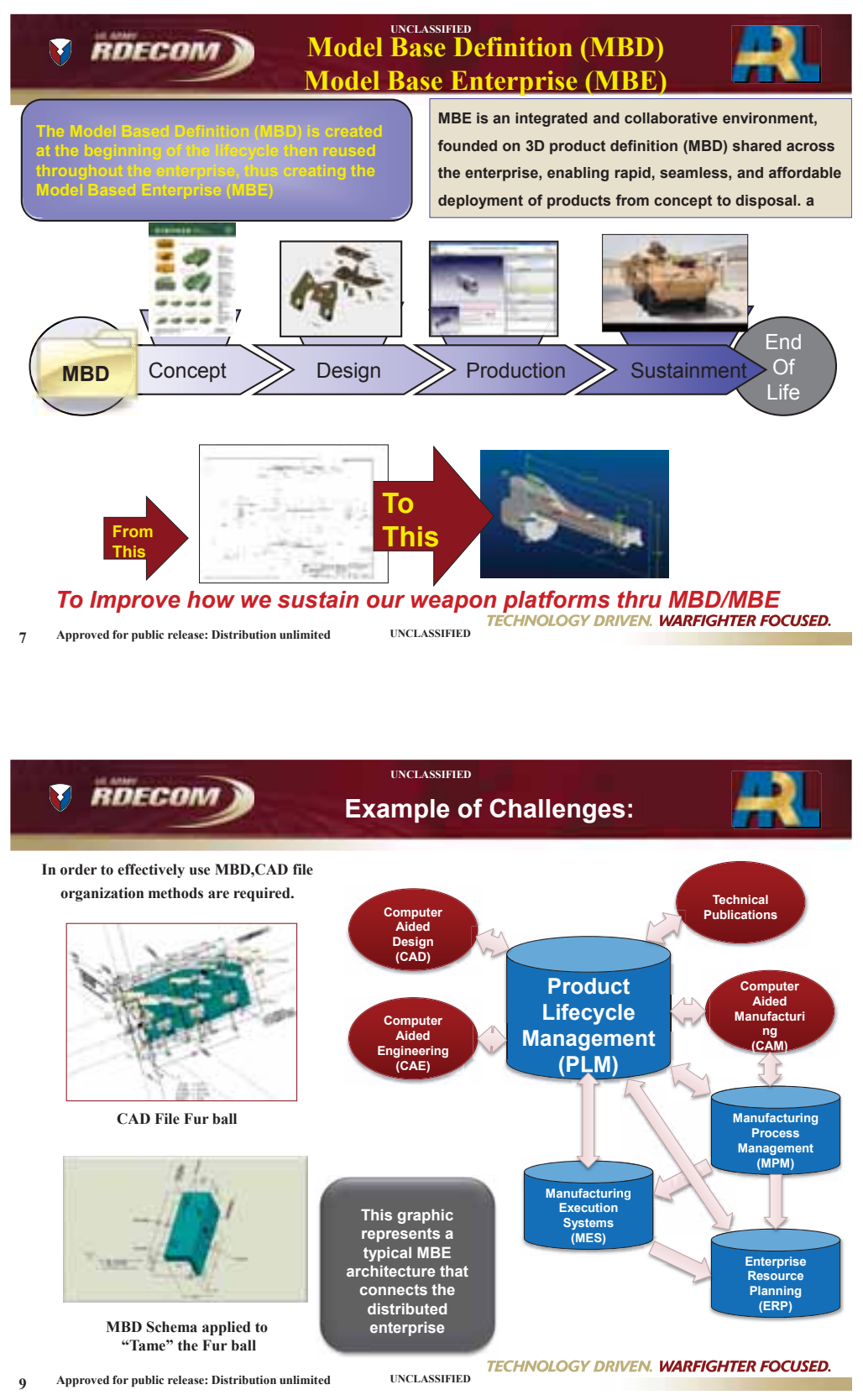

\section{B)} One Standards the Only Solutions?

Standards by themselves are not sufficient, but guidance/policy are required for implementation

Performance/Requirement (P.R.) ' $X$ '

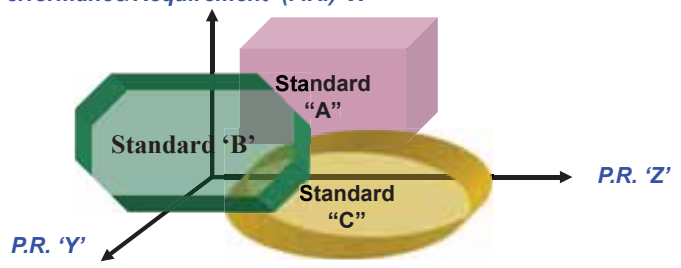

How do we determine which is the Applicable Standards based on the mission/requirements/performance to put on contracts?

Most often not one fits but several from various government/industry/associations, so how do we choose them correctly?

As technologies changes standards are usually lagging, how do we link them and speed up development to keep pace, but without overburden our acquisition personnel?

\section{(3) REEOM) ISO 10303 AP 242 Harmonization}

- AP203, Configuration controlled 3D designs of mechanical parts and assemblies.

- AP203 applies to representations of mechanical parts and assemblies.

- AP203 files typically contains the boundary representation model, assembly data, and a limited amount of other product information.

- AP214, Core data for automotive mechanical design processes

- AP214 applies to representations of data relating to automotive design.

- AP214 files typically contain colors, layers, and generic resources.

- AP242, Managed model based 3D engineering (under development)

- New AP combining AP203 and AP214

- The objective is to develop a common application protocol for the automobile and aerospace industry.

- Bundling the activities allows reacting faster industrial requirements.

- Allow for integrating technologies like UML (Unified Modeling Language) and XML (Extensible Markup Language)

- Lowers the costs for standard maintenance.

- Envisioned to become the backbone for data exchange, data-sharing, visualization, and long-term archiving.
(7) ATECOM

\section{Current \& Re} ManTech Projects

- 3D Tech Data Package (TDP) Definition

- Revision of MIL-STD-31000

- Influencing other standards

- Defining processes

- 3D Validation

- Defining a certified 3D Model

- Validation processes for the Model and the TDP

- Supply Chain

- MBD Summits to raise MBE Literacy

- Reuse of 3D TDP in Techpubs

- Influencing Standards

- Proof of concept
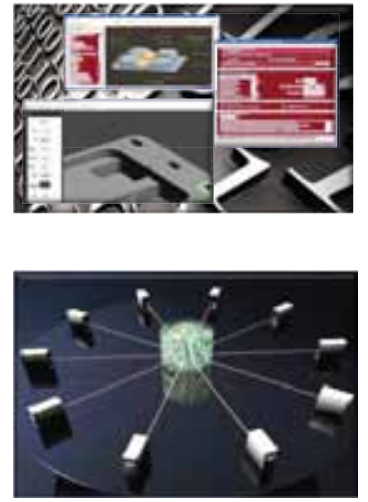

(3) तैDECOM UNCLASSIFIED
Accomplishments to Date

- Converted and updated MIL-DTL-31000C to MIL-STD-31000 (Nov. 2009)

- Held multiple workshops at NIST where over 60 SMEs participated in revision to MIL-STD-31000

- In process to seek to reactivate MIL-STD-973 Configuration Management

- Close coordination with ASME Y14.41 and AIA NAS3500

- Joined PDES Inc. to collaborate in various STEP AP development and to monitor LOTAR.

- Coordinating with NIST, NASA, USCG and DoE

- Refining annotations and delivery schemas, and validation guidebook into MIL-STD-31000

- Next MBE/TDP Summit will be held 12-15 Dec. 2011 at NIST 


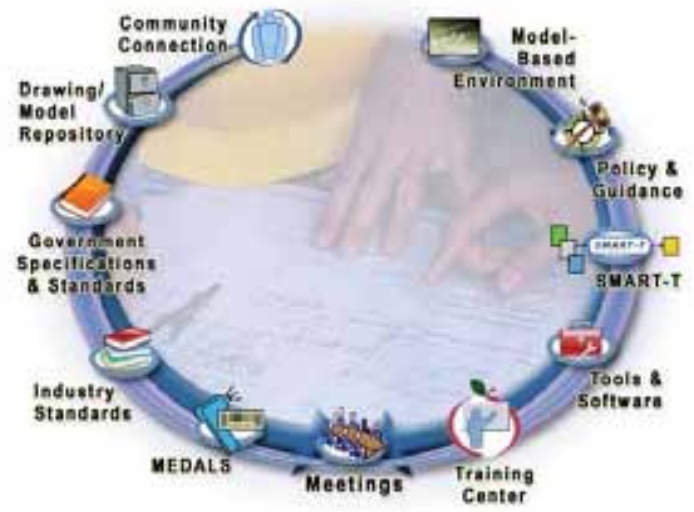

https://acc.dau.mil/dedmwg
13
DRIVEN. WARFIGHTER FOCUSED.
- The DoD has made a commitment to adopting MBE

- The team has made great progress towards creating a standard 3D TDP process, and demos.

- A process for validating 3D TDP quality is nearing completion of phase I

- We are committed to raising the MBE literacy throughout the supply chain and the DoD

- Still a long road to fully implement MBE and adoption within DoD

\section{BACK UP SLIDES}
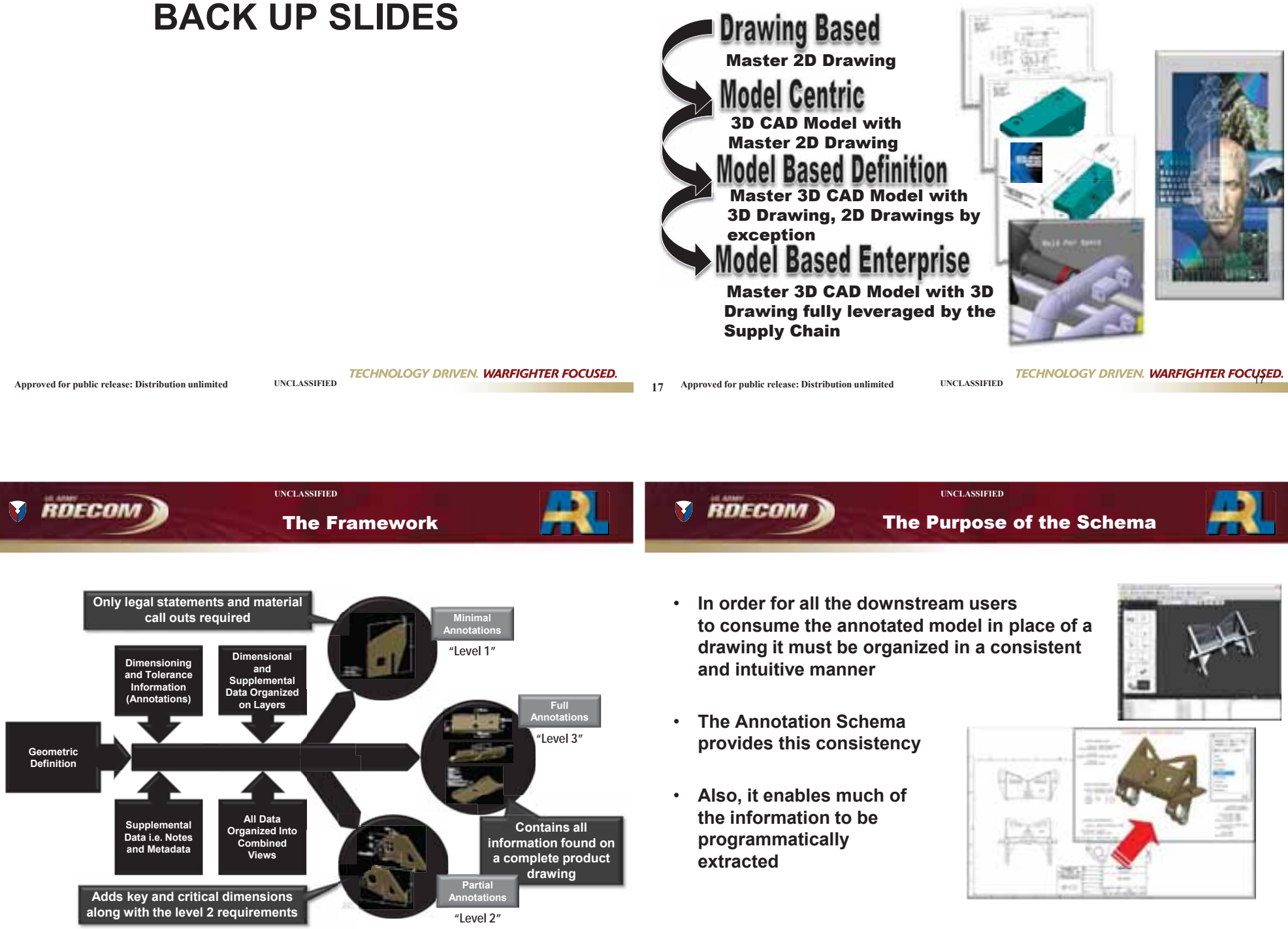

- In order for all the downstream users to consume the annotated model in place of a drawing it must be organized in a consistent and intuitive manner

- The Annotation Schema provides this consistency

- Also, it enables much of the information to be programmatically extracted

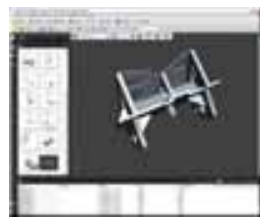



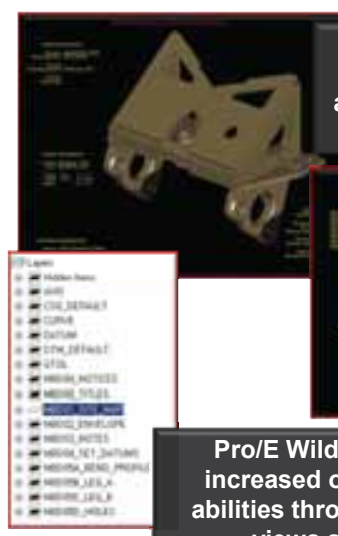

All data that is normally contained in a drawing is now available in a readable format in the Pro/E Model

Pro/E Wildfire provides

increased organizational abilities through combined views and layers

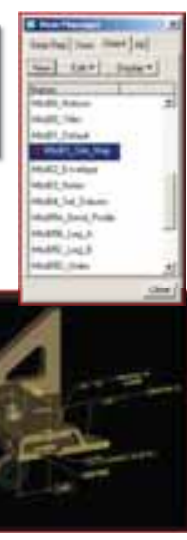

ECHNOLOGY DRIVEN. WARFIGHTER FOCUSED.

The main purpose of
the 3D TDP is to
provide all
Downstream users a
3D data set that they
can reuse with out
re-mastering the data
For suppliers this
means they will have
the ability to drive
their CAM software
straight from the
model along with
numerous other
process
All of this reduces the
time to mission for
the Warfighter

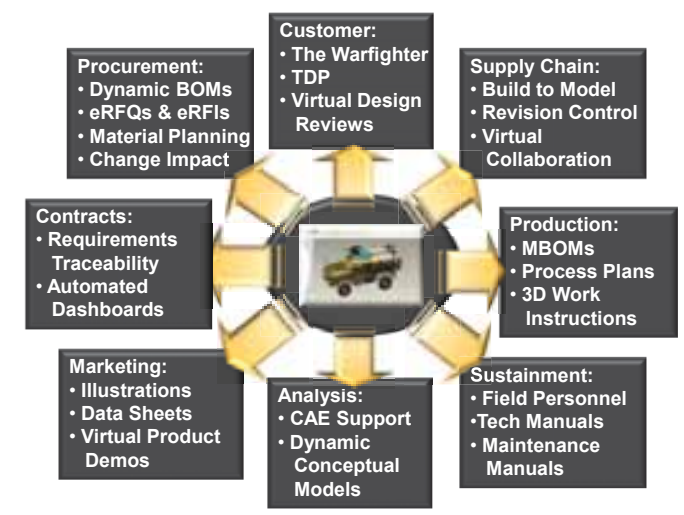

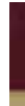

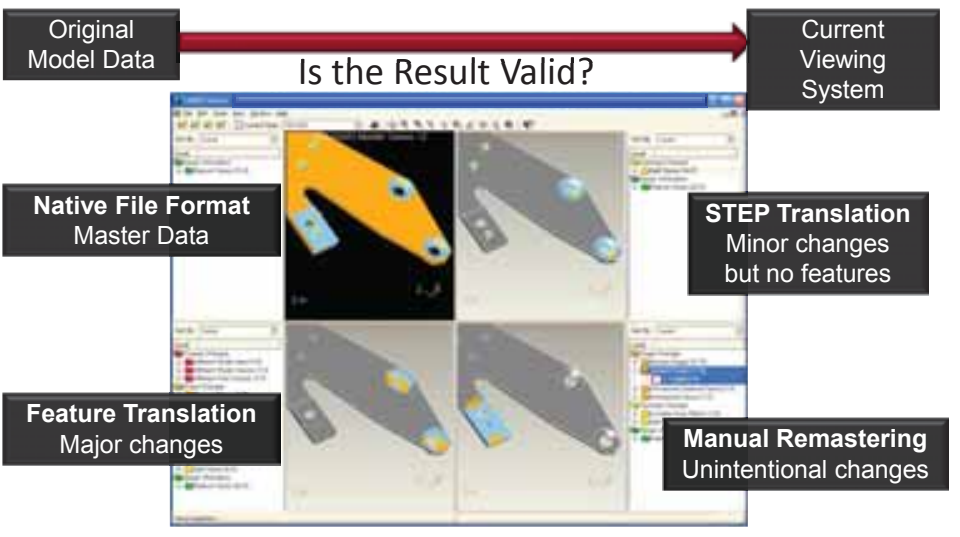

TECHNOLOGY DRIVEN. WARFIGHTER FOCYSSED.

\section{( $)$ ATECOM}

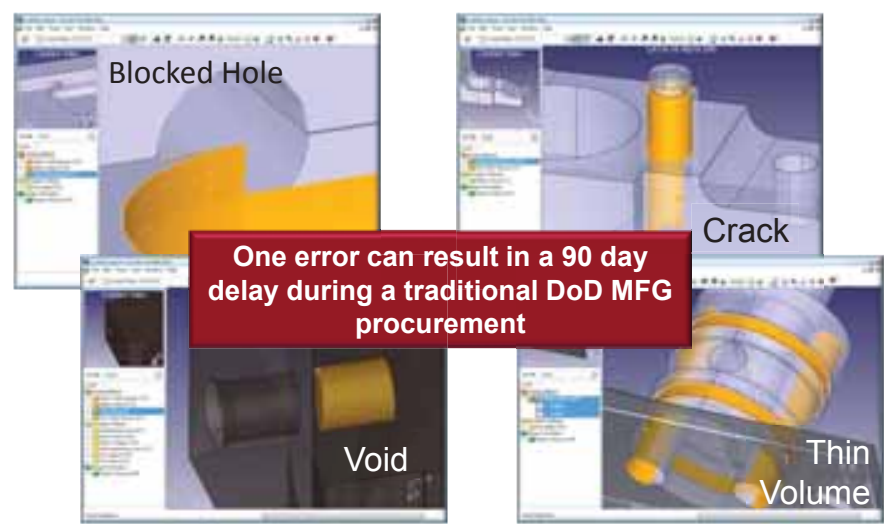

TECHNOLOGY DRIVEN. WARFIGHTER FOCYȘED.

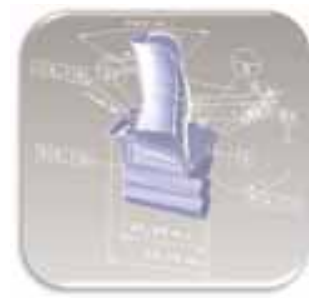

Specialized Data

Geometry Graphics

Annotations (GD\&T, PMI)

Model Structure

Model Attributes Geometry Attributes

Wireframe Geometry

Solid \& Surface Geometry

Metadata
TECHNOLOGY DRIVEN. WARFIGHTER FOCYSSED.

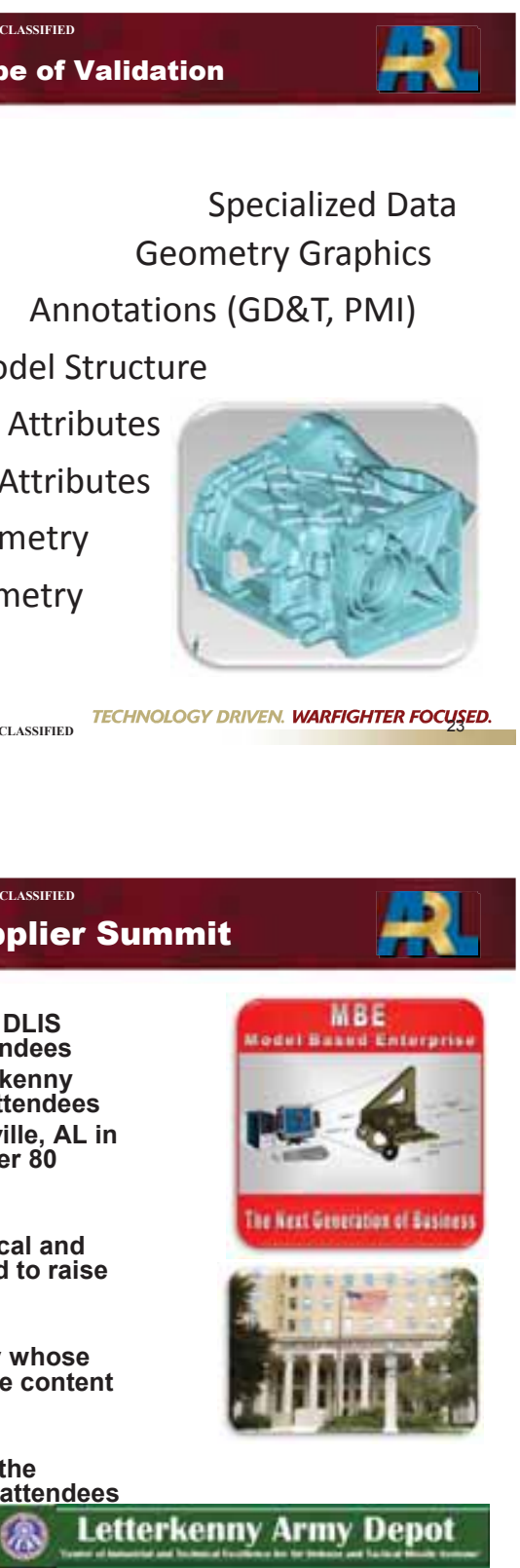

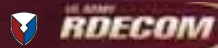

- Conducted $1^{\text {st }}$ summit at DLA - DLIS Battlecreek, MI with over 80 attendees

- Conducted $2^{\text {nd }}$ summit at Letterkenny Army Depot, PA with over 100 attendees

- Conducted $3^{\text {rd }}$ summit at Huntsville, AL in coordination with NASA with over 80 attendees

- Consisted of a full day of technical and business presentations intended to raise their MBE literacy

- Participants completed a survey whose results will be used to modify the content of the next summit

- The surveys also indicated that the summits were a success by the attendees responses 
- Product Definition within the CAD model

- Methods for organizing the PMI contained within the model (CAD Model Schema)

- Developing requirements for enabling annotated models within the light weight viewers

- PLM Schema for storing and delivering a 3D TDP

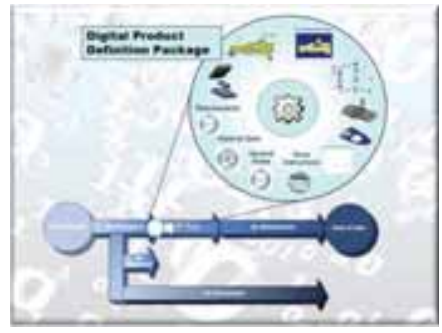

TECHNOLOGY DRIVEN. WARFIGHTER FOCUSED.

\section{enginecring laboratory}

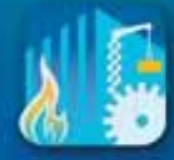

NIST Activities in

Model-Based Engineering

\section{The NIST Laboratories}

NIST's work enables

- Advancing manufacturing and services

- Helping ensure fair trade

- Improving public safety and security

- Improving quality of life

NIST works with

- Industry

- Academia

- Other agencies

- Government agencies

- Measurement laboratories

- Standards organizations

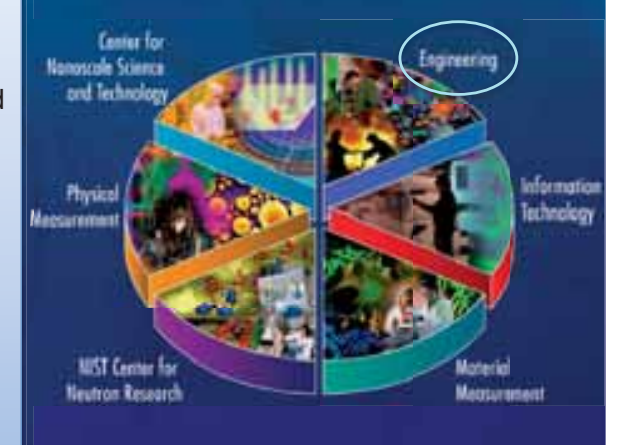

\section{Engineering Laboratory Mission}

To promote U.S. innovation and industrial competitiveness in areas of critical national priority by anticipating and meeting the:

- measurement science and

- standards

needs for technology-intensive manufacturing, construction, and cyber-physical systems in ways that enhance economic prosperity and improve the quality of life. 


\section{Engineering Laboratory Vision}

To be the source for:

- creating critical solution-enabling measurement science, and

- critical technical contributions underpinning emerging standards, codes, and regulations

that are used by the U.S. manufacturing, construction, and infrastructure industries to strengthen leadership in domestic and international markets.

EL is the primary federal laboratory serving the manufacturing and construction industries

\section{Engineering Laboratory Role in Manufacturing}

- U.S. manufacturing is challenged by aggressive competition

- U.S. manufacturers rely on enhanced innovation, productivity, and quality to compete successfully

- EL helps manufacturers to compete more effectively by providing measurement science to help advance standards and technology
Driving Manufacturing Technology Innovation Through Measurements and Standards

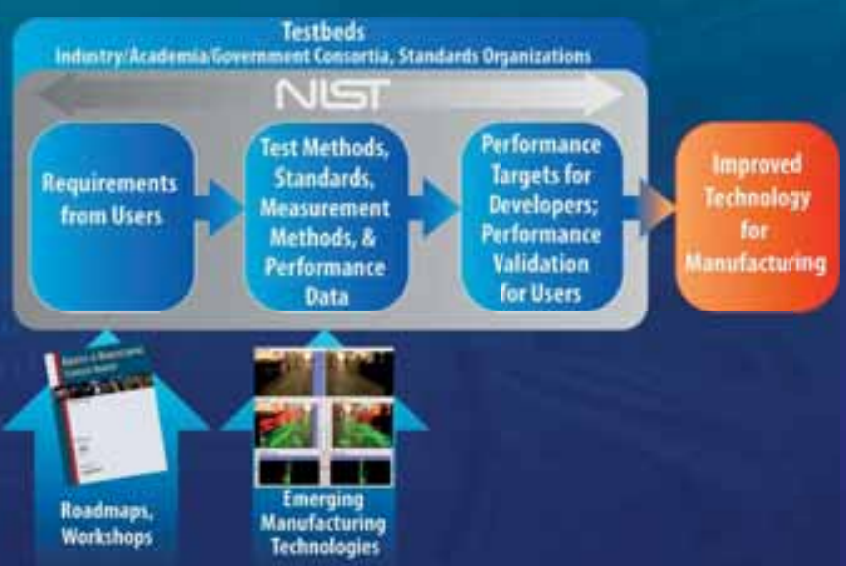

\section{EL Manufacturing Program Portfolio}

Smart Manufacturing, Construction, and Cyber-Physical Systems Strategic Goal:

- Smart Manufacturing Processes and Equipment

- Next-Generation Robotics and Automation

- Smart Manufacturing and Construction Systems

- Systems Integration for Manufacturing and Construction Applications

Sustainable and Energy-Efficient Manufacturing, Materials, and Infrastructure Strategic Goal:

- Sustainable Manufacturing

- Sustainable, High-Performance Infrastructure Materials

- Net-Zero Energy, High-Performance Buildings

- Embedded Intelligence in Buildings

\section{SMART MANUFACTURING PROCESSES AND EQUIPMENT PROGRAM}

\section{Alkan Donmez}

\section{Smart Manufacturing Processes and Equipment Program}

Objective: To develop and deploy advances in measurement science that will enable rapid and cost-effective production of innovative, complex products through advanced manufacturing processes and equipment

Measurements and standards enabling smart (self aware, self diagnosed, adaptive and optimized) processes and equipment

THRUST AREAS:

Metal-based additive manufacturing - addressing the needs to understand, identify, and reduce uncertainties in metal powder characteristics coupled with uncertainties in the AM process and equipment that lead to uncertainties in the final product

Smart machining - addressing the needs for rapidly turning new materials and designs into products by integrating modeling and simulation with real-time measurements to optimize processes and equipment

Micro- and nano-manufacturing - addressing the needs for improving the quality and yield of micro- and nano-scale products through new measurement methods for improved process control

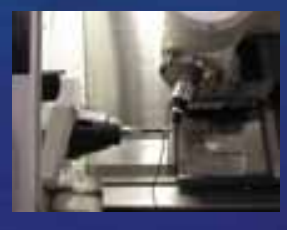

Contact: Alkan Donmez alkan.donmez@nist.gov 


\section{Metal-Based Additive Manufacturing}

Rapid art-to-part capability of fabricating complex structures - revolutionary potential

Key barriers to the widespread adoption of metal-based additive processes:

part accuracy

surface finish

material properties

process certification

process speed

data formats

lack of standards

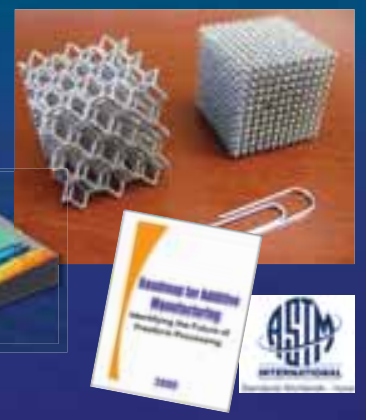

NIST role:

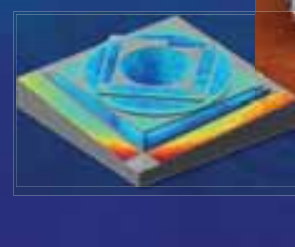

Identified barriers and research needs

Evaluated research on machine/process performance

Helped form Standards Committee F42 on Additive

Manufacturing Technologies (founded 2009)
Metal-Based Additive Manufacturing

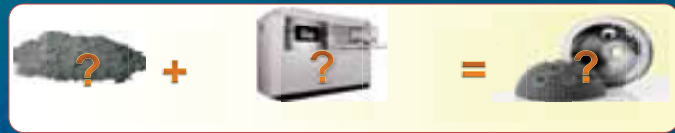

Properties of both bulk metal materials and raw metal powder

- Design of new test artifact for ASTM standard

- Powder characterization

- Mechanical testing

(indentation and fracture

testing for strength)

Non-destructive techniques (porosity, modulus)

Determine the sensitivity of part material properties to variations in powder properties
- Test methods for thermal measurements within the build chamber

- Test methods evaluating geometric errors of AM equipment

- Measurement systems and methods for in-situ monitoring and closed-loop process control

- Determine sensitivity of process parameters to final product properties

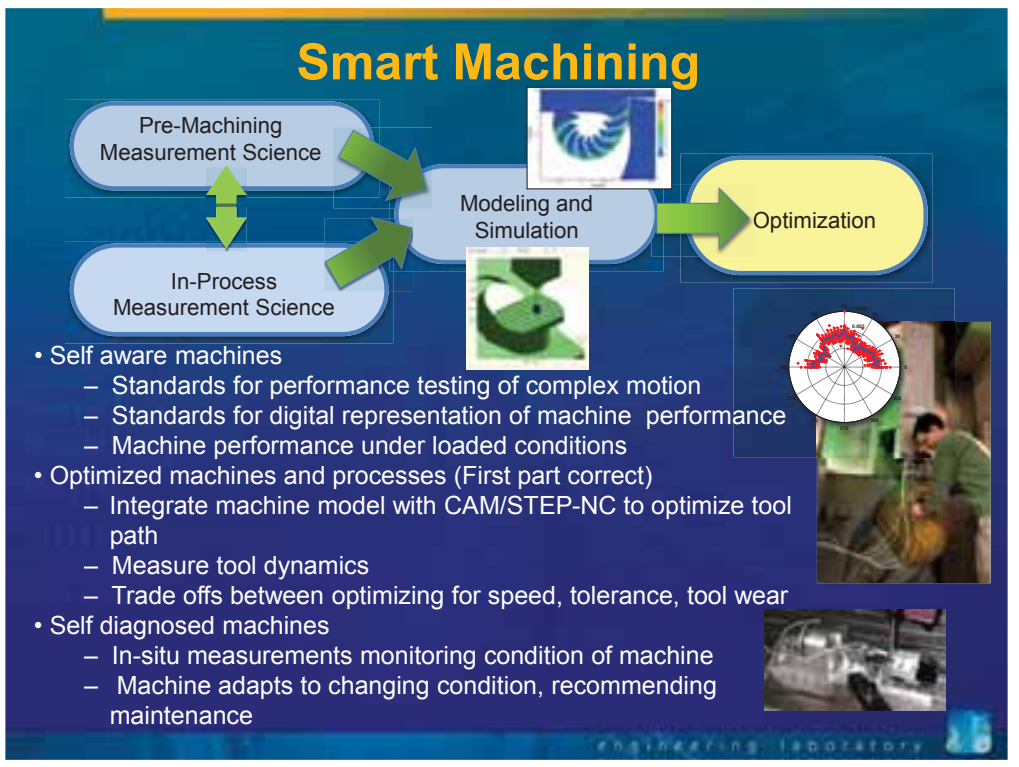

Closed-loop manufacturing of complex micro optics

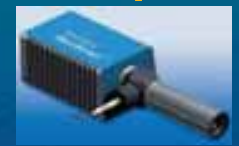

Integrate commercially available measurement system(s) with the diamond turning machine

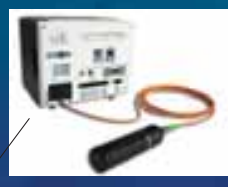

Develop \& implement workpiece reference marks

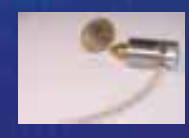

Develop test methods, measurement artifacts, $\&$ uncertainty budgets

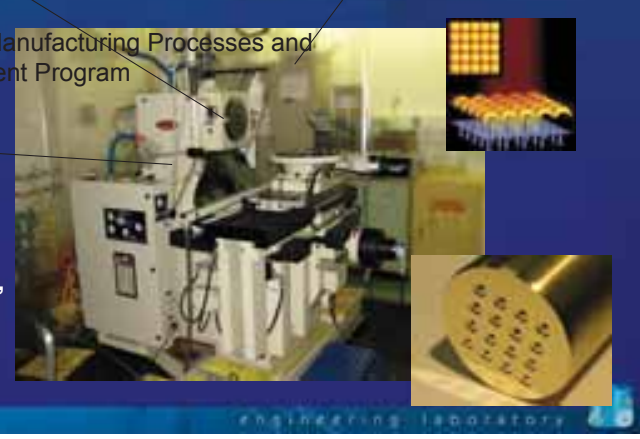

Connecting Fundamental to Applied to Practice: Bridging the Gap through a New Consortium
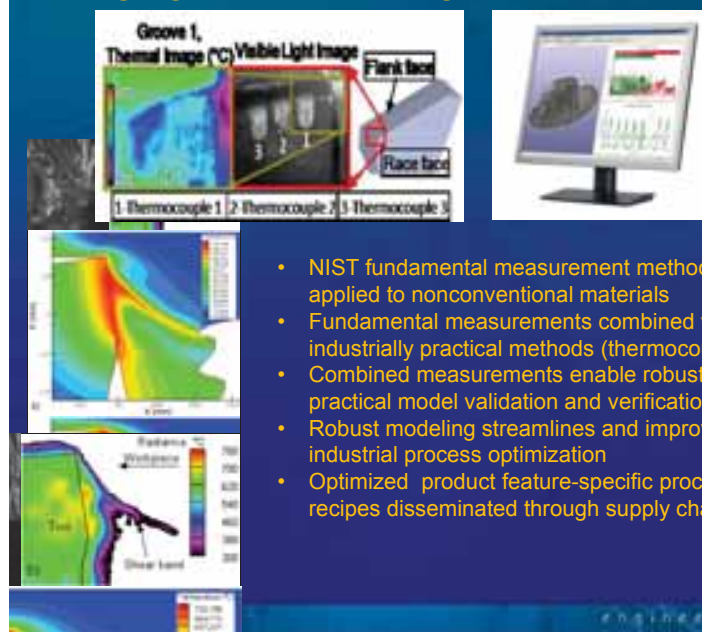

NIST fundamental measurement methods applied to nonconventional materials

Fundamental measurements combined with industrially practical methods (thermocouple) Combined measurements enable robust and practical model validation and verification Robust modeling streamlines and improves industrial process optimization Optimized product feature-specific process recipes disseminated through supply chain

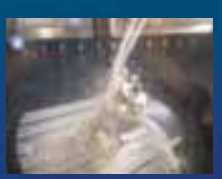
T:

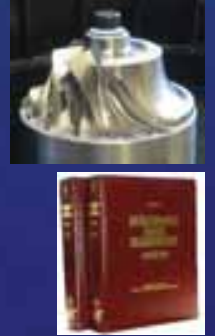

28

\section{NEMS measurement science}

Development and improvement of measurement techniques to characterize the performance of NEMS devices to be used both for in-process measurement of nanomanufacturing processes and the measurement of nano-scale products

Research activities include: - Improvement of Nanoscale Motion Microscope (NMM) and Near-field Scanning Optical Microscope (NSOM)

- Modal analysis at the nanoscale to understand variations in

fabrication and failure mechanisms - Automated measurements of multi-NEMS on a single chip as a step towards production line automation

- Interactions with MEMS/NEMS industry for a proposed Workshop

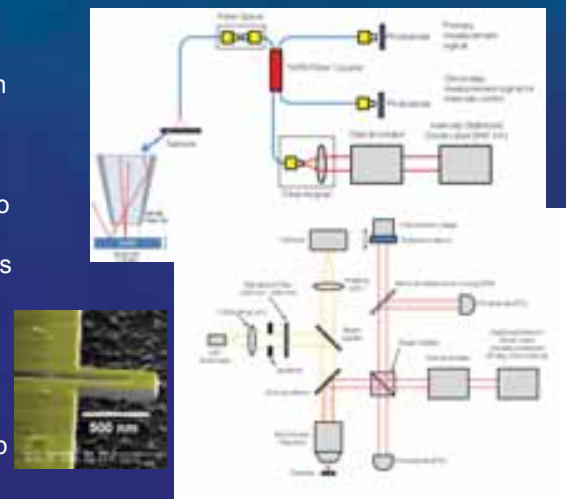




\section{NEXT GENERATION ROBOTICS AND AUTOMATION PROGRAM}

\author{
Mike Shneier
}

\section{Next Generation Robotics and Automation Program}

Objective: To develop and deploy advances in measurement science to safely increase the versatility, autonomy, and rapid re-tasking of intelligent robots and automation technologies for smart manufacturing and cyber-physical systems applications in the following thrust areas:

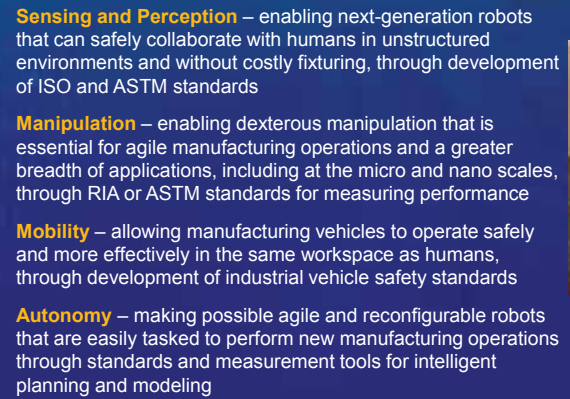

Manipulation - enabling dexterous manipulation that is essential for agile manufacturing operations and a greater breadth of applications, including at the micro and nano scales, through RIA or ASTM standards for measuring performance

Mobility - allowing manufacturing vehicles to operate safely and more effectively in the same workspace as humans, through development of industrial vehicle safety standards

Autonomy - making possible agile and reconfigurable robots that are easily tasked to perform new manufacturing operations through standards and measurement tools for intelligent planning and modeling

\section{Sensing and Perception}

- Reduce the need for fixturing

- Enable adaptation to variations in parts

- Enable in-process inspection

- Extend robots to unstructured environments

- Develop performance measures for sensors used to monitor the work area and ensure safety of people, robots, and vehicles

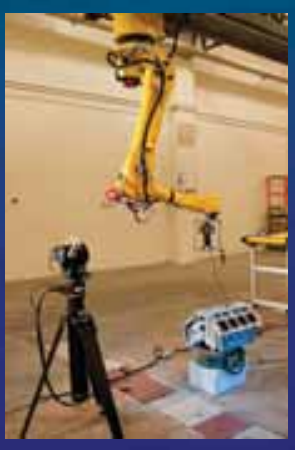

\section{Manipulation}

- Develop performance measures for dexterous manipulation

- Develop dynamic force measurements and force-based control of manipulation

- Develop collaborative manipulation strategies for safe human-robot or robot-robot operations

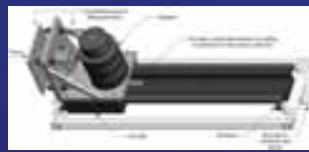

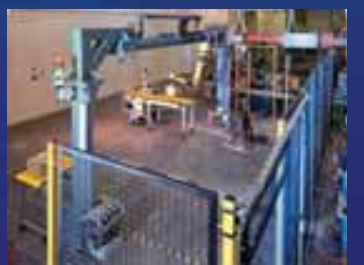

\section{Mobility}

- Develop standards for safety of manufacturing vehicles

- Develop methods to enable sensors on a vehicle to interoperate and provide combined information

- Develop standards to enable vehicles from different manufacturers to work together

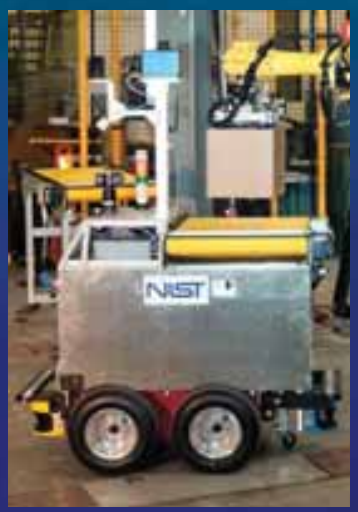

\section{Autonomy}

Develop planning algorithms for manufacturing applications

- Develop standard ways of representing information that facilitate planning and can be easily ported to new applications

- Develop performance measures for the accuracy and completeness of planning systems

- Develop standard methods to validate simulation models to ensure that they accurately reflect the real world
Develop measurement methods and sensors for micro- and nanoscale objects

Enable scale-up from the micro- to the macro-scale

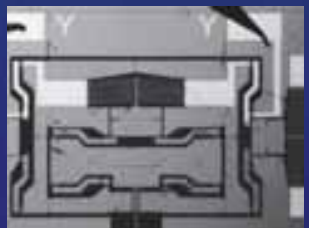




\section{SMART MANUFACTURING SYSTEMS PROGRAM}

Fred Proctor

\section{Smart Manufacturing Systems Program}

Objective: To develop and deploy advances in measurement science to enable real-time monitoring, control, and performance optimization of smart manufacturing systems in the factory

- Factory Networks - enabling cost savings and ease of integration for factory networks of equipment and sensors by developing performance and conformance tests for data exchange and cybersecurity standards through IEEE and ISA

Information Modeling and Testing - enabling seamless information exchange throughout production activities by developing validation and conformance tests for information exchange standards through ISO and the Dimensional Measurement Standards Consortium (DMSC)

Performance Measurement and Optimization enabling optimization of manufacturing across the shop floor by developing standards for measuring key performance indicators through the Association for Manufacturing Technology (AMT)

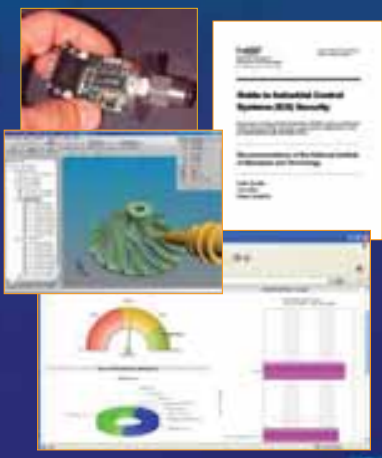

\section{Factory Networks: Testing}

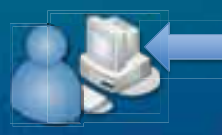

NIST's open-source factory network testing software measures the performance of networked devices to standards like Industrial Ethernet

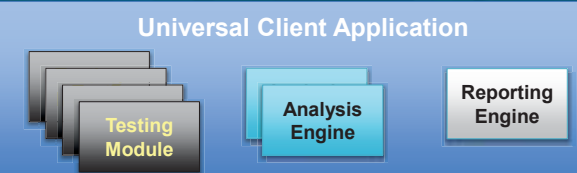

\section{9}

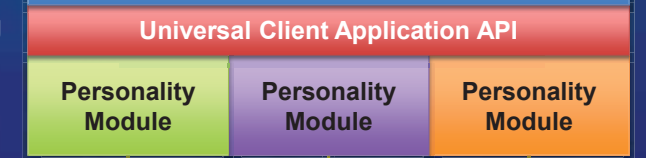

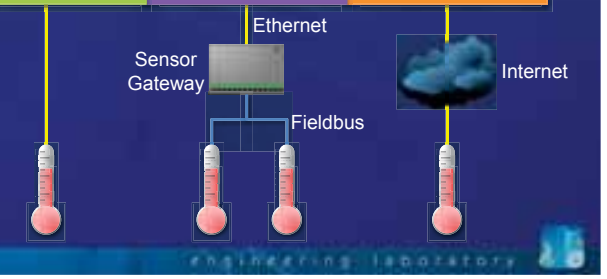

\section{Performance Measurement and Optimization}

Standards like MTConnect enable collection of real-time production information, driving "dashboard" applications that show key performance indicators

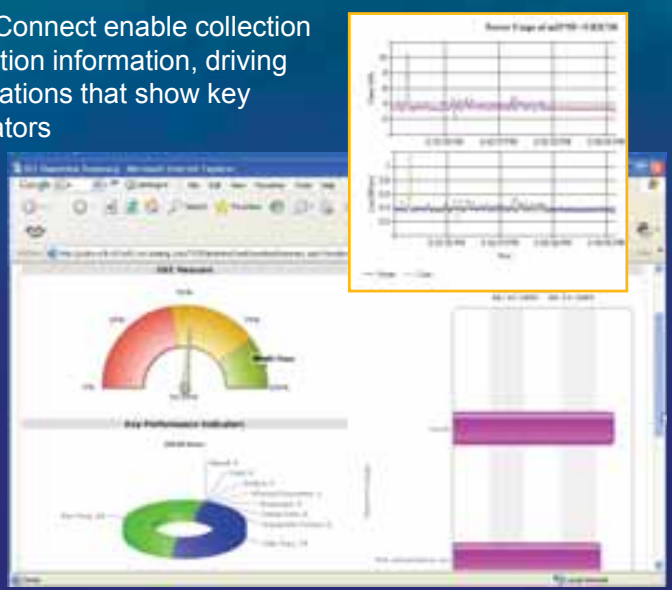

\section{Information Modeling and Testing}

NIST helps validate standards for manufacturing information exchange, and measure performance and conformance

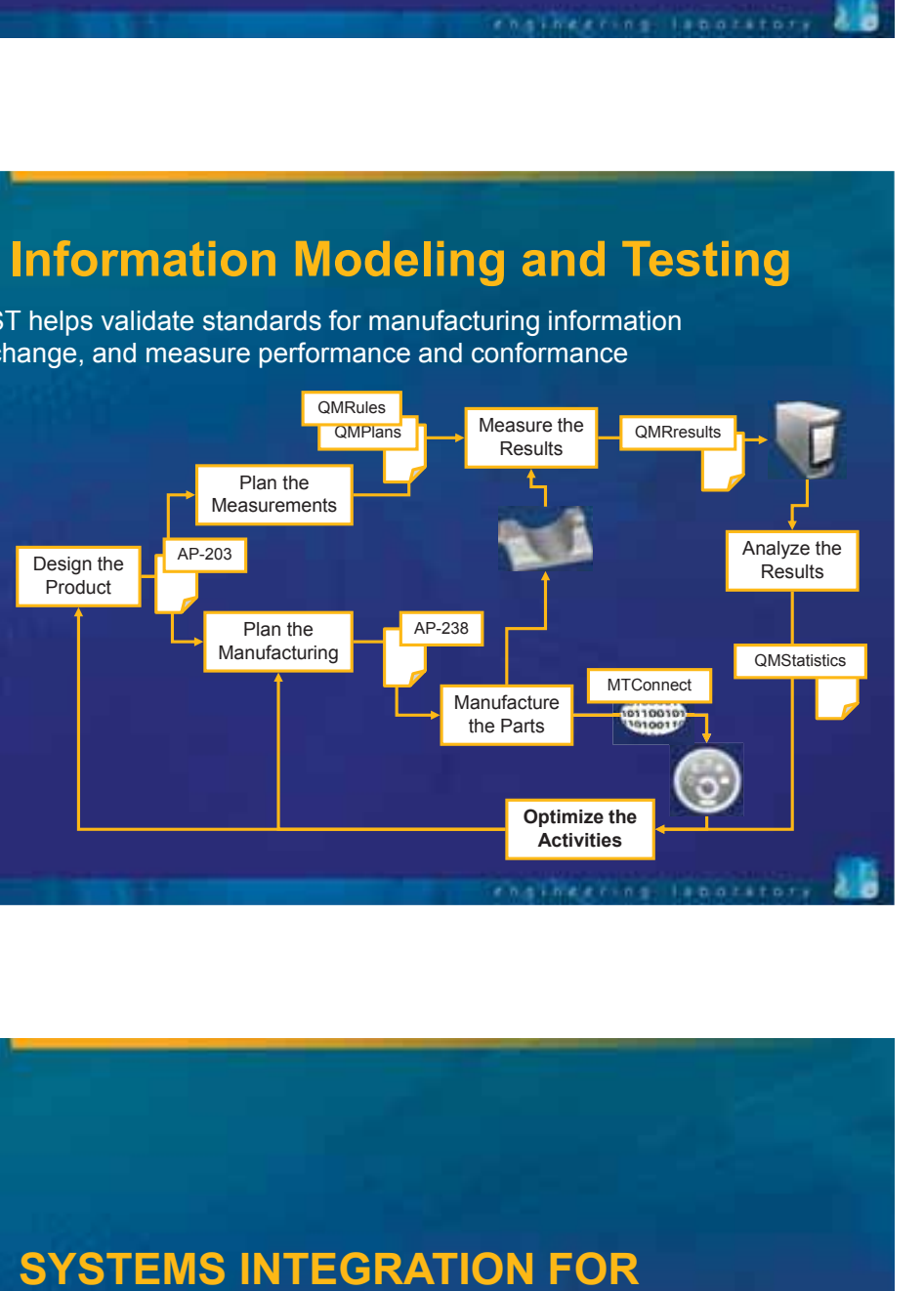

SYSTEMS INTEGRATION FOR MANUFACTURING AND CONSTRUCTION APPLICATIONS PROGRAM

Simon Frechette 


\section{Systems Integration for Manufacturing and Construction Applications Program}

Objective: To develop and deploy advances in measurement science for integration of engineering information systems used in complex

manufacturing networks to improve product and process performance

Engineering Systems Integration - Enabling system engineering standards that will reduce cycle time from product development to manufacturing

Production Network Integration - Enabling network integration standards to improve efficiency and agility, and support new manufacturing services model

Production Network Data Quality - Developing and testing standard methods for quantifying the quality of engineering and manufacturing data
SIMCA is the Gateway to Production Networks

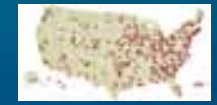

Production Network

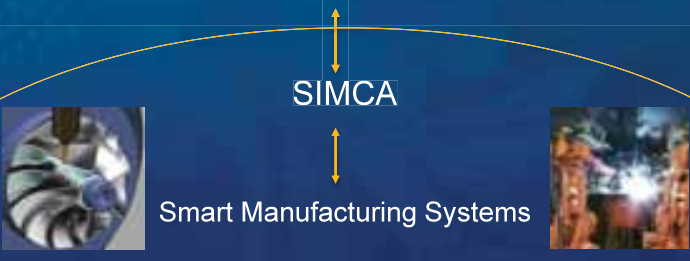

Next Generation Robotics and Automation Systems

Smart Manufacturing Processes and Equipment

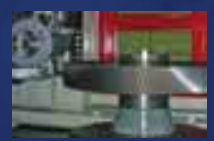

\section{A Network of Enterprises}

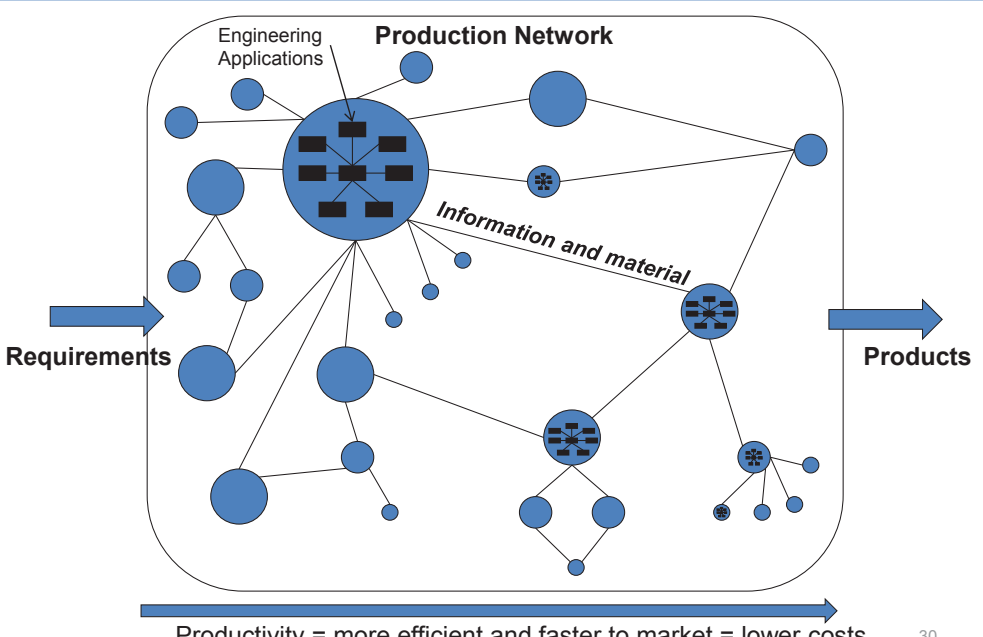

Productivity $=$ more efficient and faster to market $=$ lower costs

\section{SIMCA Strategy}

The SIMCA program addresses measurements and standards for

- model-based engineering (MBE)

- systems engineering (SE)

- production network integration

- engineering data quality
Production Network Enterprises Each have a Unique Set of Engineering Applications

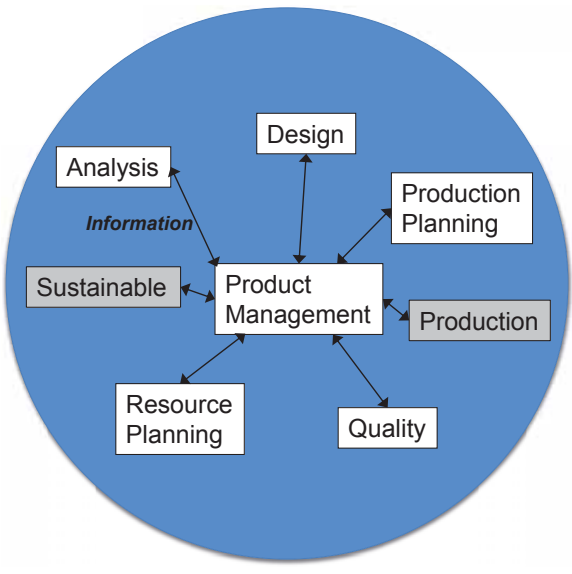

Seamless Access to Information Throughout the Product Lifecycle Greatly Improves Productivity

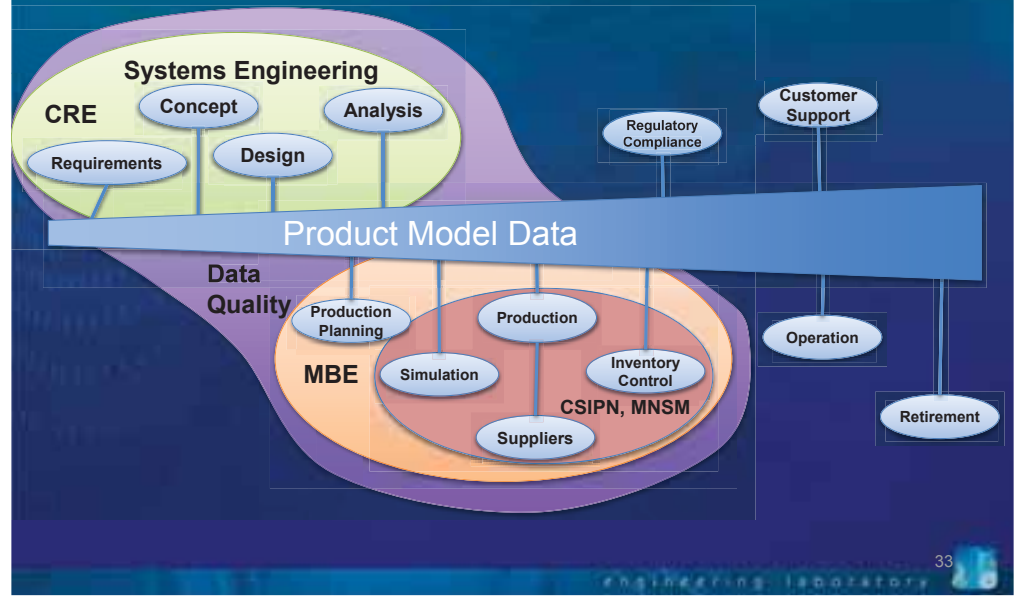




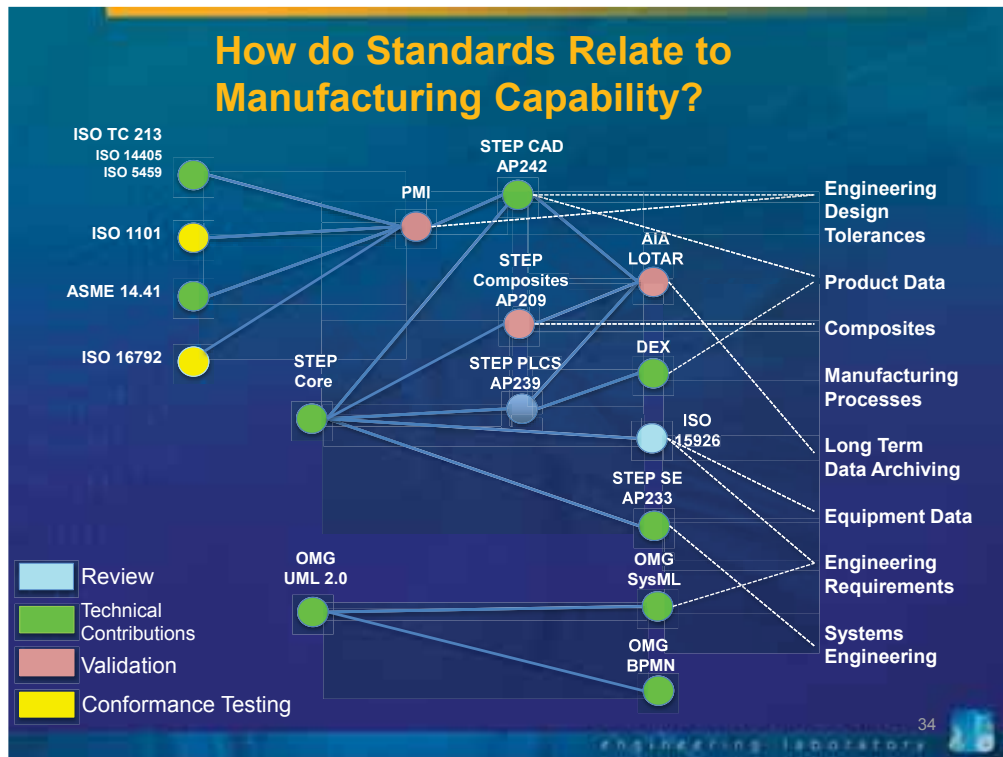

ISO PMI Standards Roadmap for CAD/CAM/PLM Software Vendors

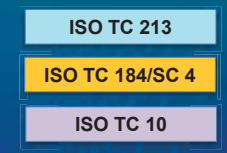

PMI 1.0 PMI 2.0

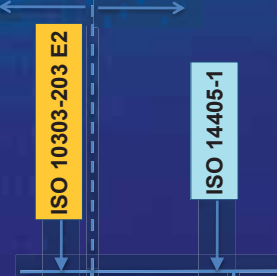

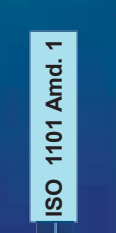

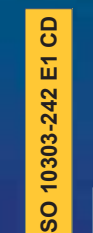

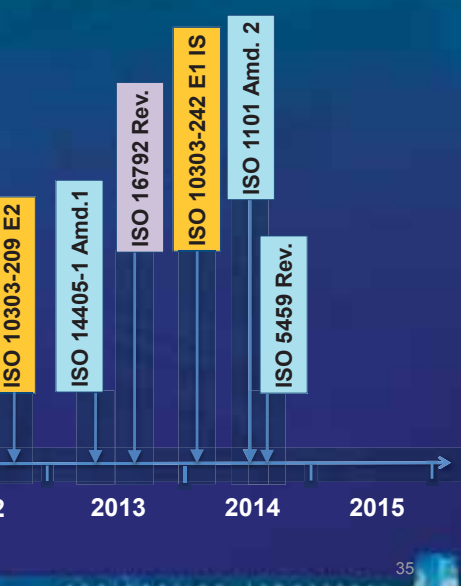

Geometric \& Dimensional Tolerance Conformance Tests are Needed to Validate New Software Tools and Integration Standards

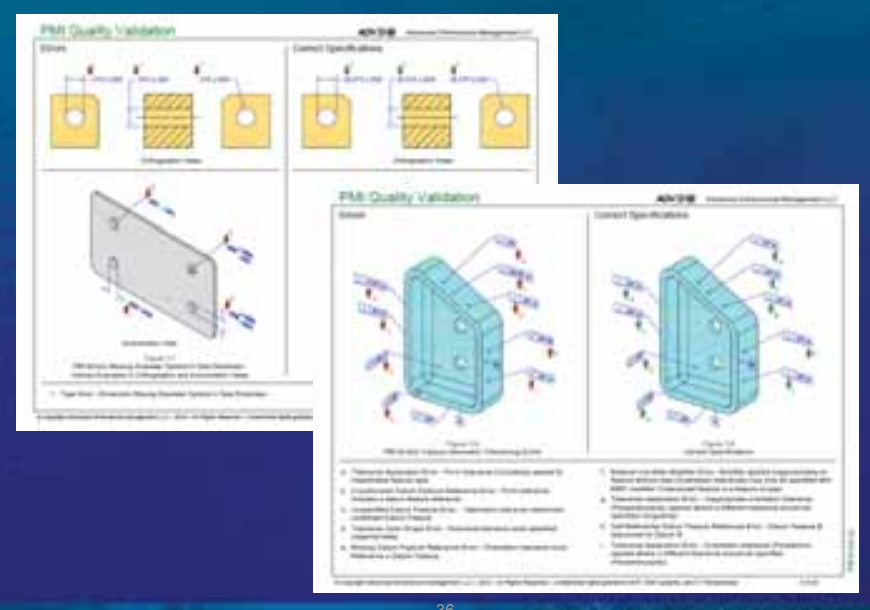

\section{Data Quality Measurement}

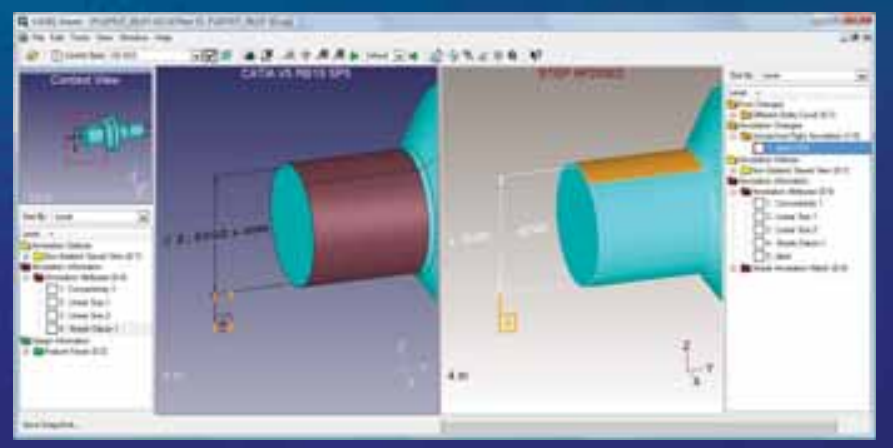

\section{Sustainable Manufacturing Program}

Objective: To develop and deploy advances in measurement science to achieve sustainability across manufacturing processes enabling resource efficiency and production network resiliency.

- Sustainable Processes and Resources

- Integration Infrastructure for Sustainable Manufacturing

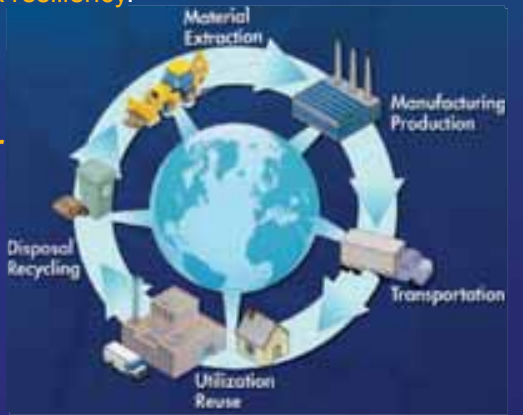

\section{Partnering Strategies with Industry}

- Standards Engagement

- Planning Workshops

- Performance Metrics and Test Methods

- Unique Facilities and Testbeds

- Modeling and Testing Tools

- CRADAs and Consortia

- Competitions at NIST Test Arenas and other venues

- "Plugfests" at Tradeshows
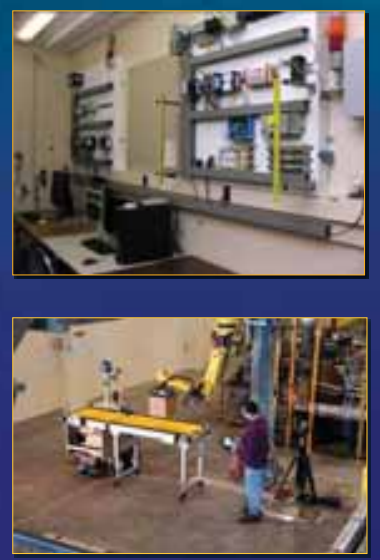


\section{NASA Integrated Model-Centric Architecture (NIMA) Concept}

Presented at the Model Based Engineering (MBE) Summit at NIST

December 12 ${ }^{\text {th }}, 2011$

Paul S. Gill
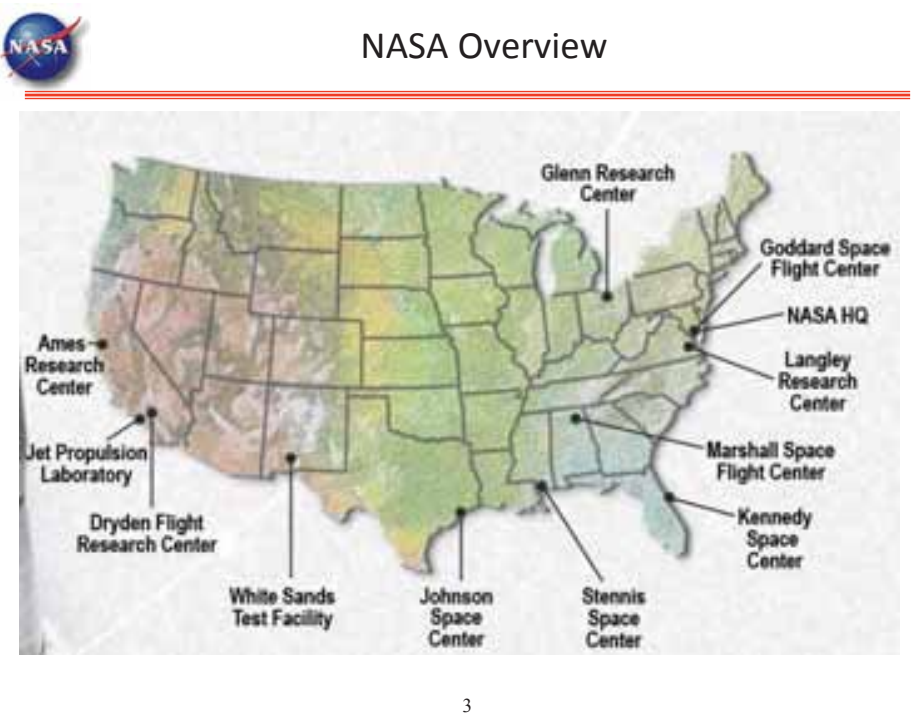

Variety of Missions (Cont'd)

- Science - Explores the Earth, solar system and universe beyond; charts the best route of discovery; and reaps the benefits of Earth and space exploration for society

- Earth: Weather, Carbon Cycle \& Ecosystems, Water \& Energ Cycles, Climate Variability \& Change, Earth Surface \& Interior, Atmospheric Composition

- Heliophysics: Heliosphere, magnetospheres, Space Environment

- Planets: Inner Solar System, Outer Solar System, Small Bodie

- Astrophysics: Stars, Galaxies, black holes, the big bang, dark energy, dark matter, planets around other suns
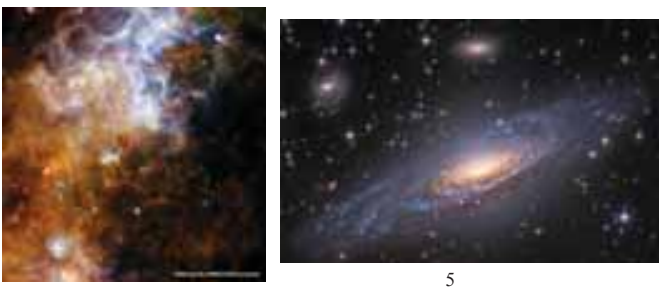
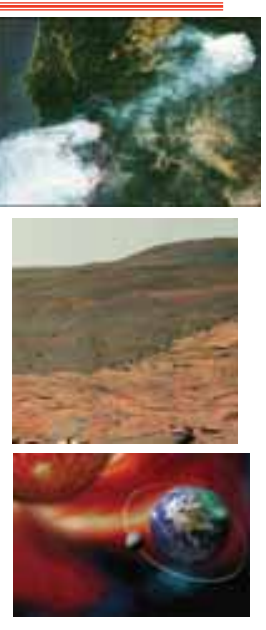

- NASA Overview

- Problem to be Solved

- Model-Centric effort

- Benefits

- Vision/Use Cases

- Determining the effect/impact of a requirement change

- Designing a system

- Performing a review

- Working a mission anomaly

- Goals

- Roadmap

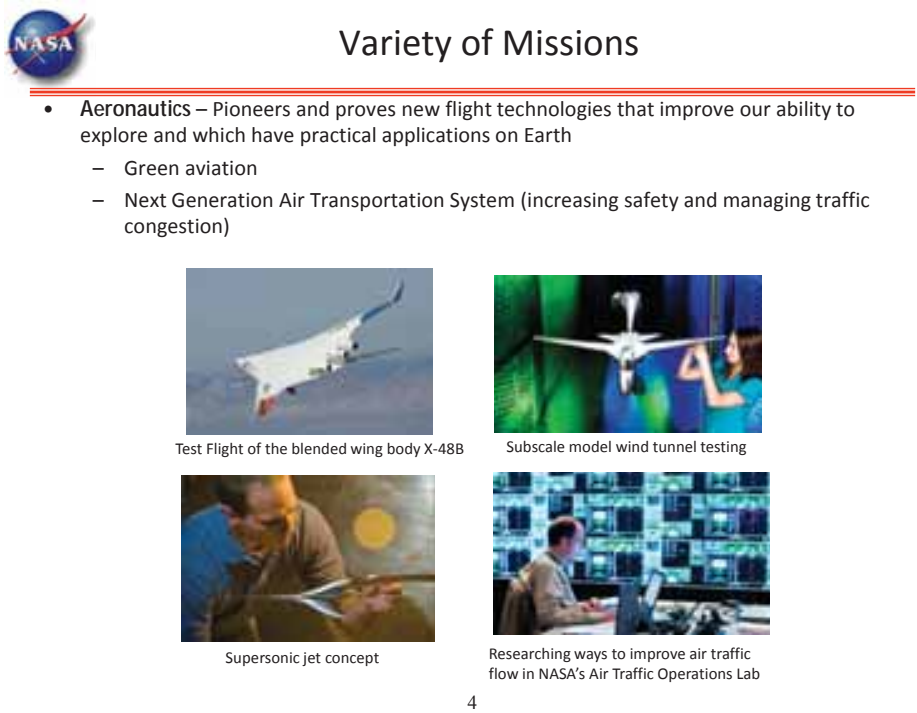

\section{Variety of Missions (Cont'd)}

- Human Exploration and Operations - Focuses on International Space Station operations and human exploration beyond low Earth orbit

- ISS

- Multi-Purpose Crewed Vehicle (Orion)

- Space Launch System

- 21 $21^{\text {st }}$ Century Ground Operations
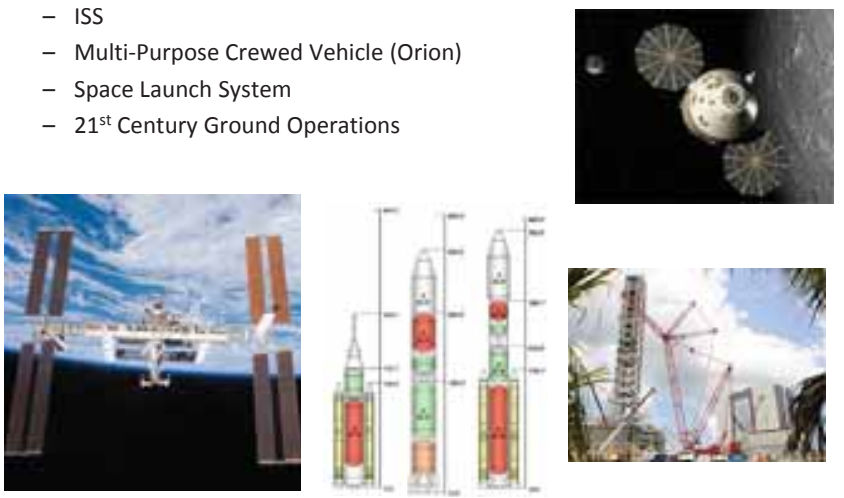
- Looking at our past experiences, our technical, cost and schedule performance needs to be enhanced in order to accomplish our future plans

- Some of the problems to be solved are:

- Lack of affordability of projects and activities

- Mission complexity is growing faster than our ability to manage it

- Not identifying design or integration problems until late in lifecycle

- Having to Search for data or supporting material during mission anomaly resolutions

- Inability to share models in a collaborative environment

- Ineffective use of precious testing time and resources

- Too many design reviews that reviews documents vice the design

- System design emerges from the pieces, not from an architecture

- Use of unvalidated models in simulations leading to incorrect/invalid results

- Moving to a more model-centric philosophy within the Agency will help resolve many of these issues

\section{Goals}

- Goal 1: Increase affordability through use of a model-centric architecture

- Goal 2: Achieve interoperability within and among programs/projects, centers and external partners through use of a model-centric architecture

- Goal 3: Inform/train invigorate workforce on model-centric architecture

- Goal 4: Improve product quality and success through use of a modelcentric architecture

\section{Model-Centric Concept}

Mission: Advance from our current documentcentric engineering practice to one in which structural, behavioral, physics and simulation-based models representing the technical designs are integrated and evolve throughout the life-cycle, supporting trade studies, design verification and system $V \& V$
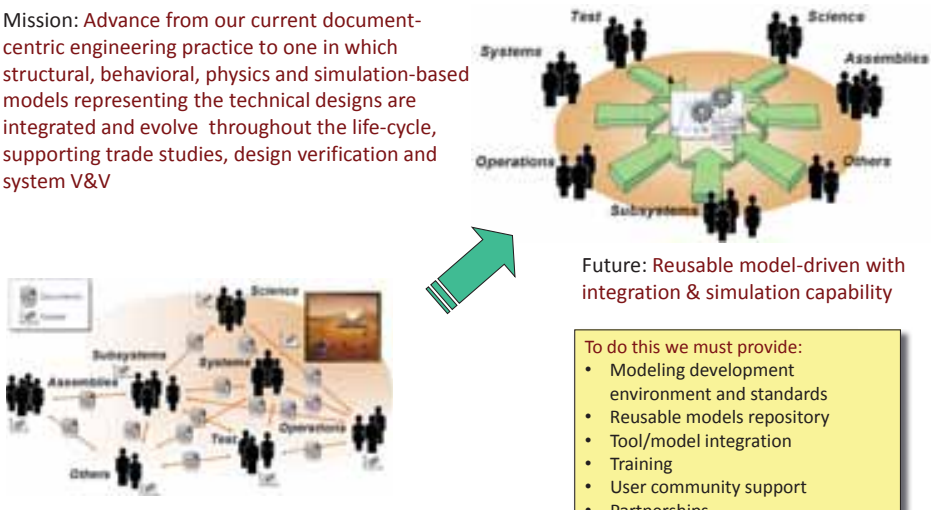

Future: Reusable model-driven with integration \& simulation capability

To do this we must provide:

- Modeling development

environment and standards

- Reusable models repository

- Tool/model integration

- Training

User community support

Today: Document driven \& standalone models

\section{Use Throughout Lifecycle}

- Use of a model-centric enterprise system throughout the lifecycle of a product will greatly enhance its quality and affordability

- Work products will be built and matured seamlessly eliminating need to re-create them over the lifecycle

- Example products are:

\begin{tabular}{|c|c|c|c|c|c|c|}
\hline Pre-Phase A & Phase A & Phase B & Phase C & Phase D & Phase E & Phase $\mathrm{F}$ \\
\hline Concept Studies & $\begin{array}{c}\text { Concept \& Tech } \\
\text { Dev. }\end{array}$ & Prelim. Design & Final Design \& Fab & $\begin{array}{c}\text { Assembly, test \& } \\
\text { Launch }\end{array}$ & $\begin{array}{c}\text { Ops \& } \\
\text { Sustainment }\end{array}$ & Closeout \\
\hline $\begin{array}{l}\text { Conceptual } \\
\text { Models }\end{array}$ & $\begin{array}{l}\text { Requirements } \\
\text { Functional }\end{array}$ & $\begin{array}{l}\text { CAD designs } \\
\text { Analysis Models }\end{array}$ & $\begin{array}{l}\text { Refined CAD } \\
\text { Refined }\end{array}$ & $\begin{array}{l}\text { Integration } \\
\text { Simulations }\end{array}$ & $\begin{array}{l}\text { Operations } \\
\text { Anomalies }\end{array}$ & $\begin{array}{l}\text { Decommissioning } \\
\text { Simulations }\end{array}$ \\
\hline Cost Estimation & Flows & $\begin{array}{l}\text { Prototype test } \\
\text { data } \\
\text { Refined Costs }\end{array}$ & $\begin{array}{l}\text { Analysis } \\
\text { Engineering } \\
\text { Data } \\
\text { Manufacturing }\end{array}$ & $\begin{array}{l}\text { Verification } \\
\text { Certification }\end{array}$ & $\begin{array}{l}\text { Simulations } \\
\text { Science Data }\end{array}$ & $\begin{array}{l}\text { Data Archiving } \\
\text { Final Costs }\end{array}$ \\
\hline
\end{tabular}

Enhances Sound Engineering Practices and Experience - Does Not Replace It! 


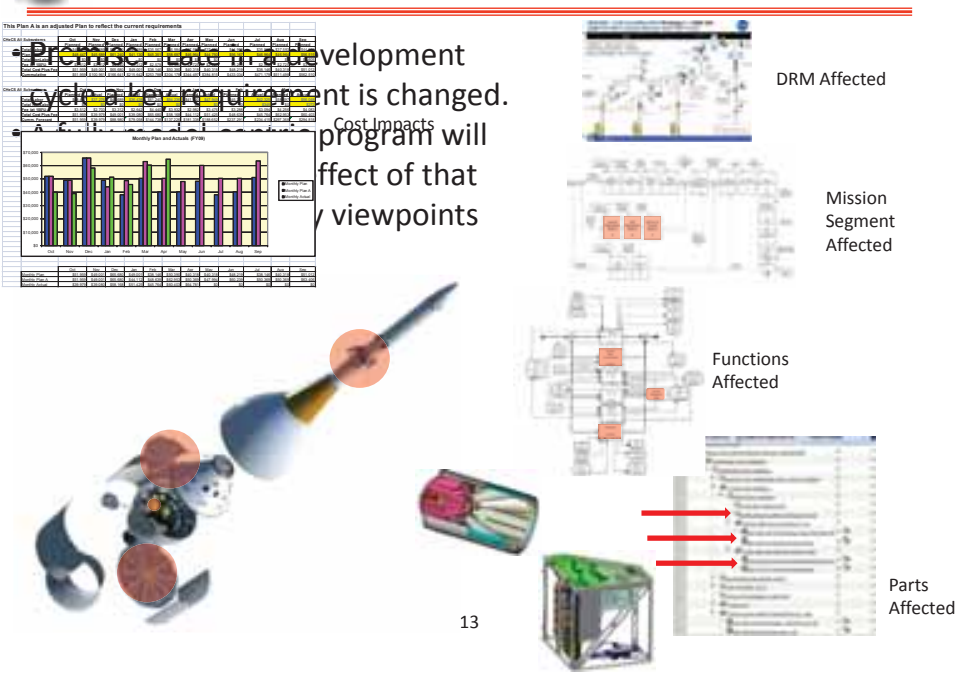

\section{NASA}

\section{IFA Data Needs $<4$ hrs: Partial List}

$\checkmark$ As-designed/as-purchased/as-tested/as-built/as-flown product structure and definition

$\checkmark$ Circuit card schematic

$\checkmark$ Specifications (e.g., materials, acceptance testing)

$\checkmark$ Where (else) used

$\checkmark$ Location and status of spares

$\checkmark$ Firmware, software, parameters

$\checkmark$ Circuit card testing and failure history

$\checkmark$ Impact analysis of failure (e.g., FMEA)

$\checkmark$ Failure history of components in similar settings

$\checkmark$ History of component/card/sub-system behavior over course of mission

$\checkmark$ Trades/Design Rationale

ACCESS to the Right data by the Right People at the Right Time is the desired end state.

\section{Scenario 2: Development Data Deluge}

We are seeing some very large amounts of data created during Design \& Testing

$\checkmark$ Scale of product, types of analysis \& testing, procurement strategy affect this

$\checkmark$ But no project or product is immune

Illustrative Cases from Constellation Program (CxP)

$\checkmark$ Core Input for Analysis: Outer Mold Line

$\checkmark$ Analysis, Testing \& Simulation Data Deluge

$\checkmark$ Sample Documents \& CAD Models: Ares \& Orion at PDR

\section{Documents: Ares FPDV revewed $\sim 50 U$ documents and two arawings wit} $\sim 38,000$ documents in Ares ICE Windchill Project Folders

CAD: 16 months later at Orion PDR, LMSSC delivered 11,000 discrete 3D models for Service Module, Crew Module, Launch Abort System (with $\sim 250,000$ versions, iterations, or variants in LMSSC's Windchill vault)
10 years ago we developed a Flagship Class spacecraft.

Nearing the end of a very long cruise mode, the

vehicle must be configured for planetary arrival.

While coming out of cruise, the self-monitoring system on the CEU indicates a device on one processor card is not functioning properly.

Mission team has 12 hours to fix the problem prior to entering into orbit or the mission will be lost.

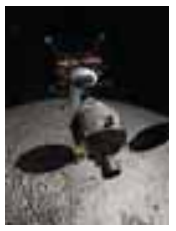

The Question at hand: What data will be needed, and how does a PM plan for it a decade or more beforehand?

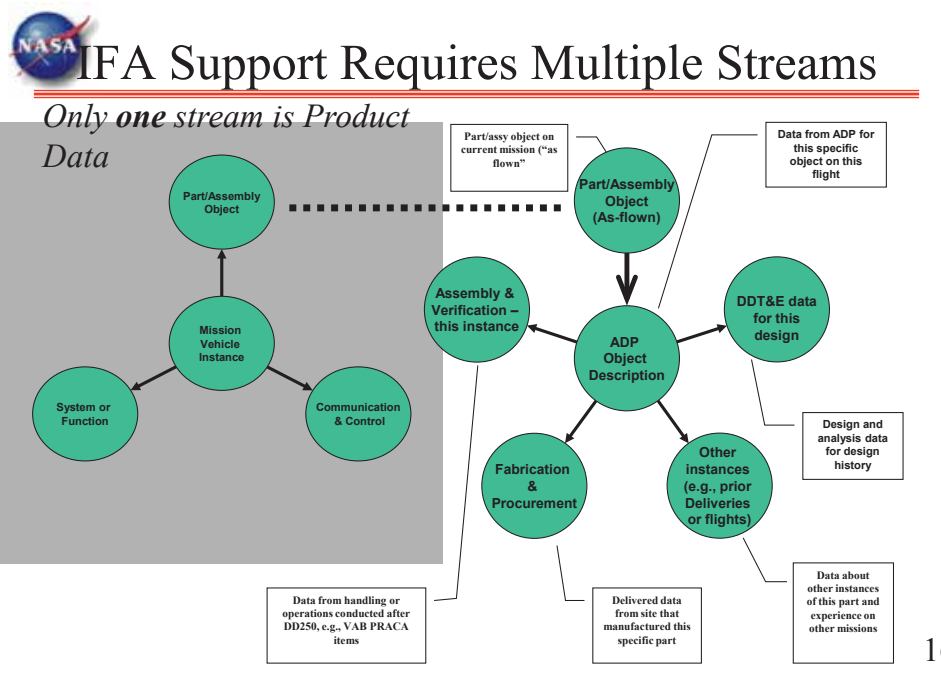

Notional Model for Multi-path Product Data Streams

"How Big is the Problem"?" (Life Cycle Data Management Challenge)

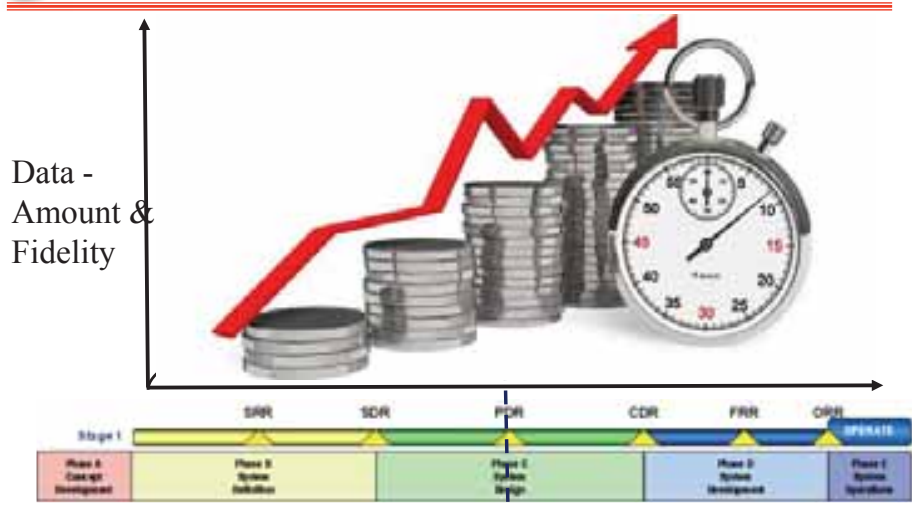

The amount, type, and fidelity of the data generated and requiring storage and access increases over the program life cycle. The scale and complexity of the storage and retrieval system will need to respond to these challenges. 


\section{How do we establish a Model Centric Environment and Culture?}

\section{Communities of Practice}

- This effort is primarily the integration and expansion of the work already being performed separately in the following Communities of Practice (CoP):

- Model-Based Systems Engineering (MBSE)

- Product Data and Lifecycle Management (PDLM)

- Models and Simulation (M\&S)

- Computer Aided Design (CAD)

- Mechanical CAD

- Electrical CAD

- The tools and methodologies are being employed by these CoPs in support of existing and future Project and Programs

- By having a common vision we will be able to coordinate and enhance this work in a more effective way, learning and leveraging off each others discoveries and insights

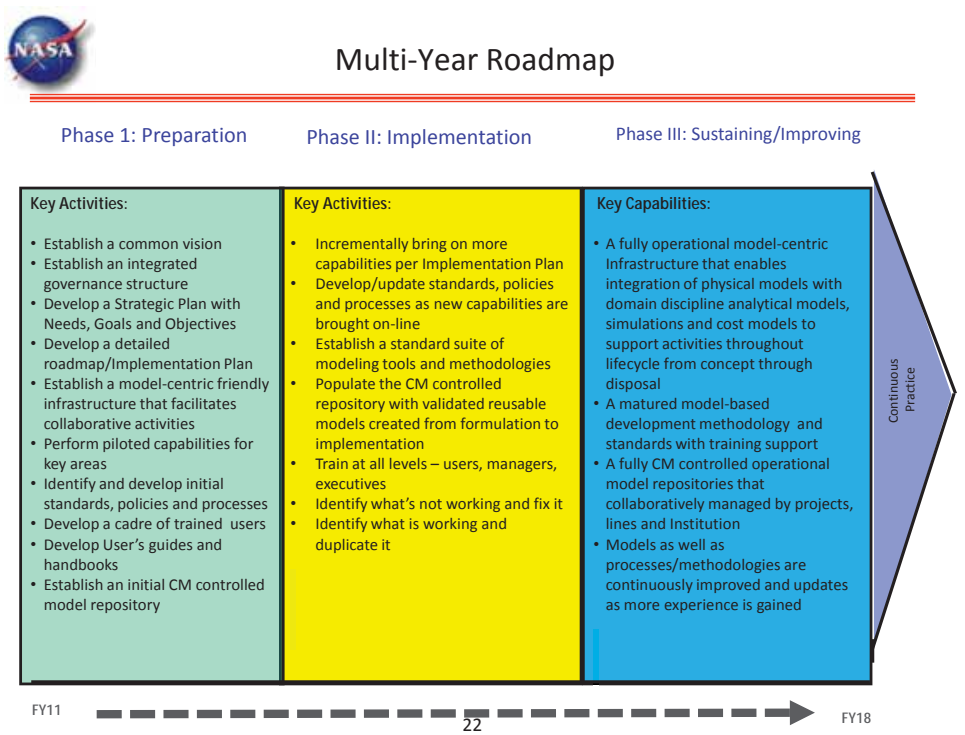

Team 1: Benchmarking - this team will be doing benchmarking trips and research. Trips will be to external organizations such as Boeing, LM, ATK, Whirlpool, etc. and will also be internal to other NASA centers. Also included are web and literature searches to determine the real value of moving an organization to a model-centric basis.

- Team 2: Foundations - this team will look at the basics needed for this effort framework, data integrity, reuse of models, etc.

- Team 3: Current Architecture - this team will identify the current existing architectures at each of the centers and its readiness to handle moving to a model-centric culture. Includes identification of any issues and gaps with the current IT structure.

- Team 4: ConOps - this team will work on a more detailed Concept of Operations depicting how we would use a model-centric architecture, use cases, examples, etc.

- Team 5: Communications Plan - this team will identify who are our stakeholders, what are their expectations and how will we need to communicate with them to ensure the success of moving to a model-centric culture.

- Team 6: Pilots - this team will identify the work that is currently being performed at each of the centers and determine if there are additional pilots that need to be initiated in FY12 in order to move a area forward in accomplishing the model-centric architecture

- Team 7: Workforce Capabilities - this team will look at what capabilities/skills will be needed to accomplish a model-centric culture, what capabilities/skills we already have, determine capability/skill gaps and develop a training plan for closing that gap.

Benefits

- Moving to a model-centric culture will provide NASA many benefits

- Enhanced affordability

- Increased ability for collaboration

- Identification of problems earlier

- Quicker and more accurate diagnosis and resolution of mission anomalies

- More effective use of testing resources

- Better cost estimation and control

- Better, more effective design reviews

- Quicker understanding of cost, schedule and technical impacts of requirement or design changes

- Enhanced ability to do systems engineering

- Quicker and more accurate analysis/simulations

\section{In Closing}

NASA Programs face non-trivial challenges re: Product data

$\checkmark$ Distributed, production \& use over extended life span

$\checkmark$ Mixture of internal and external sources - Centers, primes, academia; NASA cannot control how things are done

$\checkmark$ Need access to PRE-RELEASE product data

$\checkmark$ Early decision support

$\checkmark$ High analysis demands, high volumes of ancillary data

$\checkmark$ Long project life cycles

$\checkmark$ Need for IFA reach-back

$\checkmark$ Need a flexible solution within NASA due to project diversity 


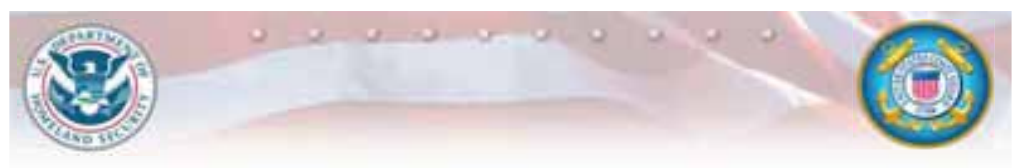

\section{December 2011 \\ AFFORDABLE READINESS THROUGH MODEL BASED ENTERPRISE (MBE)}
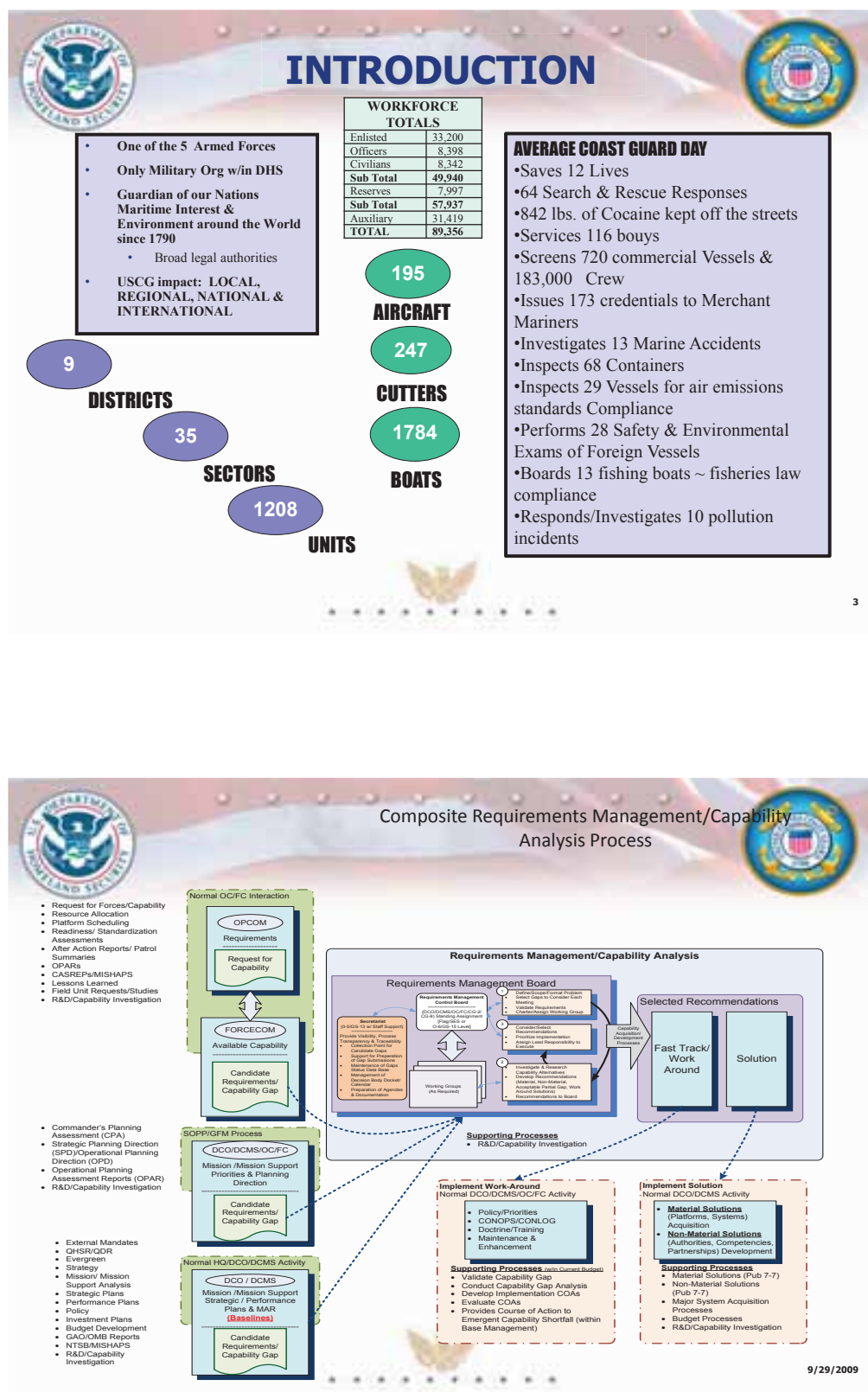

- CG Introduction

- CG Definition of Logistics

- Vision \& Concept of Operations

- Scope

- Approach

- Deliverables

- Risks \& Discussion

\section{Agenda}
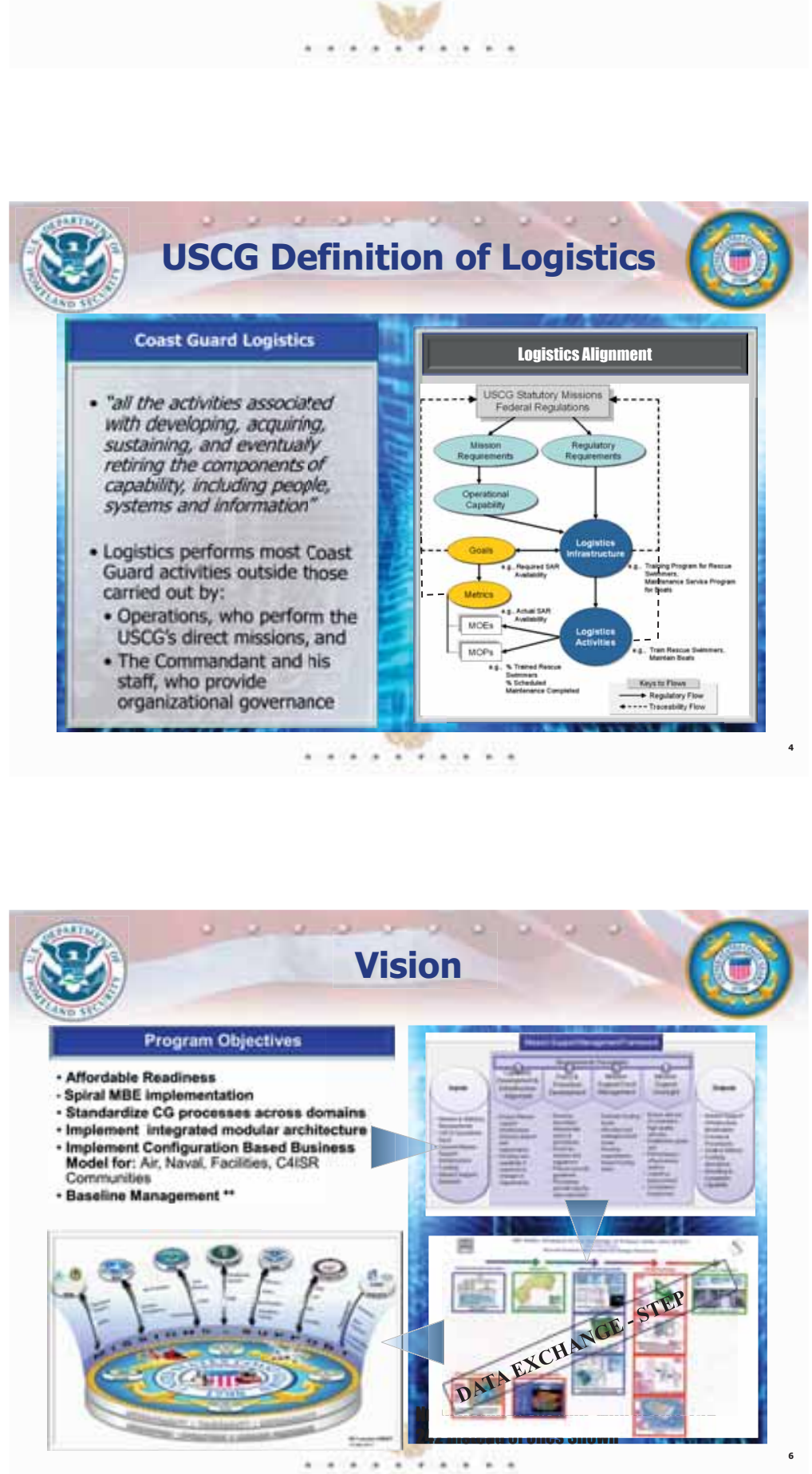

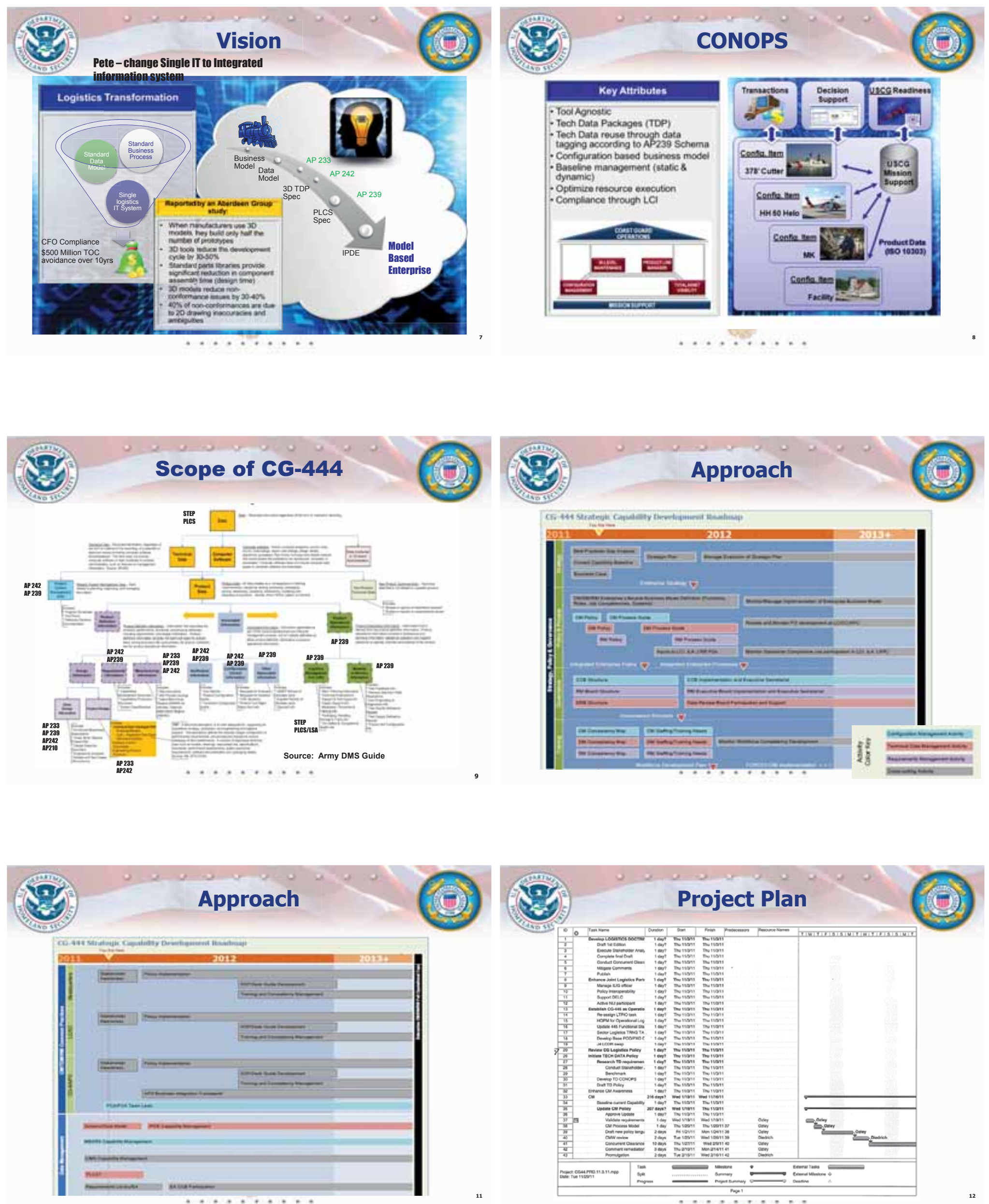


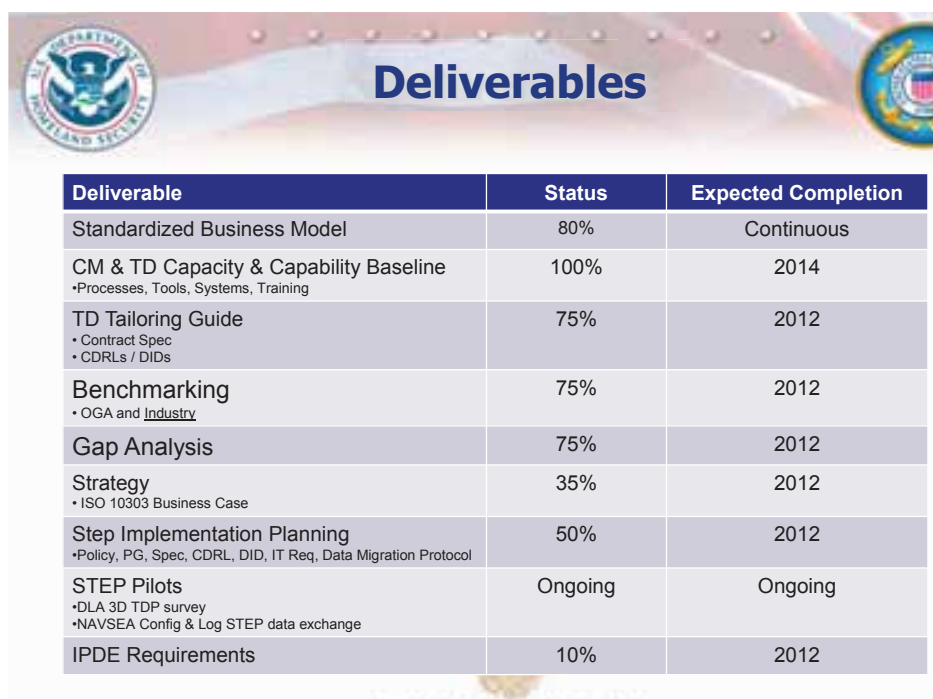

$\ldots \ldots, \ldots$
USCG CM/PDM CAPABILITIES \& CAPACITIES BASELINE ANALYSIS

- Methodology: Conduct an independent assessment of existing CM and PDM capabilities (Aviation, Surface, Shore, and C4I Communities)

Assessment covered: Policy, Spec \& Standards, Tool s \& Capabilities, Processes, and Training, Staffing, \& Resources

What's Working :

- Configuration Planning and Control

MPC/Technical Manual Development, Management, and Distribution

- Efforts Underway to Resolve Gaps:

Policies and Standards

- Concise, Actionable, and Enforceable

- Developing Framework for Product Data Life Cycle Management (PDLCM) Data format/compatibility Data Rights

Exchange Capability

Tools and Capabilities

- IPDE CONOPS

- IPDE Requirement Definition

- IPDE Interface Control Documents
USCG CM/TDM CAPABILITIES \& CAPACITIES

\section{BASELINE ANALYSIS}

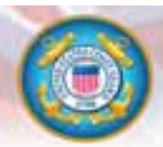

- CG LIMS

- Legacy Data Strategy

Processes

- Baseline Managemen

- Communication

Metrics

Process and Data

- Compliance

Training, Staffing, and Resources

- CM Certification Programs

- CM Core Competencies

- Competency Alignment within the Organization

- PDM?

- Approach

Systems Engineering Approach for Business Model Development \& Management

Leverage Government and Industry Best Practices

Benchmarking Opportunities with Government and Industry

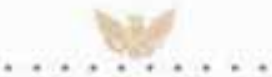

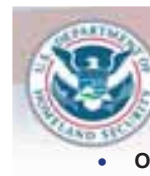

USCG CM/TDM CAPABILITIES \& CAPACITIES BASELINE ANALYSIS

Our Methodology: Conduct an independent assessment of existing $\mathrm{CM}$ and TDM policies, processes, tools, and infrastructure capabilities in the CG Aviation, Surface, Shore, and C4I Communities

Assessment covered 4 major areas: Acquisition Policies and Standards, Tool \& Capabilities, Processes, and Training, Staffing, \& Resources

Baseline established through interviews with CG SMEs

- What's Working :

- Configuration Planning and Control

Technical Manual Development, Management, and Distribution

- Efforts Underway to Resolve Gaps:

- Acquisition Policies and Standards

- Writing CG Policy and Process Guide to be more Concise, Actionable, and Enforceable

- Developing Framework for Product Data Life Cycle Management (LCM) Data Rights Data Rights Tailoring Guidance

Tools and Capabilities

- IT LCM Infrastructure CONOPS

- IPDE Requirement

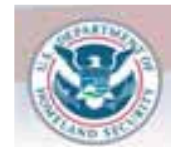

USCG CM/TDM CAPABILITIES \& CAPACITIES BASELINE ANALYSIS

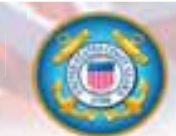

- CG LIMS

- Legacy Data Strategy

Processes

Baseline Management

- Communication

Metrics

Process and Data

- Compliance

Training, Staffing, and Resource

- CM Certification Programs

- CM Core Competencies

- Competency Alignment within the Organization

- TDM?

- Approach

\footnotetext{
Taking a Systems Engineering Approach for Management of Enterprise Capability

Leveraging Government and Industry Best Practices

Discussing Benchmarking Opportunities with Government and Industry CG more aligned to Industry with regard to our desires to execute Configuration and Technical Data
Management
}

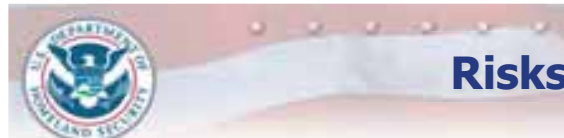

- No comprehensive STEP pilot

- No Proven Spec

- Limited STEP expertise

- Competing Standards

- Organic Ability to Sustain

- Process Independence

- Data Schema Interface Control

- Revisions to APs make end-state a moving target

- Funding constraints

- ERPmplexity and coordination of efforts govern MILSTD 973 EIA 649 orkforce (AWF) WG CG CM WG GEIA-STD-0007 - cBRechmarkingshithntrgdistrit and OGAFecycle Logistics WG PDRD MIL-STD 31000 RACER / NSERC CG TDM WG CG SDLC WG RRPB

\section{CG-LIMS \\ CDMD-OA VLS \\ MEAR \\ NE-TIMS ADMIS \\ Powerlog-J DOORS}




\section{Overview}

Model-Based Engineering/Manufacturing

Review from the $\mathrm{Y}-12$ National Security Complex

\section{MBE/TDP Summit}

December 12, 2011

Donna F. Bennett

Manager, Engineering Analysis \& Technology Engineering

B\&W Y-12

\section{NASA}

\section{Who Are We?}

- The Y-12 National Security Complex is a premier manufacturing facility dedicated to making our nation and our world a safer place

- Operated by B\&W Y-12 for the National Nuclear Security Administration (NNSA), Y-12 plays a vital role in the Department of Energy's (DOE's) Nuclear Security Enterprise (NSE)

\section{http://www.y12.doe.gov/}

Uranium Center of Excellence

Located in Oak Ridge, Tennessee

More than 8,000 uniquely skilled, dedicated employees
- Introduce the Y-12 National Security Complex

- nearly 70 years of expertise in science and technology

- Discuss the unique facilities, technology capabilities, knowledge and expertise that $\mathrm{Y}-12$ offers,

- as part of the Nuclear Security Enterprise, for finding solutions to scientific and technological challenges

- Describe Y-12 programs and partnerships

- providing a wide network of specialists with an array of knowledge and skills

- Open the door to future collaborations

- working with federal agencies and others to advance science and technology to meet national and global needs

\section{Y-12-One Part of DOE's NNSA}

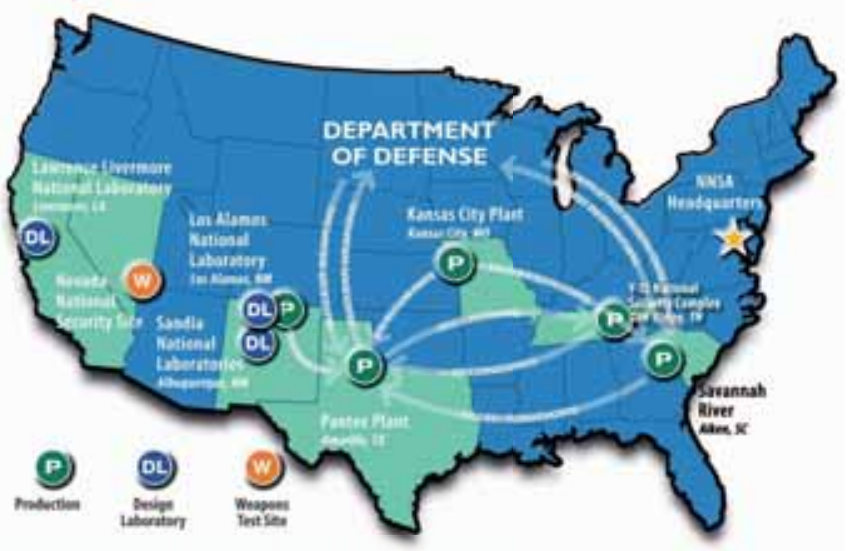

12 NATUNAL SELURIT COMALE

\section{Y-12 National Security Complex Missions}

- Sustain a safe, secure and effective nuclear arsenal

- Processes highly enriched uranium for the U.S. nuclear Navy to propel nuclear submarines

- Prevent nuclear proliferation and nuclear terrorism

- Solve global security challenges
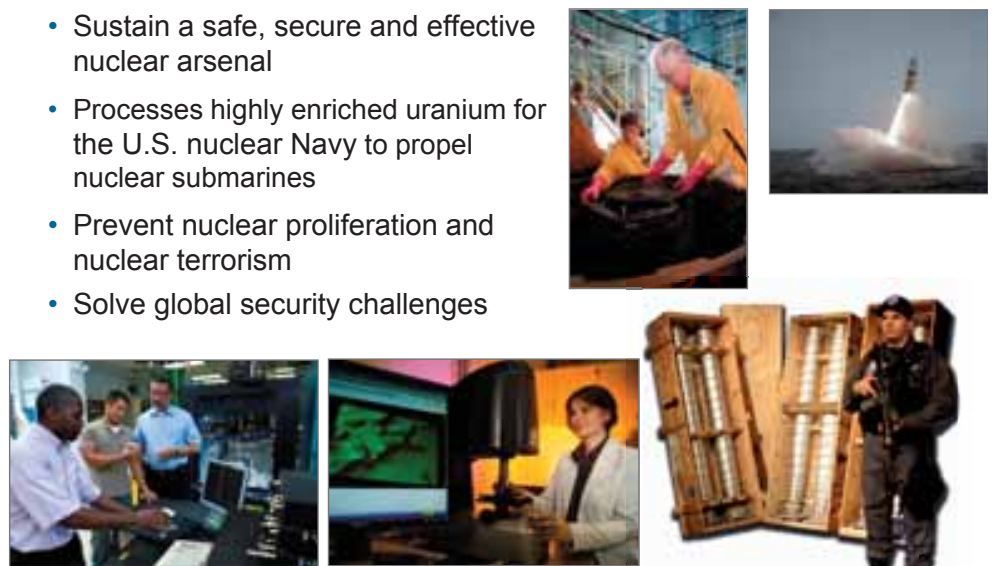

\section{Y-12 Engineering}

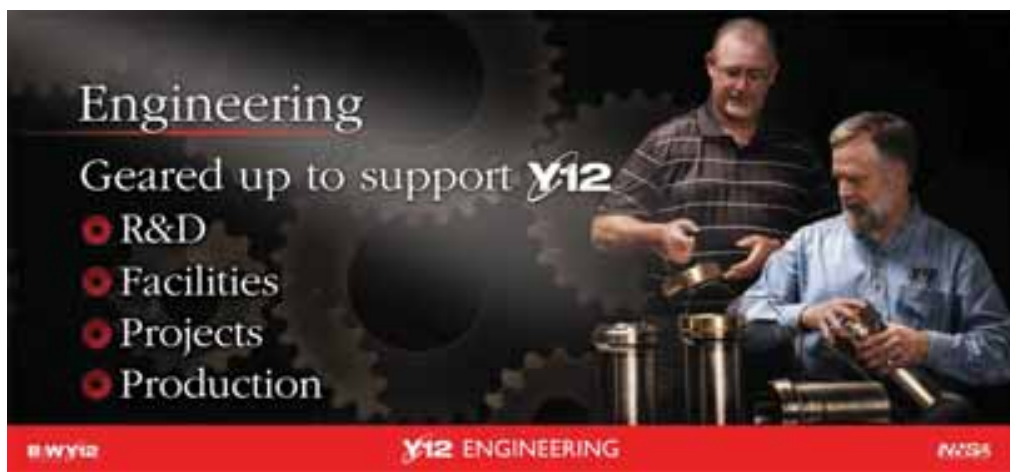

Engineering has 626 employees including 88 Development employees 


\section{Four Core Areas of Research and Development}

- Technology development, maturation and deployment activities at the $\mathrm{Y}-12$ Complex focus on four core areas:

- Defense Programs

- Transformation

- Complementary Work

- Basic Science
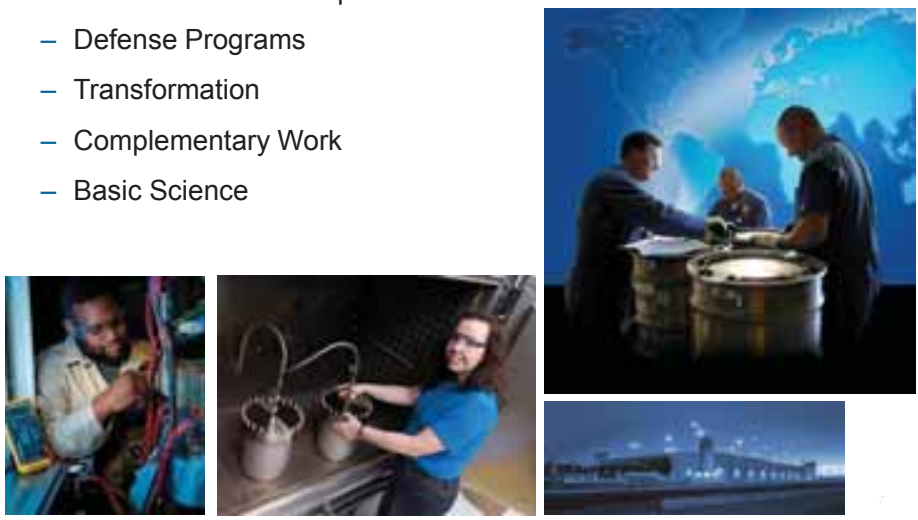

XI2 NATIONAL SECURTT COMPLS.

\section{Model-based Engineering and Manufacturing (MBE/M)}

- Y-12 is modernizing the business of science-based stockpile stewardship by creating and using 3-D geometric models for

1. Defining the refurbished stockpile product

2. Supporting certification, and

3. Integrating design, engineering and manufacturing activities across the NSE

ORNL Topaz Detector Array Tank, TOPAZ DAT

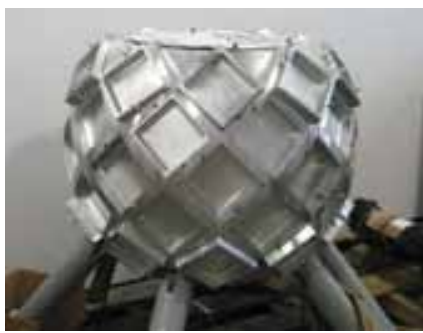

MBE/M (cont.)

- $\mathrm{MBE} / \mathrm{M}$ is used at various project stages

- Total life cycle

- Life extension program (LEP)

- Uranium Processing Facility (UPF)

- Single phase of life cycle

- Conceptual design only

- Design only

- Manufacturing (fabrication/inspection)

- Blend of several phases

\section{Y-12 Model-Based Engineering}

\section{Y-12 effectively integrates model-based engineering and manufacturing}

(MBE/M)

\section{Y-12 Effectively Integrates Model-Based Engineering/Manufacturing (MBE/M)}

- MBE/M concepts are applied during

- Design and analysis/simulation

- Manufacturing

- Inspection

- Packaging

- Projects often involve hazardous materials

- Y-12 expertise ensures that MBE/M is applied safely and securely

\section{MBE/M Technology Applied to Many Projects}

- Packaging Engineering designs packaging for shipping/transporting nuclear materials

- Life Extension Programs (LEPs)

- Full product life cycle

- Started MBE/M pilot project for NSE in FY 2002

- Integrated Glove Box System (IGBS) for dismantlement project installed FY 2010

- Uranium Processing Facility (UPF) ongoing 


\section{Packaging Engineering}

- Long history of successful designs in a wide variety of containers and shipping packages

- Thermal and impact analysis experience and capability

- Complete support solution, including concept design, end-user support, maintenance and decommissioning

- Experience with certification of hazardous material packages in a strictly regulated environment
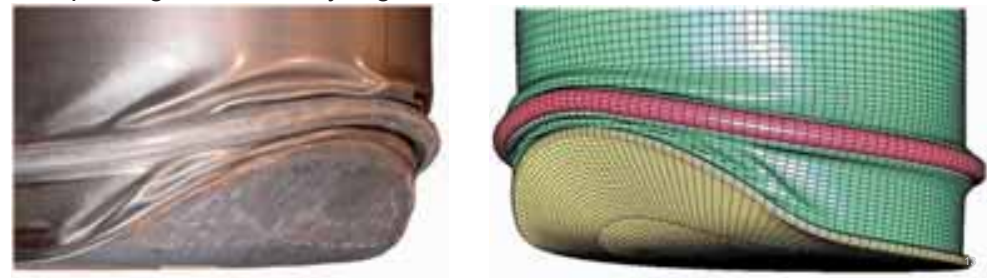

YII NATIONAL SECURTY COMPLS

\section{MBE/M Saves Packaging Engineering Time, Money}

- Cradle-to-grave design authority over packages used on-site and worldwide

- Model-centric approach eases communication among customers, analysts, manufacturers, users and regulators

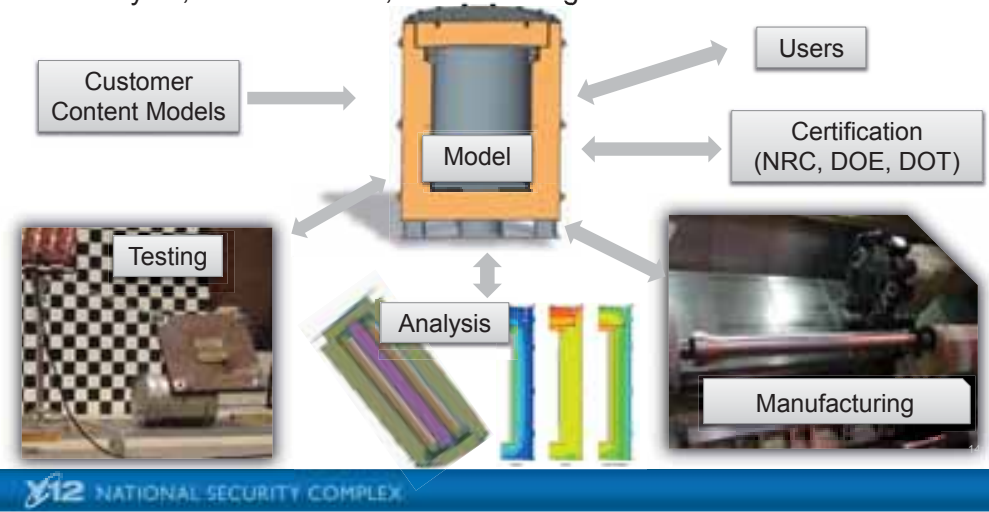

Packaging Engineering Using Virtual Testing

3-D Scan of ES-4100 Abnormal Surface Feature

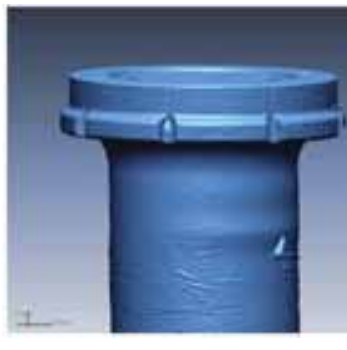

1.

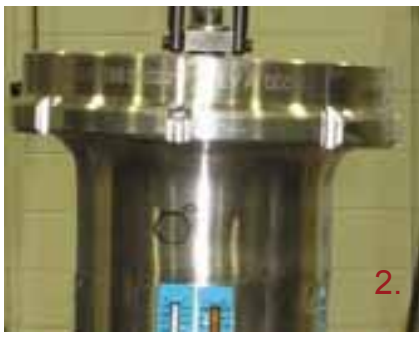

1. 3-D scanner creates virtual model after physical testing-good for capturing data

2. Photo of item for comparison

3. Finite element analysis (FEA) used for virtual testing/refining design (creates prediction of item after testing)

Yie NATIONAL SECURIT COMPLSX

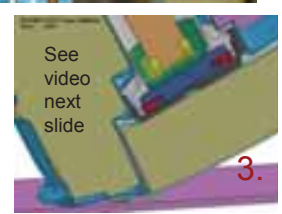

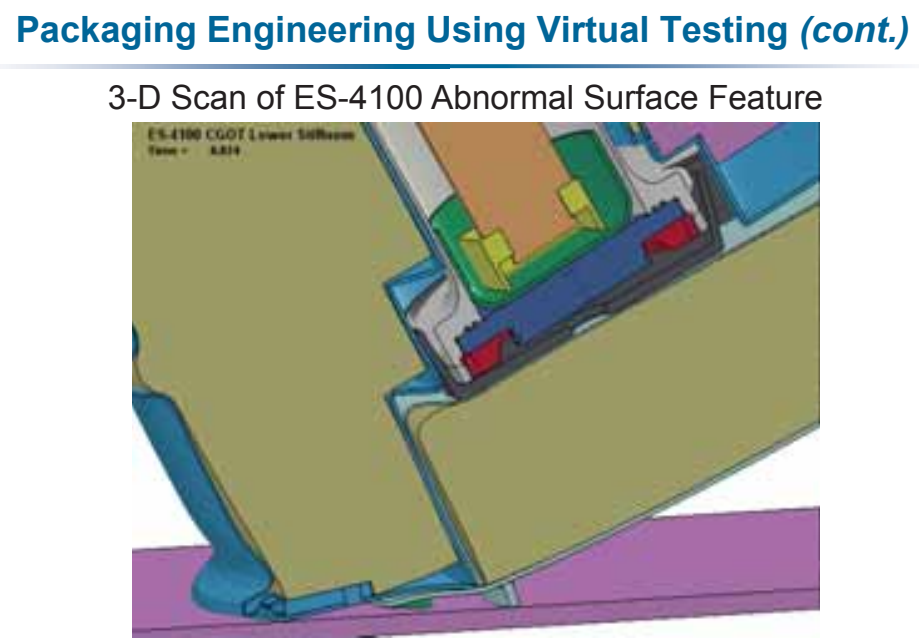

XI2 NATIONAL SECURIT COMDLS.

\section{Life Extension Program-Pilot Project}

- MBE/M concepts were applied in all life cycles in this project

- Conducted first pilot MBE/M project between design agency and Y-12 starting in FY 2002

- Developed business rules around MBE/M needs and requirements

- Developed verification process for electronic Pro/Engineer model

- Embraced concept of trinity (drawing, model, pdf or tiff for legacy standard format)

- Conducted MBE/M workshop to help facilitate change of $\mathrm{Y}-12$ culture

\section{Cost difference...}

$\$ 575,000$ (drop test) vs $\$ 40,000$ (MBE) 


\section{Life Extension Program-Pilot Project (cont.)}

- Used Pro/E models in tooling design

- Completed process planning using work-in-process models

- Programmed numerical control (NC) machines directly from Pro/E model

- Used models for analysis and simulation at various stages

- Captured coordinate measuring machine (CMM) inspection data electronically for documentation for as-built models

\section{Life Extension Program-Pilot Project (cont.)}

- A process for verifying Pro/E models was deployed in FY 2002 and was used in FY 2003 for models-based product definition received from the design agency

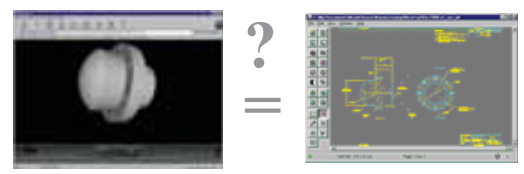

Model verification-a very important $1^{\text {st }}$ step

- The process addresses

- Geometric integrity and translatability

- Standards compliance

- Pro/E model and Pro/E drawing consistency

- Design intent (in addition to normal design reviews

- Policy and guidelines developed

\section{Integrated Glove Box System (IGBS)}

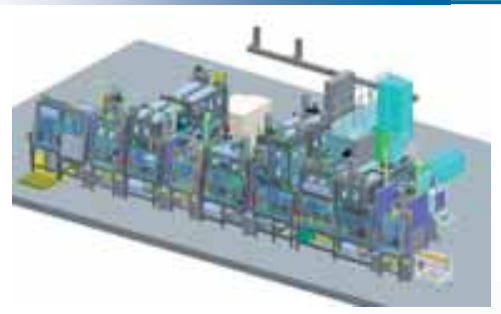

- Multiple glovebox zones with fully integrated environmentally interlocked system

- hoists, one in each zone

- fully integrated machine tools

- ventilated hoods

- drum transfer system

\section{IGBS Implementation Completed in FY 2010}

- Designed as general-purpose glovebox in existing facility

- Designed by outside architect engineer

- Manufactured by external subcontractor

- Used currently for specific purpose (dismantlement)

- Modeled legacy weapons parts in Pro/E

- Designed all machining and inspection fixtures in Pro/E

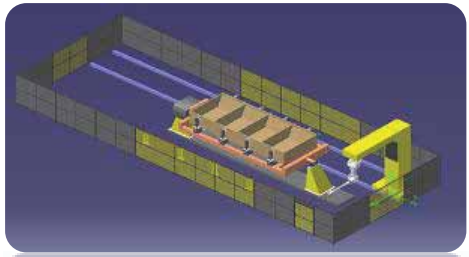

Xi2 NATIONAL SECU OTM GOHPLS

\section{Support to Uranium Processing Facility (UPF)}

\section{IGBS Applied MBE/M Technologies}

- Process operation was simulated in Delmia and Pro/E Manikin software

- Generic facility (IGBS) presented many challenging requirements - Large dismantlement part

- Very little operating room available

- Virtual process planning identified and avoided several trouble spots in fixture designs

- Simulations were provided for operator training

- Simulation was an excellent communication tool for commissioning activities
Modernization to $\mathrm{Y}-12$

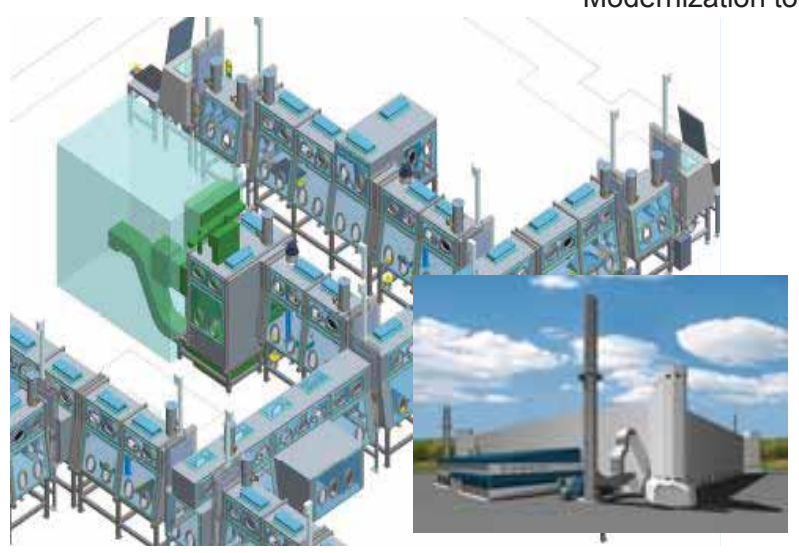




\section{UPF Applies Many MBE/M Concepts}

- Conceptual design

- Used knowledge capture to support MBE/M

- Used Extend software models for process design

- Varied facility design virtually to evaluate cost/schedule impact

- Ergonomic design

- Reviewed fit and function of proposed design

- Avoided costly design flaws not typically caught before facility walk-down

- Avoided health and safety problems with ergonomic design

\section{UPF Design for Ergonomic Consideration}

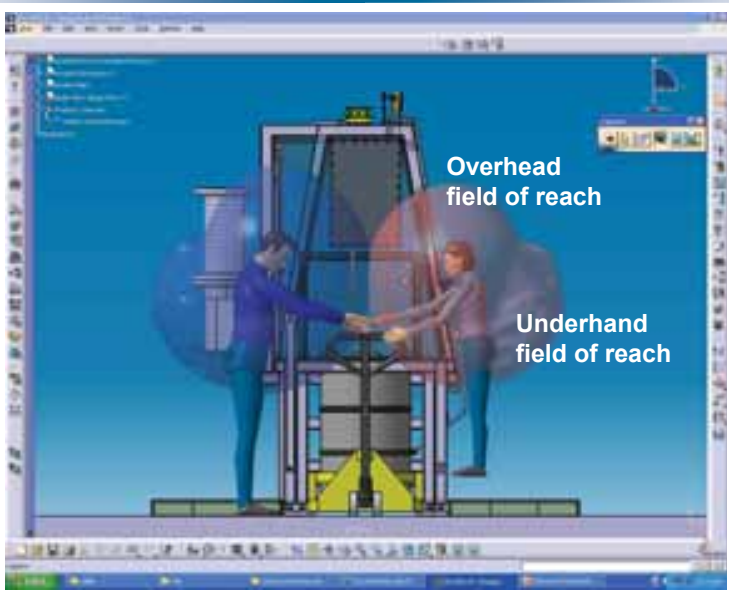

YI2 NATIONAL SECURIT COMPLSX

\section{Y-12 Partnerships and R\&D Programs}

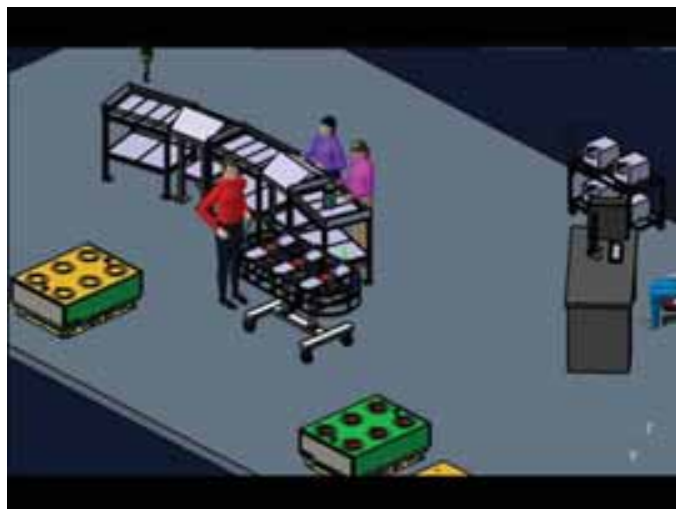

XI2 NATIONAL SECURIT COMPLS.

XIE NATIONAL SECURIT COMPLEX

\section{Y-12 Participation in IMOG}

- Interagency Manufacturing Operations Group (IMOG)

- Oldest NSE working group (60+ years)

- Involves participation from majority of NNSA sites

- SMEs exchange technical information-on design, manufacturing and acceptance problems - to maintain the manufacturing operations capability of the DOE weapons complex (NSE)

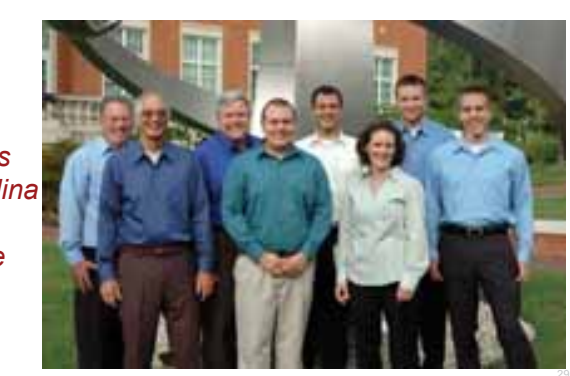

Y-12 researchers and members of the University of North Carolina at Charlotte-recipients of an R\&D 100 Award in 2010 for the Modulated Tool-Path Chip Breaking System

- Georgia Tech

- Syracuse University 


\section{Y-12 Participation in MBIT}

- Models Based Integrated Tools, a model-based working group, was formed 15 years ago and consists of managers, SMEs, from all NSE sites as well as other DOE labs and vendor of ProE - PTC

"Before all NSE sites adopted the computer software ProEngineer (ProE), each site had its own computer-aided design (CAD) system. The Department of Energy spent lots of time, effort, and money so the different CAD systems could communicate...

"We find a lot of value in [MBIT] relationships. When new ProE versions roll out, we all save money by avoiding reinventing the wheel or paying consultants."

- Y-12 Steering Group Rep Y-12 Information Technology

\section{Snapshot of MBIT}

- MBIT members

- Lawrence Livermore National Laboratory

- Sandia National Laboratory, California

- Los Alamos National Laboratory

- Sandia National Laboratory, New Mexico

- Pantex Plant

- Savannah River National Laboratory

- Y-12 National Security Complex

- Kansas City Plant

- Parametric Technology Corporation (PTC)-vendor for standardized design tool Pro/Engineer

The network saves money in licensing fees and in economies of scale in processes and techniques

\section{Benefits of MBIT Participation}

"By participating in MBIT, Y-12 engineers, designers, drafters, and numerical-control part programmers can share knowledge across the Nuclear Security Enterprise. That information exchange maximizes efficiency and quality in the creation of models, drawings, and machine tool programs and in file management."

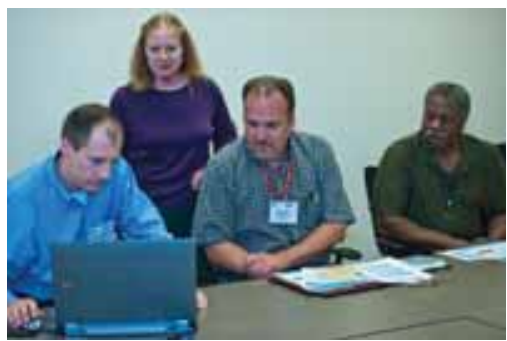

- Manager, NC Machining Y-12 Mechanical and Manufacturing Engineering

\section{Summary}

- Y-12 has diverse experience in all stages of design and manufacturing. This history gives $\mathrm{Y}-12$ a unique, in-depth understanding of the engineering and manufacturing challenges that confront national security

- Model-based approach guarantees success through excellence in manufacturing

- Y-12's work with other NSE sites and Y-12's programs and partnerships create a vast network of highly skilled specialists and research facilities

-We look forward to expanding partnerships to advance science and technology to meet national and global security needs

\section{What Does MBIT Do?}

- Develops and maintains model-based standards and best practices for product realization

- Brings together users, SMEs, managers and vendors

- Serves as the user voice to communicate business and technical requirements related to model-based tools and processes

- Promotes common tools and processes that support NSE programmatic missions

- Promotes seamless sharing and reuse of models and associated data within the NSE and with commercial partners

- Forms strategic partnerships with vendors that support NSE product realization activities

- Collaborates with outside industry to share lessons learned and validate MBIT's vision and guiding principles 


\section{Model Based Enterprise Impact on Organizational Behavior}

James DeLaPorte

Partner and Business Transformation Leader jamesdelaporte@nextec-et.com

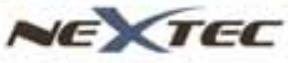

MBE and Organizational Behavior

- A body in motion stays in motion, A body at rest stays at rest

\section{- Recent CELEBREX Commercia}

- A body in motion tends to stay in motion unless acted on by an outside force

$$
\text { - Sir Isaac Newton }
$$

- Organizations behave the same way

- They are difficult to move

- MBE is that outside force

NE TEC

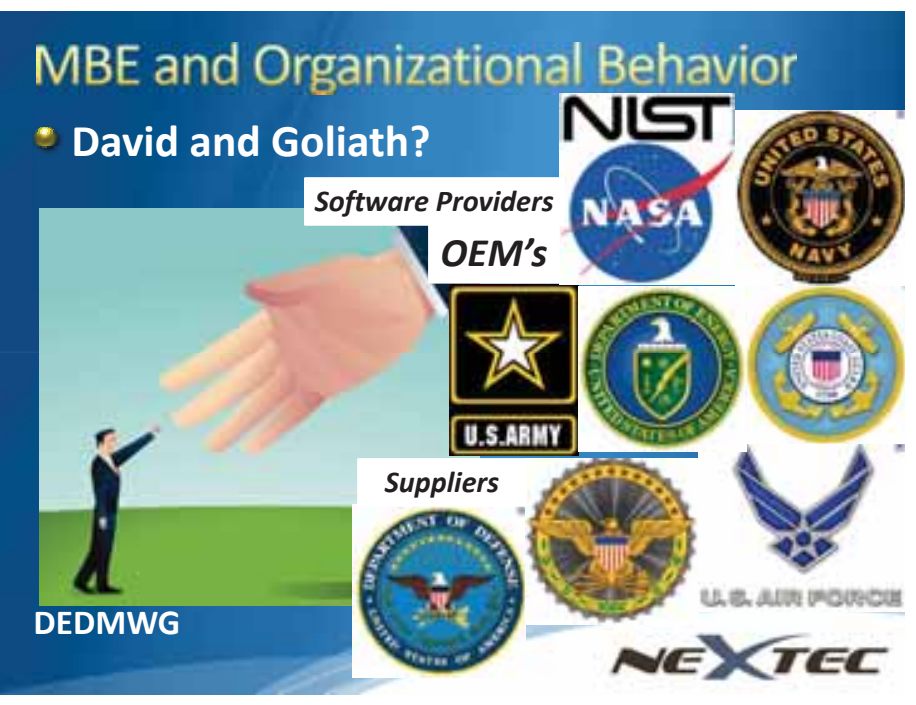

\section{MBE and Organizational Behavior}

\section{- Why is this?}

- People are multifaceted and complex

- People make sense of past behavior by forming beliefs that rationalize it

" "It makes sense to me why we do this"

- Effect is to escalate commitment to these beliefs

- People avoid embarrassment or threat to self - "We have always done it this way"

- These human characteristics cause organizational behaviors to persist in the face of new realities

- Michael Beer Harvard University

\section{MBE and Organizational Behavior}

Why is this?

- Organizations are complex open social systems

- Organizations develop distinct and persistent behavior patterns or culture

- Culture is the beliefs, assumptions and resultant behaviors defined by the leaders

- Leaders teach new members methods of thinking, perceiving and problem solving

- Managers select new members based on similarities to these traits

s Strengthens the culture

AE TEC

\section{MBE and Organizational Behavior}

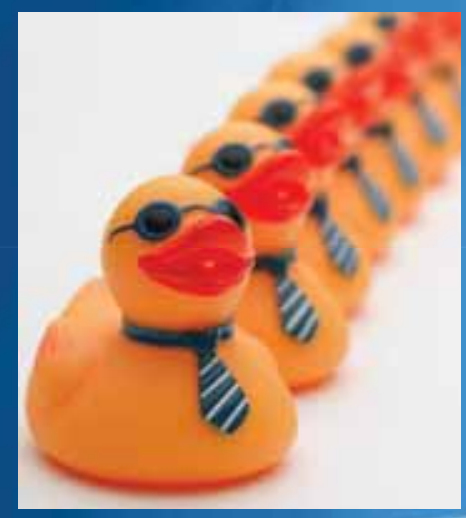

Organizational

Commitmet

"Keeping your ducks in a row" 
MBE and Organizational Behavior

- Model Based Enterprise represents a fundamental shift to 3D from 2D for all major internal organizations

* Engineering - design and configure in 3D

- Operations - build to 3D graphical instructions

- Quality - inspect and buy off to 3D

* Service and Support - 3D support documentation

- Information Technology - store and distribute 3D

- Finance and Contracts - budget and deliver 3D

- All organizations will need to adapt

AE TTEC

\section{MBE and Organizational Behavior}

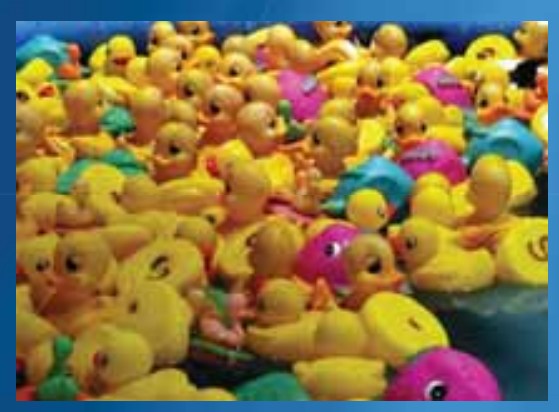

Change can be chaotic

"But what do I do without a drawing?"

\section{MBE and Organizational Behavior}

- Need to rebuild each organization around the exclusive use of 3D

- Engineering - the hardest to pull the drawing from

- Operations - need to become PC and App savvy

- Quality - may need updated training in GD\&T

- Service and Support - learn to read 3D instruction

- IT - new processes for application management

- Finance and Contracts - identify cost advantages

- New organizations will be flexible

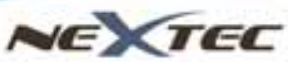

\section{MBE and Organizational Behavior}

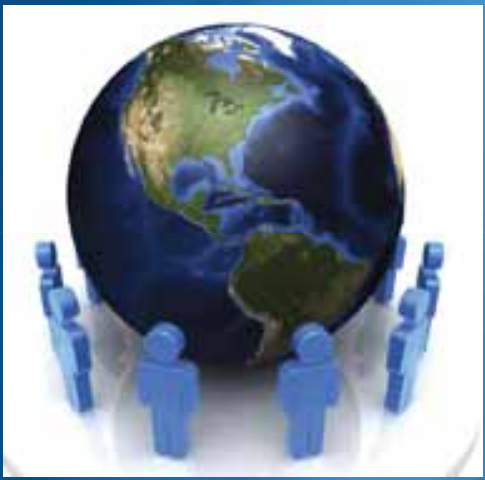

Can we really move the continents?

\section{MBE and Organizational Behavior}

- How do we affect such change?

- Empower leaders at all levels

- The folks closest to the topics know them best

- Redesign the Organization Chart

- Adapt to changing roles and responsibilities

- Trust and encourage people to think anew

- Unlock the internal process innovations

- Actively pursue the resolution of conflict

- Get it out - don't let it brew 


\section{MBE and Organizational Behavior}

- People will follow the new behaviors defined by the organizational leaders

- Keeping people involved and informed will increase the individual commitment to the new norms

- This commitment will stabilize and sustain the new organizations

- The new organizational behavior will be much more dynamic and flexible
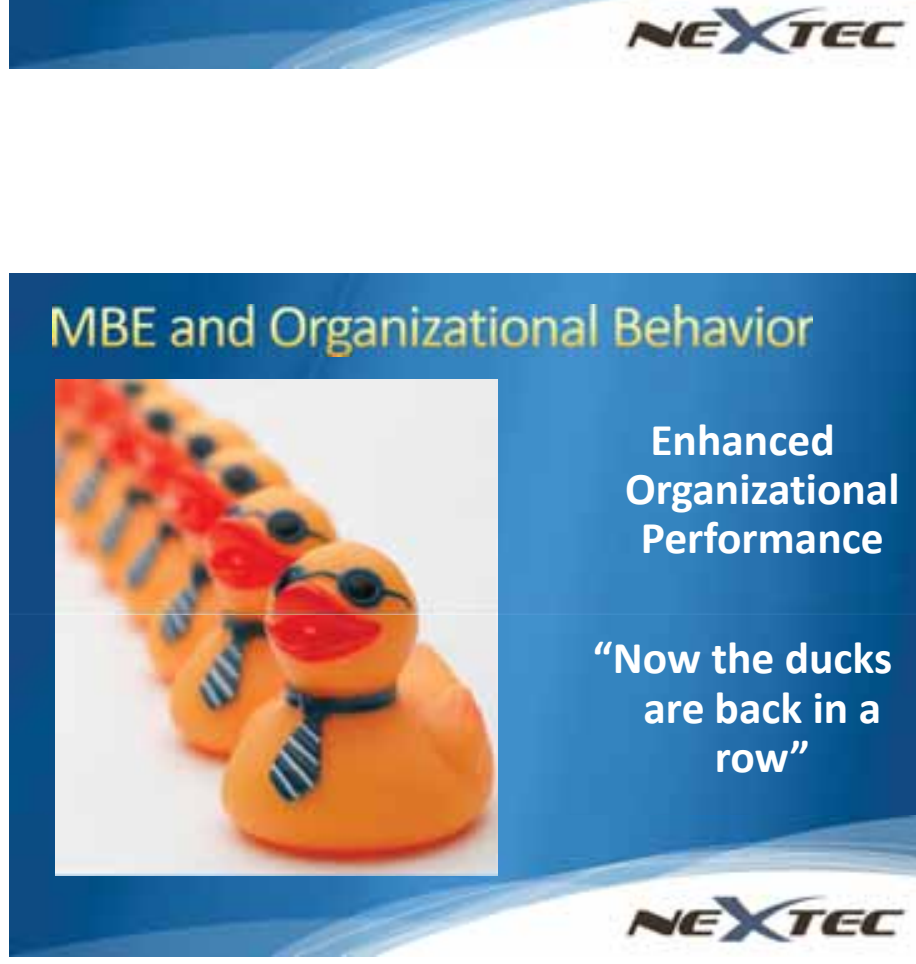

\section{Engineered Resilient Systems (ERS): A DoD Perspective}

Resilience: Effective in a wide range of situations, readily adaptable to others through reconfiguration or replacement, with graceful degradation of function

ERS: a DoD-wide science and technology priority

- Established to guide FY13-17 defense investments across

DoD Services and Agencies

- Ten year science and technology roadmap under development

- Five technology enablers identified

"...our record of predicting where we will use military force since Vietnam is perfect. We have never once gotten it right.

There isn't a single instance ... where we knew and planned for such a conflict six months in advance, or knew that we would be involved as early as six months ahead of time.

\begin{tabular}{l|l} 
we need to have in mind the greatest possible flexibility & The Honorable Dr. Robert M. Gates
\end{tabular} and versatility for the broadest range of conflict... $22^{\text {nd }}$ Secretary of Defense

Uncertain futures, and resultant mission volatility, require affordably adaptable and effective systems - done quickly

\section{MBE and Organizational Behavior}

- Strategy to define the new behaviors

- Consider these questions:

- What are we doing today that we are not going to be doing in the future?

- and equally important -

- What are we going to be doing in the future that we are not doing today?

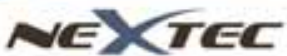

\section{Engineered Resilient Systems (ERS) DoD Science and Technology Priority}

Mr. Scott Lucero

Deputy Director, Strategic Initiatives

Office of the Deputy Assistant Secretary of Defense

(Systems Engineering)

Scott.Lucero@osd.mil

December 12, 2011
The Problem Goes Beyond Process: Need New Technologies, Broader Community

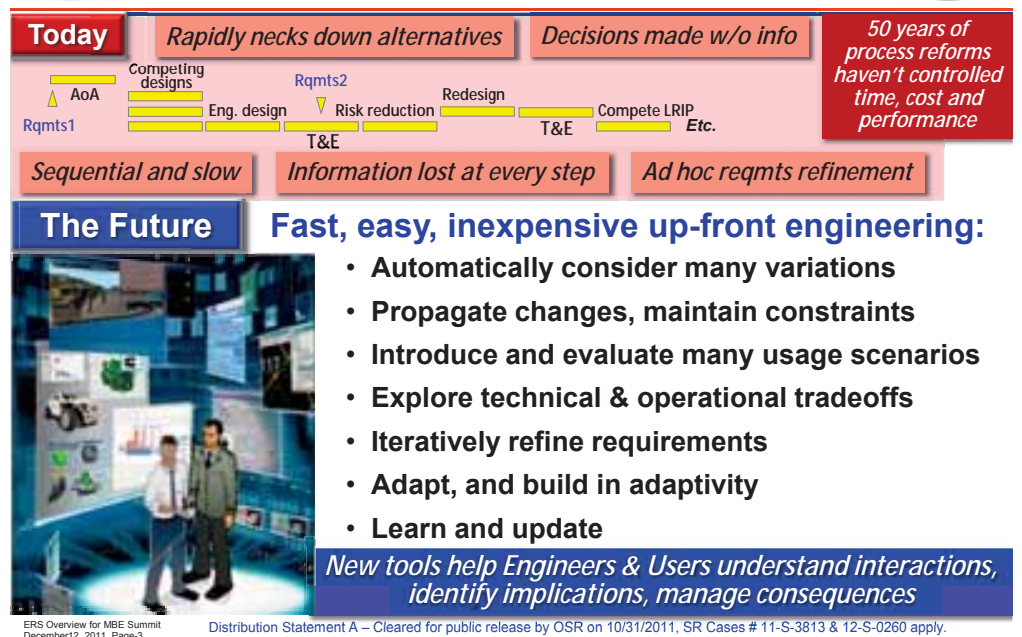




\section{Engineered Resilient Systems} Key Technical Thrust Areas

\section{Systems Representation and Modeling}

- Capturing physical and logical structures, behavior, interaction with the environment, interoperability with other systems

Characterizing Changing Operational Contexts - Deeper understanding of warfighter needs, directly gathering operational data, better understanding operational impacts of alternative designs

\section{Cross-Domain Coupling}

- Better interchange between "incommensurate" models - Resolving temporal, multi-scale, multi-physics issues across engineering disciplines

Data-driven Tradespace Exploration and Analysis - Efficiently generating and evaluating alternative designs, evaluating options in multi-dimensional tradespaces

Collaborative Design and Decision Support - Enabling well-informed, low-overhead discussion, analysis, and assessment among engineers and decisionmakers
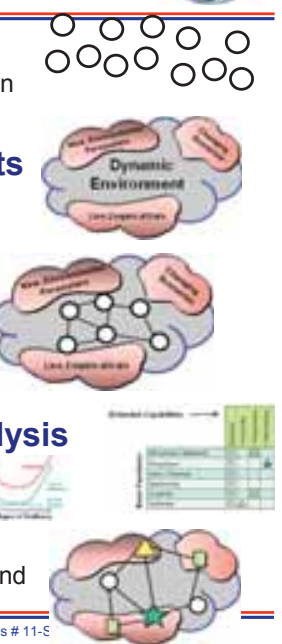

System Representation and Modeling: Technical Gaps and Challenges

\begin{tabular}{|c|c|c|}
\hline Technology & 10-Yr Goal & Gaps \\
\hline $\begin{array}{l}\text { Capturing } \\
\text { - Physical and } \\
\text { logical structures } \\
\text { - Behavior } \\
\text { - Interaction with } \\
\text { the environment } \\
\text { and other } \\
\text { systems }\end{array}$ & $\begin{array}{l}\text { Model } 95 \% \\
\text { of a complex } \\
\text { weapons } \\
\text { system }\end{array}$ & $\begin{array}{l}\text { - Combining live and virtual worlds } \\
\text { - Bi-directional linking of physics-based } \\
\text { \& statistical models } \\
\text { - Key multidisciplinary, multiscale models } \\
\text { - Automated and semi-automated } \\
\text { acquisition techniques } \\
\text { - Techniques for adaptable models }\end{array}$ \\
\hline
\end{tabular}

We need to create and manage many classes (executable, depictional, statistical...) and many types (device and environmental physics, comms, sensors, effectors, software, systems ...) of models
Characterizing Changing Operational Environments: Technical Gaps and Challenges

\begin{tabular}{|c|c|c|}
\hline Technology & 10-Yr Goal & Gaps \\
\hline $\begin{array}{l}\text { Deeper } \\
\text { understanding of } \\
\text { warfighter needs } \\
\text { Directly gathering } \\
\text { operational data } \\
\text { Understanding } \\
\text { operational } \\
\text { impacts of } \\
\text { alternatives }\end{array}$ & $\begin{array}{c}\text { Military } \\
\text { Effectiveness } \\
\text { Breadth } \\
\text { Assessment } \\
\text { Capability }\end{array}$ & $\begin{array}{l}\text { - Learning from live and virtual } \\
\text { operational systems } \\
\text { - Synthetic environments for } \\
\text { experimentation and learning } \\
\text { - Creating operational context models } \\
\text { (missions, environments, threats, } \\
\text { tactics, and ConOps) } \\
\text { - Generating meaningful tests and use } \\
\text { cases from operational data } \\
\text { - Synthesis \& application of models }\end{array}$ \\
\hline
\end{tabular}

"Ensuring adaptability and effectiveness requires evaluating and storing results from many, many scenarios (including those presently considered unlikely) for consideration earlier in the acquisition process."

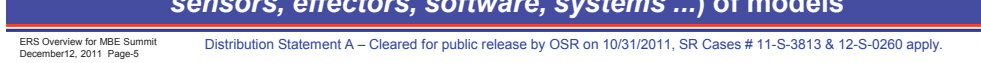

Distribution Statement A - Cleared for public release by OSR on 10/31/2011, SR Cases \# 11-S-3813 \& 12-S-0260 apply.

\begin{tabular}{|c|c|c|}
\hline Technology & 10-Yr Goal & Gaps \\
\hline $\begin{array}{c}\text { Better } \\
\text { interchange } \\
\text { between } \\
\text { incommensurate } \\
\text { models } \\
\text { Resolving } \\
\text { temporal, } \\
\text { multi-scale, } \\
\text { multi-physics } \\
\text { issues }\end{array}$ & $\begin{array}{l}\text { Weapons } \\
\text { system } \\
\text { modeled } \\
\text { fully } \\
\text { across } \\
\text { domains }\end{array}$ & $\begin{array}{l}\text { - Dynamic modeling/analysis workflow } \\
\text { - Consistency across hybrid models } \\
\text { - Automatically generated surrogates } \\
\text { - Semantic mappings and repairs } \\
\text { - Program interface extensions that: } \\
\text { - Automate parameterization } \\
\text { and boundary conditions } \\
\text { - Coordinate cross-phenomena simulations } \\
\text { - Tie to decision support } \\
\text { - Couple to virtual worlds }\end{array}$ \\
\hline
\end{tabular}

Making the wide range of model classes and types work together

effectively requires new computing techniques (not just standards)

\section{Cross-Domain Coupling: Technical Gaps and Challenges}

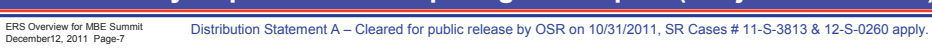

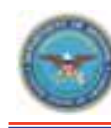

Tradespace Analysis: Technical Gaps and Challenges

\begin{tabular}{|c|c|c|}
\hline Technology & 10-Yr Goal & Gaps \\
\hline $\begin{array}{c}\text { Efficiently } \\
\text { generating } \\
\text { and } \\
\text { evaluating } \\
\text { alternative } \\
\text { designs } \\
\text { Evaluating } \\
\text { options in } \\
\text { multi- } \\
\text { dimensional } \\
\text { tradespaces }\end{array}$ & $\begin{array}{c}\text { Trade } \\
\text { analyses } \\
\text { over very } \\
\text { large } \\
\text { condition } \\
\text { sets }\end{array}$ & $\begin{array}{l}\text { - Guided automated searches, selective search algorithms } \\
\text { - Ubiquitous computing for generating/evaluating options } \\
\text { - Identifying high-impact variables and likely interactions } \\
\text { - New sensitivity localization algorithms } \\
\text { - Algorithms for measuring adaptability } \\
\text { - Risk-based cost-benefit analysis tools, presentations } \\
\text { - Integrating reliability and cost into acquisition decisions } \\
\text { - Cost-and time-sensitive uncertainty management via } \\
\text { experimental design and activity planning }\end{array}$ \\
\hline
\end{tabular}

Exploring more options and keeping them open longer, by managing complexity and leveraging greater computational testing capabilities

\section{Collaborative Design \& Decision Support: Technical Gaps and Challenges}

\begin{tabular}{|c|c|c|}
\hline Technology & 10-Yr Goal & Gaps \\
\hline $\begin{array}{c}\text { Well- } \\
\text { informed, } \\
\text { low- } \\
\text { overhead } \\
\text { collaborative } \\
\text { decision } \\
\text { making }\end{array}$ & $\begin{array}{c}\text { Computational } \\
\text { / physical } \\
\text { models bridged } \\
\text { by 3D printing } \\
\\
\text { Data-driven } \\
\text { trade decisions } \\
\text { executed and } \\
\text { recorded }\end{array}$ & $\begin{array}{l}\text { - Usable multi-dimensional tradespaces } \\
\text { - Rationale capture } \\
\text { - Aids for prioritizing tradeoffs, } \\
\text { explaining decisions } \\
\text { - Accessible systems engineering, } \\
\text { acquisition, physics and behavioral models } \\
\text { - Access controls } \\
\text { - Information push-pull without flooding }\end{array}$ \\
\hline
\end{tabular}

ERS requires the transparency for many stakeholders to be able to understand and contribute, with low overhead for participating 


\section{What Constitutes Success?}
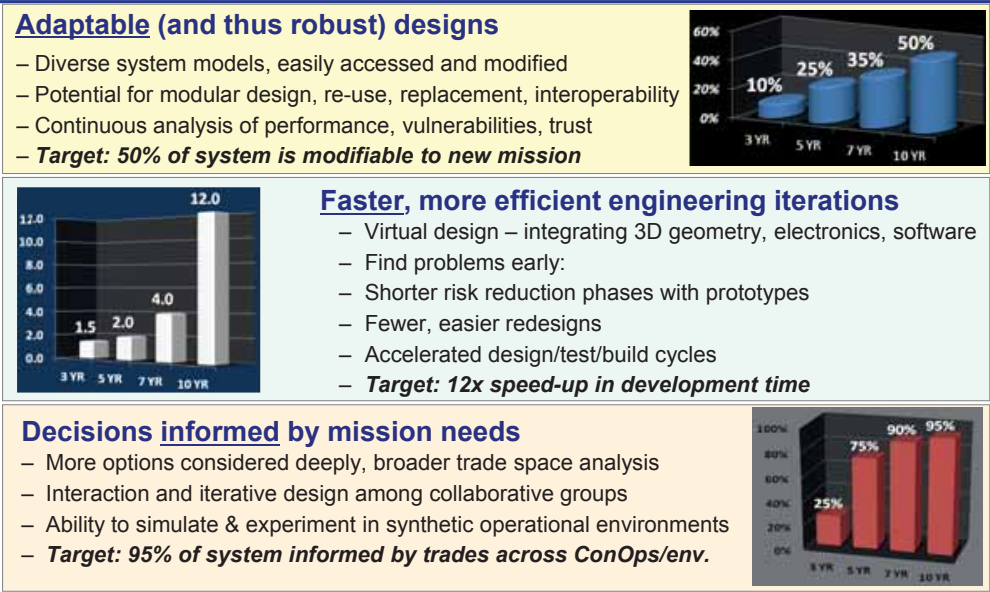

ecisions informed by mission needs

- More options considered deeply, broader trade space analysis

- Interaction and iterative design among collaborative groups

- Ability to simulate \& experiment in synthetic operational environments

Target: $95 \%$ of system informed by trades across ConOps/env.

Faster, more efficient engineering iterations

- Virtual design - integrating 3D geometry, electronics, softwar

Shorter risk reduction phases with prototypes

Fewer, easier redesigns

- Accelerated design/test/build cycles

- Target: 12x speed-up in development time

ERs Overiew for MEE Summit
Deceomberi2, 2011 Page-10
Distribution Statement A - Cleared for public release by OSR on 10/31/2011, SR Cases \# 11-S-3813 \& 12-S-0260 apply.

\section{ASCCA Applied R\&D}

\section{NDEMC: A Public-Private Partnership to bring MS\&A and HPC to SME's}

Dennis Thompson

Sr. VP SCRA

and

Technical Project Manager for NDEMC
SCRA Proprietary

\section{Engineering: Critical to Capability Delivery}

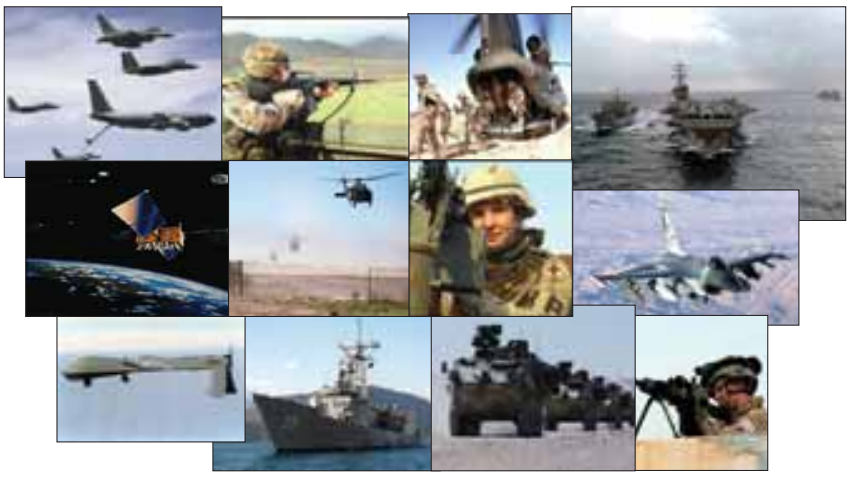

Innovation, Speed, and Agility

http://www.acq.osd.mil/se

\section{STCRA Example of a Successful PPP}

The National Digital Engineering and Manufacturing Consortium (NDEMC) is being developed for the purposes of piloting a program to promote adoption and advancement of Modeling Simulation and Analysis (MS\&A) in Small Manufacturing Enterprises (SMEs) and the U.S. manufacturing supply chain, initially focused in the U.S. Midwest. The end goal is to give U.S. based manufacturers tools that will help them be more competitive in the global economy and help retain and grow a strong manufacturing in the U.S.. NDEMC has two initial focuses:

Create a single point of entry portal that will support Software as a Service (SaaS) in a cloud environment that will link High Performance Computing (HPC) providers, university researchers and other technical support and private sector consultants.

Do a series of demonstration project that prove the business case for MS\&A and HPC in the SME community and develop a replicable model that can be expanded to other regions of the U.S.
Public Private Partnerships (PPPs) are innovative methods used by the public sector to partner with the private sector, who bring capital and expertise to deliver projects on time, on budget and meeting expectations. PPP's are effective and efficient ways of deploying solutions at scale for the social and economic benefit to the public

PPPs are important tools to bridge innovation strategies where the marketplace has not been effective at scale to date. PPPs can provide a number of specific benefits to enhance economic development and economic return through:

- increased product quality at same or lower cost

- higher levels of service

- reduced risk

- decreased time to market

enhanced capabilities offered in bidding

- the creation of highly-skilled technical workforces 


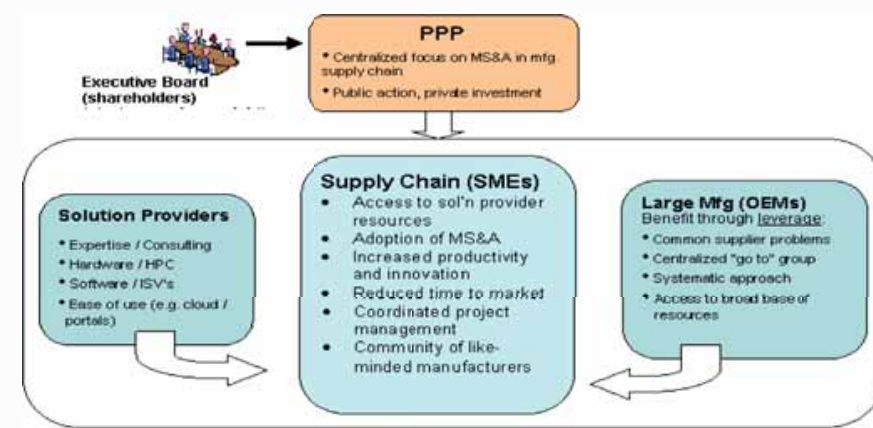

- Need catalyst for SME entry into, and advancement of, digital mfg infrastructure \& operations Centralize and systematize approach through the Consortium; leverage commonalities across Benofitus min through in
$1 / 3 / 2012$

SCRA Proprietary
NDEMC is developing and fostering a new manufacturing focused community linking:

- U.S. Manufacturers,

- Commercial software developers,

- Hardware vendors,

- Universities, and

- National laboratories

\section{GSCRA}

\section{NDEMC (2) Thrusts Areas}

\section{GSCRA}

NDEMC Portal

1. Teams of experts provide specialized consulting/training in MS\&A

Deployed to SME sites for personalized consulting and training

Based at institutions with modeling and manufacturing expertise

SMEs
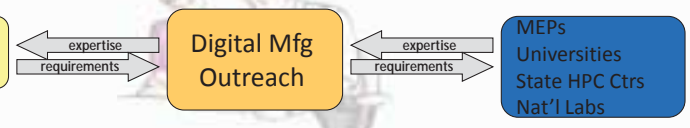

2. On-line manufacturing portal tor computation

Access to broad base of expertise

On-line interactive professional education

Cloud-based computing resources

Easy web-based access to engineering and manufacturing software

Deployed field consultant/ trainers will be key to ensuring these two thrusts complement, and are informed by, each other
Portal will have (4) major pieces:

1. Commercial financial transaction capabilities (like amozon.com)

2. Searchable catalog/database of MS\&A software's and other analysis software's

3. MS\&A tech support/counseling from a trusted $3^{\text {rd }}$ party (universities, etc)

4. MS\&A consulting service providers

\section{SSCRA}

\section{NDEMC}

\section{SSCRA Benefits of NDEMC}

NDEMC is designed to accommodate the broad MS\&A needs of SMES

- Common issues / leveraging

SMEs can share solutions and influence $3^{\text {rd }}$ party development

Domain application portals simplify usage of codes

Needs served by existing commercial codes and readily available hardware resources

VS.

- Highly customized needs and requirements

SMEs require specialized capabilities not currently available in commercial software

Collaboration with external R\&D may be needed (universities and/or national laboratories)

In both cases, community promotes efficiency
- OEMs

- Increased collaboration with supply chain

- More innovative, integrated, and efficient supply chain

- Access to large community of MS\&A/HPC expertise and influence

- Software Providers

- Increased market penetration of products

- First-hand access to requirements for product development roadmaps
SMEs

Reduced time to market

Enhanced throughput

Reduced waste

Increased safety and sustainability

Reveals critical information to inform decision-making.

U.S. Government Highly skilled U.S. workforce Increased global competitiveness 


\title{
SSCRA
}

NDEMC Progress To Date

- (7) Demonstration projects launched in November. All will be completed within 90 days (first of 30-40 demonstration projects)

- Demonstration projects will include MS\&A applications across the entire product life cycle

- Case studies will be developed and published on all demonstration projects

- Portal is underdevelopment with direct linkage to High Performance Computing (HPC) through a cloud application

- Created a searchable catalog of (143) software's available to SMEs through the portal

- Negotiating with other software supplier to expand the catalog of products available to the SMEs

The DoD has a number of active programs that could benefit from the work of NDEMC and build off of it instead of reinventing it.

Examples:

- Advanced Manufacturing Enterprise (AME)

- Model Based Engineering (MBE)

- Connecting American Manufacturing (CAM)

- DARPA's Open Manufacturing

- Others????

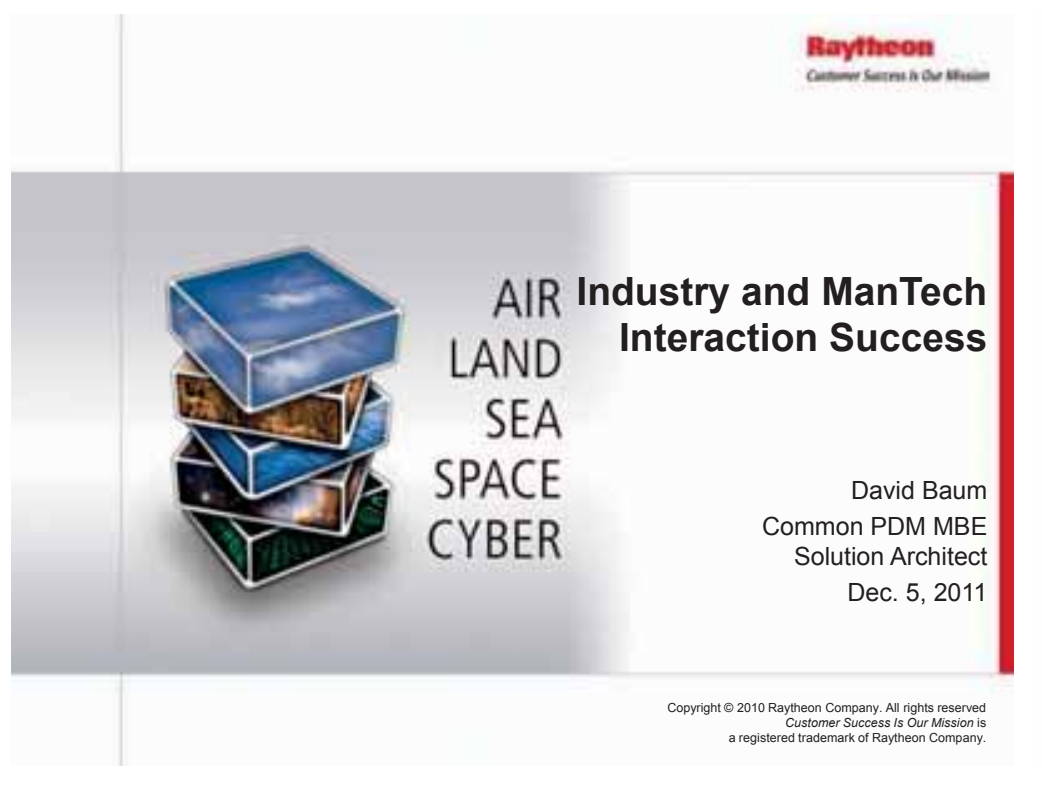

\section{Industry and ManTech Interaction Success}

\author{
Raytheon Corporation \\ Hardware Engineering \\ Common Product Data Management (PDM) \\ Model Based Enterprise (MBE) Solution Architect \\ David Baum \\ Dec. 5, 2011
}

\section{Who We Are}

- Who we are and what we make at Raytheon

- Our EDS \& IPDS Support Standards of Excellence across multiple Businesses

- Our Common PDM Information System

- Raytheon's MBE

- Use Case Standards for MBD models.

- ManTech Projects \& their value to Raytheon

\begin{tabular}{|c|c|c|c|c|}
\hline $\begin{array}{l}\text { Who we } \\
\text { are at }\end{array}$ & $\begin{array}{l}\text { Business } \\
\text { Process }\end{array}$ & $\begin{array}{c}\text { Targeting } \\
\text { MBD }\end{array}$ & $\begin{array}{l}\text { Capability } \\
\text { Roadmap }\end{array}$ & $\begin{array}{l}\text { Leveraging } \\
\text { DoD Funds }\end{array}$ \\
\hline Raytheon & $\begin{array}{l}\text { Integration } \\
\text { Need }\end{array}$ & Benefits & $\begin{array}{l}\text { \& Use } \\
\text { Cases }\end{array}$ & $\begin{array}{l}\text { For } \\
\text { MBD }\end{array}$ \\
\hline
\end{tabular}

- A technology and innovation leader specializing in defense, homeland security and other government markets throughout the world

- 2010 net sales: $\$ 25$ billion

- 72,000 employees worldwide

- Headquarters: Waltham, Mass.

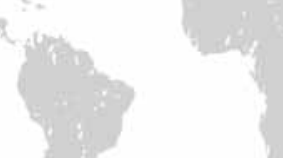




\section{Our Strategy}

- Focus on key strategic pursuits, Technology and Mission Assurance to sustain and grow our position in our four core defense markets:

- Sensing: Expand beyond traditional RF/EO to new growth focus areas, including multi-mission areas.

- Effects: Leverage kinetic energy-based expertise into EW, directed energy and cyber markets.

- C3I: Broaden market presence in communications, C2, networking and knowledge management.

- Mission Support: Expand beyond product support, engineering services and training

- Leverage our domain knowledge in all markets, including Homeland Security and Cybersecurity.

- Expand international business by building on our relationships and deep market expertise.

- Continue to be a Customer Focused company based on performance, relationships and solutions.
What We Make

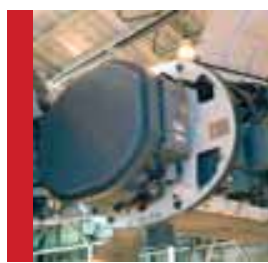

\begin{tabular}{l|l} 
Core Market: & Core Market: \\
Sensing & C3I (Command, \\
Technologies that & Control, \\
acquire data and & Communications and \\
create accurate, & Intelligence) \\
reliable information & Integrated real-time \\
for effective & systems that optimize \\
battlespace & operational planning \\
decisions. & and execution.
\end{tabular}
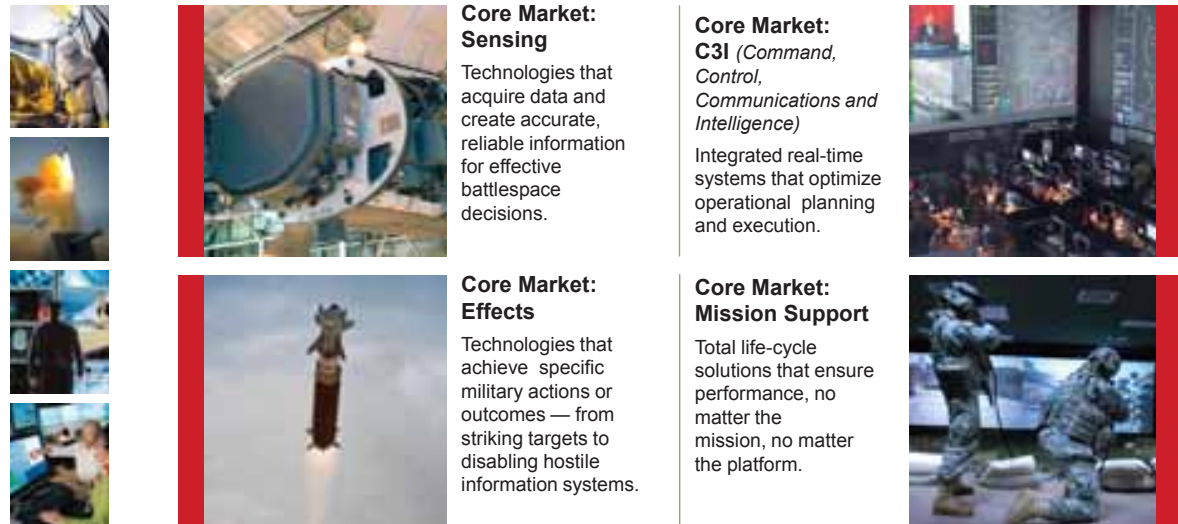

Core Market: Effects

Technologies that achieve specific military actions or outcomes - from striking targets to disabling hostile information systems.

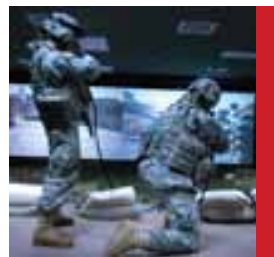

\section{A technology-driven growth strategy}

\section{Common Design Controls and Practices}

- Common Product Data Management (PDM) Workflows

- Engineering Documentation Standards (EDS)

- IPDS Best Practices for MBE in Process Asset Library (PAL)

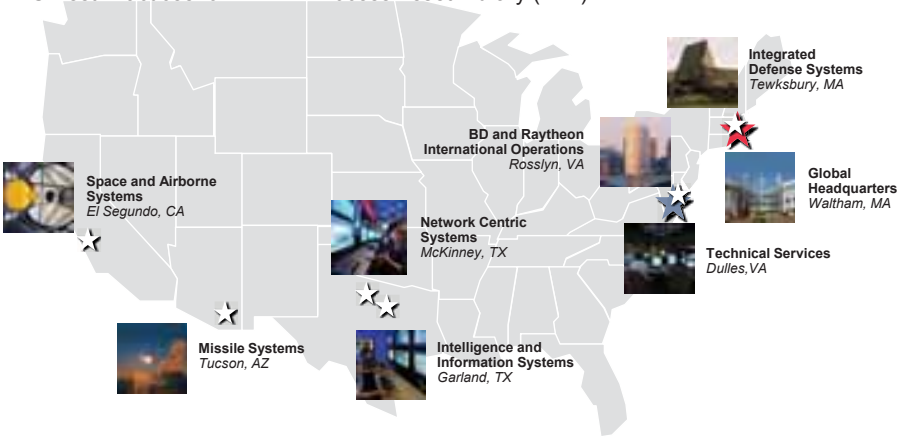

72,000 employees; 2010 net sales: $\$ 25$ billion
National Defense Industry Association Position Raytheon High Level MBE Benefits

- Reduce time to acquisition of first article for systems and solutions

- More complete evaluation of the trade space

- Earlier risk identification and mitigation

- Concurrent and collaborative engineering

- Design reuse

- Accelerated development

- Reduce the time to implement planned and foreseen changes in systems

- Design reuse

- Rapidly evaluate changing threats and explore trade space

- Enhance Reliability

- Earlier and continuous requirements and system verification

- Identify and resolve errors/issues/fewer post-fielding issues

- Enhance Interoperability

- Inclusion of the operating environment and external interfaces in system models

- Early and continuous interface and interoperability verification

Reference:

Final Report MBE Subcommittee

Jeff Bergenthal (Subcommittee Lead)

NDIA Systems Engineering Division

M\&S Committee, February 2011
DoD TRL \& MRL Requirements by Life Cycle Phase

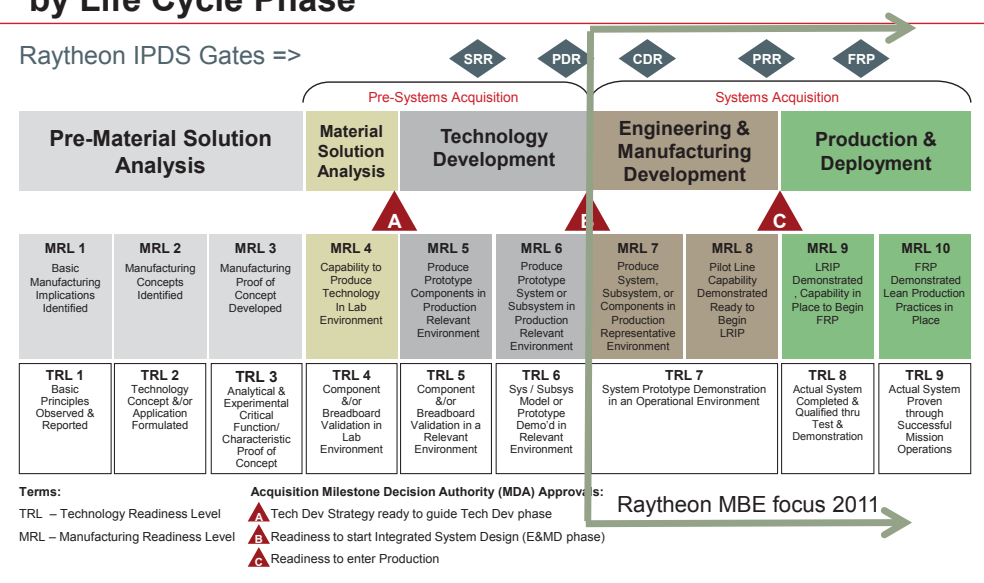

Predefined TRL \& MRL Levels must be met at Program Milestones

Raytheon
Model Based Enterprise Capability Development

\section{- Complexity \& Functions requires System Decomposition}

- Model Based Definition (MBD) - 2011

- Enterprise MBD Specification completed in 2010

- MCAD Models that are Qualified for defined Life Cycle Use Cases (Standards)

- New visualization tools (ProductView)

- Model Based Manufacturing (MBM) - 2012

- Global supplier communication and support of product IP

- MCAD Models transitioned from "As Designed" to "As Planned"

- Derivatives from MCAD models used for process plans.

- Model Based Systems Engineering (MBSE) - 2013

- Virtual verifications at the core of these capabilities

- Requirement allocations \& derivations

- "As Verified" status linked to PDM

- Model Based Life Cycle Support

- Reuse of MBD for technical manuals

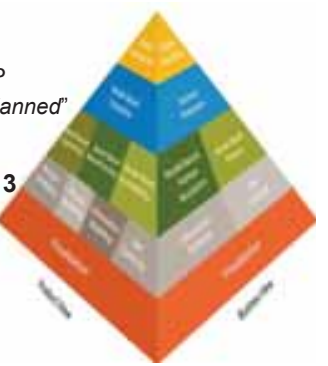

Model Based Enterprise Framework is Common PDM 


\section{Common PDM MBD Capability Use Case Requirements}

Raytheon

- Authoring - defining all the features, annotations, and attributes required of a model for its defined use cases.

- Checking - verifying that all Hardware Development Plan (HDP) specified "use cases", and modeling standards are met for model integrity before formal release to PDM.

- Design Review - verifying that the model is complete for form, fit, and function

- Concurrent Engineering - inputs (analysis, annotation, feature changes, etc.) to the design model from functional SME's determined to be critical to the part/assembly.

- Configuration Management - identification of all correct attribute data for formal control.

- Manufacturing Process Flow

- First Article Inspection - Identification of critical features/dimensions in mode

- Assembly Aids - extraction of parts list; geometry for assembly aids/work instructions - CNC Programming - geometry and tolerances needed to drive CNC programming

- Supplier Review - distribution of a formally controlled model with all information needed for review of HDP planned "use cases".

- Technical Manuals - similar to Assembly Aids with identification of replaceable assemblies.

\section{Use Cases Keep Model Development in Scope}

\section{Exploring Solutions For Improved Interoperability}

- Customer / Supplier Interoperability During Collaborative Design (CSI)

- Solution addressing AFRL BAA: 08-08-PKM

Air Force Research Laboratory

Defense Manufacturing Science \& Technology (MS\&T)

High Performance Manufacturing: Model Based Enterprise

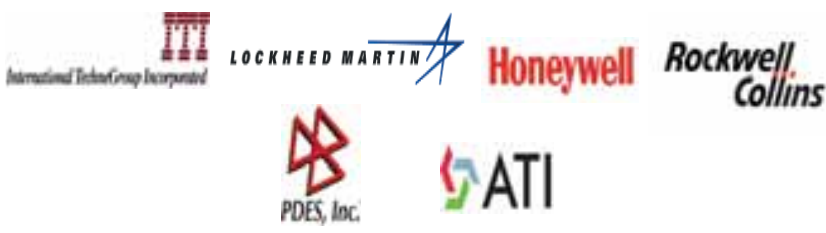

\section{Vision}

CSI Overview

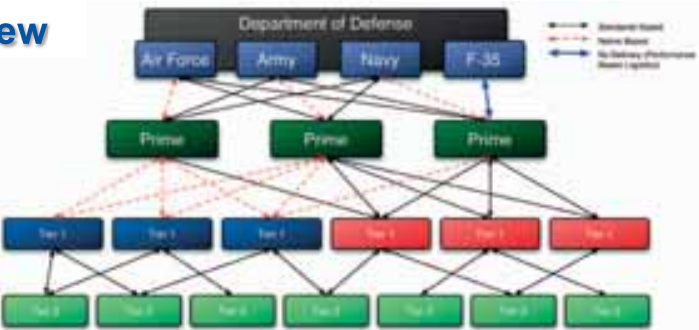

DoD Problem:

Warfighter Benefits:

Lack of defined data exchange format requirements between suppliers and custom

Reduced costs and higher quality data. Improvements in business practices will be seen in:

- Less cost to deliver products to the warfighter by sks and manipulation of the data

Capture, validate and test "data-contract" requirements by assessing the requirements, evaluating the highest priority requirements, and developing prototype solutions for the

Using the DEXcenter, ITI will develop CSI modules, to

include contract mapping tools, and software libraries

Conduct a demonstration to highlight the savings achieved

- Less time for new capabilities to reach the warfighter because of streamlined processes through the supply

chain during early product development phases

Cost savings are estimated to be over $\$ 35$ million per major program

A flexible, configurable, standards based system which automates common tasks associated with Customer Supplier Interoperability

- Easily / quickly configurable to handle different contract requirements

- Leverages existing ITI technologies (DEXcenter, PDElib, CADscript, CADfix, CADIQ, etc)

- Supports typical requirements like: - Model preparation Removing / adding / hiding dat Organization Coordinate system

Renaming Abstraction / simplificatio Adding IP / ITAR notes

Translation Neutral standards (STEP, IGES) CAD Native formats Visualization

- Validation

- Geometry, topology, PM

- Delivery

Encrypted

- IP protection

IP protection
ITAR controls

Direct (https web, sftp) or via PLM

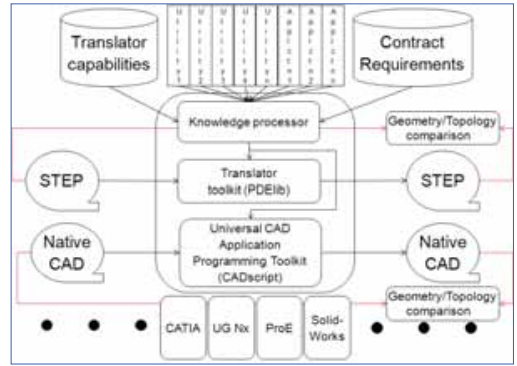

Tracking / auditing
Accelerating MBE deployment - CSI contract addendums
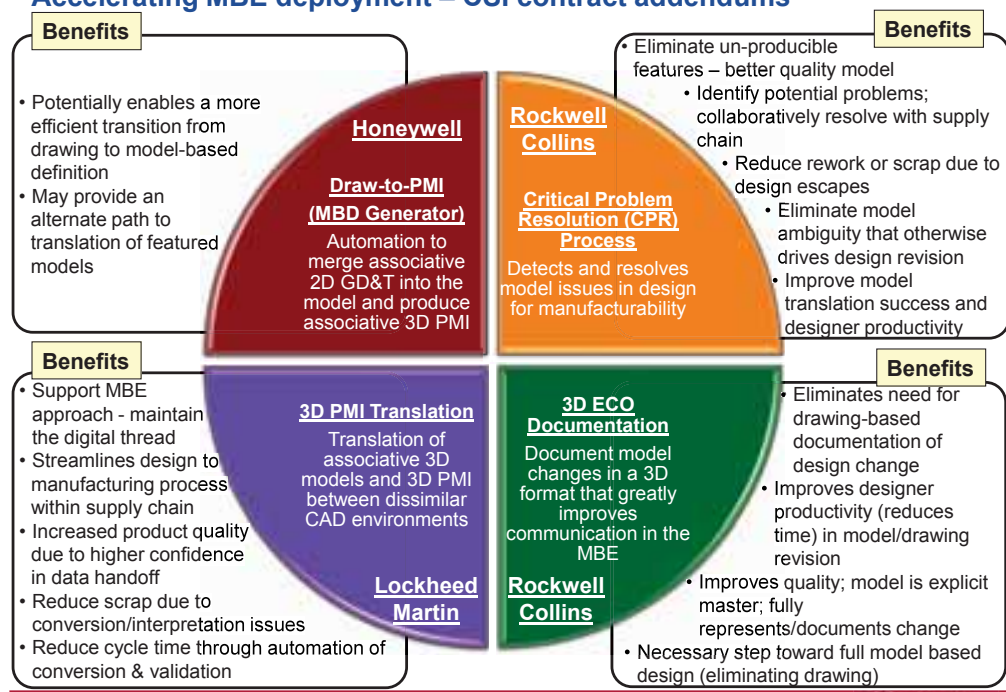

\section{ManTech Projects Leveraged}

Addendum 1 to Statement of Work Customer/Supplier Interoperability during Collaborative Design (CSI)

Task 3.1 - 3D Mode Comparison and Validation for ECOs: The contractor shall develop a prototype solution that integrates 3D Modeling Comparison and Validation for ECOs with the existing CSI platforms. The 3D ECO Documentation capability will document differences in 3D Model Based document difer in in the a r The in the model. That changed model could then be compared to the original model and all differences would be reported in a 3D viewing format with annotations sufficient to highlight each change and permit the user to graphically manipulate the model.
Piloting CADIQ model comparison capability, with Pro/E models, to identify model changes during change management process.

Use Case Applications: -MBD Authoring -MBD Checking -Configuration Management -Concurrent Engineering 


\section{ManTech Projects Leveraged}

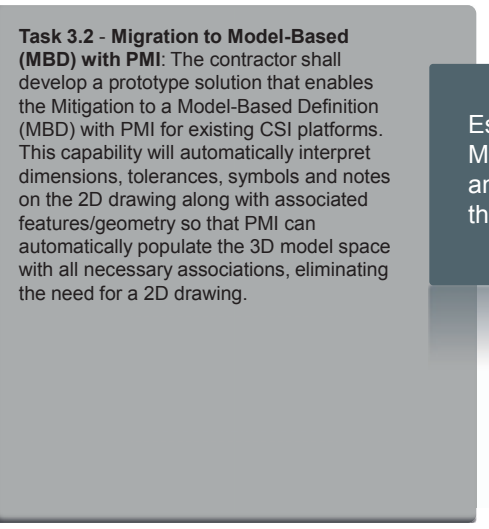

Established a Raytheon Standard MBD Schema, with start parts and PDM attributes, for use with tools that enable Model-Based Definition".

Use Case Applications: -MBD Authoring Standards -MBD Checking Standards

\section{ManTech Projects Leveraged}

Raytheon

Task 3.4 - Critical Problem Resolution for Manufacturing: The contractor shall develop a prototype solution that

demonstrates a critical problem resolution (CPR) process to remedy manufacturing in the design process. The CPR process should identify critical manufacturing problems and their corresponding resolutions, and integrate with the existing CSI platform. The results of this continuous analysis should be fed into the configuration files for quality tools that can be used to validate engineering models prior to engineering release and manufacturing.
Raytheon is developing MBD model qualifications \& workflows that are prioritized by modeling defect causes

Use Case Applications:

-Design Review

-Concurrent Engineering

- First Article Inspection

-Assembly Aids

- CNC Programming

-Supplier Review
Task 3.3 - PMI Conversion Process

Enhancements: The contractor shal

develop a prototype solution that
demonstrates PMI conversion capabilities to

enable the translation of PMI data in one

CAD system (source system) to a second

CAD system (target system). The PMI

conversion capability will track the

dimensions, text, tolerances and symbols

along with the associated features/geometry

of the source system as the translation of

processed and associated with the

appropriate features/geometry in the target

system.
Raytheon is working with its industry partners, PTC and ITI, to validate conversions of CAD file formats.

Use Case Applications:

-Configuration Management

- Supplier Review

-Technical Manuals

\section{MBE for Quality Measurement: Opportunities and Challenges}

\section{Design, Manufacturing, and Quality: Islands of Automation?}

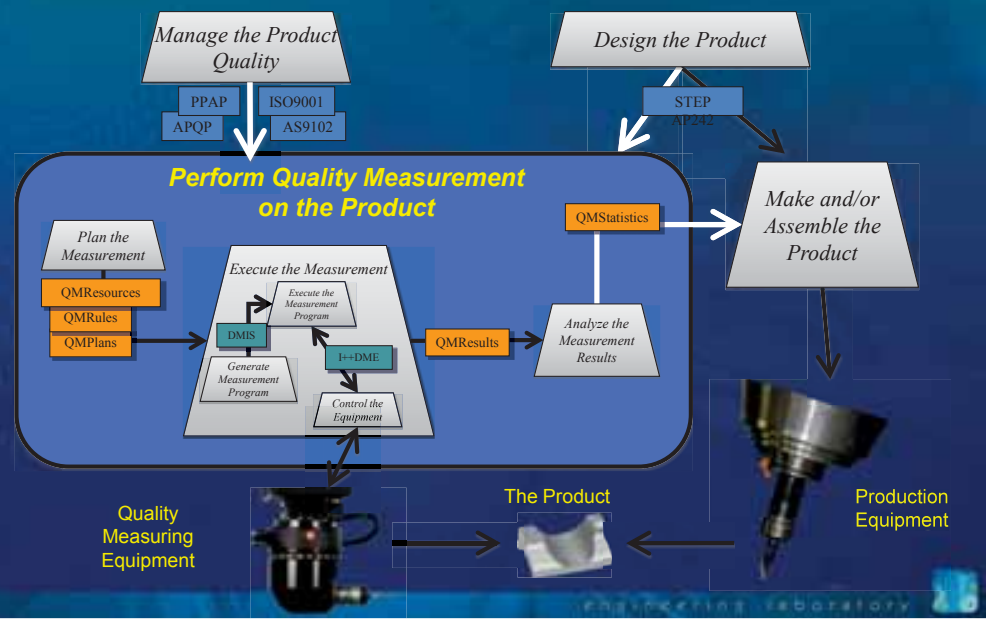

\section{Challenges with MBE for Quality}

- Natural cultural resistance

- Relatively small community

- Small-sized vendors

- Excessive costs

- "Native CAD interfaces"

- Engineering rework:

- Sometimes reverting to blueprints

- Redefining/defining datums/features

- Manually ballooning of drawings per AS9102

- Loss of IO due to mergers and acquisitions 


\section{Challenges with MBE for Quality}

- Link with QMS is paper-based or spreadsheet-based, not digital

- Document revision control

- CAD vendors reluctant to provide digital and fully semantic association between PMI and Geometry

- Slowly moving standards-based CAD + PMI

- Crowded and unreadable drawings

\section{Opportunities with MBE for Quality}

- Centralized data model for CAD/PMI/QMS/Inspection

- Increased automation

- Increased product quality

- Easier to manage engineering changes

- Easier to visualize deviations of actuals from nominals

- "Notes" and "balloons" are

unambiguously associated with models/features/tolerance frames

\section{Introductions}

- Curtis Brown, Honeywell FM\&T

- Ray Admire, LMCO

- Bill Tandler, MultiMetrics

- Nick Orchard \& Ron Snyder, Rolls Royce

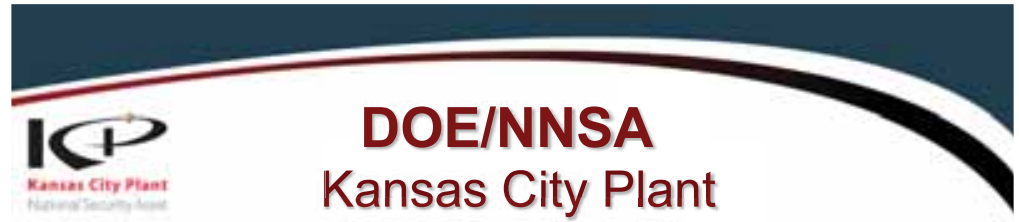

Product Tolerance Representation

Critical Requirements for Product Definition and Metrology Interoperability

Technology that Reduces the Complexity of:

Representing \& Exchanging Fully Semantic Model-Based Tolerancing \& Generating Correct CMM Measurement Programs for Rapid Certification

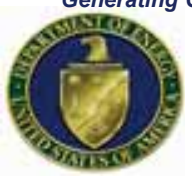

Curtis W. Brown, P.E. Principal Mechanical Engineer

MBE/TDP Summit 12 December 2011

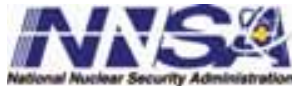

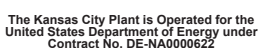

\section{Agenda}

\section{Fully Semantic Tolerance Definition (PMI)}

- Understanding

- Critical Requirements

- Enablers to Manage Complexity

- Feature-Based Tolerancing (FBTol) Brief

- Feature-Based Measuring (FBMeas) Brief

- Optional Demonstration (via .wmv video)

\section{- Progress PMI Agenda (Way Forward)}

- Collaboration

\footnotetext{
Other Government Agencies - Work for Others (WFO)

Companies - Cooperative Research \& Development Agreement (CRADA)
} 


\section{Overview}

- Status of Complete \& Unambiguous Product Modeling

- Today's product definition systems successfully deliver the representation and exchange of nominal shapes.

- Unfortunately, no one can manufacture nominally shaped parts.

- However, we can make parts that fit and function according to correctly specified and accurately conveyed product tolerances.

- Correct, complete \& unambiguous, and verified tolerance definitions are the critical enabler for realizing:

- successful representation, consumption, and/or exchange of product models for next generation automation applications

- return on investment promised by MBE

- Presently, there is likely no single CAD-based system available with the level of robustness to adequately represent and transfer product tolerance information.

We make products for national security.

\section{Overview}

- Status of Complete \& Unambiguous Product Modeling

- Requirements for a Fully Semantic Tolerance Definition

- Basic Understanding of Model-Based Product Tolerance Technology

- Promote a Fully Semantic Representation and Exchange of Tolerance Definitions

- Demonstrate a Product Tolerance Application and Rapid Metrology Generation Application (optional)

- Investigate Opportunities to Progress the Realization of Investments Promised by Model-Based Enterprise.

We make products for national security.

\section{Regrettably}

"Nobody can build perfect parts....

but we can build parts that fit and function,

\section{by applying and communicating functional product tolerance information."}

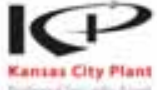

\section{Overview}

- Status of Complete \& Unambiguous Product Modeling

- Requirements for a Fully Semantic Tolerance

Definition

- Basic Understanding of Model-Based Product Tolerance Technology

- Promote a Fully Semantic Representation and Exchange of Tolerance Definitions

- Representation vs Presentation (Annotation) - FBTol

- Tolerance Related Standards

- ASME Y14.X

- ISO 13030 STEP AP203e2

- ISO 13030 STEP AP242

- Process Related Standards

- ISO 13030 STEP AP238

- DMSC's QIF - QMP

We make products for national security.

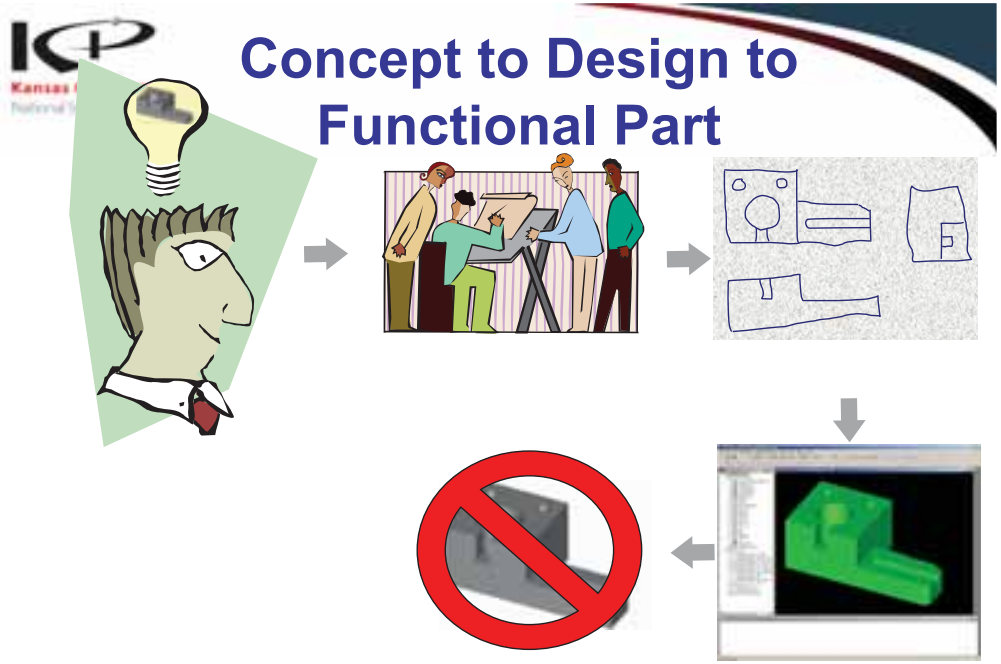

We make products for national security.

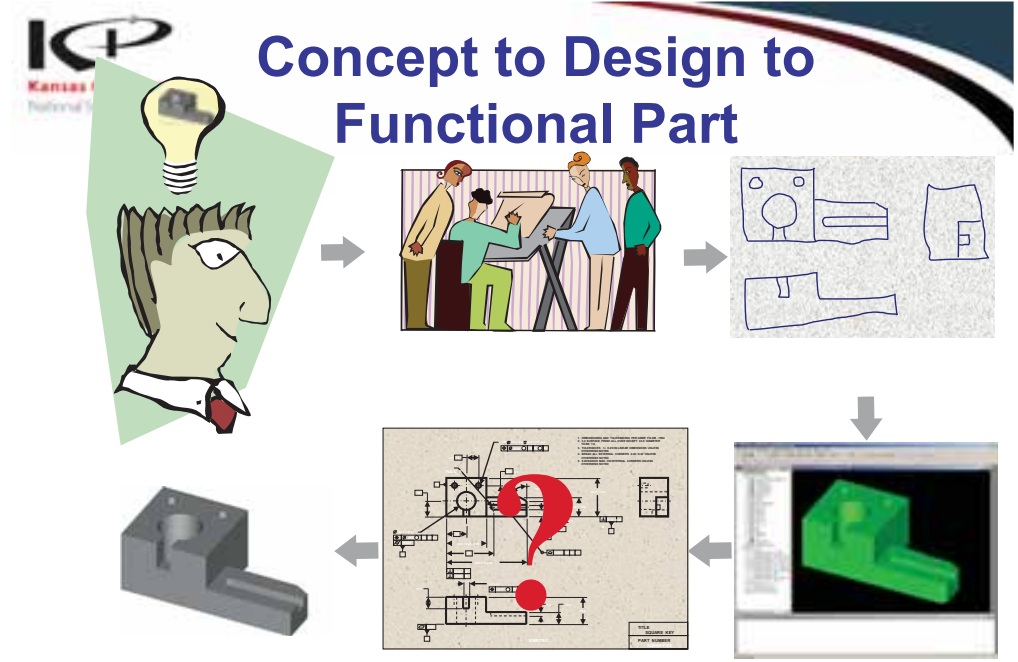

We make products for national security. 


\section{IP} Kanas City Hant Cost of a Design Error

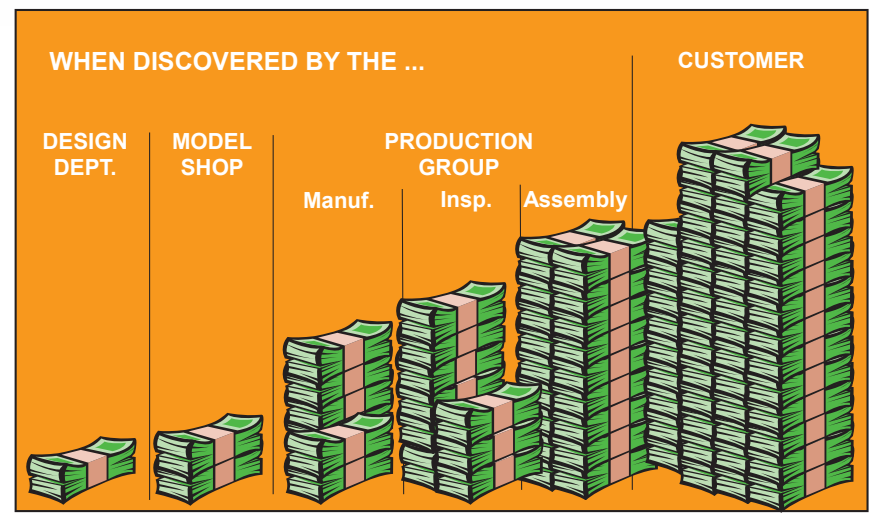

We make products for national security
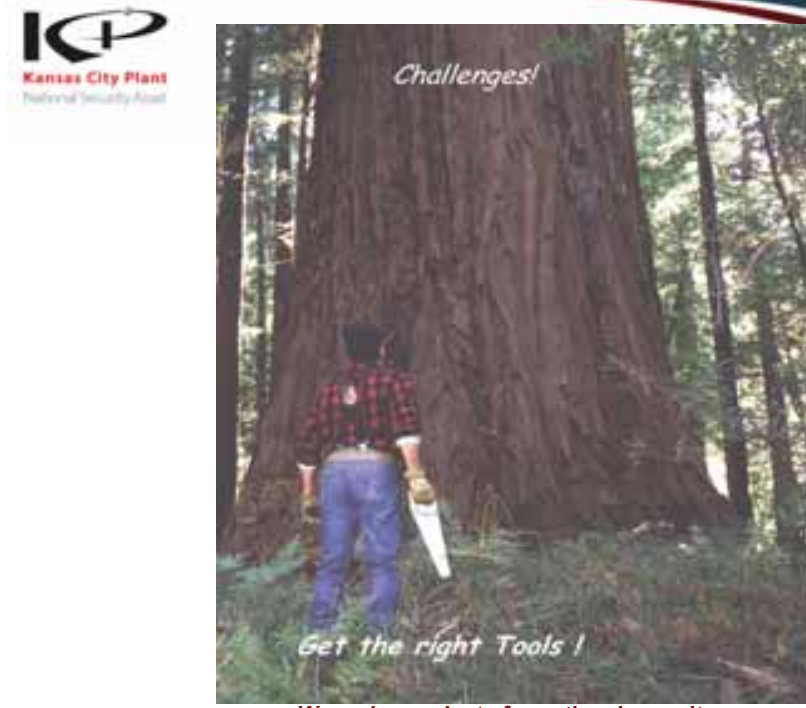

We make products for national security.

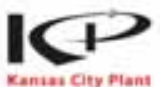

\section{Tolerance Checking}

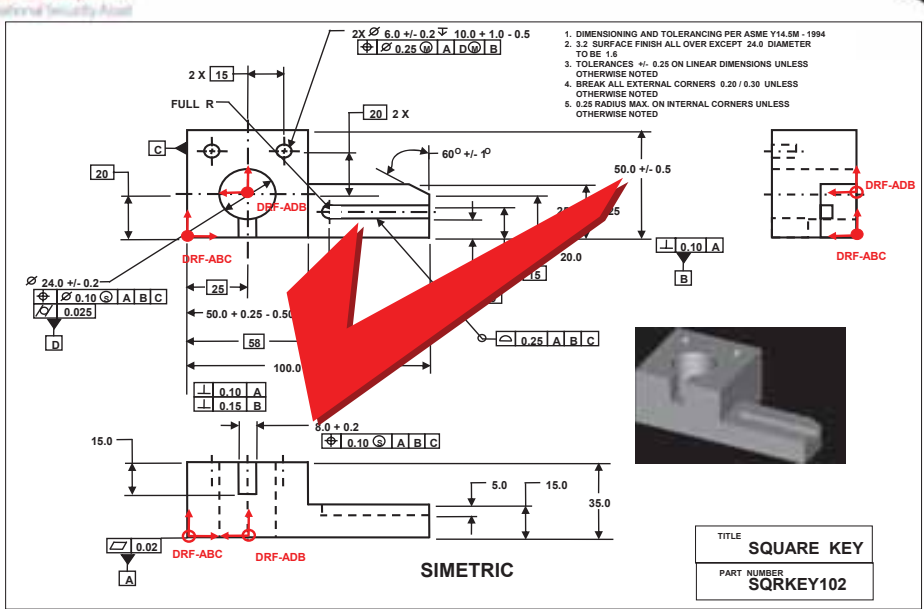

We make products for national security.

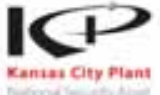

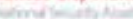
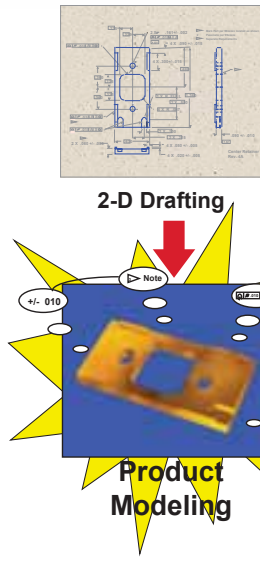
Modeling
Transformation of Product Definition

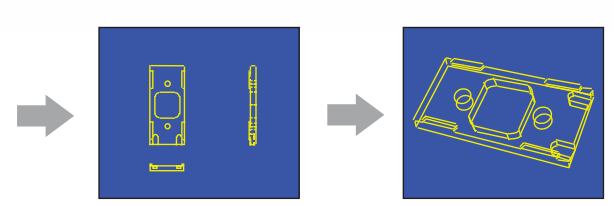

2-D Wireframe
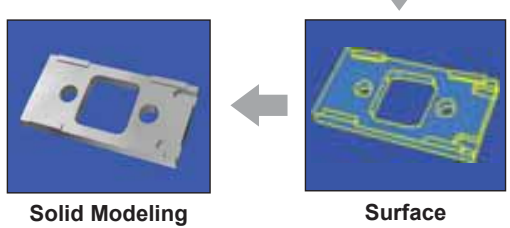

Surface Modeling

We make products for national security.

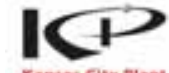
Kanias City Plan
Current Product Definition Challenges

\section{Challenges}

\section{INCOMPLETE AND AMBIGUOUS PRODUCT DEFINITION}

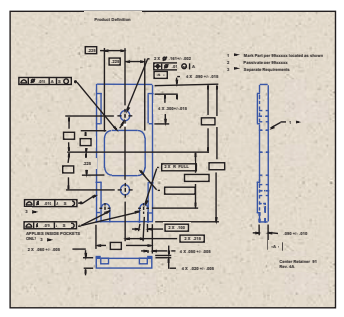

\section{INCOMPLETE PRODUCT DATA EXCHANGE}

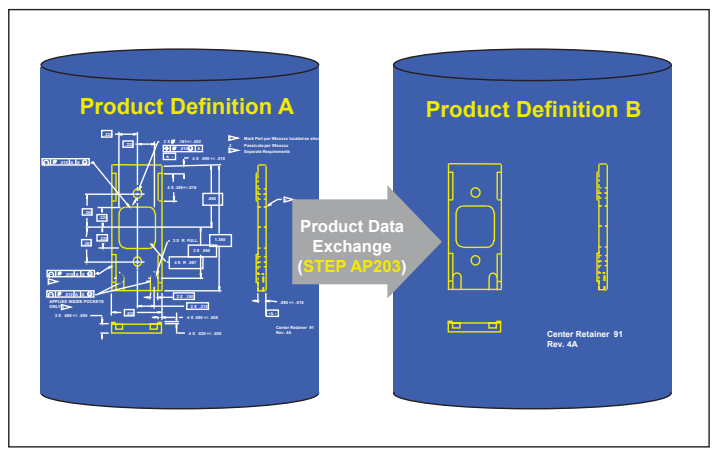

We make products for national security 


\section{Current Product Definition}

\section{Challenges}

Augment Product Tolerance Information for Downstream Applications
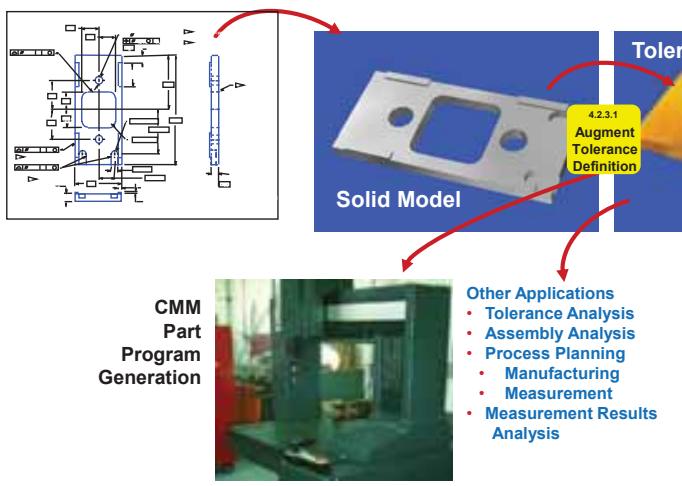

We make products for national security.
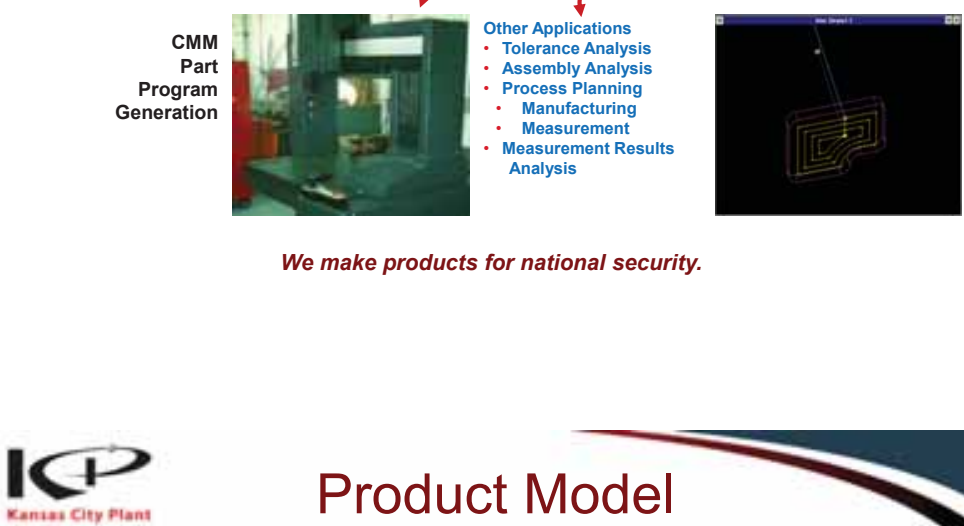

Product Model Tolerances

"It is the representation, not the presentation."

\section{"One can create the presentation}

(e.g., ASME Y14.41)

from a validated representation."

We make products for national security.

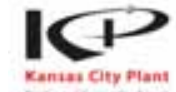

\section{Model-Based Tolerance Requirements}

- Augment a Solid Shape w/ Product Tolerances

- Implement the Notion of Tolerance Features (collection of one or more topological face entities)

- Fully Semantically Represent Tolerances

- Dimensional / Coordinate Tolerances (e.g., Size, Distances, Angles)

- Geometric Tolerances (e.g., Position, Profiles, Flatness, Perpendicularity)

- Surface Textures

- Specifications (e.g., Thread Specs., Welding)

- General Property Attributes (e.g., Notes, Markings, Cosmetics)

- Criticality Designation

- Designate Functionally Important Tolerance Features as Functional Datum Features

- Build Datum Reference Frames from Datum Features

- Assign DRFs to Appropriate Tolerances

\section{So What's the Problem?}

Current electronic product definition systems represent and/ or exchange only a segment of the required product's design completely and unambiguously.

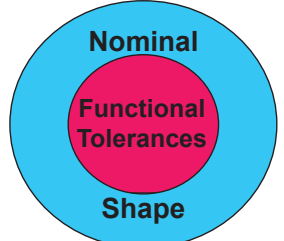

NEED: Fully Semantic, Complete, Unambiguous \& Correct Tolerance Definition, NOT just Annotations!

We make products for national security.

ISO 2768-1

"The Designer's Challenge"

"Tolerancing ... should be complete to ensure that all aspects of a feature are controlled. Nothing shall be implied or left to judgement in the workshop or in the inspection department"

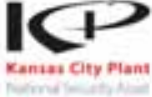

\section{Model-Based Tolerance Requirements}

- Purposely Associate Tolerances to Appropriate Tolerance Feature(s)

- Recognize Tolerance Features (Auto, Interactive)

- Infer Correct Tolerances Automatically

- Per ANSI Y14.5

- Per Company Standards

- Check, Validate, \& Score Piece-Part's Functional Tolerance Definition

- Publish Application Programmers Interface Suite

- Extend Tolerance Analysis

- Integrate with Existing Applications

- Support Downstream Applications (e.g., Measurement)

- Exchange Tolerance Definition to other Product

Definitions we make products for national security. 
Mechanical Model-Based Progression

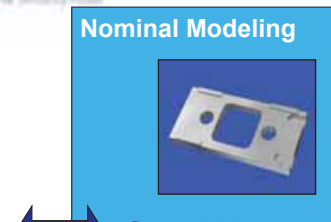

AP203 Solid Modeling

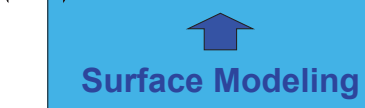

IGES 3D Wireframe

$\longleftarrow$

2D Wireframe

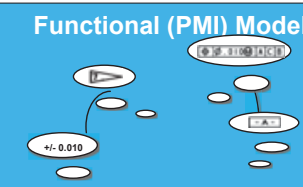

Fully Semantic produces 3D annotation

Partial Semantic

w/Annotation

3D Annotation AP203e2

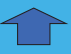

2D Annotation

FBTol progresses Annotation like Solid Modeling progressed Wireframes
FBTO1

Feature-Based Tolerancing ${ }^{\text {TM }}$

a Component Technology for

Fully Semantic Product Modeling.
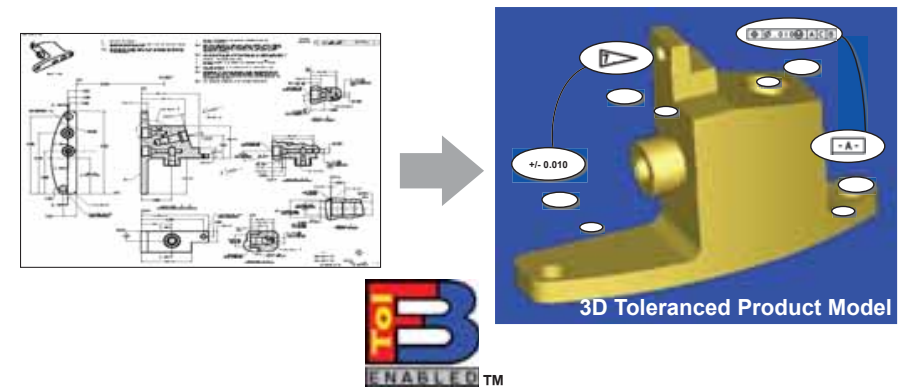

Augmenting Solid Model Shapes With Complete and Unambiguous Part Tolerances and Other Non-shape Attributes (i.e., Virtual Drawing)

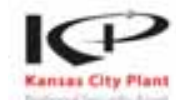

\section{Multiple Perspective of} Shape Features
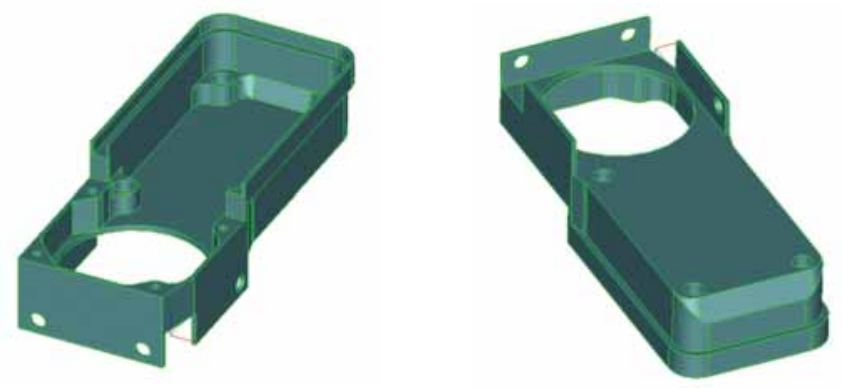

We make products for national security.

\section{A Tolerance Feature}

\section{Taxonomy from FBTol}

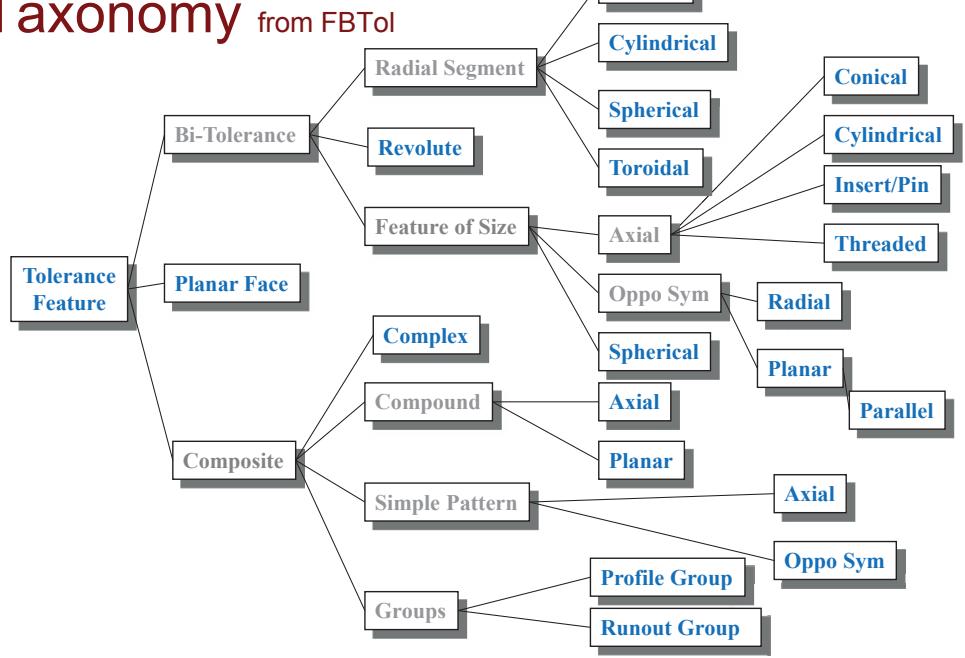

Multiple Perspective of Shape Features

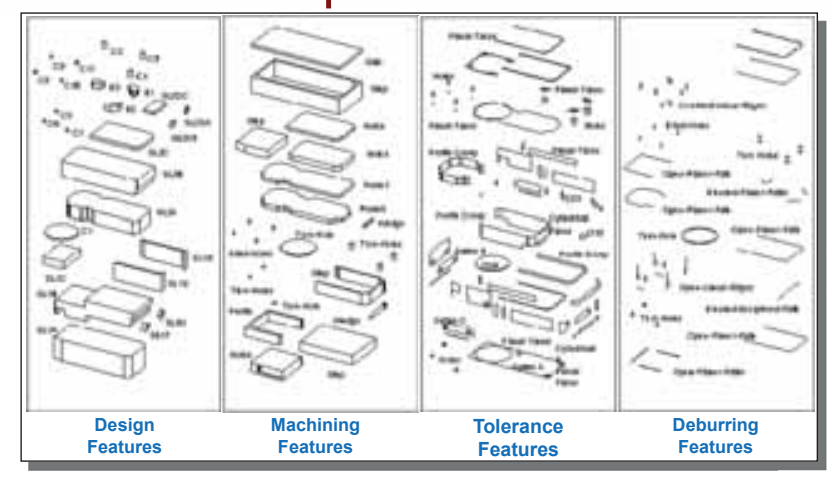

倠

We make products for national security

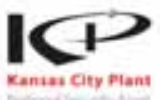

Datum Reference Frame

\section{A datum reference frame is defined by three mutual perpendicular datum planes.}

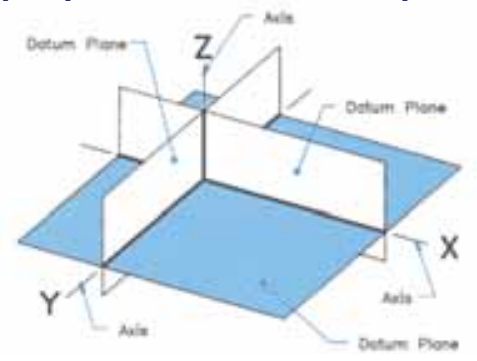

We make products for national security 


\section{Datum Reference Frames from FBTol}

\section{$\phi|\phi 0.14 \otimes|$ A|B $\mid C$}

- Presented within a Geometric Tolerance Feature Control Frame

- Defined by One, Two, or Three Datum Features

- Defines Explicit Mathematical Coordinate System

- Constructed from Left to Right Order of Precedence

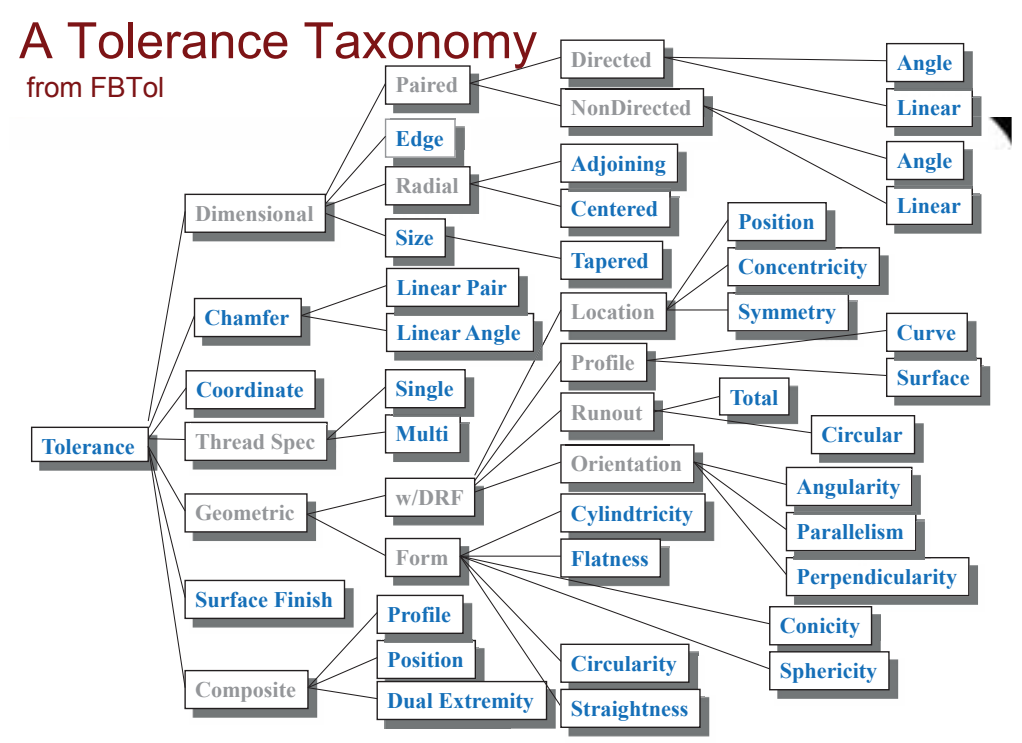

We make products for national security.

\section{Datum Reference Frame} from FBTol

$\phi|\phi 0.14 \otimes|$ A $|B| C \mid$

- Classified per DRF's Datum Feature(s)

- Class (e.g., planar, axial, full)

- Precedence within DRF

- Geometric Relationship with other Datum Features

- Simple and Compound Datum Features

- Extends ASME Y14.5.1M-1994 - DRFs

- Accommodates Compound Datum Features (e.g., S-T)

- Introduces Part Master DRF Concept

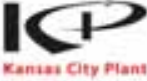

\section{General Property Attribute}

- Notes

- Specifications

- Cosmetic

- Markings

- . . .

- Assign to any entity.

We make products for national security.
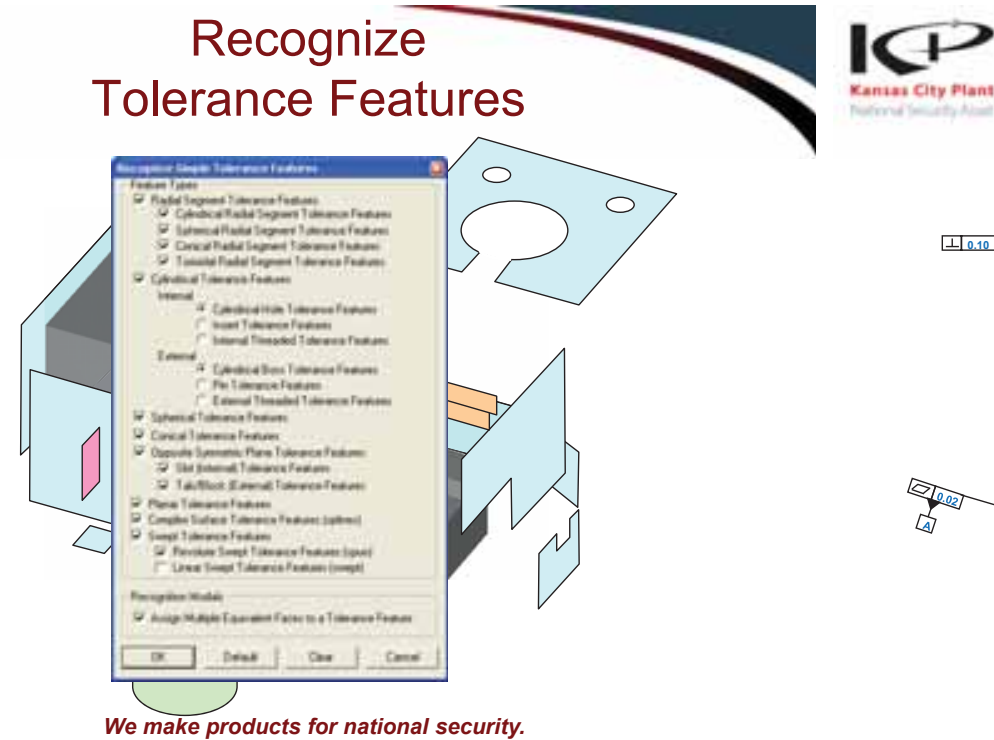

Infer Correct Product Tolerances

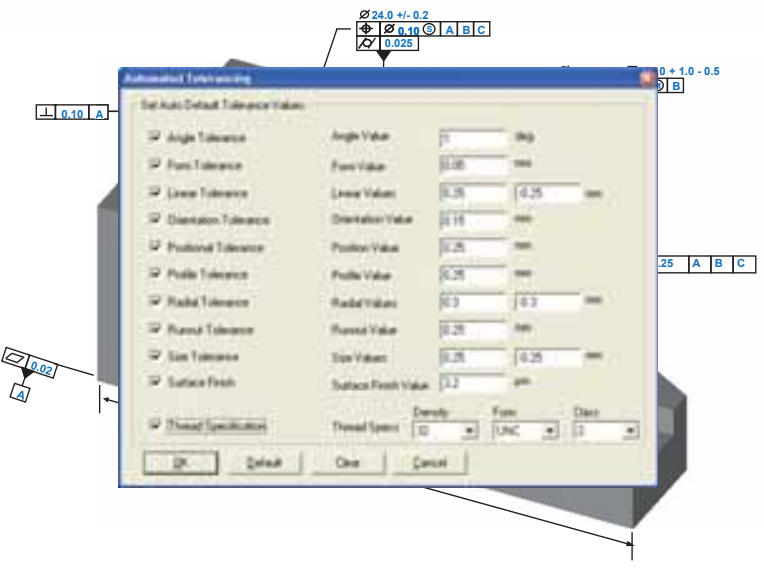

We make products for national security. 


\section{Check / Score Tolerance Definition}

Document Spelling \& Grammar
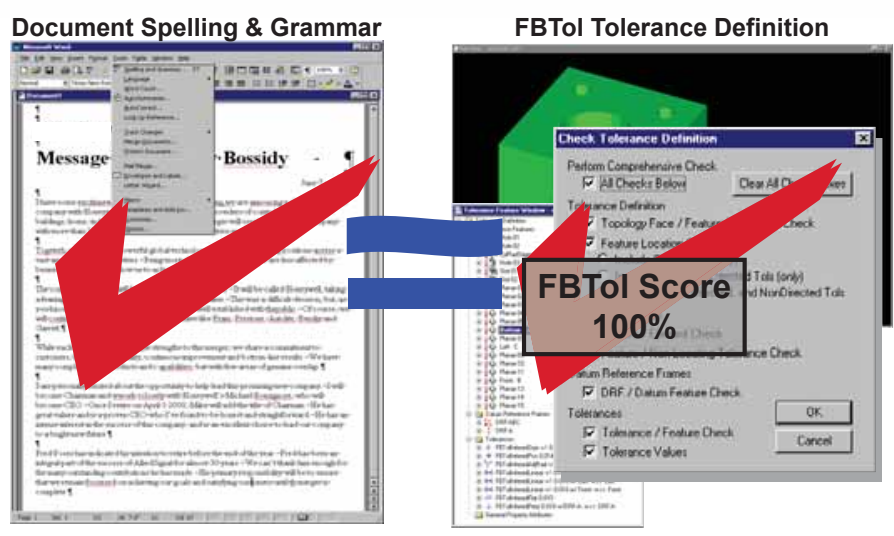

We make products for national security.

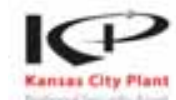

\section{Tolerance Definition Issues} AMBER2
We make products for national security.
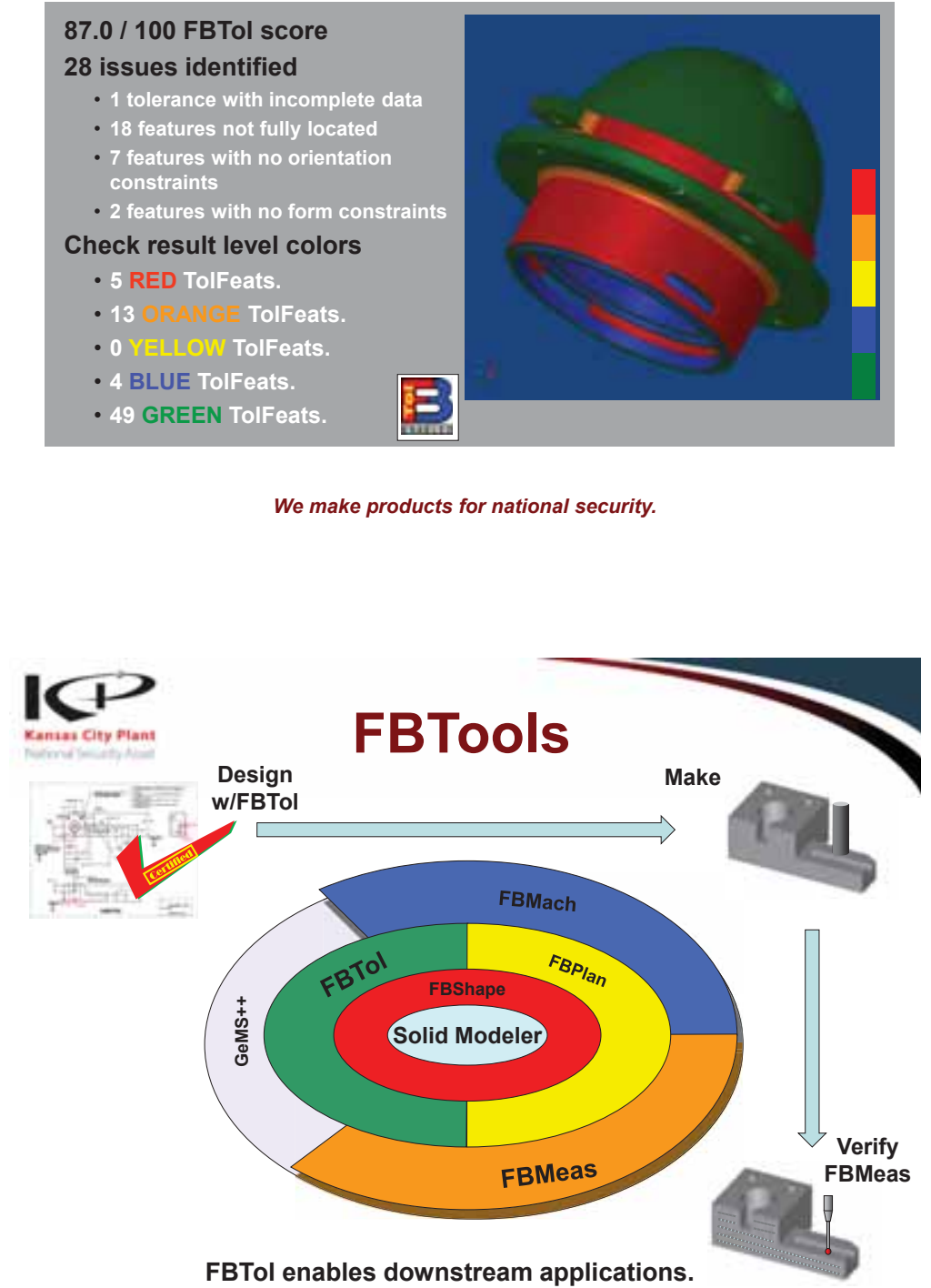

We make products for national security.

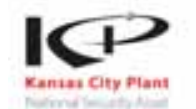

FBTol Check Score: 86.9 Lifting Plate

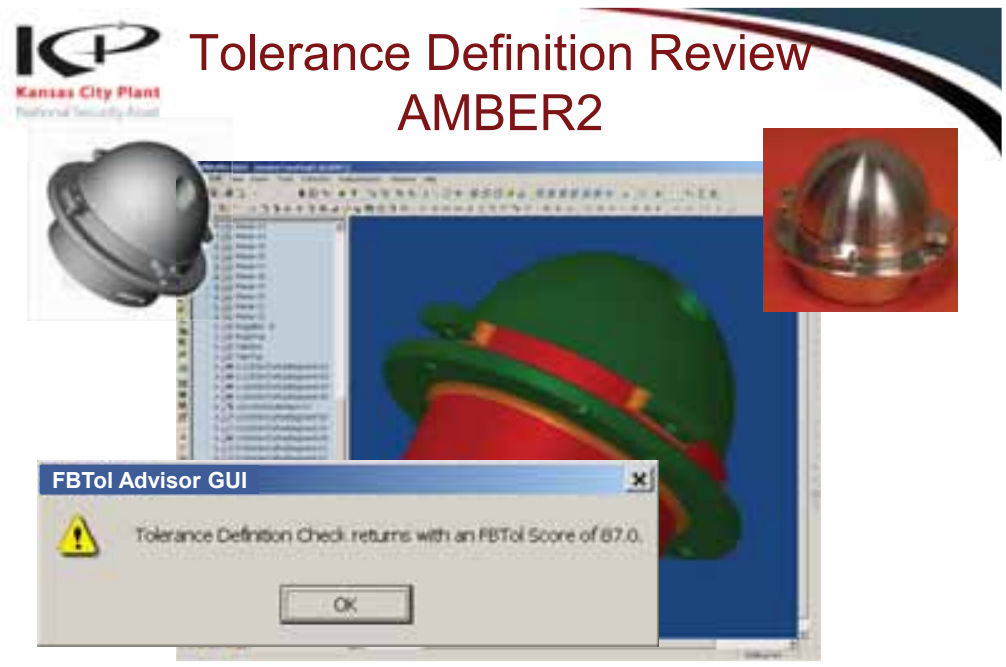

We make products for national security.

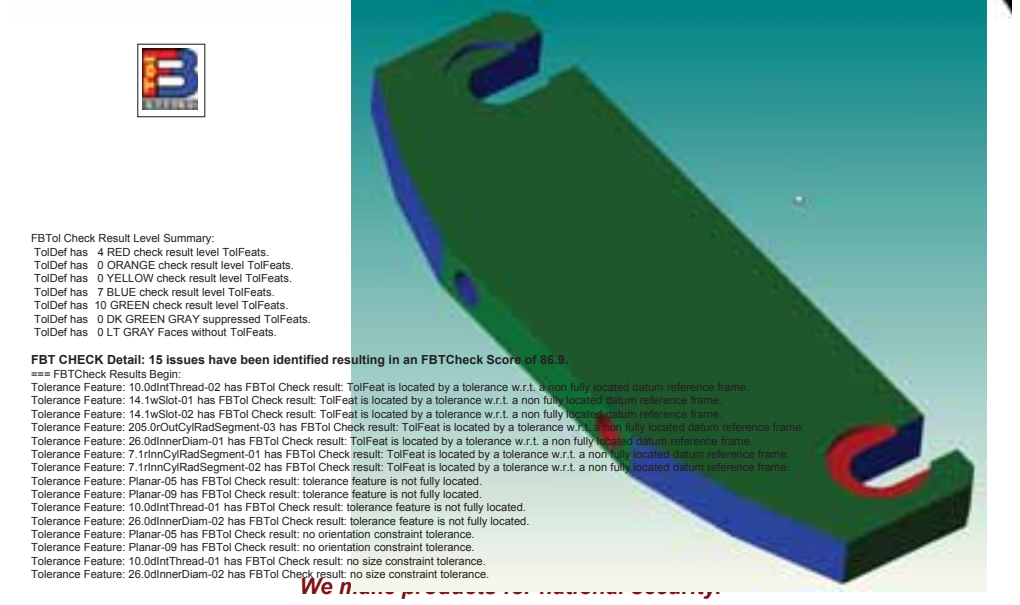

1

Application Programmers Interface

\footnotetext{
- Direct Interfaces

- API Interfaces

// api_fbt_new_tol_def

// api_fbt_create_tol_feat

/I api_fbt_attach_face_to_tol_feat

// api_fbt_get_tolerances_of_tol_feat

/l api_fbt_check_tol_ent

// api_fbt_get_gen_props_of_tol_ent

// api fbt create tolerance

// api_fbt_attach_tolerance_to_tol_feat

// api_fbt_detach_tolerance_from_tol_feat

// api_fbt_get_tol_feats_of_tolerance

// api_fbt_show_tolerance

/l api fbt_get_tol_value

// api_fbt_get_or_construct_datum

// api fbt construct drf

// api_fbt_create_gen_prop_attrib
} 


\section{FBTol at the KCP}

FBTol $^{\mathrm{TM}}$ Technology Deployed as:

$\mathrm{FBTO}^{\mathrm{TM}}$ Advisor standalone, with ACIS \& Parasolid solid modelers

Module inside of FBMeas ${ }^{\mathrm{TM}}$ Advisor

Reviewed over 175 Production Model / Drawings

Average FBTol score 81.9/100

Average 19.0 issues per analysis

Example: Launch Accelerometer Assembl

FBTol Analyzed 23 Parts in this Assembly

21 parts contained a total of 289 issues

All 52 suggestions where accepted

Modeling Problems Uncovered

Customers more Receptive of Design Input

Considered Best Practice for new Product Programs

We make products for national security.

\section{FBTol Benefits}

- Product Modeling

- Defines the next generation of product definition

- Tolerance Definition

- Creates and represents fully semantic 3D functional tolerances

- Feature Recognition

- Recognizes tolerance features automatically

- Tolerance Inference

- Infers correct tolerances automatically

- Product Design Validation

- Checks and grades piece part tolerance representations

- Semantics for Display of Annotations

- Provides basis for graphical annotations

- Model-Base Applications

- Provides explicit tolerance data for downstream applications

- Tolerance Data Exchange

- Generates and / or validates complete and unambiguous exchange

\section{FBTol - Tactics \& Strategies}

Max - Min Material Part

Create maximum and least material part from FBTol tolerances

Automated Drawing

Generate drawings from validated FBTol tolerance definition

\section{CAD System Augmentation}

Enable CAD systems / applications with smart 3D tolerances

Tolerance Data Exchange

Exchange of tolerance data from system to system (AP203e2, AP242)

\section{Feature-Based Measurement Planning}

Use FBTol for model-based measurement planning and auto

generation of CMM measurement part programs

We make products for national security.

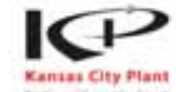

\section{Coordinate Measurement} Cost Budget

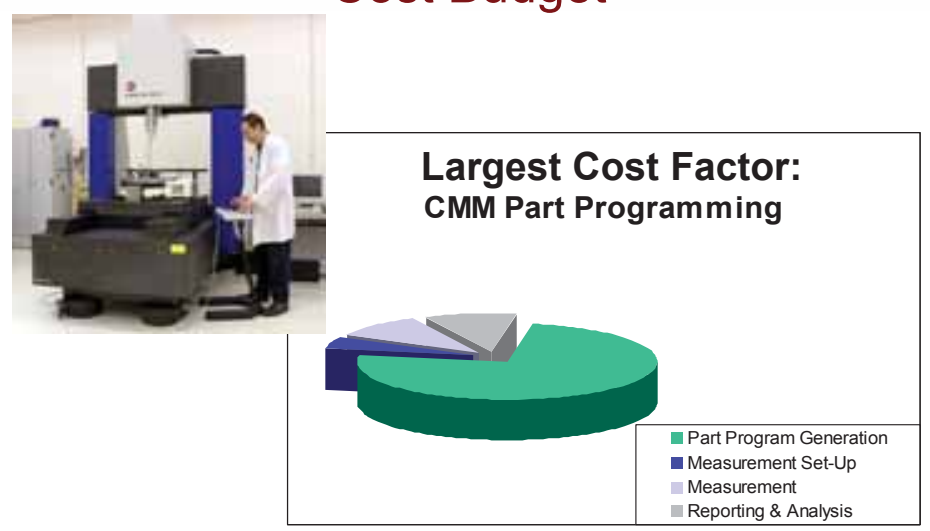

We make products for national security.

Dimensional Metrology Enterprise

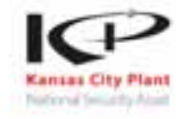

Product

Definition

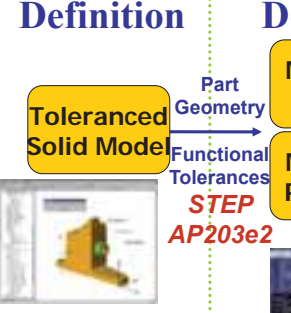

Process

Definition

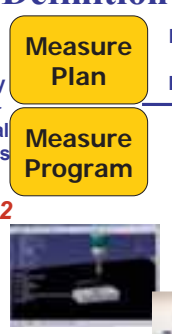

We make products for national security.

Measure
Plans \&
Program
Process

Execution

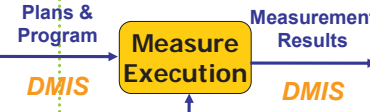

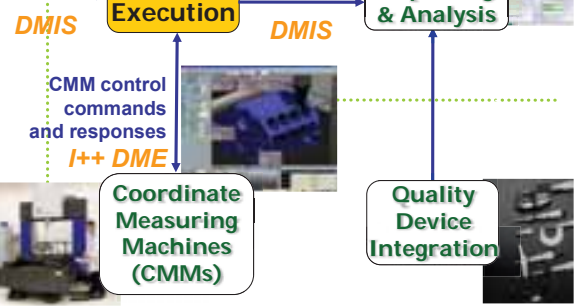

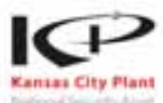

Kanas City plant

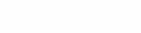

\section{Feature-Based Measuring ${ }^{\text {TM }}$}

a Component Technology for

Measurement Process Planning \& Part Program Generation

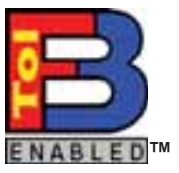

Transforms Product Requirements (Functional Tolerances) into a Measurement Action Plan that Produces a Viable ISO Standards-Based Dimensional Metrology Part Program 
Requirements for Next Generational Measurement Process Planner

\section{Automation:}

- Full Semantic Representation of Tolerances

- Measure Feature Recognition

- Part Coordinate System Recognition

- Measurand Determination

- Measure Point Generation

- DME Resource Selection

- Sensor Accessibility Analysis

- Workpiece Placement

- Sensor Selection \& Orientation

- Measurement Plan Inference

- Measurement Plan Centric

- Inter \& Intra Feature Clearance Moves

- Measurement Part Program Output (ISO DMIS) We make products for national security.
Solid Modeler Kernel (Parasolid, ACIS) Feature-Based Tolerancing (FBTol) Advisor

Feature-Based Measuring (FBMeas) Advisor

- From Tolerances, Auto Recognize Measure Features, Part Coordinate Systems, Measurands

- Distribution PtMeas

- Determine Resources (Sensors, CMMs)

- Generate CMM Measure Plan

- Output ISO DMIS Part Program

We make products for national security.

\section{Demonstration}

From a Solid Model ....

to a Full-Semantic Toleranced Solid Model

to a Validated Tolerance Definition

to a Measurement Process Plan to a CMM Part Program
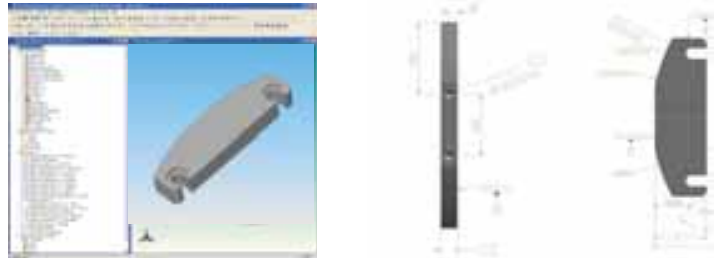

...Model to Plan to Program in 10 Minutes We make products for national security.

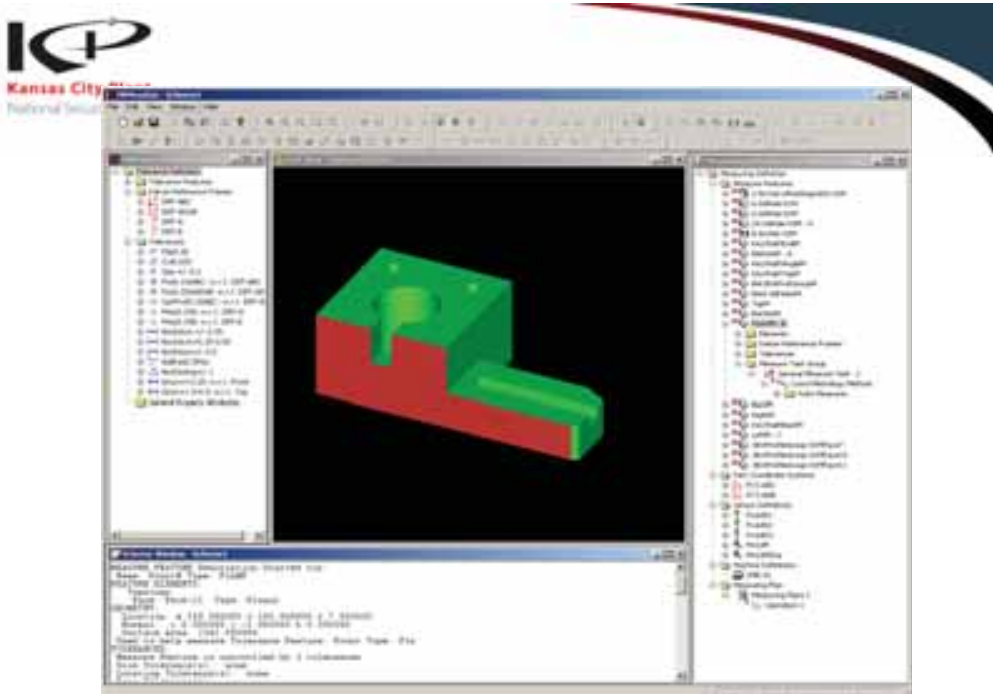

We make products for national security

\section{Fly-By Demonstration}
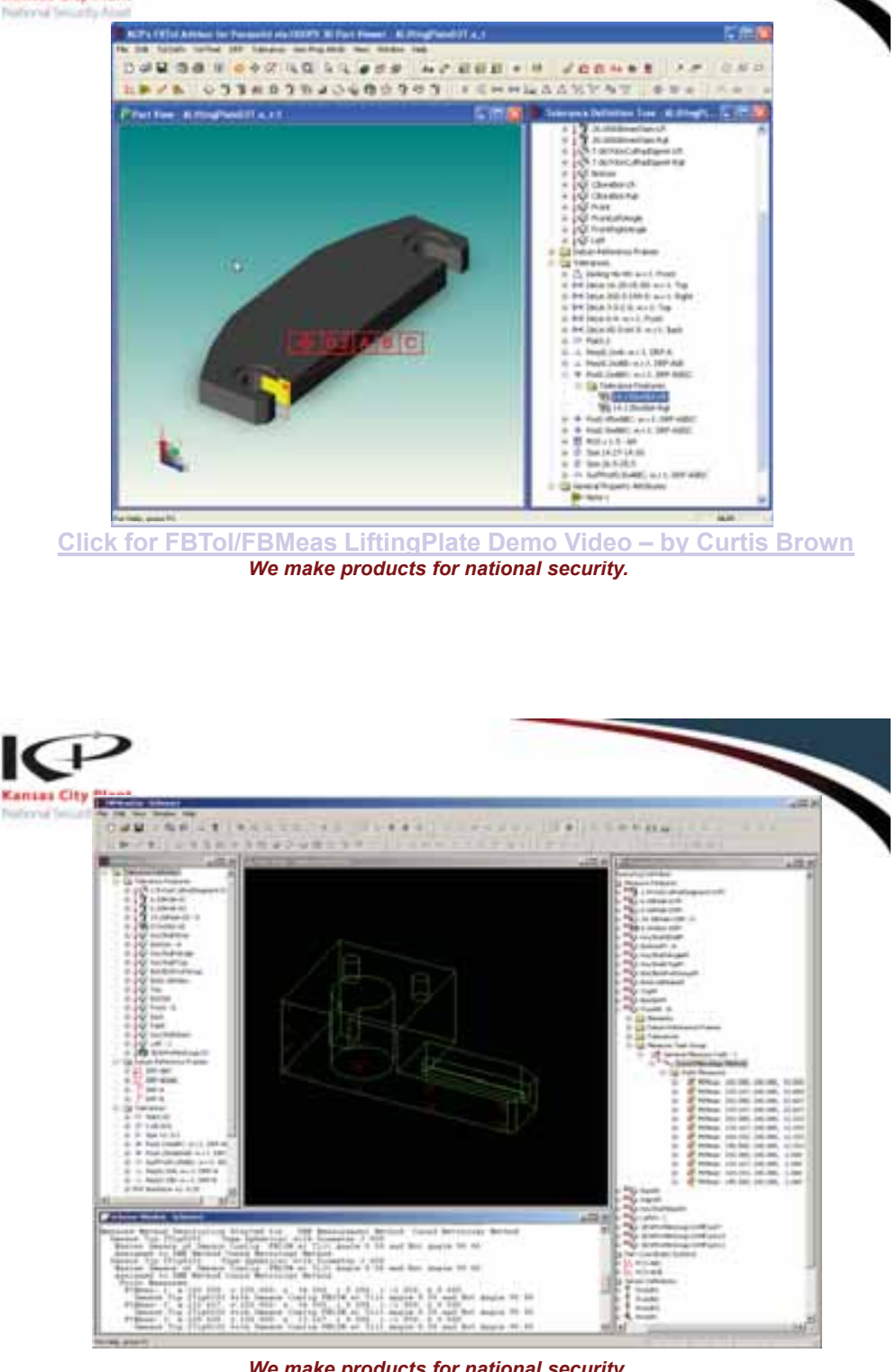


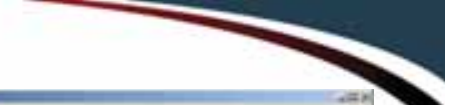

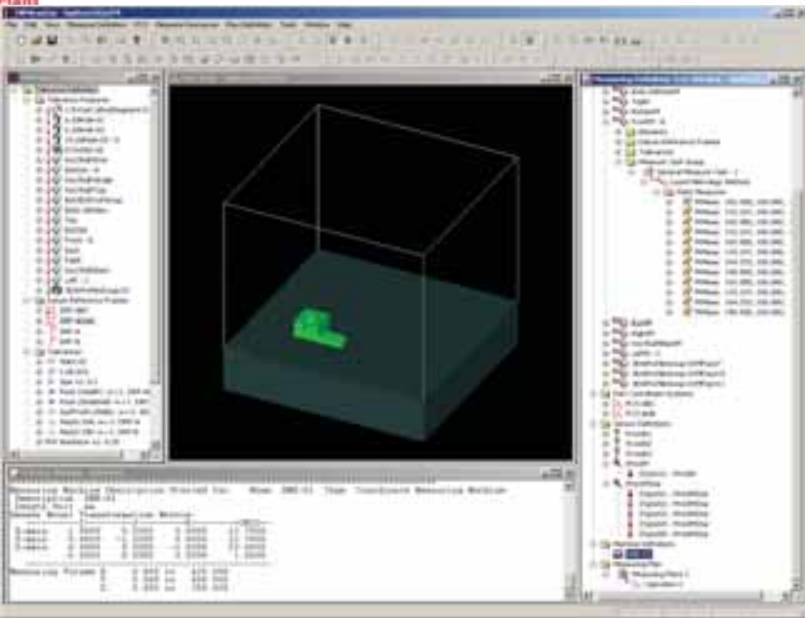

We make products for national security

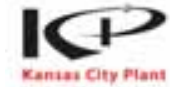

\section{Summary}

- Feature-Based Tolerancing

- Manages the complexity of ASME Y14.5 GD\&T of piece parts.

- Represents and checks part designs per standards.

- Enables next generation (smarter) automation.

- Could be integrated into a leading CAD system with the appropriate partnering.

- Feature-Based Measuring

- Manages the complexity of rapidly generating valid CMM part program to dimensionally certify products.

- Demonstrates a next generation manufacturing application from toleranced enable solid models

- Functional prototype that could be extended/enhanced with partners.

- Partnering

- Collaborate a common agenda

- Progress your agenda

\section{Rolls-Royce}

\section{MBD For Dimensional Quality Within a Heterogeneous Supply Chain}

ARMY/NIST MBE Summit - December 13 th 2011

\author{
Nick Orchard Rolls-Royce plc \\ Ron Snyder Rolls-Royce Corporation
}

\section{Partnering Mechanisms:}

- Work for Others (WFO) Contract services from the $\mathrm{KCP}$ as cost recovery only.

- Cooperative Research \& Development Agreement (CRADA) KCP and partner collaborate in creating new Intellectual Property

- Licensing KCP Intellectual Property for the purpose of maturation and commercialization of KCP technologies.

\section{Way Forward:}

- Progress Shared Agendas - Mandates NNSA (KCP) invented technology be transferred to the benefit of the US economy and/or US industry.

We make products for national security.

\section{Questions?}

Curtis W. Brown, P.E.

Principal Mechanical Engineer

Kansas City Plant

816-997-3548 • cbrown@kcp.doe.com

We make products for national security.

\section{Rolls-Royce today}

We design,
develop,

manufacture and

support power

systems for use

on land, sea and air.
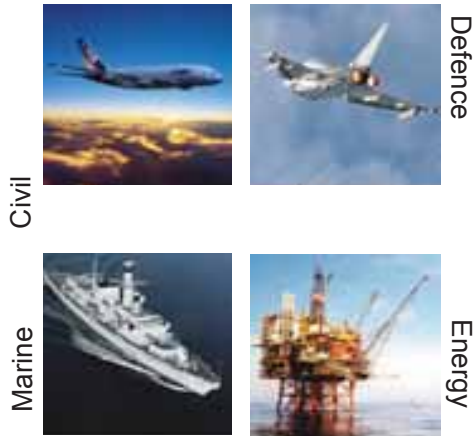


\section{Extending our portfolio}

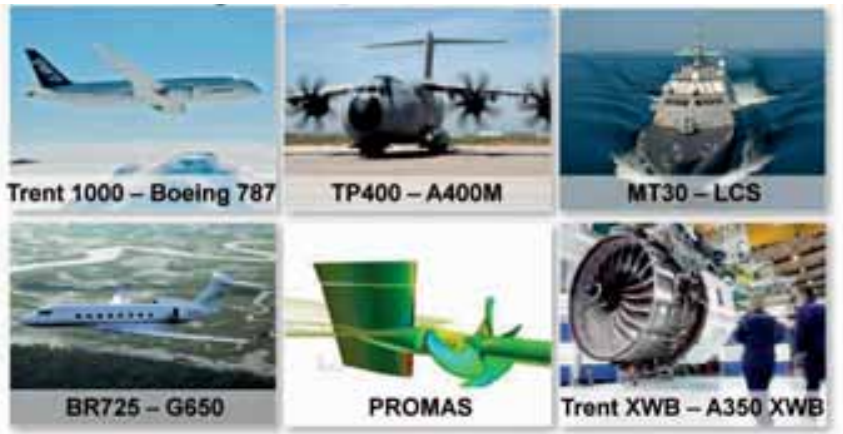

\section{Rolls-Royce}

\section{A truly global company}

9000 engineers spread over 8 countries worldwide

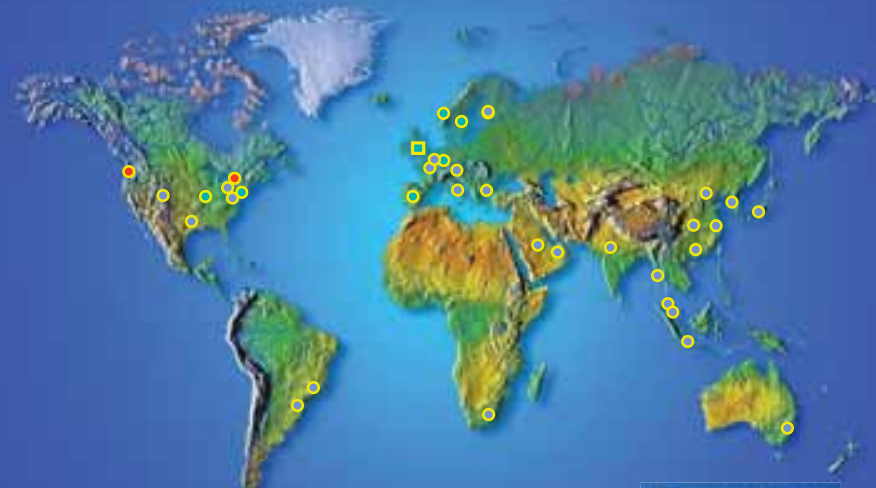

- Engineering center

Rolls-Royce
RRC Engines for Military and Commercial Applications
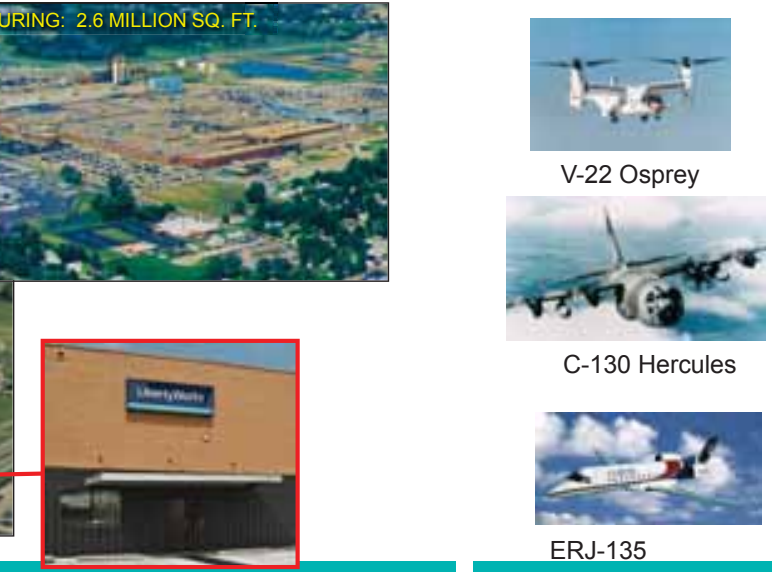

13 Rolls-Royce

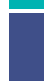

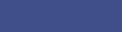

V-22 Osprey

C-130 Hercules

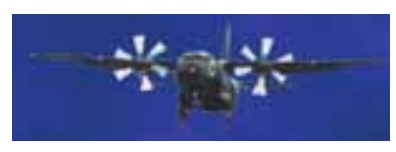

C-27J Spartan

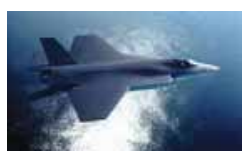

Joint Strike Fighter

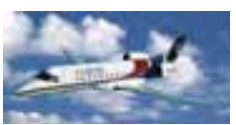

ERJ-135

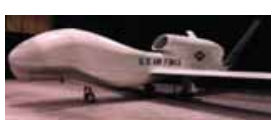

RQ-4A Global Hawk

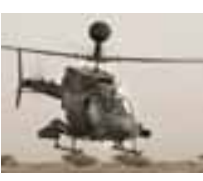

Kiowa

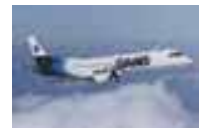

SAAB 2000

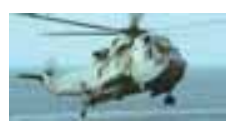

Sea King

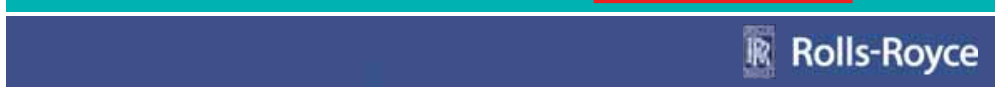

13. Rolls-Royce
Unique STOVL technology for JSF

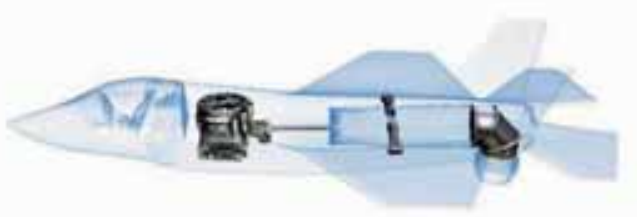

- 50 years STOVL experience

- 20,000 lbs thrust engine

- Development contract $\$ 1.5 b n-$ Good progress

- F-35B variant ( -450 aircraft) is expected to remain in service after 2050

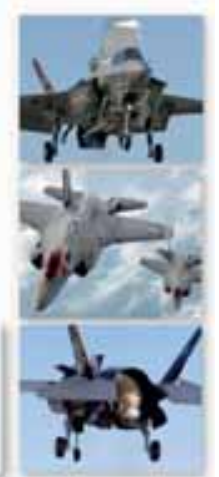

- Pratt \& Whitney - V2500

- GE F136 development

- Honeywell T800 


\section{We don't make cars}

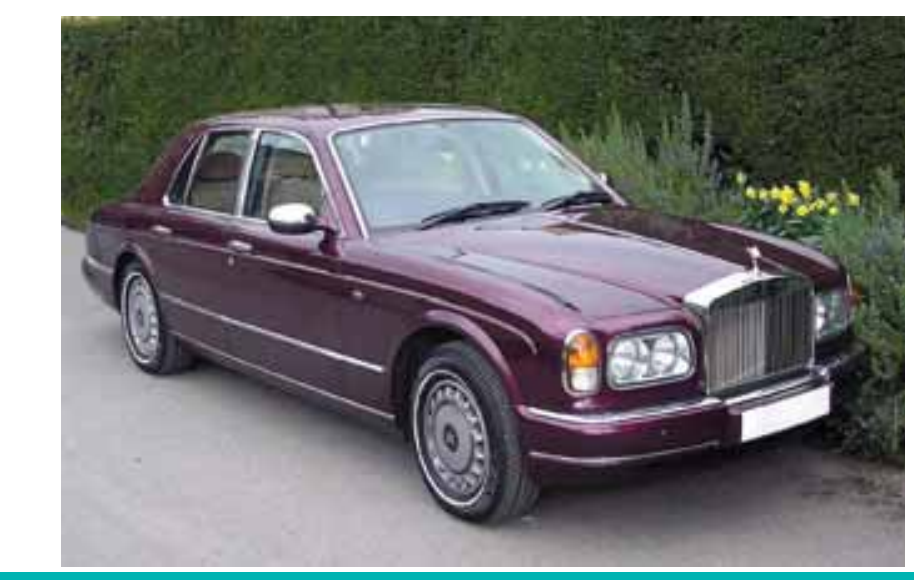

13 Rolls-Royce

\section{A History of CAD/ CAM - Rolls-Royce GTSC}

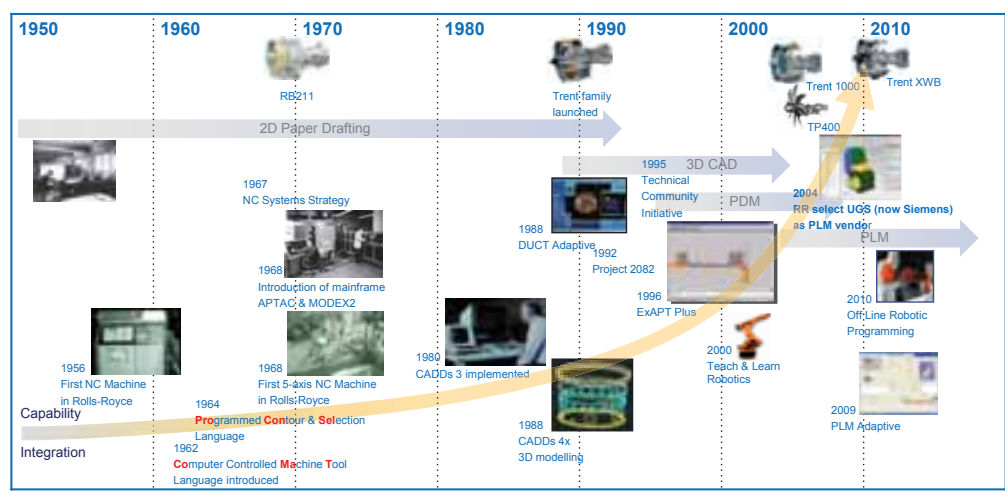

- Migration from "Best in breed" applications to "Fully integrated solutions" - Deployed solutions need to support Product Lifecycles in excess of 25 years

\section{IR Rolls-Royce}

Sustainable world-class performance though cross-functional process and systems integration

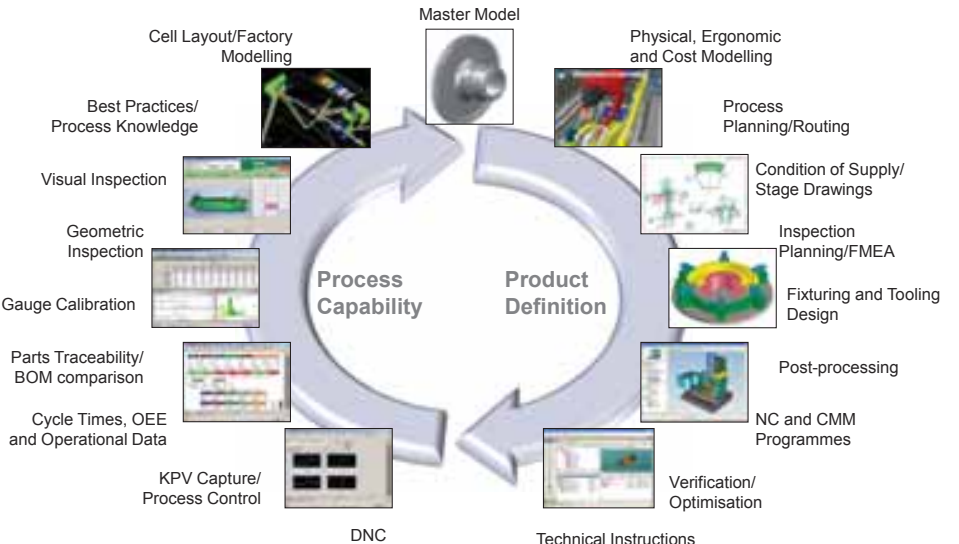

13. Rolls-Royce
How does CAM deliver the vision?

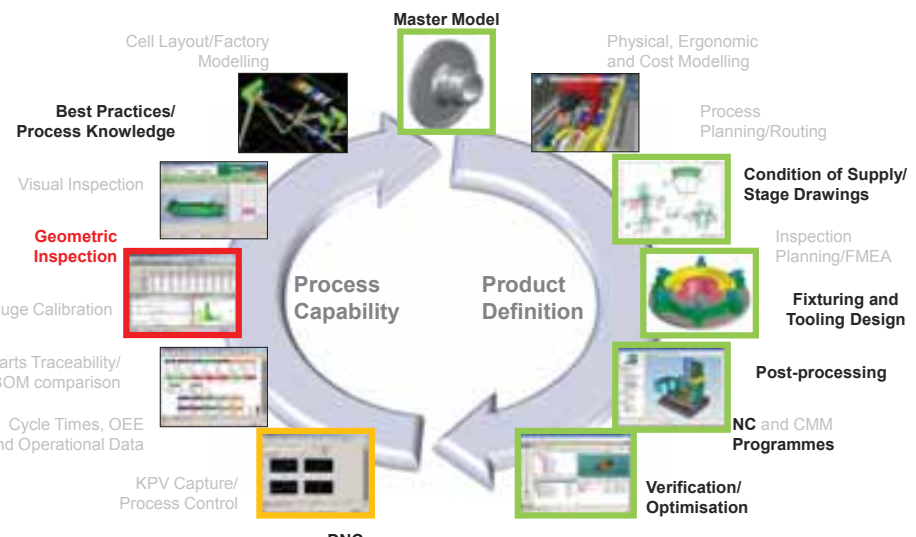

13 Rolls-Royce
"A Day in the life of an ME" Traditional CAM Today (Example)

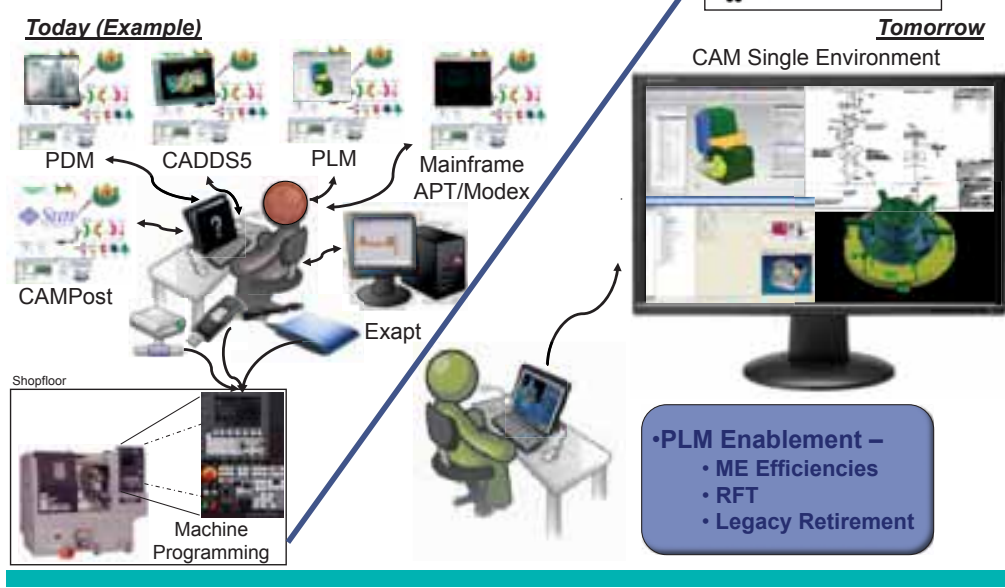

What is CAM Capability Development in PLM? 14

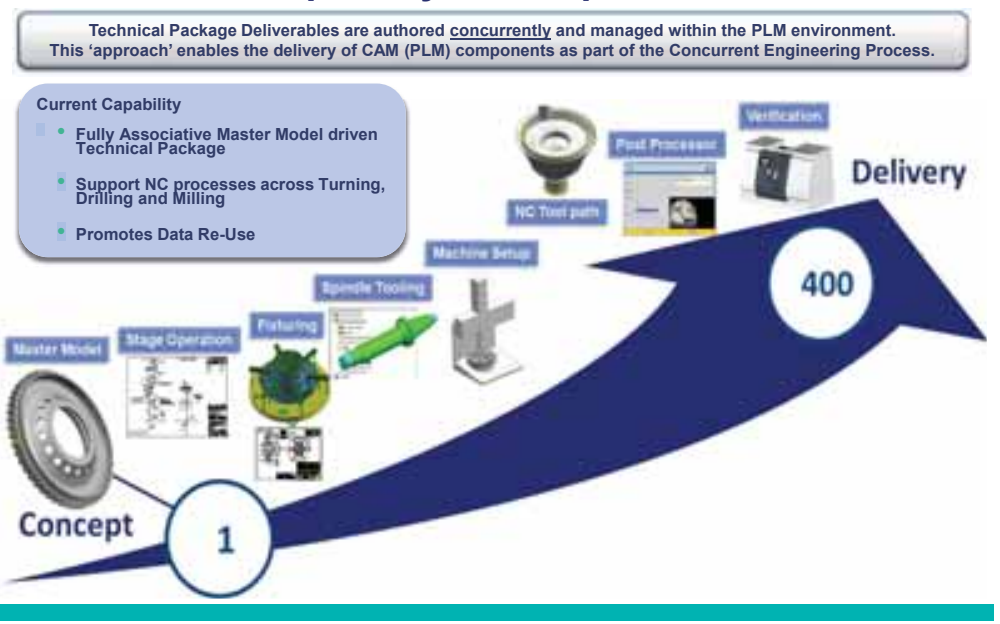


PLM ‘supporting' R-R's Concurrent Engineering Process

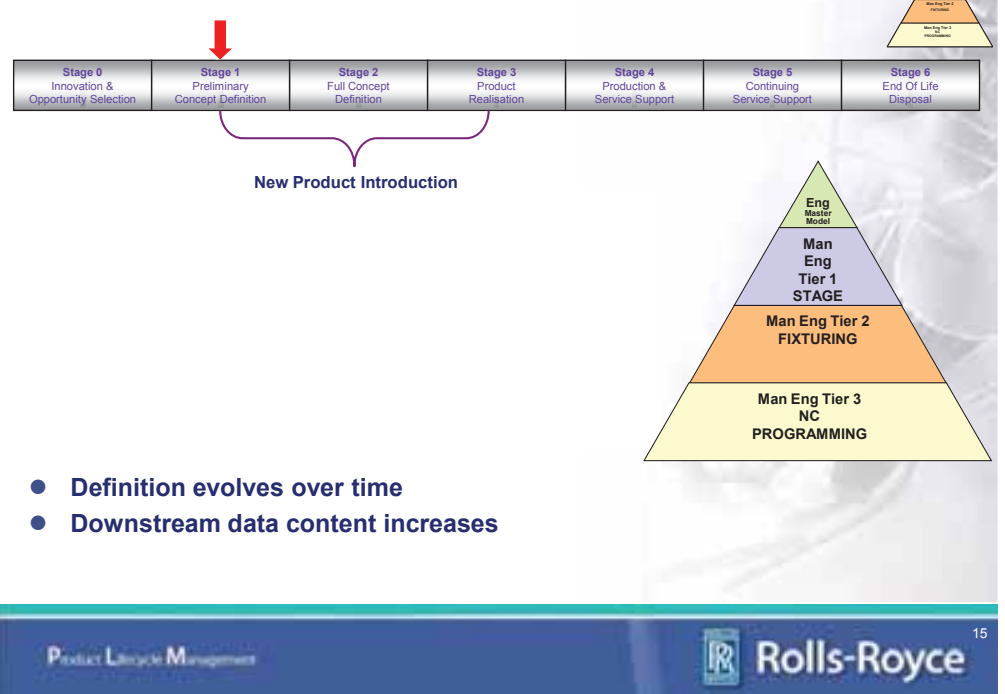

\section{Manufacturing Pull or Engineering Push?}

- Stage Inspection

- Manufacturing Engineering Populate Model

- Machining Knowledge Editor (CAM) utilises PMI to aid feature recognition and recommend cut strategy

- Final Inspection

- Engineering Populate Final Definitive Engineering Master

- Manufacturing Engineering extract for:

- FAIR

- IPC

- CMM Program

- SPC and Process Excellence

\section{Rolls-Royce}

\section{Populated CAD Models}

- Design Perspective
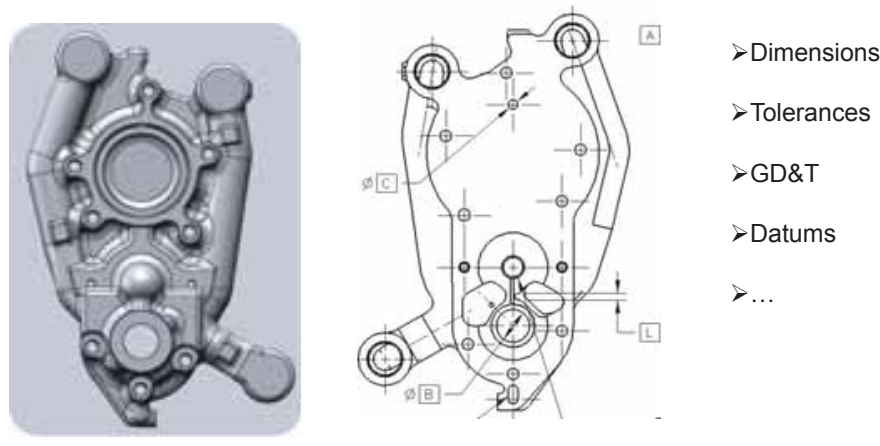

\section{What is PMI?}

- Product and Manufacturing Information is a set of annotation tools used to document products in 3D environments

- It allows definition of more useful information than is possible on a 2D drawing

- For example, each PMI object can have associated geometry, thereby conveying information to downstream applications

- PMI objects include:

- 3D Dimensions

- Datums

- Datum targets

- Feature control frames

- 3D annotations

- Notes

- Symbols

- Geometric tolerancing

- Security markings

- User defined PMI

- PMI Section Views

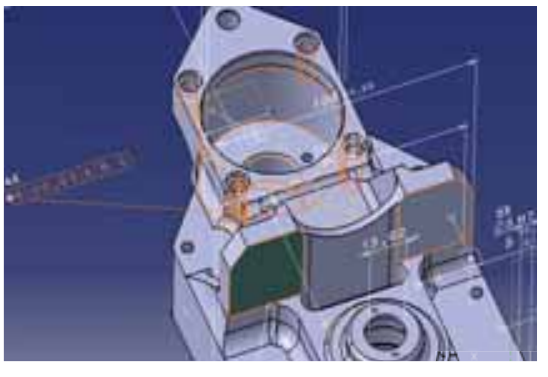

18 Rolls-Royce

\section{CAD Models - Can one size fit all?}

- As built or in-process Manufacturing dimensions don't always match Design Model

- Design models must be built with Stress Analysis and Manufacturing in mind

\footnotetext{
Analysis doesn't like included Blends and Radii in the CAD Model

$>$ CNC programmers and Quality Engineers do!
}

\section{Populated CAD Models}

- Manufacturing Perspective
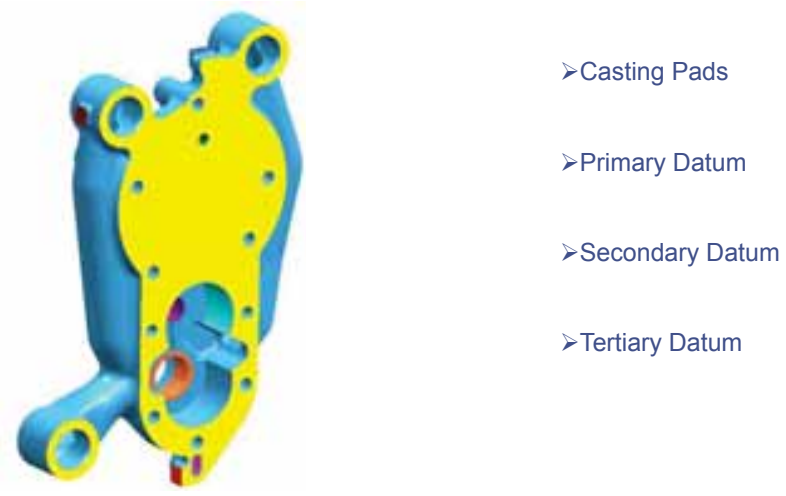


\section{Populated CAD Models}

- 3D Scanning Perspective

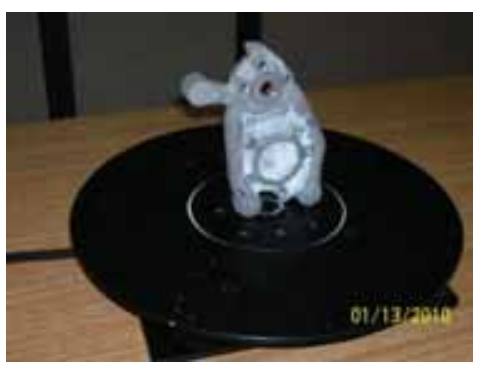

$>$ Optical or Scanning CMM

$>$ Point Cloud Data

$>$ Is it valid?

$>$ Density?

$>$ Standards?

\section{Rolls-Royce}

\section{Populated CAD Models - Points to Consider} Models

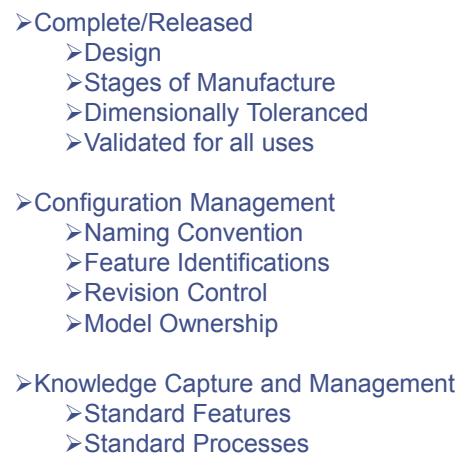

\section{Populated CAD Models - Points to Consider}

Optical Scanning

$>$ How do we make decisions when using point cloud data?

$>$ How do we define the "right" number of points?

$>$ Qualification of the Optical Based Inspection Standard

$>$ Industry Lack of Optical Based Inspection Standard

>VDI/VDE are still a CMM Based Spec.

\section{Rolls-Royce}

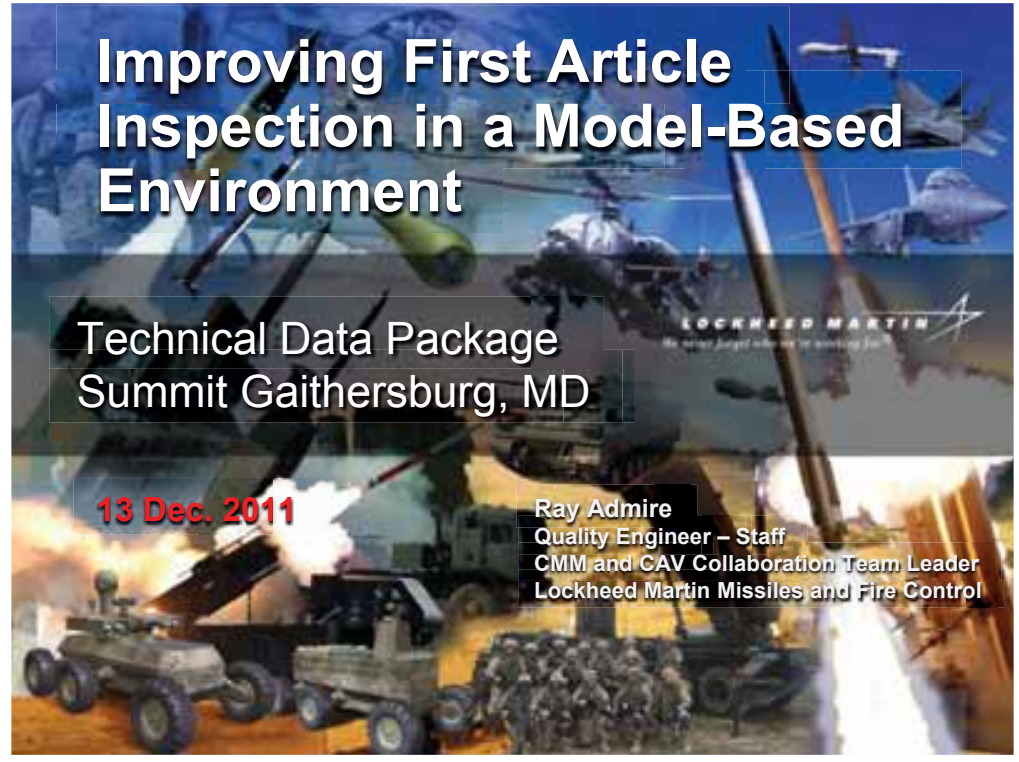

\section{Agenda}

- Mission and Vision

- Challenges in Our Industry \& Supply Chain Risk

- DMSC \& Value of Information Exchange Standards

- CAV

- Improving first article inspection in a model centric environment

- The Importance of FAI

- Using Tools to improve AS9102 Compliance

- QMS Pilot Project

- Business process mitigates against successful FAI for Many Weapons Systems

\section{Rolls-Royce}

\section{Mission and Vision}

Oug VIsjos

Powered by Innovation, Guided by Integrity, We Help Our Customers Achieve Their Most Challenging Goals

C) V/J

- Do What's Right

- Respect Others

- Perform With Excellence

Our Mjissios

To Provide Superior Weapon Systems and Advanced Technologies that Protect Our Warfighters

Fundarsestal Busjs Our Business is Not the Objective ... It is the Result 


\section{Peoples Lives are At Stake....}
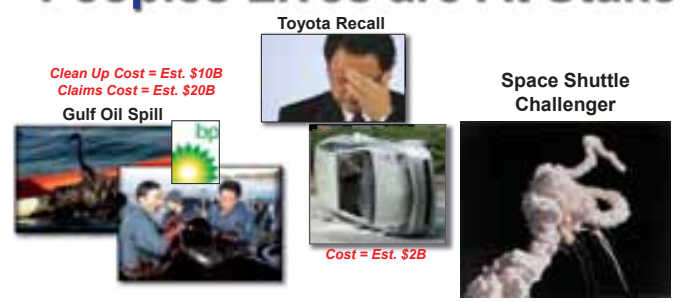

IMPACTS

- Loss of Reputation

- Financial Loss

- Product Performance

- Product Recall

- Loss of Business
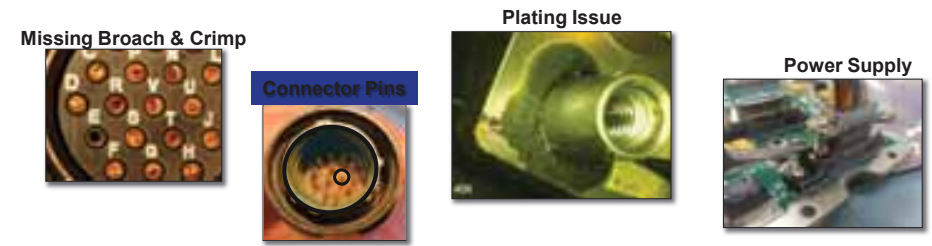

A Great First Article Inspection Can Catch Mistakes

\section{Supply Chain Quality Risks}

Risks

- Domestic and International Economy

- $2^{\text {nd }}$ and $3^{\text {rd }}$ Tier Supplier Performance

- Government Policy Changes

- International Trade Regulations

- Increased GIDEP Notifications

Preventing Difficult to Detect Risks

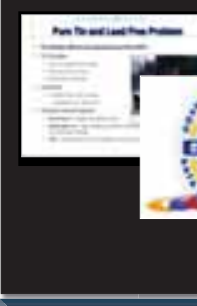

99.99\% Success Rate Is Unacceptable
Quality Pressures

- Supply Chain, $2^{\text {nd }} \& 3^{\text {rd }}$ Tier

- Experienced Talent

- Supplier Value Stream

- Fixed Price

- Non Traditional Quality is Less Tangible

- Technical Challenges

Various Quality Strategies

- Development - COTS/MOTS

- Production - Service

- Life Cycle - Software

- Subcontracts - Hardware

- Distributors • Labs

\section{CAV \& FAI Critical to Success}

\section{CAV}

-Characteristic Accountability \& Verification (CAV) a process used to ensure that all Critical and Major product technical data package and manufacturing product technical data package and manufacturing
and quality plans, and to ensure that manufacturing and quality plans, and to ensure that manufactu
planning includes controls adequate to ensure continued conformance of these characteristics.

-All Components shall be subjected to First Article Inspection in accordance with AS9102. Those with Critical and/or Major Characteristics shall be subjected to recurring First Article Inspections. Critical or Major characteristic inspection shall be performed at the lowest possible component leve that allows adequate inspection of the Critical or

Major characteristic.

What Are The Requirements characteristics are defined and accounted for in the
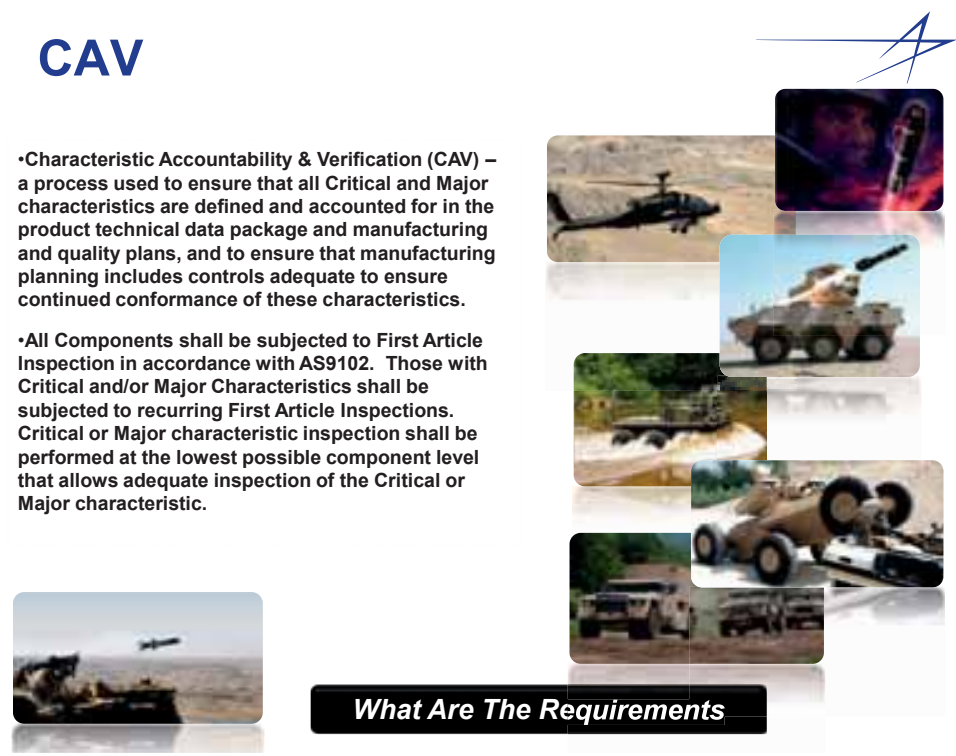

Top Product Definition Issues

-CAD data (including GD\&T) does not flow seamlessly to downstream processes when components are not from same vendor.

-GD\&T data is not associated with individual features of the part (the CAD model) which makes it impossible to automate inspection process programming. If GD\&T information is expressed as annotations in CAD files or as notes on drawings, it is not available to automated computer processes that can use it.

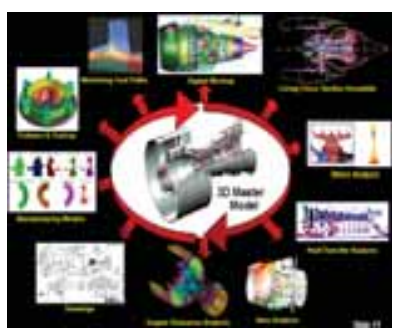

-It is difficult if not impossible to know if a vendor truly supports a standard as advertised. When a vendor claims that its product conforms to a standard, there is often no means of certifying that the product actually does conform to the standard as claimed. There continues to be divergence in the product actually does conform to the standard as claimed. There continues to be divergence in the major companies have adopted internal variations in the way that they interpret and apply the standards. It is believed that this practice will result interoperability problems in the near future. The standards effort must be international, involving multiple government standards organizations.

-Crosscutting Issue: There are currently no "consensus" approaches to the interconnection of components/systems. The "big picture" needs to be defined before unified efforts can be developed to solve this important problem. There is no shared vision between vendors and users for interoperability

\section{Top Inspection Process Definition Issues}

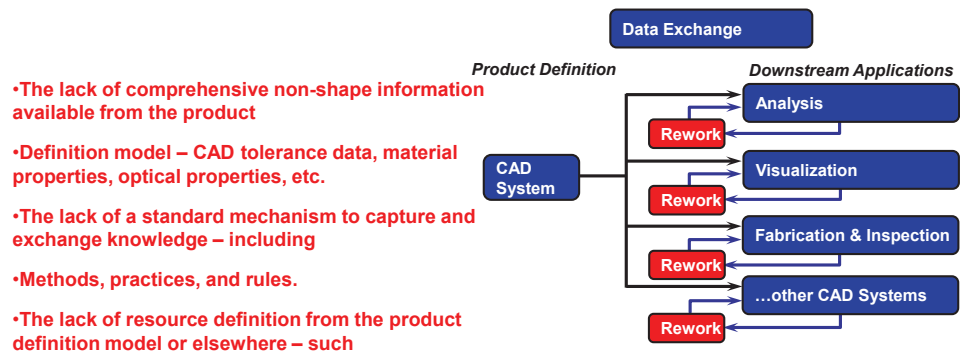

-As inspection equipment capability, capacity, available configuration, performance,

-Measurement uncertainty, etc.

-Does DMIS support all measuring devices?

-The macro-to-multiple-micro planning interface is not well defined.

\section{Benefits of Model Centric}

- Shorten Design Cycle \& Improve Quality by Eliminating Parallel Data Paths

- Avoid conflicts between model and drawing

- Minimize risks associated with data re-creation

- Minimize costs by facilitating data reuse

- No need to recreate model dimensions to capture design intent

- Enable design activities to better collaborate through sharing models

- Enable the future management of key characteristics (per AS9100) and their relationships to product definition data

- Enhance Downstream Data Sharing via Configuration Managed Models

- Enhance Visualization

- Model use in Documentation

- Streamline simulation to optimize the total product design throughout the lifecycle

- Manufacturing Engineering and our suppliers fabricate and Inspect from model data

- Competitive Industry Requirement

- Leverage efficiencies related to the use of standards for data exchange and electronic data transfer throughout our supply chain 
Why the $\mathrm{FAl}$ is so important

- Customer requirement

- Reassurance that we are compliant to specifications

- Repeatable process

- Parts are built correctly

- Assure the shop/supplier is capable

What You Need to Perform FAl

- Knowledge of FAI Process

- Work Instructions/Planning for part (SAP)

- BOM/Parts List

- FAl Checklist

- Vaulted Drawing and all engineering requirements

\section{TDP Process}

QE / SQFE Process

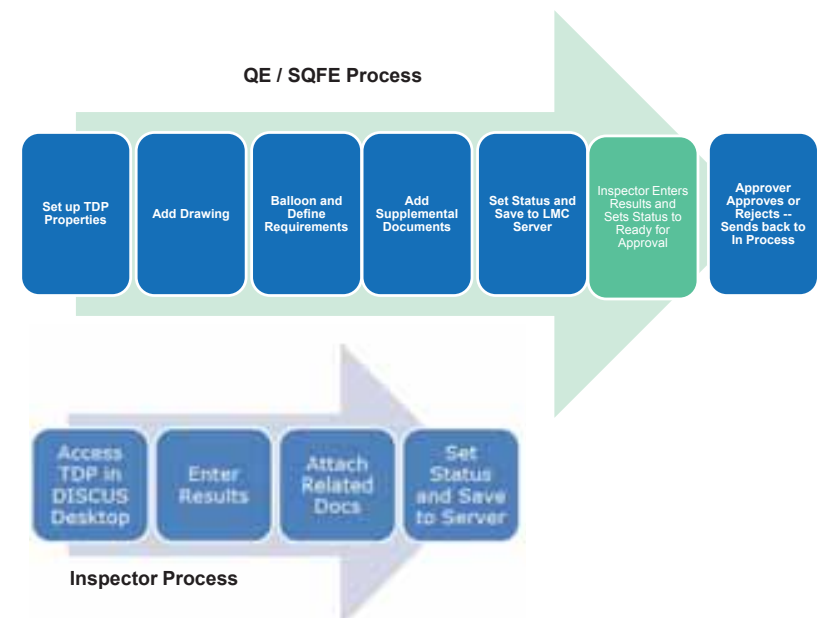

Inspector Process

\section{New DISCUS Process}
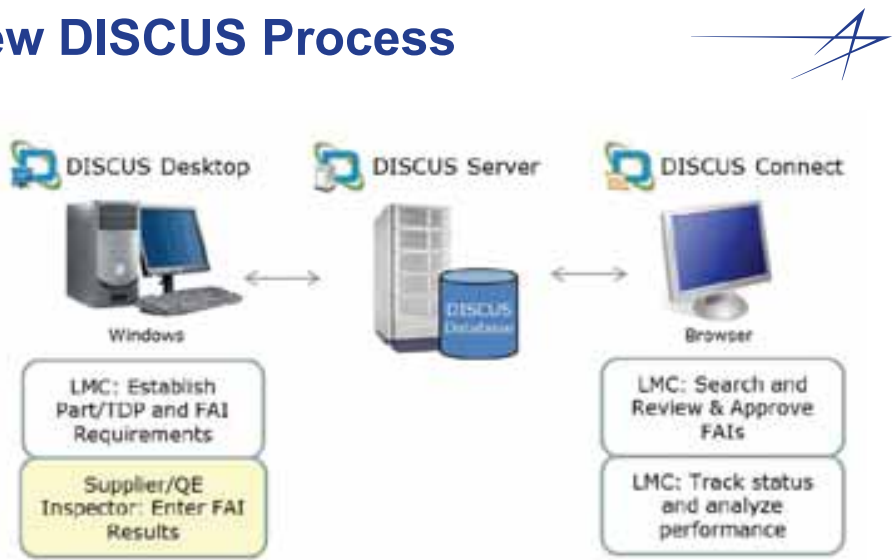

\section{QIF Activity Model}

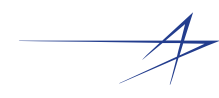

\section{DMSC Organization}
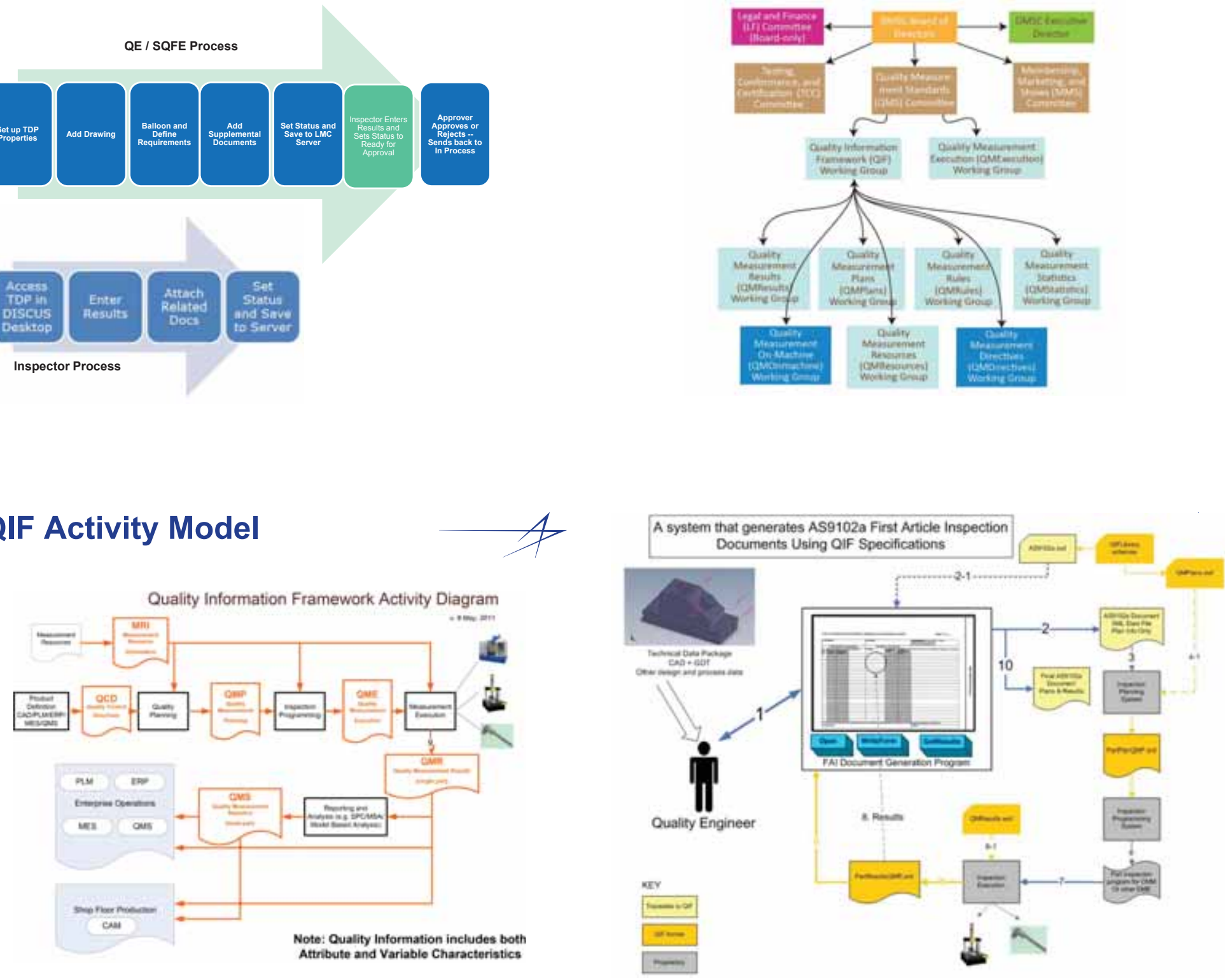
QMS Pilot Project (NIST-LMC)
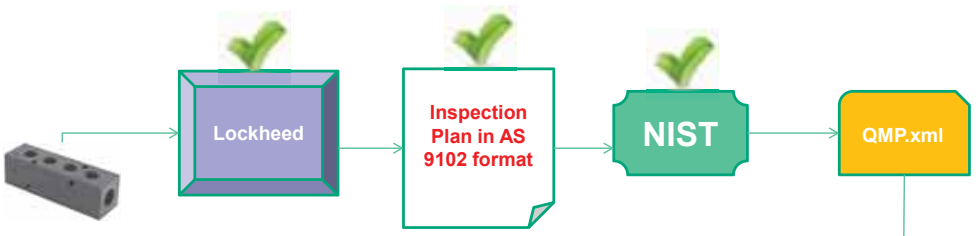

$C A D+G D \& T$

Project Stage 1 Benefits: provides example XML file, validates QMP schema.

Project Stage 2

\section{DMIS}

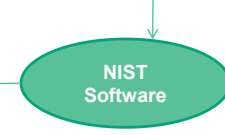

Quality Measurement Planning Pilot Project

Hypothetical Stage 3: A measurement planning solution provider may export QMP from its planning software. This stage is only doable when the first two stages are successfu and attract interest from Lockheed management level and vendors.

\section{QMS Pilot Project (NIST-LMC)}
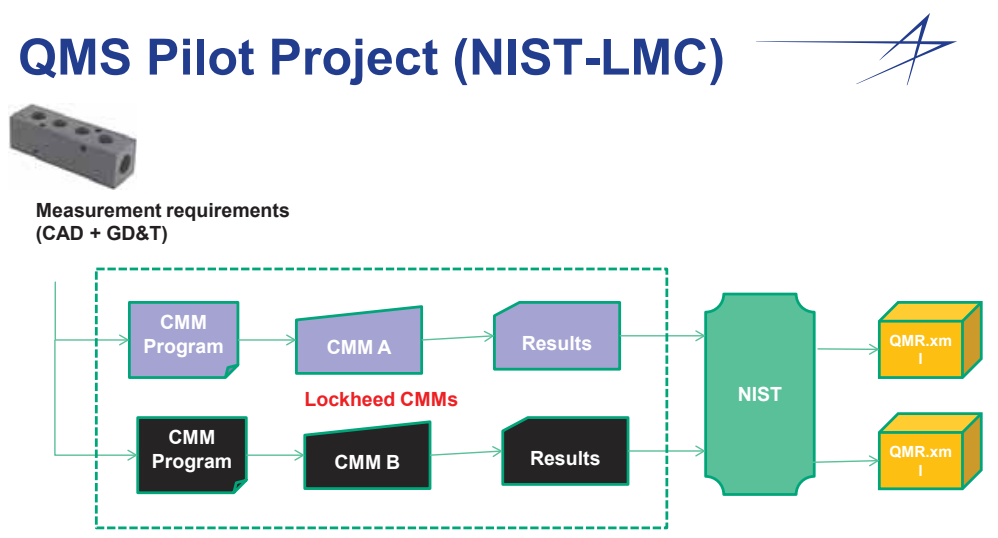

Quality Measurement Results Pilot Project

Project Stage 1: Benefits: validate QMR schema; provides example QMR files; demonstrates interoperability of QMR.

Hypothetical Stage 2: A CMM software vendor may generate/convert measurement results in QMR.

This stage is only doable when the first stage is successful and attracts interest from Lockheed management and a vendor.

\section{In Summary}

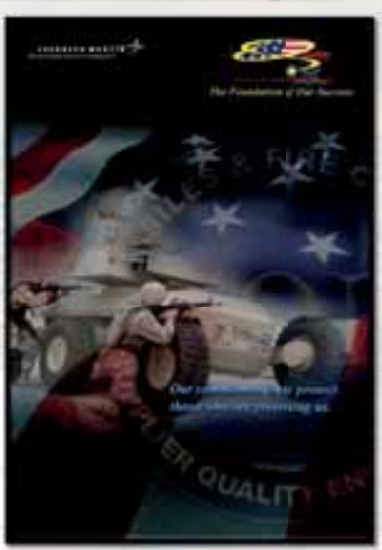

\section{Automation Improves Our} Success

- Customer Expectations

- Complexity of Industry and Risks

- Result of Failure is Severe

- MFC Expectations

Product Definition and

Requirements are Vital

Protecting the Customer's Interest

MBE-TDP Summit Conference Gaithersburg MD 2011-12-13

Bill Tandler

A SmartGD\& ${ }^{\mathrm{TM}}$ Presentation

\title{
The Key to Intelligent GD\&T
}

\section{MBD}

The Key to Intelligent GD\&T and

\author{
Intelligent GD\&T
}

The Key to functional MBD 


\section{Presentation Overview}

1. Objectives

2. MBD and its Promises

3. GD\&T and its Promises

4. An Example: "Decorative" versus "Functional" GD\&T

5. An-Example: "Functional" GD\&T and Metrology!

6. Conclusions

\section{Objectives}

1. Review MBD and GD\&T to assess their promises.

2. Present ideas for helping them fulfill their promises.

AM MULTI METRICS, iNC.

SmartGD\&T

\section{Review \& Assessment of MBD}

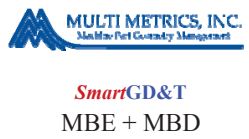

2) What is MBD for? Among many other things . .

To enable the intelligent application of GD\&T controls in the 3D model space, and their intelligent transfer to largely automated downstream processes.

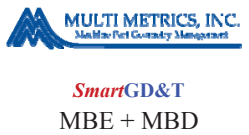

1) What is MBD? Among many other things ..

A computational environment which creates a truly functional connection between the 3D features of a machine part and the tolerance zones defined by GD\&T to limit their imperfection.

3) What are MBD's promises?

1. To vastly improve the ability of mechanical engineers to produce fault tolerant, functional designs right from the get-go.

2. To largely automate the Tolerance Stack-Up Analysis process.

3. To completely automate coordinate metrology. 


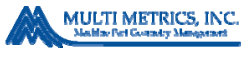

SmartGD\&T

$\mathrm{MBE}+\mathrm{MBD}$

4) Does MBD fulfill its promises?

At this point, only to a very limited extent !

Copyright $\mathcal{2} 2011$ by Multi Metrics, Inc. Menlo Park, CA All Rights Reserved

\section{MULTI METRICS, INC. \\ SmartGD\&T \\ $\mathrm{MBE}+\mathrm{MBD}$}

5) What limits the ability of MBD to fulfill its promises?

2. In spite of recognizing its benefits, widespread confusion caused by the complexity of GD\&T, leads many potential users to simply avoid it and certainly to fail to even wonder if GD\&T "encoding" could ever be intelligently supported.

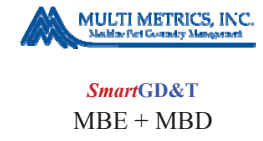

5) What limits the ability of MBD to fulfill its promises?

4. The still limited intelligence of current MBD products, and their less than brilliant ergonomics, leads to further reductions in enduser interest and demand.
5) What limits the ability of MBD to fulfill its promises?

1. The continuing inadequacy of, and confusion surrounding certain Y14.5 and ISO 1101 definitions of GD\&T concepts, tools and rules, makes fully comprehensive MBD implementation impossible at this juncture.

Very sad!

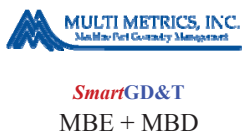

5) What limits the ability of MBD to fulfill its promises?

3. The messy maze (FUR BALL) of GD\&T callouts which commonly swarm around MBD enhanced 3D models causes even pro-GD\&T users to still prefer the 2D drawing environment, thus further limiting interest in MBD systems.

5) What limits the ability of MBD to fulfill its promises?

5. Limited enduser demand for intelligent GD\&T encoding leads to limited interest on the part of CAD companies to invest in their refinement, leaving MBD still far from being able to fulfill its promises. 


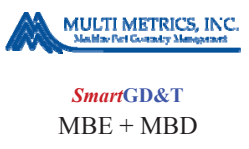

6) What's the impact of MBD's Failure to fulfill its promises?

1. Continued mis-use of GD\&T in the $2 \mathrm{D}$ drawing environment.

2. Low enduser demand for MBD due to ignorance of its potential and therefore low incentive for developers to invest in its refinement.

Oh BAD ! So SAD ! Makes one terribly MAD !

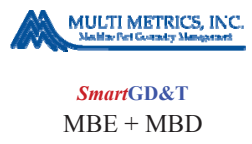

7) How can MBD be made to fulfill its promises?

1. By cleaning up the foundations of GD\&T to enable intelligent MBD implementation.

2. By moving forward with the development of a truly smart, highly ergonomic MBD based GD\&T encoding engine, in the absolute certainty of payback when the champagne hits the fan.
MULTI METRICS, INC:

SmartGD\&T

\section{Review \& Assessment of GD\&T}

\section{$\mathbf{G}_{\text {reat }} \mathbf{D}_{\text {eal of }} \mathbf{T}_{\text {ime }}$}




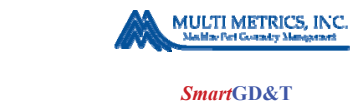

and in fact the...

\section{Greatest $\mathbf{D}_{\text {esign }} \mathbf{T}_{\text {ool }}$ \\ ever !}

MULTI METRICS, INC.

SmartGD\&T

And without

GD\&T

all

Tolerance Stack-Up Analysis

$\&$

Coordinate Metrology

are meaningless
MULTI METRICS, INC.

SmartGD\&T

\section{GD\&T}

is therefore all about

managing imperfect geometry

perfectly!

MULTI METRICS, INC.

SmartGD\&T

\section{$\underline{\text { Purpose of GD\&T }}$}

\section{Most people would say ...}

The main purpose of GD\&T is to communicate Design intent unambiguously to manufacturing and inspection!

Copyright @ 2011 by Multi Metrics, Inc. Menlo Park, CA All Rights Reserved

The primary purpose of GD\&T, is to ensure that what we communicate is worth communicating, namely represents manufacturable, assemblable and operational parts. 


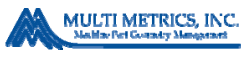

Definition of GD\&T

GD\&T is a symbolic language for
1. researching
2. refining and
3. encoding

the functions of each feature of a part and for maximizing the fault tolerance of a Design,

in order - through decoding - to

1. guarantee assemblability through truly functional, Tolerance Stack-Up Analysis

2. reduce manufacturing cost by setting precise, achievable objectives

3. turn inspection into a scientific process

Copyright 02011 by Multi Metrics, Inc. Menlo Park, CA All Rights Reserved

AM MULTI METRICS, INC.

SmartGD\&T

\section{How is GD\&T used in Manufacturing?}

GD\&T does not specify manufacturing PROCESSES !

It merely specifies manufacturing OBJECTIVES, and serves only to guide the selection and management of manufacturing processes.

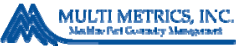

SmartGD\&T

3) What are GD\&T's Promises?

1. To guarantee absolutely reliable tolerance stack-up analysis on which to base acceptance or revision of the code.

2. To guarantee absolutely reliable communication of design intent, to enable manufacturing to make it right the first time.

3. To enable absolutely reliable, fully automatic coordinate metrology.

\section{How is GD\&T used in Design?}

1. For researching the functional interaction between mating product components during early design stages,

2. For refining the geometry of certain features in order to maximize the fault tolerance of a design,

3. For guaranteeing the assemblability of in spec mating parts through tolerance stack-up analysis, and

4. For encoding the functions of each feature of a part in absolutely unambiguous terms to specify its geometric requirements for manufacturing and inspection.

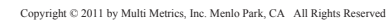

\section{How is GD\&T used in Inspection?}

\section{GD\&T does not specify inspection OBJECTIVES !} It specifies inspection PROCESSES in their entirety.

Without GD\&T, metrology, and therefore effective assessment of end product quality and manufacturing process quality are simply impossible

4) Does GD\&T fulfill Promises?

\section{Almost, but with great difficulty!}


MULTI METRICS, INC.

SmartGD\& T

5) Why does GD\&T fail to fulfill its Promises?

1. Due to the difficulty of mastering its necessary complexity, namely the complexity of its code which enables it to deal effectively with the complexity of imperfect real geometry.

2. Due to the continuing imprecision of certain concepts, tools and rules defined in the ASME Y14.5 and ISO 1101 Standards.

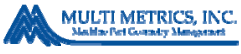

SmartGD\&T

7) How can GD\&T be enabled to fulfill its promises?

1. By being reduced to crystalline sets of concepts, tools, rules, processes and best practices in refined versions of the current Standards - or - for example as captured in the heuristics of SmartGD\& $\mathrm{T}^{\mathrm{TM}}$ Technology!

2. By then being empowered by intelligent, ergonomic implementation in the world of MBD.
SmartGD\&T

6) What's the impact of GD\&T's failure to fulfill its promises?

Huge wastes of time struggling to interpret GD\&T

decorated drawings and the the cost of getting it wrong.

Reduced interest on the part of users and developers in perfecting MBD, the only hope we have for reliably managing and partially or completely automating:

1. The GD\&T encoding process.

2. Tolerance stack-up analysis.

3. Inspection processes.

\section{"Decorative" versus "Functional" GD\&T}

SmartGD\&T 
"Decorative" versus "Functional"

GD\&T

Encoding the functions of the Features of a

Flat Edged Vacuum Flange

\section{Functional Objectives}

1) One face of the flange shall be flat within $0.01 \mathrm{~mm}$ to create a reliable vacuum seal with an O-ring in a mating flange.

2) The opposing face shall be located within $1 \mathrm{~mm}$ but parallel to the first within $0.1 \mathrm{~mm}$.

3) The bolt hole pattern shall be loosely centered in the flange but otherwise tightly controlled to serve as a locating feature.

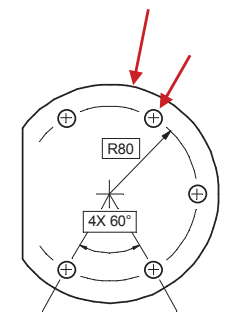

"Decorative" versus "Functional"

GD\&T

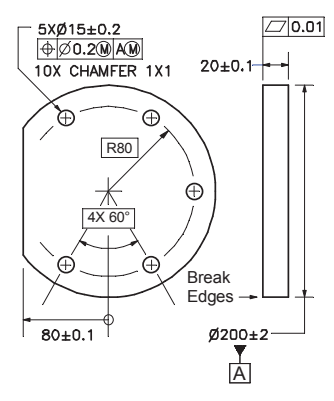

First cut !

How are we doing?

"Decorative" versus "Functional"

GD\&T

Second cut!

How are we doing?

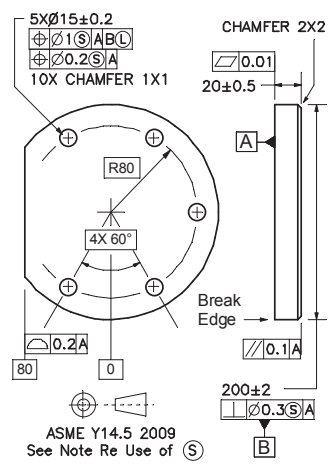

"Decorative" versus "Functional"

GD\&T

Encoding the functions of the Features of a

Flat Edged Vacuum Flange

\section{Functional Objectives}

1) One face of the flange shall be flat within $0.01 \mathrm{~mm}$ to create a reliable vacuum seal with an O-ring in a mating flange.

2) The opposing face shall be located within $1 \mathrm{~mm}$ but parallel to the first within $0.1 \mathrm{~mm}$.

3) The bolt hole pattern shall be loosely centered in the flange but otherwise tightl controlled to serve as a locating feature.

4) The left hand edge of the flange shall be tightly controlled relative to the bolt pattern to reliably align and locate a mating part.

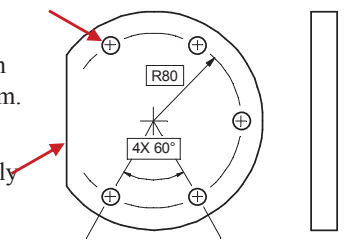

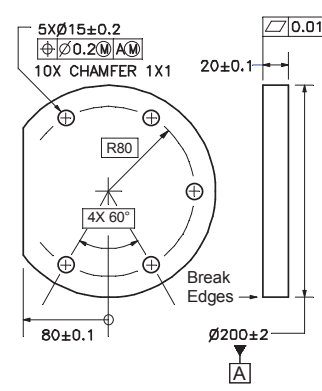

1. Part symmetry should have been broken but was not.

2. Thickness tolerance was made tighter than necessarily to control parallelism.

3. Datum Feature A is non-functional for the purpose assigned to it.

4. The Tolerance Zone Size modifier (M) on Position does not encode the location function of the bolt pattern.

5. The control on the flat edge in no way represents the required constraints.
"Decorative" versus "Functional"

GD\&T

The

\section{"functional"}

Drawing

1. The symmetry is broken.

2. The thickness is controlled loosely and the flatness and parallelism of the faces independently and functionally.

3. A Y14.5 Standard is referenced and the projection preference is specified.

4. The Datum Features are functional.

5. The bolt hole pattern and the flat edge are controlled in a manner to fully represent their functions in a highly fault tolerant way.

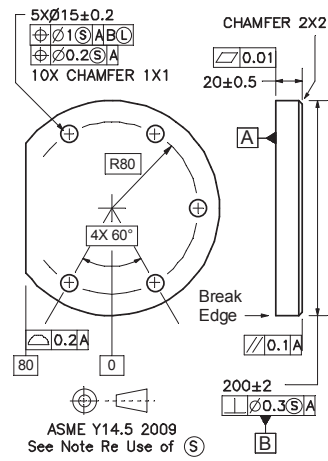


"Decorative" versus "Functional" GD\&T

"decorated"

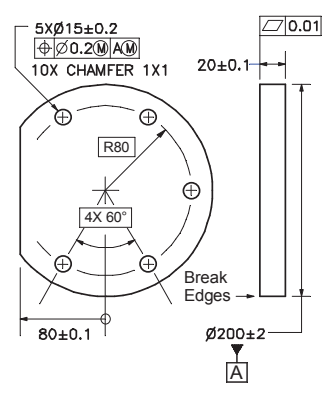

Copyright $\odot 2011$ by Multi Metrics, nnc. Menlo Park, CA All Rights Reserved "functional"

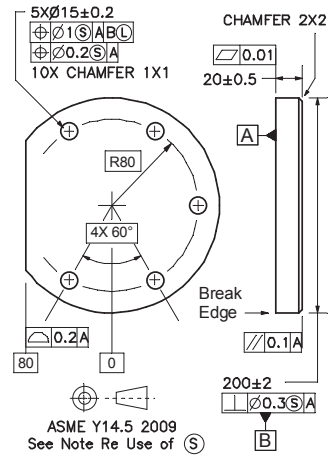

MBD “Functional" GD\&T

Complete Automation

of the

Coordinate Metrology Process

MULTI METRICS, INC.

SmartGD\&T

\author{
"Functional" Grodr
}

MULTI METRICS, INC.

SmartGD\&T

\section{An Example of Coordinate Metrology}

Process Automation

Based on

InnovMetric Inc.'s

PolyWorks Inspector ${ }^{\mathrm{TM}}$ V12

A Multi Metrics, Inc. SmartGD\&T TM Technology

Licensee 

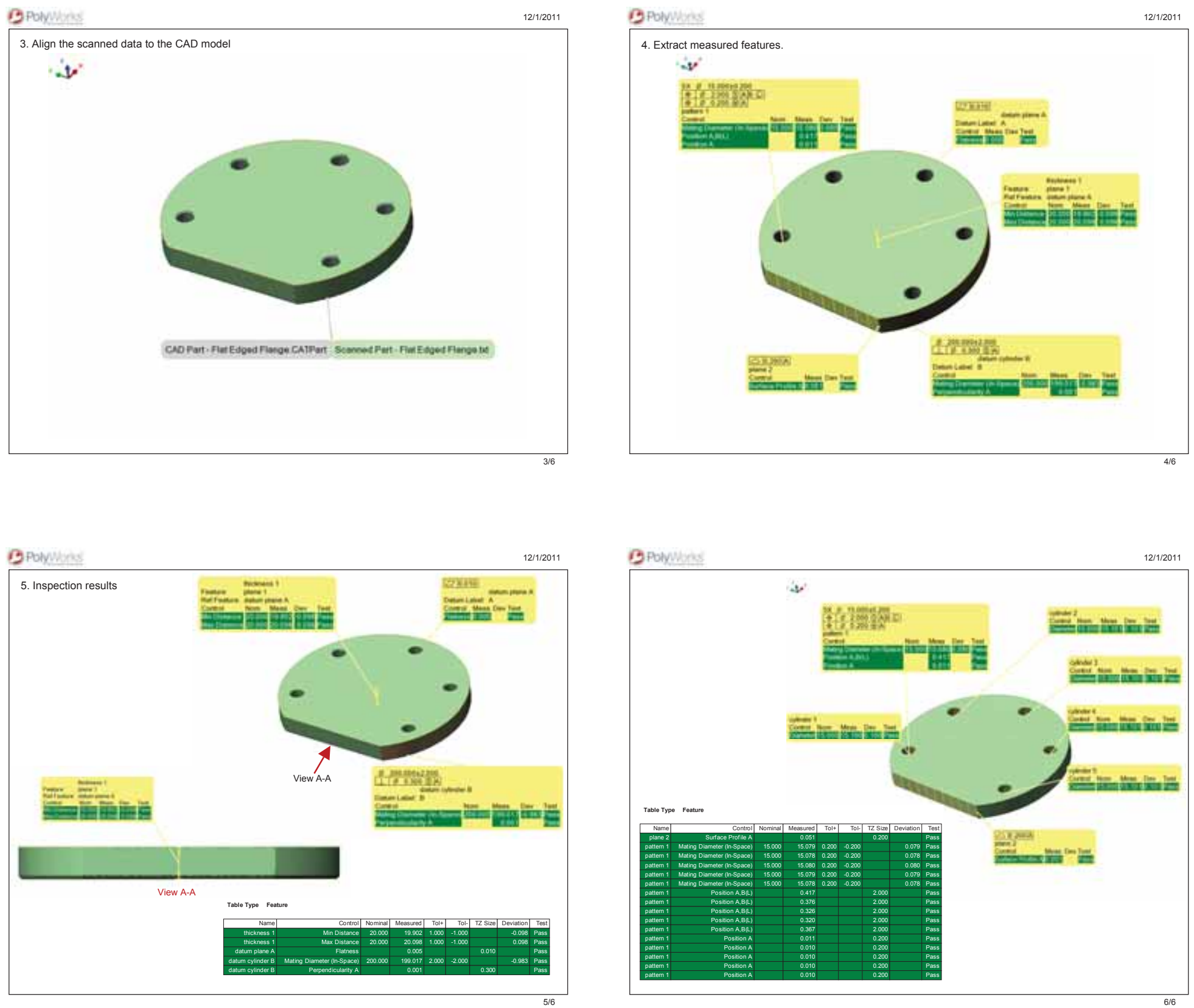

\section{MULTI METRICS, INC. \\ What is SmartGD\&T?}

SmartGD\&T is a rule-based, process driven approach to either the ASME Y14.5M 1994 or ISO 1101 standard, which makes it possible to "encode" and "decode", rather than "interpret" GD\&T, and get it right the first time.

1. GD\&T is the ultimate tool to enable useful MBD.

2. MBD is the ultimate tool to enable functional GD\&T.

3. It is time to clean up the ISO and ASME GD\&T Standards.

4. It is time to start investing in heavily MBD development. 


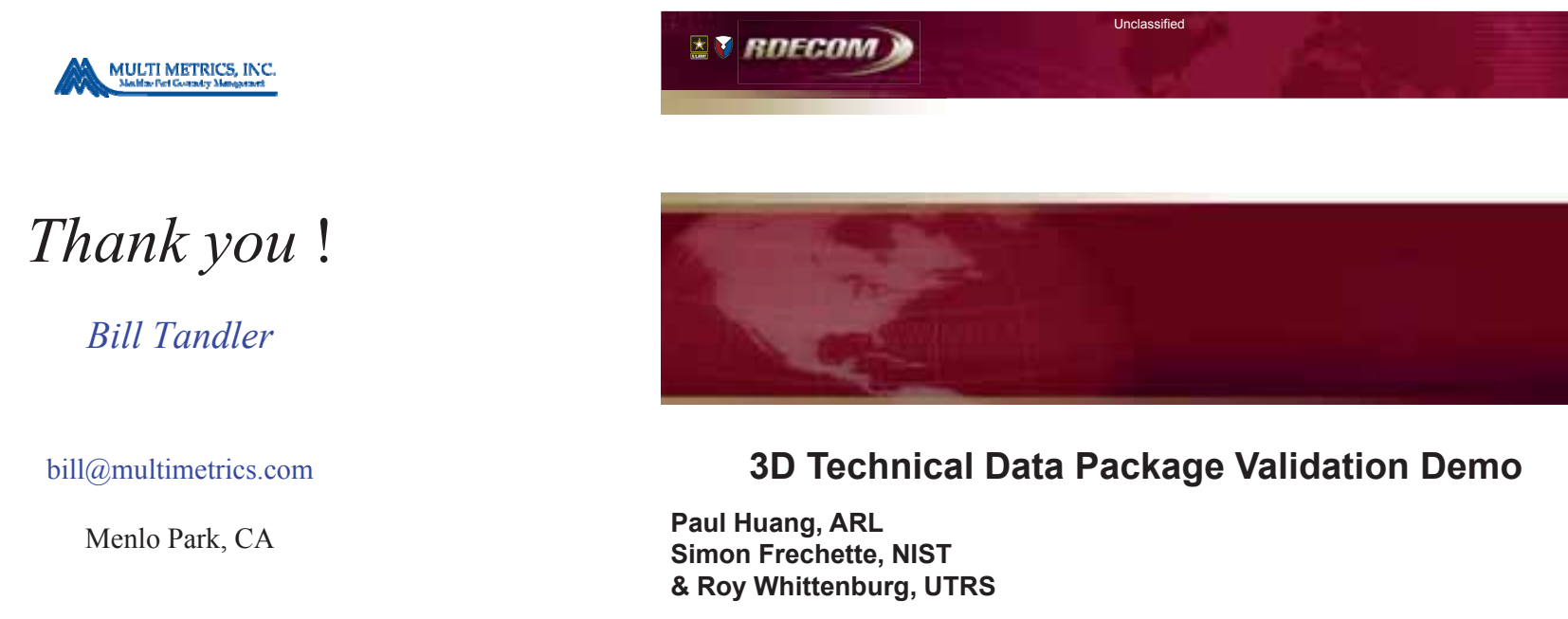

Date: $11 / 01 / 2011$

\section{太 RDECOM \\ Agenda}

- Project Overview

- The Demo

-Model Creation

-PLM Check In

-Derivative Creation

- Conclusions

-Questions?

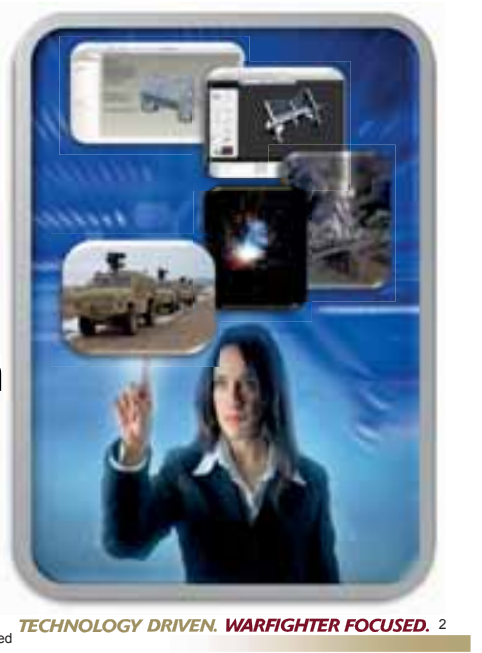

\section{주 RDECOM \\ The Project}

- Objective: To provide a process to Verify and Validate that the Data Quality of the 3D TDP is sufficient for manufacture

- The Team: A multi service and industry set of subject matter experts

- Government: - Industry:

$\begin{array}{lll}\text { - Army } & \text { - ITI TranscenData } & \text { - Jotney } \\ \text { - Navy } & \text { - Elysium } & \text { - Vistagy } \\ \text { - NIST } & \text { - PTC } & \text { - Anark } \\ \text { - DLA } & \text { - BAE Systems } & \text { - I-Cubed } \\ & \text { - Boeing } & \text { - Tetra4D }\end{array}$

太્ $\odot$ RDECOM

\section{Project Overview}
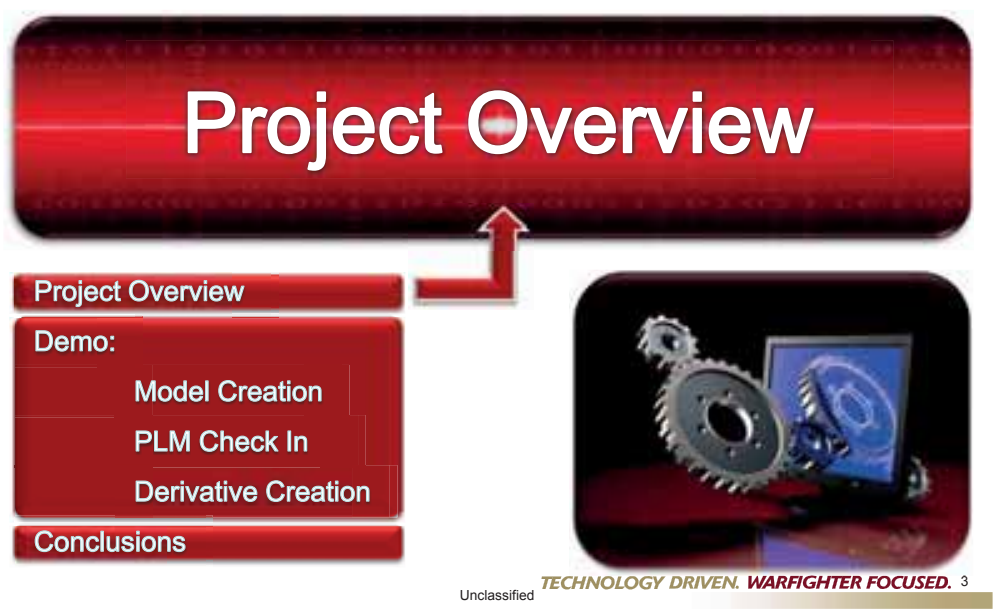

\section{(5) RDECOM $\quad$ The Need}

- Since the DoD is inherently 2D and drawing based there is no method of verifying the quality of the 3D data they receive

- As a result the prevailing view is that the data is not reliable for use by in the non design portions of the lifecycle

- When used it is often translated into a new format possible introducing more errors

- All of this has fostered an inherent distrust of the data that could be reused in the lifecycle thus driving up cost and time to mission 


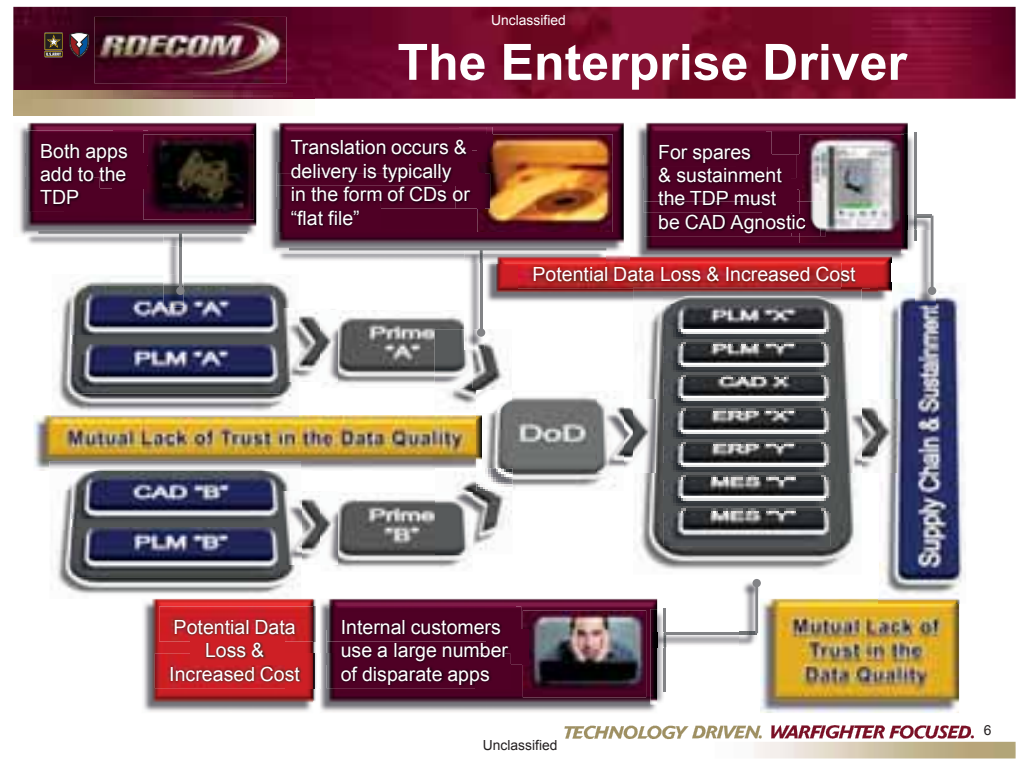

\section{EO RDEGOM}

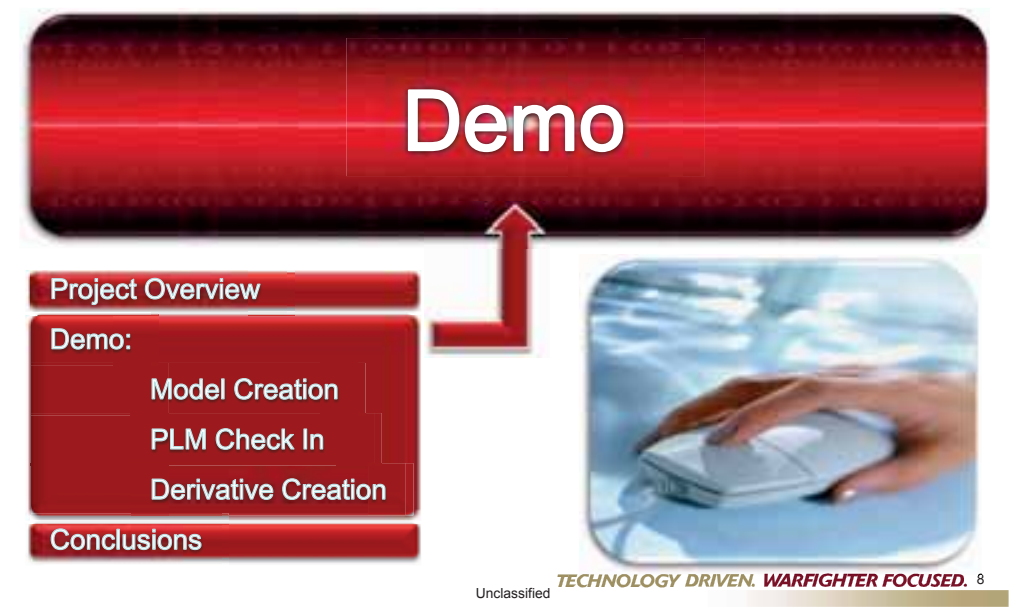

\section{太 RDECOM}

\section{Model Creation}
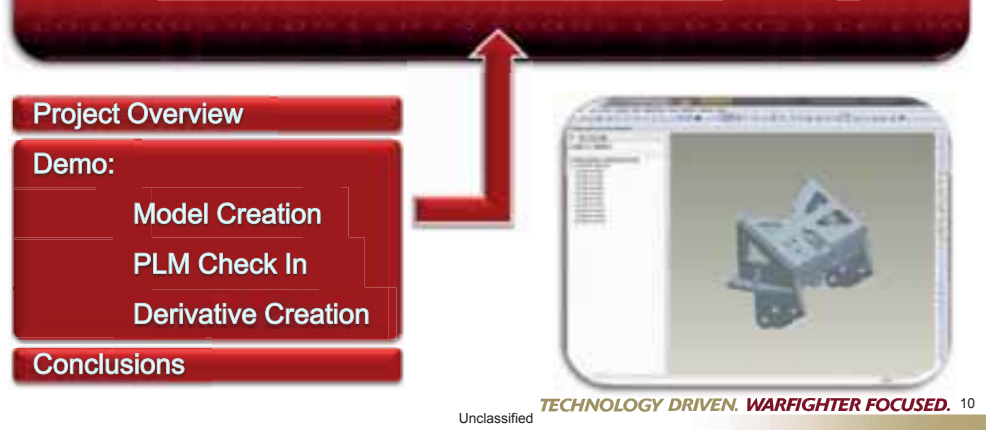

\section{The Approach}

The team have taken a process approach that focuses on defining what needs to be validated and then works with industry to fill any technology gaps.

Two examples are the Validation Guidebook and the verification of derivative models
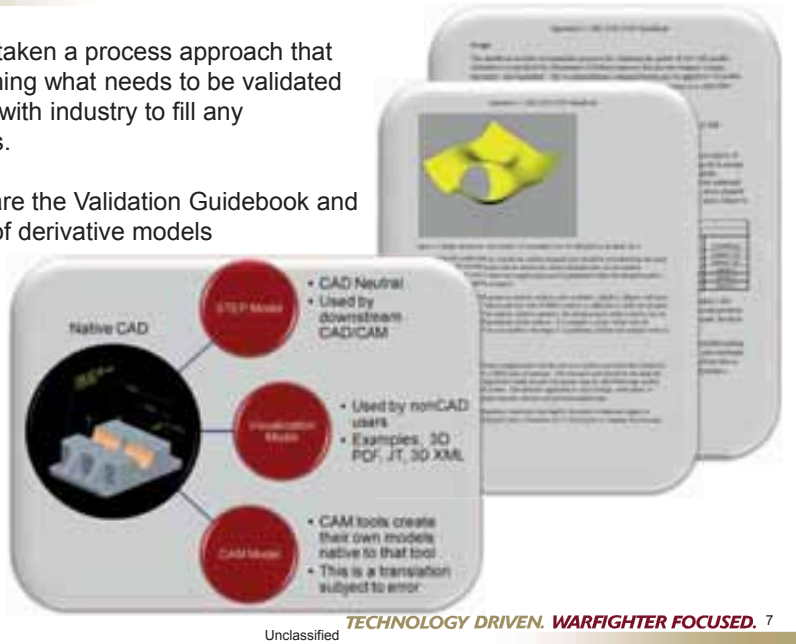

\section{太}

- What follows is a demonstration of how validation tools could be inserted into the typical Model Process

- It centers on three typical milestones

- We will follow a data set through this process
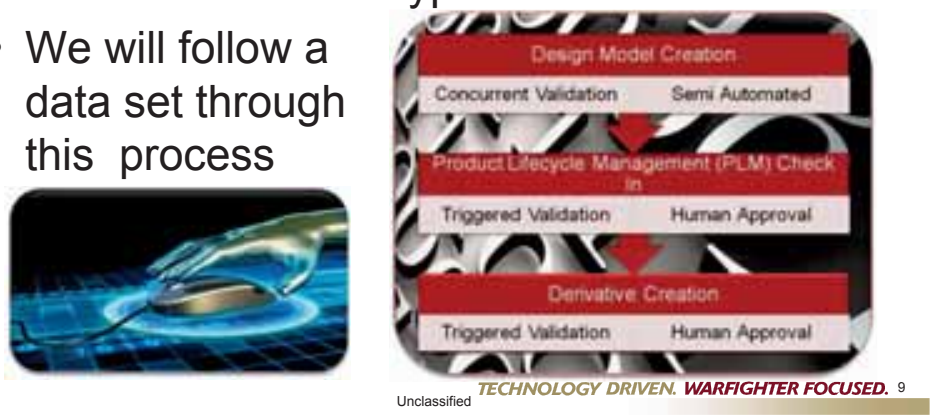

\section{The Milestone}

- As the name states the Model Creation milestone covers the act of building the model

- This is further broken down into segments, each of which has its own validation point

- These checks can and should be done multiple times or interactively before a step is completed in order to catch the problem when it is the easiest to fix, early...

\section{Early Error Detection $=$ Reduced Time $\&$ Cost} Unclassified TECHNOLOGY DRIVEN. WARFIGHTER FOCUSED. 11 


\section{[0 RDEEOM Typical Modeling Process}

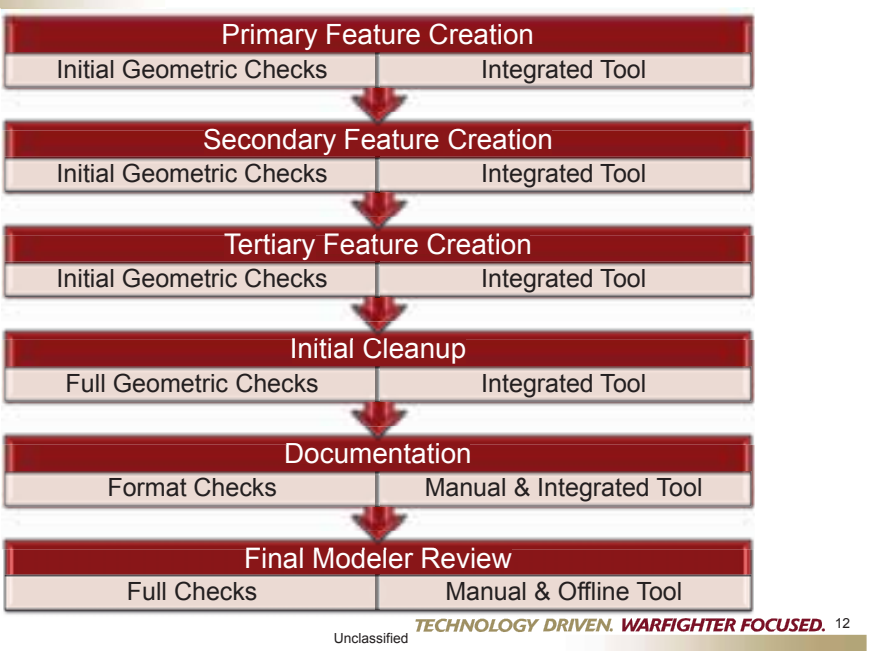

\section{太}

- Besides Geometry and Design checks, organizational or schema rules can be enforced

- Example: Datum Features should be Blanked on Layers

- Identified by feature number

- Moved to layer to remove warning

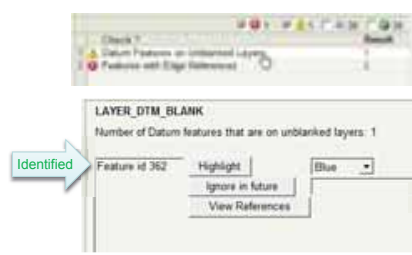

Images provided by PTC

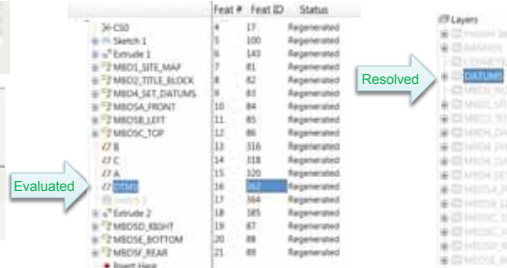

TECHNOLOGY DRIVEN. WARFIGHTER FOCUSED. 14

\section{太}

- Example: Directs designer to run interference check

- Software finds 5 interferences with volumes

- Interfering parts are outlined in yellow \& green

- Overlapping volume region displays in red

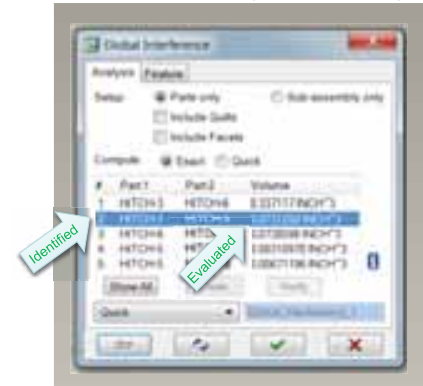

Images provided by PTC

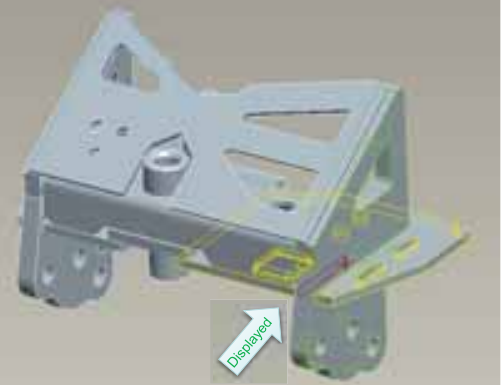

Unclassified TECHNOLOGY DRIVEN. WARFIGHTER FOCUSED. 16
- Results Example

8- Errors

$\triangle$ - Warnings

(i)- Information

0 - Pass

- Most errors can be identified early and fixed on the fly

- Process:

$>$ Identify > Evaluate >Display \& Resolve

\section{ive Quality Reporting}

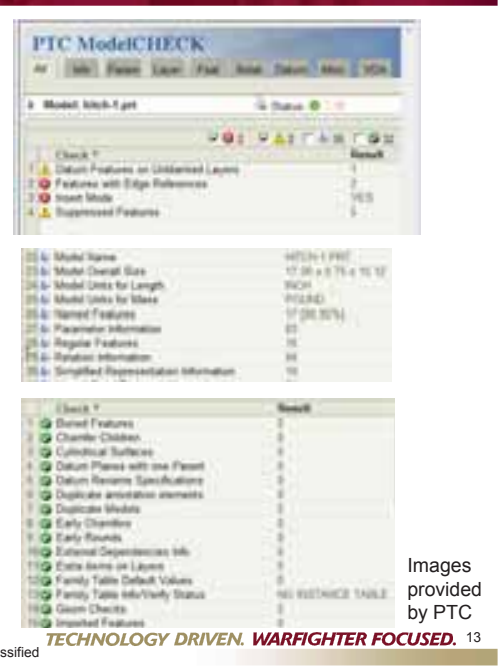

\section{(E) RDECOM Reuse Quality Checks}

- Issues that can effect the reuse of the model are also checked

- Feature with Edge References. issue for child geometric features

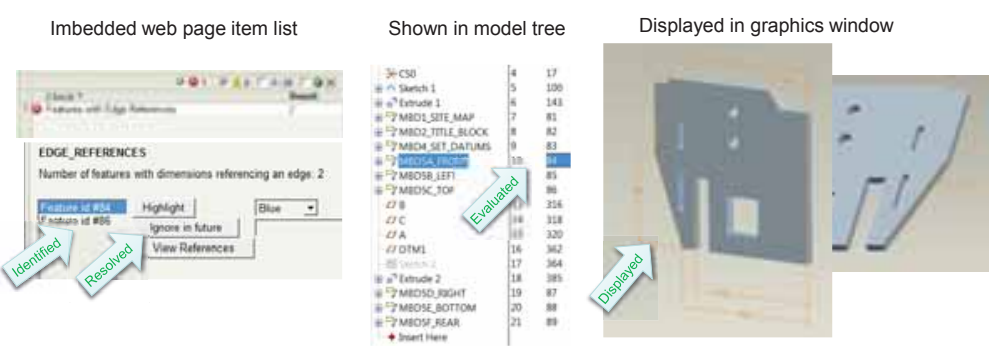

Images provided by PTC TECHNOLOGY DRIVEN. WARFIGHTER FOCUSED. 15

\section{太७ RDECOM}

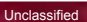

\section{(1)}

\section{PLM Check In}

Project Overview

Demo:

Model Creation

PLM Check In

Derivative Creation

Conclusions
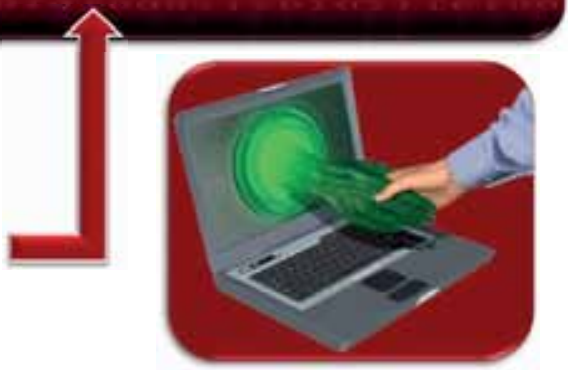

TECHNOLOGY DRIVEN. WARFIGHTER FOCUSED. 17 


\section{The Milestone}

- Once a model has been created it is typically placed or "checked in" to a Product Lifecycle Management (PLM) tool

- At this point a series of checks are run verifying its quality

- If the model does not pass these checks it is not allowed to enter the repository

- At this point it is ready to be shared with others in either a released or unreleased state

\section{太 RDECOM Full Data Quality Checks Are Run}

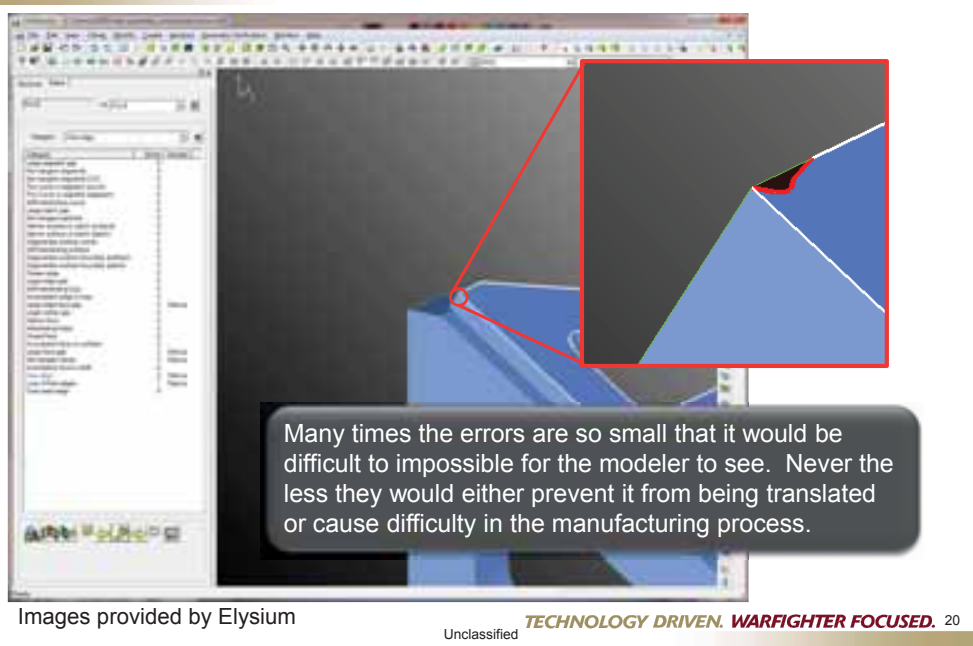

\section{The Milestone}

- Once released to downstream customers and often before that, every model will eventually be translated into another format for consumption

- The translated model is called a derivative

- This derivative must be validated just like the original

- But in addition to checking for normal quality errors it must be checked to make sure it does not deviate from the original

\section{(x) RDECOM Models Are Scored And Reports Saved}

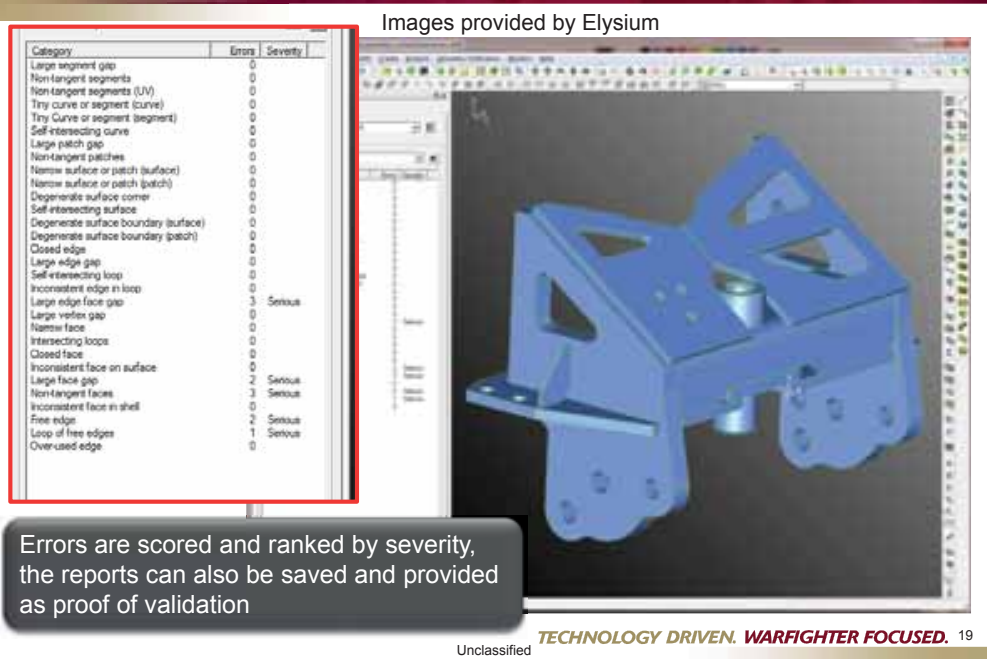

\section{太O RDEGOM}

\section{Derivative-Creation}

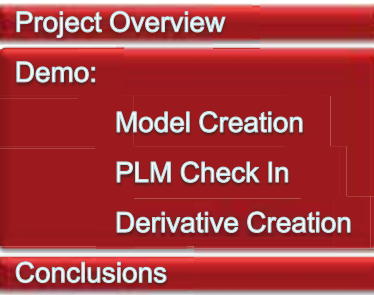

太T RDECOM Translation Validation Testing

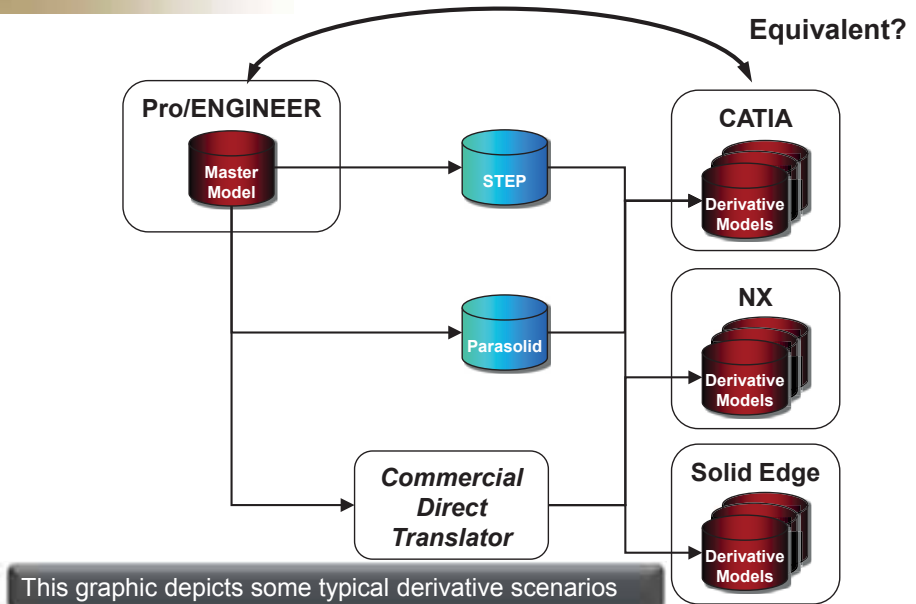

This graphic depicts some typical derivative scenarios

Images provided by ITI TrancenData 


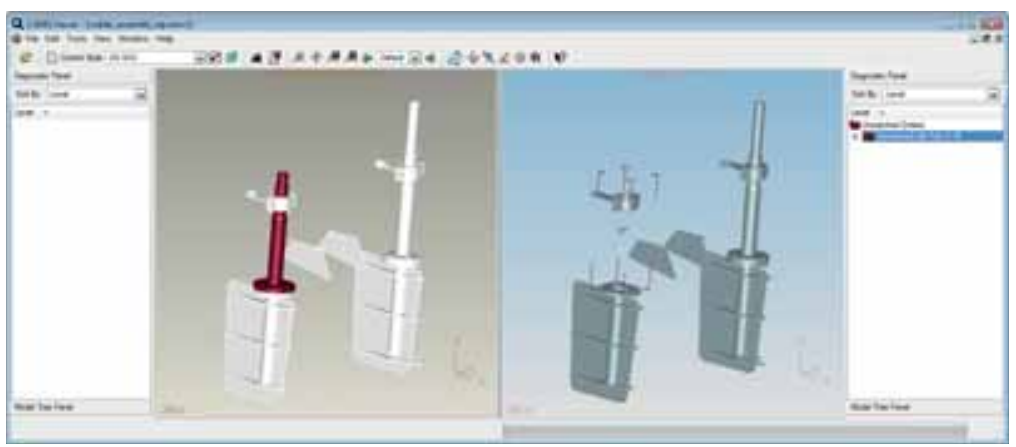

During direct translation from ProE to NX the highlighted part was lost

Images provided by ITI TrancenData Unclassified TECHNOLOGY DRIVEN. WARFIGHTER FOCUSED. 24

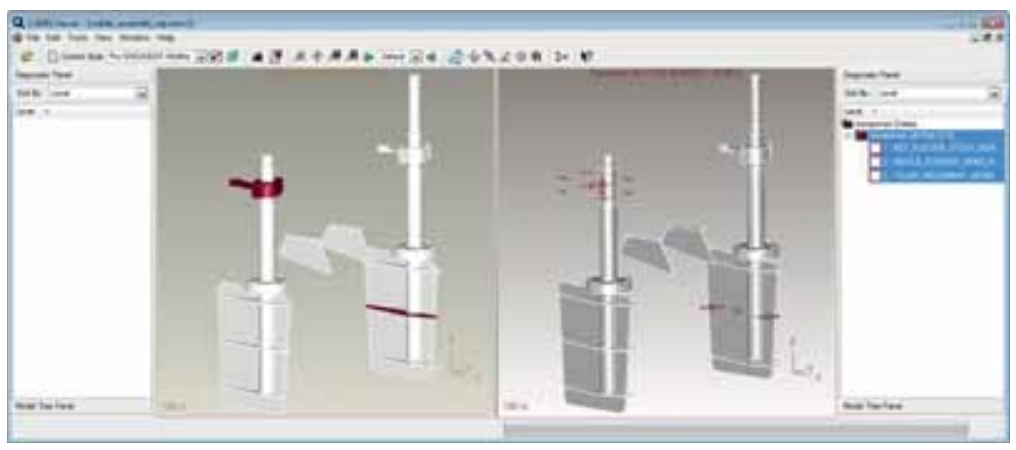

During Parasolid translation from ProE to Solid Edge the highlighted parts were lost

Images provided by ITI TrancenData

Unclassified TECHNOLOGY DRIVEN. WARFIGHTER FOCUSED. 25

\section{¿ $\odot$ RDECOM PMI Translation Validation Testing}

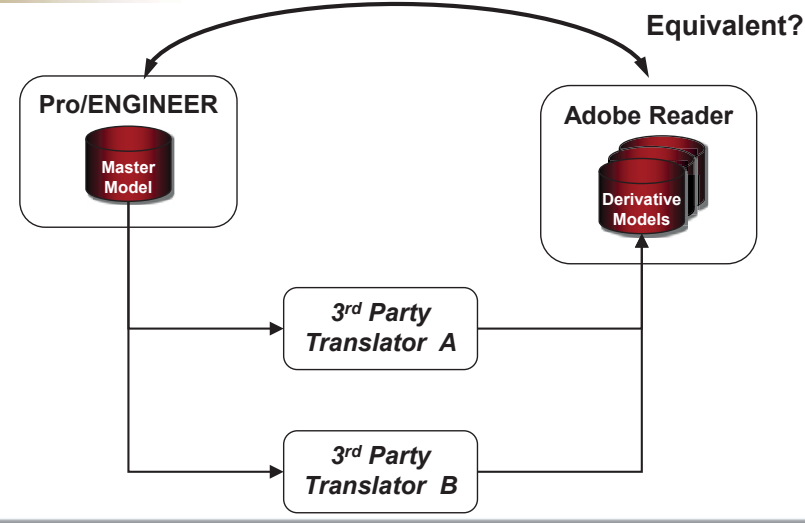

A growing use case is the translation to Adobe 3D PDF. At this point we will also address the Product Manufacturing Information quality

Images provided by ITI TrancenData

Unclassified TECHNOLOGY DRIVEN. WARFIGHTER FOCUSED. 26

\section{太}

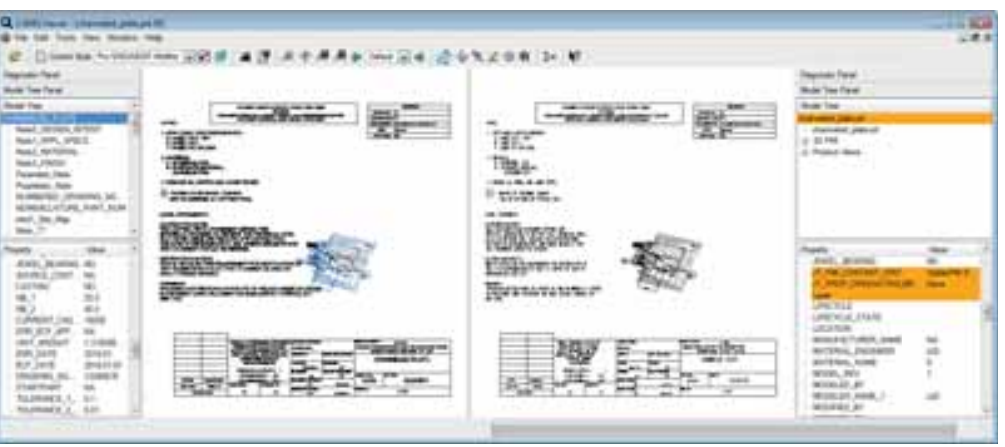

During export from ProE to 3D PDF confusing attributes were added to the model

Images provided by ITI TrancenData TECHNOLOGY DRIVEN. WARFIGHTER FOCUSED. 27

\section{¿『 RDECOM PMI Font Validation Example}

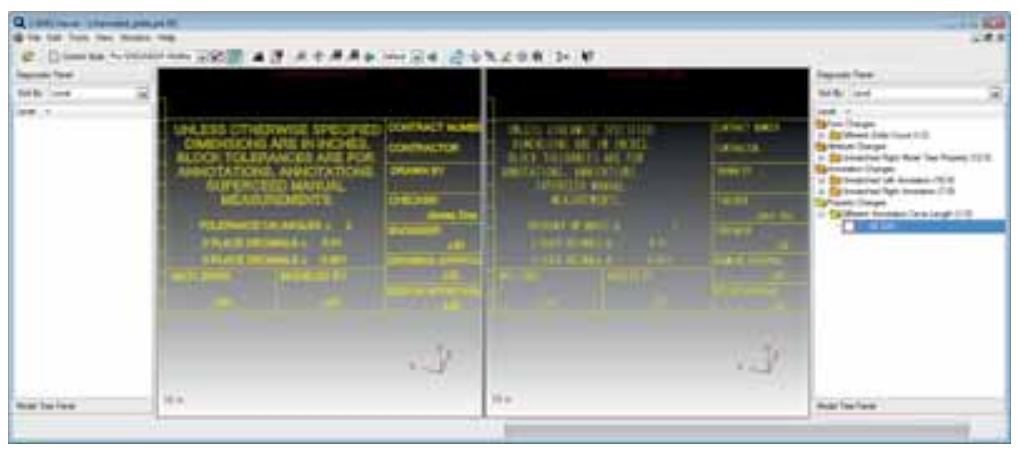

During export from ProE to 3D PDF the text font in this title block changed

Images provided by ITI TrancenData TECHNOLOGY DRIVEN. WARFIGHTER FOCUSED. 28

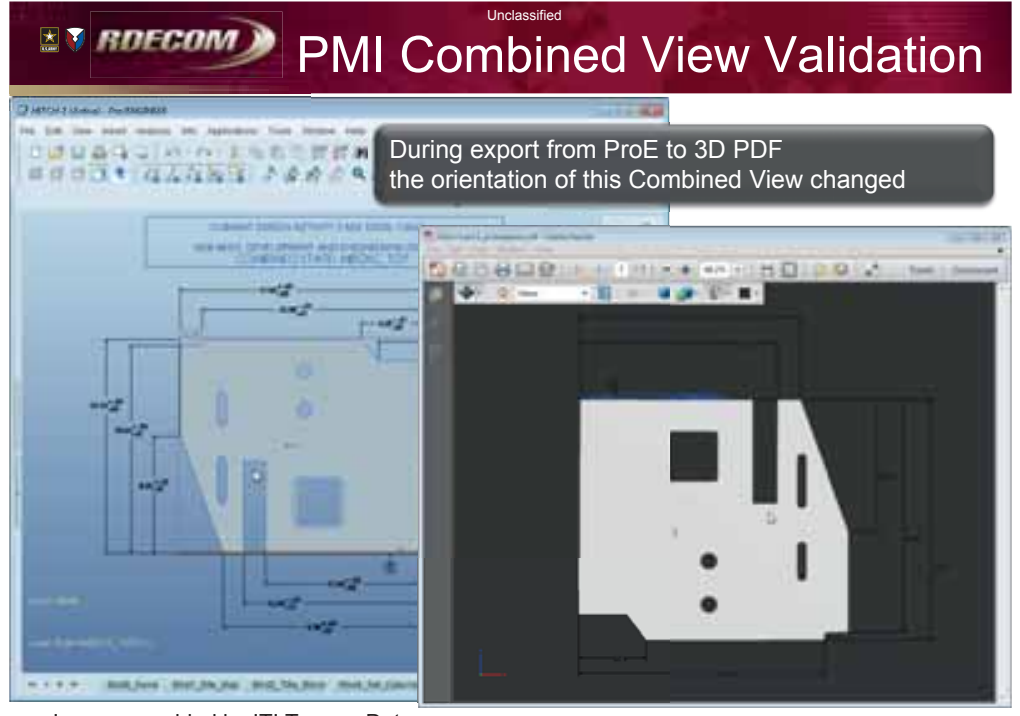

Images provided by ITI TrancenData 


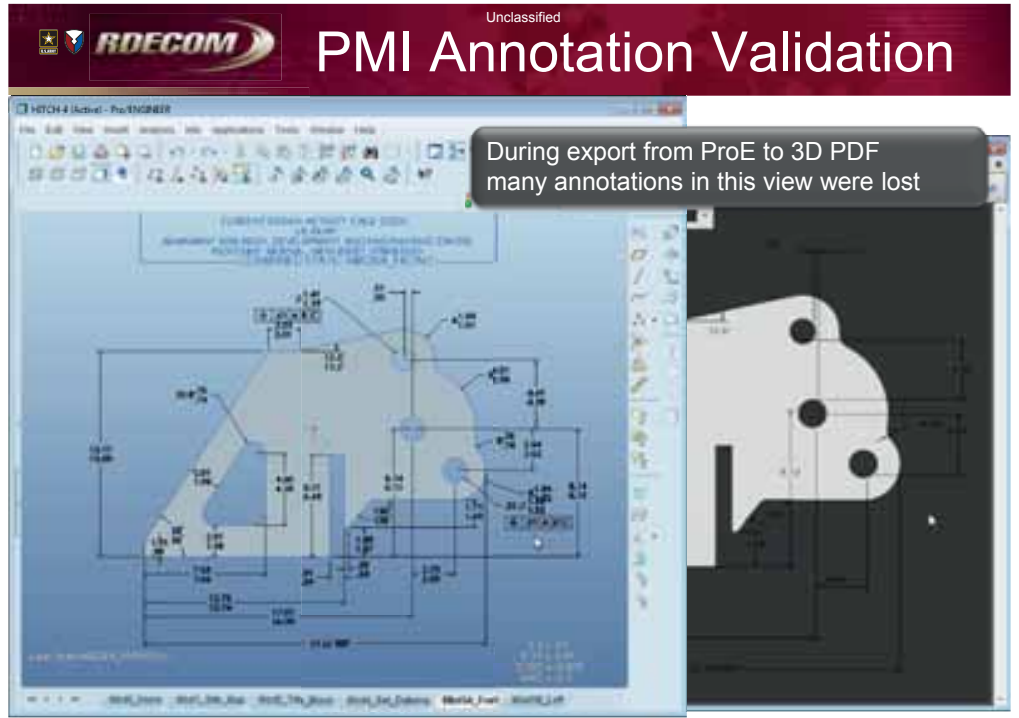

Images provided by ITI TrancenData
Unclassified TECHNOLOGY DRIVEN. WARFIGHTER FOCUSED. 30

\section{太 0 RDECOM PMI Note Placement Validation}

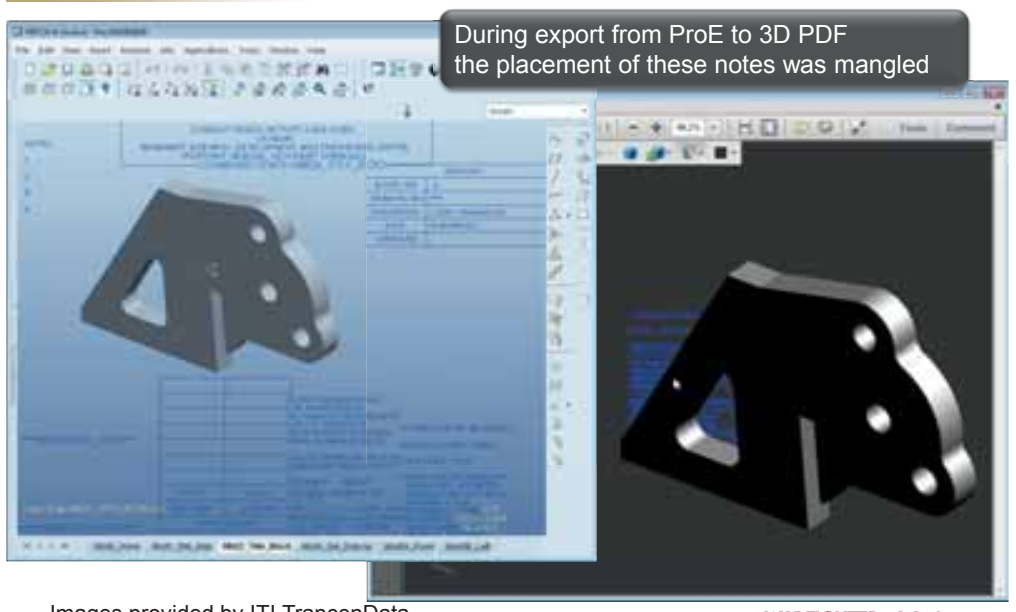

Images provided by ITI TrancenData Unclassified TECHNOLOGY DRIVEN. WARFIGHTER FOCUSED. 32

\section{I0 RofGom PMI Dimension Validation}

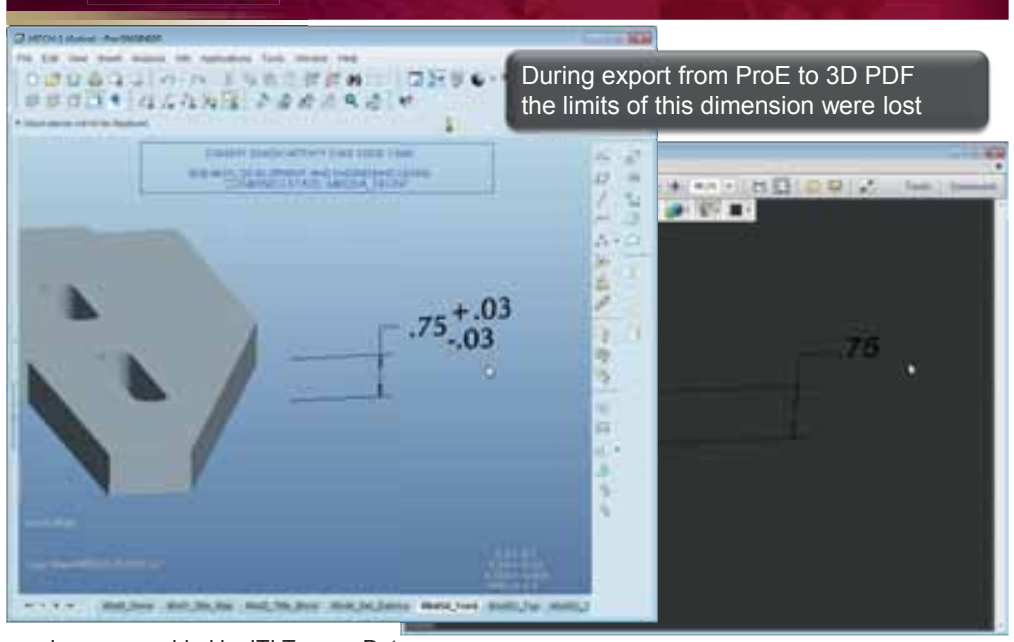

Images provided by ITI TrancenData

Unclassified TECHNOLOGY DRIVEN. WARFIGHTER FOCUSED. 31

\section{$\star \nabla R E C O M$}

\section{Conclusions}

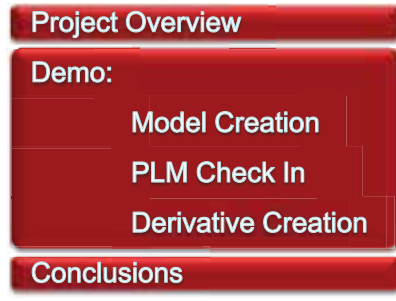

Conclusions

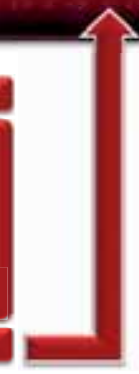

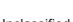

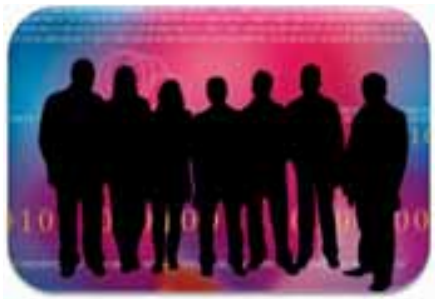

TECHNOLOGY DRIVEN. WARFIGHTER FOCUSED. 33

\section{太V RDECOM \\ Wrapping It All Up}

- Validation and Verification (V\&V) needs to occur at many points in the lifecycle of a model

- Derivative $\mathrm{V} \& \mathrm{~V}$ is at least as important as that of the native model

- It is a combination of automation and human in the loop process

- Its end goal is to increase the model data quality and thus increase the trust of consumers of the model

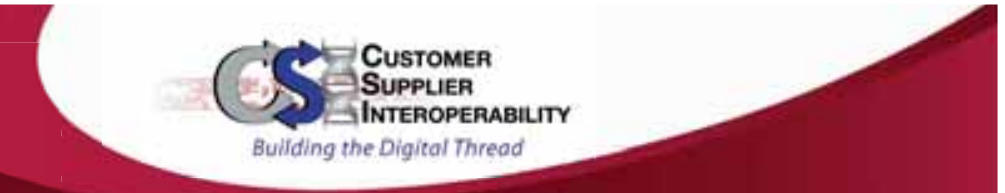

Reducing new product introduction time and cost through more effective collaboration

John Gray

ITI TranscenData

December 14, 2011

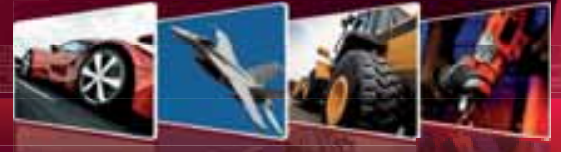


International TechneGroup, Inc. (ITI)

- Background

- Founded in 1983

by Dr. Jason Lemon

- Privately held

- Headquarters - Cincinnati, $\mathrm{OH}$

- Global Presence

- North America

- Europe

- Asia Pacific

- Business Offerings

- Engineering Process Improvement Consulting (CP/PD ${ }^{\mathrm{TM}}$ )

- Analysis, Simulation, Test and Reliability Engineering Services

- Product Data Integration \& Interoperability (TranscenData Business)
ITI TranscenData History
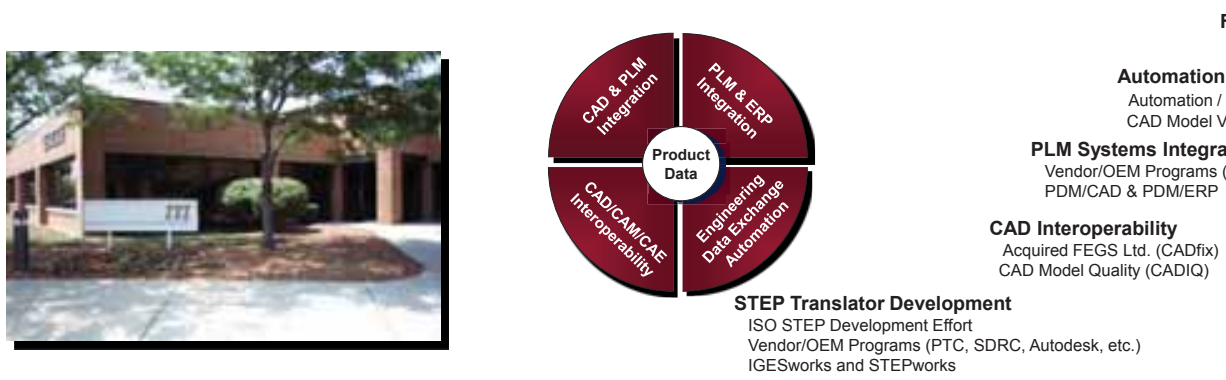

IGES Translator Development

IGES Standard Development Effort

Major Industrial IGES Translators (Chrysler, Ford, etc.)

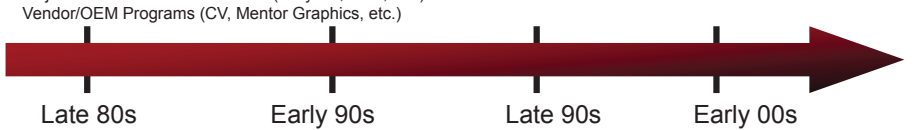

3 | "DISTRIBUTION STATEMENT A. Approved for public release; distribution is unlimited. Case Number 88ABW-2011-5822."

Cotern:

\section{"A billion here, a billion there and pretty soon you're talking real money."}

- Attributed to the late Senator Everett Dirksen

- Senator Dirksen was referencing the US budget and how relatively small items in the budget ( $\$ 1 \mathrm{~B}<.03 \%$ of US budget) can add up to great costs

- Interoperability is similar

- No one has an explicit "interoperability" budget. Rather interoperability costs are spread throughout other operating costs and are incurred with every technical data exchange.

- An individual exchange is not unreasonably expensive (maybe an hour, a few hours, or even a few days)

- When a program lasts $40+$ years and includes more than 4 million exchanges, the hidden "interoperability" costs can easily exceed \$1 B

- A modest savings of just $1 / 2$ hour per interoperability exchange can save 12,000 person years and $\$ 200 \mathrm{M}$ in labor costs alone

\section{Interoperability: A \$ 1 Billion + Problem}

- Interoperability Cost Analysis of the U. S. Automotive Supply Chain

NIST, US Department of Commerce, March 1999

"Interoperability is the ability to communicate product data across different production activities. It is essential to the productivity and competitiveness of many industries because efficient design and manufacturing require the coordination of many different participants and processes that rely on a digital representation of the product."

"This study estimates that imperfect interoperability imposes at least \$1 billion per year, on the members of the U.S. automotive supply chain."

Today's DoD annual imperfect interoperability costs likely exceed $\$ 2 B$

\section{Why Is Interoperability Important?}

- Drivers for Government / Defense

- Reducing both development and sustainment costs

- Deploying systems for use in the field sooner

- Improved reliability during operation

- Complying with new MIL STD 31000 initiative for MBD exchanges

- Strategies for success depend on collaboration and interoperability

- Leverage supply chain

- Use best resources effectively

- Focus on core competencies

- Rely on partners for their competencies and cost effectiveness

- Eliminate inefficiencies

- Shorten cycles and cost by eliminating non-value added work

- Innovation

- Focus resources on better designs

- Quality

- Reduce / eliminate mistakes to contain development and sustainment costs

- Incorporate additional MBD requirements

- More complete and readily usable technical data exchanges

- Validated

- Visualization

\section{Exploring Solutions For Improved Interoperability}

- Customer / Supplier Interoperability During Collaborative Design (CSI)

- Solution addressing AFRL BAA: 08-08-PKM

Air Force Research Laboratory

Defense Manufacturing Science \& Technology (MS\&T)

High Performance Manufacturing: Model Based Enterprise

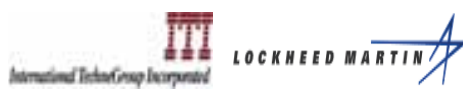

Honeywell

DOE,

STI
Collaborative

Collins 
CSI Overview

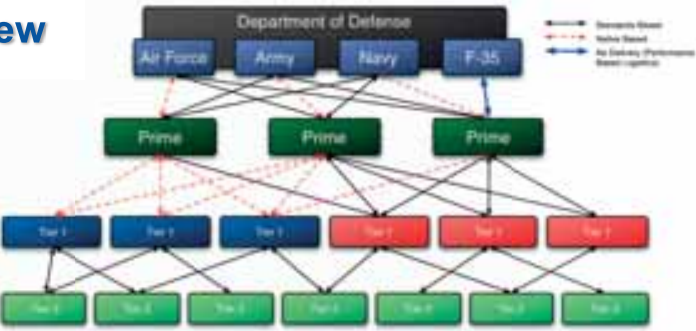

DoD Problem:

Warfighter Benefits:

Lack of defined data exchange format requirements between suppliers and custo

Reduced costs and higher quality data. Improvements in business practices will be seen in:

- Less cost to deliver products to the warfighter by liming non-value added daym of the data

Capture, validate and test "data-contract" requirements by assessing the requirements, evaluating the highest priority requirements, and developing prototype solutions for the

Using the DEXcenter, ITI will develop CSI modules, to

include contract mapping tools, and software libraries

Conduct a demonstration to highlight the savings achieved

- Less time for new capabilities to reach the warfighter because of streamlined processes through the supply

chain during early product development phases

Cost savings are estimated to be over $\$ 35$ million per major program

\section{Focus of program}

- Review "data contract" language and current methodologies used by industry to support contract requirements or negotiate changes to contract requirements

- Analyze failures (unable to comply or cost prohibitive to comply) in the process to support "data contracts" - Prioritize these failures in terms of frequency of occurrence and impact if the failure occurs as well as the cost impact

- Identify processes that can be automated to improve compliance with "data contracts"

- Demonstrate some of these automation capabilities and the associated savings if deployed in the industrial base
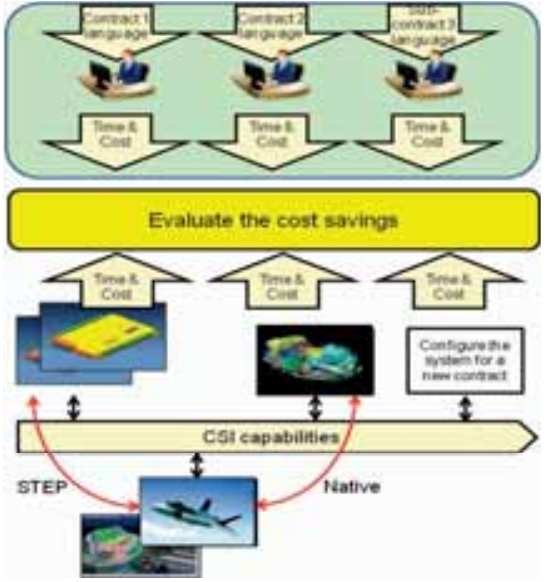

Example contract language and non-value added tasks in organizing and reformatting data

\begin{tabular}{|c|c|c|}
\hline (an OEM's requirement to suppliers) & $\begin{array}{l}\text { Defense-Army } \\
\text { (a customers requirements to the } \\
\text { prime contractor) }\end{array}$ & (an OEM's requirement to suppliers) \\
\hline $\begin{array}{l}\text { - CATIA V5 shall be used for 3D Solid } \\
\text { Model } \\
\text { - No assembly constraints shall be } \\
\text { active } \\
\text { - Red and orange colored geometry is } \\
\text { not to be used } \\
\text { - Individual files sizes to be less than } 30 \\
\text { MB } \\
\text { - All parts to be SolidM } \\
\text { - No hidden/no show elements } \\
\text { - Provide separate file with interface } \\
\text { points and vectors } \\
\text { - Files must be in engine coordinates } \\
\text { - Provide list of differences/changes } \\
\text { since last transmittal }\end{array}$ & $\begin{array}{l}\text { - Layers shall be named in accordance } \\
\text { with the naming convention in ProE } \\
\text { per xxxx Modeling STD 100T Rev G } \\
\text { ( } 26 \text { pages of rules). } \\
\text { - The contractor shall provide a 3D Solid } \\
\text { Model in Pro/Engineer, Version } \\
\text { Wildfire } 3 \text {, Intralink } 9.0-P D M \\
\text { and } 9.0 \text { Intralink } 3.4 \text { of all new } \\
\text { parts. } \\
\text { - If the proposed change is adding a } \\
\text { new part for which a drawing or solid } \\
\text { model does not exist, the Contractor } \\
\text { shall provide a solid model and 2D } \\
\text { drawing of the entire affected } \\
\text { assembly/installation with their } \\
\text { package. }\end{array}$ & $\begin{array}{l}\text { 3D CAD models must be AutoCAD: } \\
\text {-have geometry positioned relative to } \\
\text { supplied origin (XO,YO,ZO). } \\
\text {-be created in accordance with 3D Level } \\
\text { of Detail CAD Modeling. } \\
\text {-use the layer key styles, system } \\
\text { definitions and routing preferences } \\
\text { contained within the supplied AutoCAD } \\
\text { template. } \\
\text {-have a maximum of } 50 \text { layers for } \\
\text { addititional bespoke model space objects. } \\
\text {-use supplied custom fittings catalogue. } \\
\text {-use the default names for structural } \\
\text { member styles. } \\
\text {-be saved showing a 'Top' (Plan) view of } \\
\text { the geometry. } \\
\text {-be saved on the Model Space tab. }\end{array}$ \\
\hline
\end{tabular}

Deviations from optimal internal operations (inside customers, suppliers or prime contractors) cause delays, rework, changes, increased cost and inefficient use of staffing resources

10 | "DISTRIBUTION STATEMENT A. Approved for public release; distribution is unlimited. Case Number 88ABW-2011-5822.

\section{Example Contract Requirements}

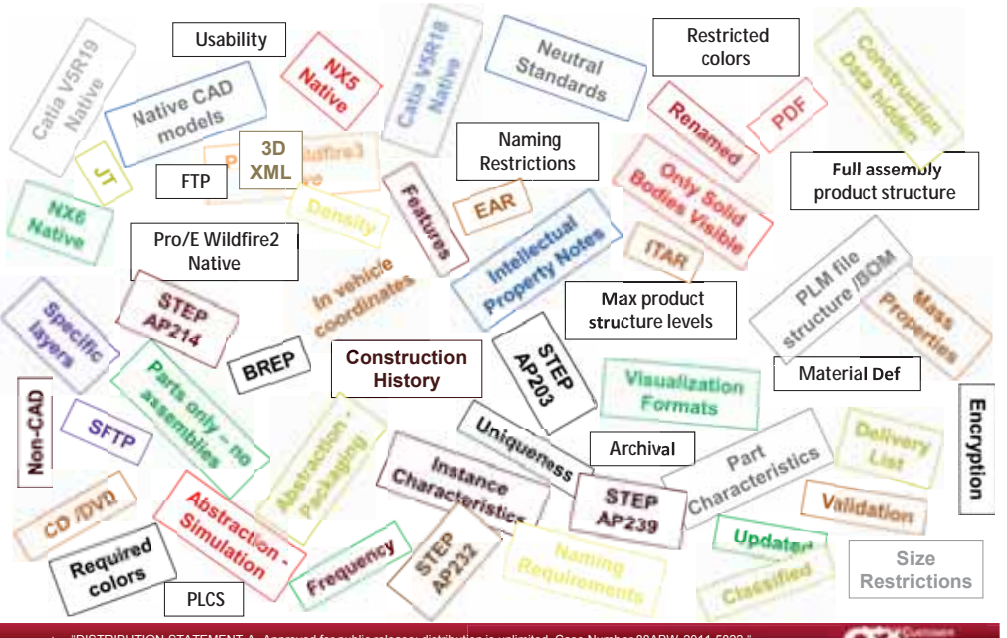

11 | "DISTRIBUTION STATEMENT A. Approved for public release; distribution is unlimited. Case Number 88ABW-2011-5822."

\section{F-35}

The $\mathrm{F}-35$ program has been used in CSI because it is typical of large, complex DoD programs.

Examples of CAD data interoperability issues and potential cost impacts:

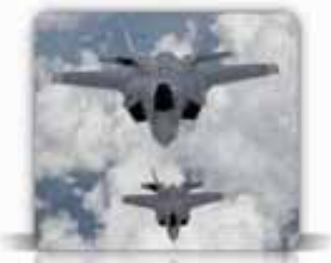

- Lockheed M artin Aero attempted to enforce CATIA V4 model delivery on F-35 SDRL's

- Response to bids by several suppliers showed an impact

in excess of \$1M for some suppliers - contract clause not invoked.

- Alternative approach - use STEP and/or take native models and convert at LM Aero

- Early design activity resulted in several hundred models being exchanged/year

- Lockheed Martin Aero heritage program impacts

- Several instances occurred over last 5 years on F-16 contracts where LM Aero was required to take complex designs in $\mathrm{NX}$ for conversion to V4 \& V5 for internal design activities (several hundred man hours for conversion/clean-up incurred)

- F-22 Tooling task requiring NX engine envelope model being converted to V4 (6 month conversion/cleanup task)

\section{Example Problem Areas and Estimated Cost}

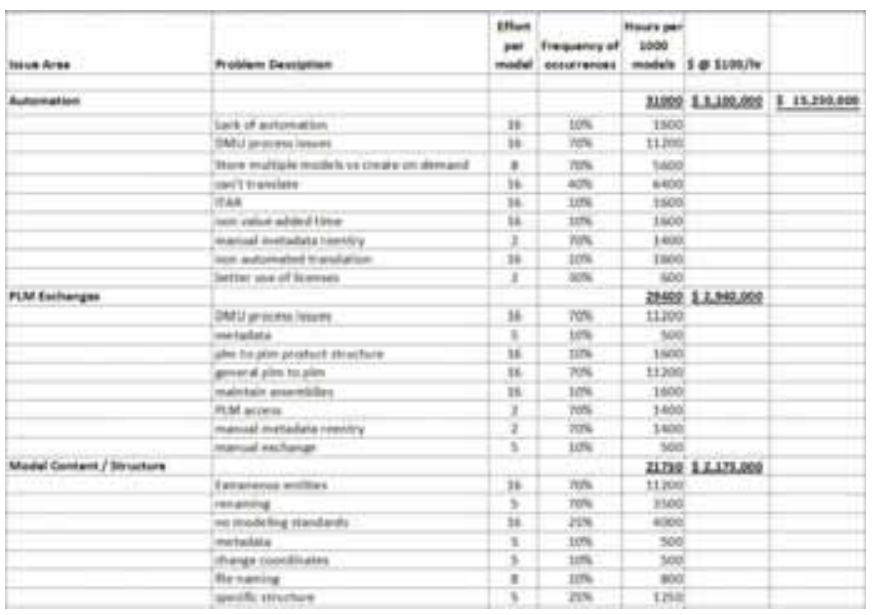




\section{Example Problem Areas and Estimated Cost}

\begin{tabular}{|c|c|c|c|c|}
\hline Neduen Nodel Sar. & & & & 1248013.300 .000 \\
\hline & 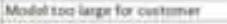 & is & ma & 112000 \\
\hline & 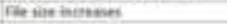 & 36 & ex & $\operatorname{sen}$ \\
\hline & Fetiontap &. & ats & $\infty 0$ \\
\hline \multirow[t]{8}{*}{ 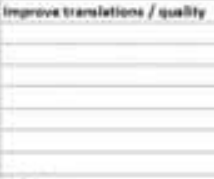 } & & & & 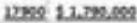 \\
\hline & adtiendrion & 3 & 200 & 1600 \\
\hline & Verzioi upsate enron. & 16 & 100 & 1000 \\
\hline & contilesing & it & $\cos$ & 6050 \\
\hline & 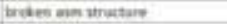 & 3 & 30 & $n 00$ \\
\hline & neints anembles: & 16 & 306 & $16000^{\circ}$ \\
\hline & mos unve adent tims & 3 & as & 1000 \\
\hline & 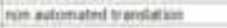 & $3 \mathrm{th}$ & $15 \mathrm{~s}$ & 1000 \\
\hline \multirow[t]{5}{*}{ velitation } & & & & 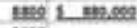 \\
\hline & Aat tivericion: & \# & 200 & 1000 \\
\hline & Vervion uppote ensen & it & $30 \mathrm{x}$ & 1600 \\
\hline & Co veditation ef meglier inates & 36 & ms & 4000 \\
\hline & Sot wais edsetting & is & 200 & 1600 \\
\hline \multirow{6}{*}{ othe } & & & & 2002,20009 \\
\hline & itak & 14 & sen & 1600 \\
\hline & Diementas & 3 & as & $1250^{\circ}$ \\
\hline & doulatere & $s$ & 200 & $\infty 0$ \\
\hline & 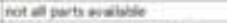 & 3 & 100 & 3600 \\
\hline & 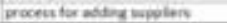 & 36 & $30 \mathrm{~s}$ & 1600 \\
\hline
\end{tabular}

Model Based Enterprise Capability Levels

Level 0: Model Centric Drawings for Design and Manufacturing All activity based upon a 20 drawing package throughout lifecycle - Level 1: Model Based Manufacturing

The $2 D$ drawing is master but manufacturing uses natural $C A D$ files Level 2: Native CAD Based Manufacturing

The $2 \mathrm{D}$ drawing is master but manufacturing uses native $C A D$ files -Level 3: Model Based Definition

The $3 D$ annotated CAD model is the master file for the enterprise

-Level 4: Model Based Definition With Data Management

The master $3 \mathrm{D}$ annotated $C A D$ model and viewable are delivered via PLM

-Level 5: Model Based Definition With Automated Technical Data Package Full digital product definition with associated TDP is delivered via PLM

-Level 6: MBD With Automated TDP and On Demand Enterprise Access Both the digital definition and TDP are delivered via the web in real time

\section{CSI Vision}

A flexible, configurable, standards based system which automates common tasks associated with Customer Supplier Interoperability

- Easily / quickly configurable to handle different contract requirements

- Leverages existing ITI technologies (DEXcenter, PDElib, CADscript, CADfix, CADIQ, etc)

- Supports typical requirements like:

- Model preparation

Removing / adding / hiding dat

Organization

Coordinate systems

Renaming

Abstraction / simplificatio

- Adding
Translation

Neutral standards (STEP, IGES)

CAD Native formats

- Visualizatio

- Validation

- Delivery

Geometry, topology, PMI

- Encrypted

- Encrypted

IP protection
- ITAR controls

ITAR controls
Direct (https web, sftp) or via PLM

- Tracking / auditing

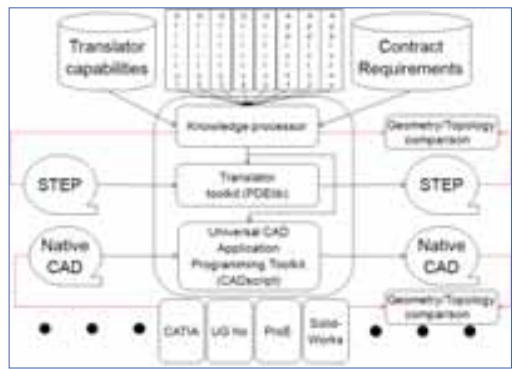

Cotern:
Existing Capabilities and Tools

- Standards

STEP AP203, AP214, AP232, AP239

CAD vendor STEP translator support

- ITIDEXcenter / CADIQ

Existing flexible, highly configurable automation framework

- Database driven

- Workflow engine

Translations with automated validation

Delivery

- https, sttp, ftp

Security, encryption, tracking

Regulatory compliance

- ITI PDElib toolkit

Toolkit for working with standards (STEP, IGES, DXF)

Conversions between various formats

Geometry manipulation

- ITI CADscript toolkit

Abstracted CAD API access

Generalized functions which can access enabled CAD systems

Read data from native CAD models

Modify data in native CAD models

- ITI Proficiency direct Feature Based Translator

Translate between CAD systems while maintaining features

Convert 3D Model plus associated drawing to MBD PMI

- ITI CADfix

Direct BREP translation

Proficiency

CADIQ

DeXcenter

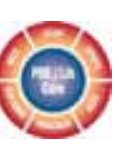

$\sum_{\text {Pots }}$

axen:

17 | "DISTRIBUTION STATEMENT A. Approved for public release; distribution is unlimited. Case Number 88ABW-2011-5822."

\section{Scenario With Automated System}

- System components

- Database (Unique contract options/workflows)

- Workflow engine

- CAD translators (CAD neutral, direct)

- Validation software

- Model Preparation components developed per CSI
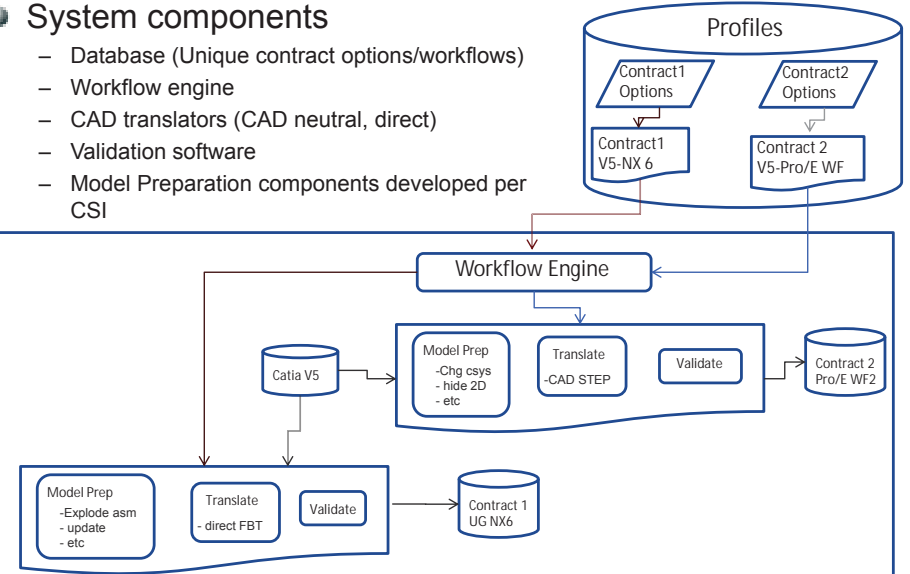

\section{Example Demonstration Scenario (High level view)}

Original Process (High Level Summary)

8 = Requires Human Interaction

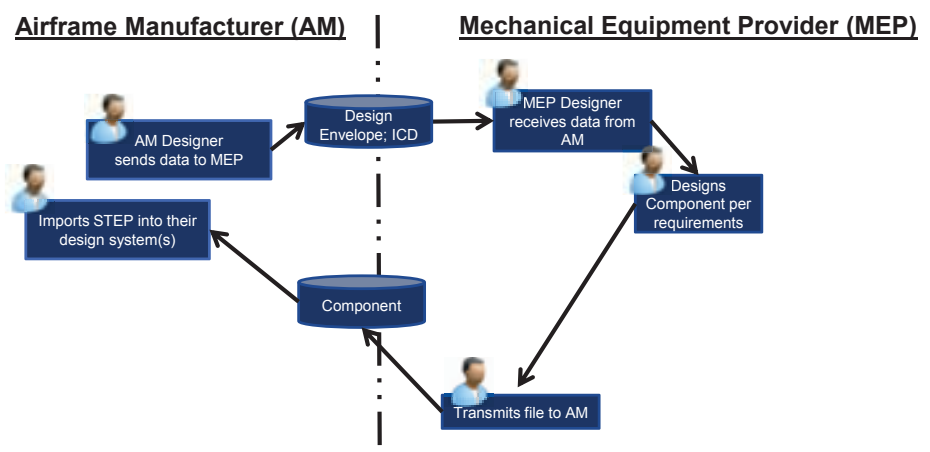




\section{Example Demonstration Scenario (Detail view)}

Original Process (Detailed)

$\$=$ Requires Human Interaction

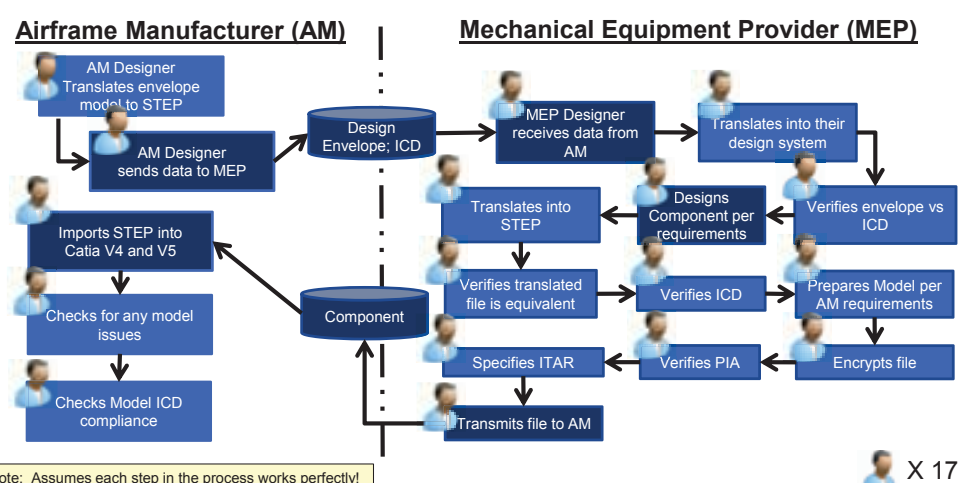

*Note: Assumes each step in the process works perfectly!

$8 \times 17$

\section{Example Demonstration Scenario (Detail view)}

\section{CSI PROCESS}

S = Requires Human Interaction $8=$ Automated by CSI

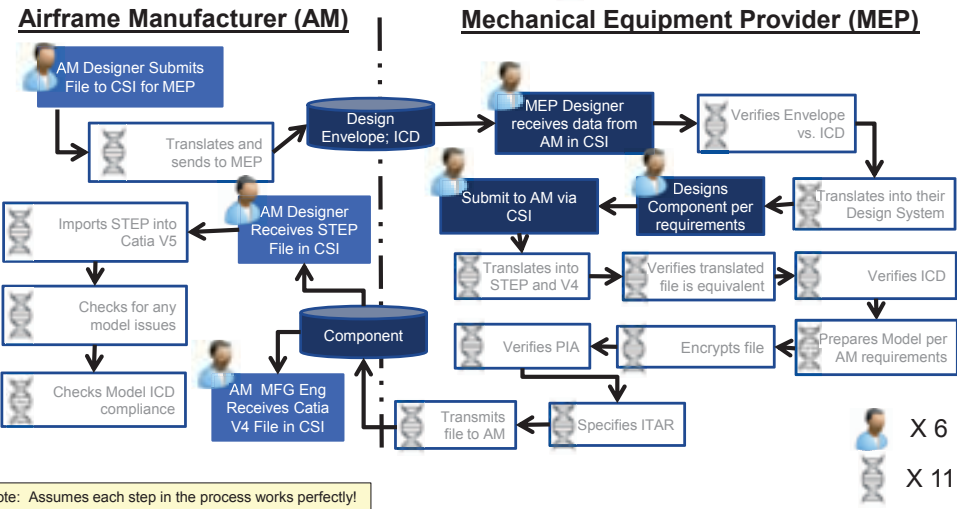

"Note: Assumes each step in the process works perfectly!

22 | "DISTRRBUTION STATEMENT A. Approved for public release; distribution is unilinited. Case Number 88ABW-2011-5822"

Qx:
Video Demonstration of CSI developed technology Lockheed Martin - Honeywell Typical Data Exchange

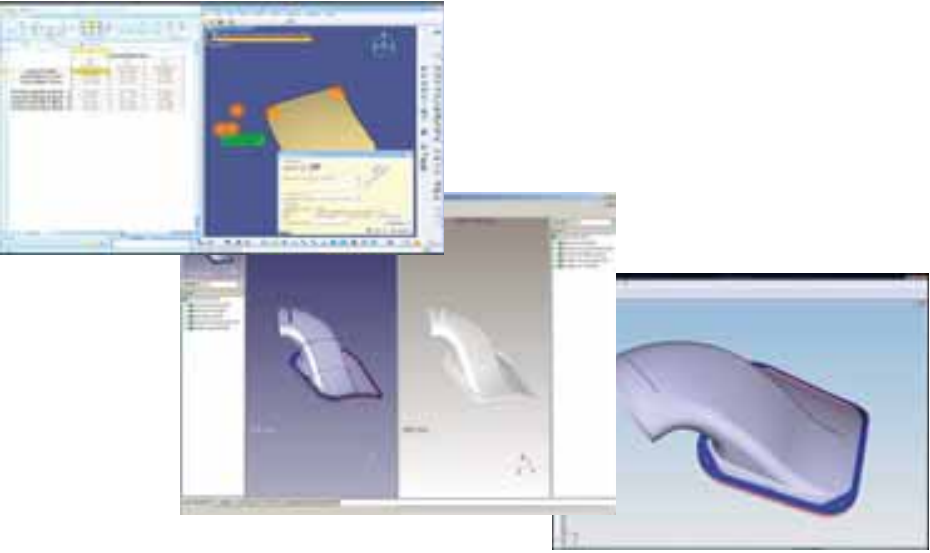

21 | "DISTRIBUTTON STATEMENT A.Approved for public release; distribution is unilinited. Case Number 8BABW-2011-5822.

Q6:-
Video Demonstration of CSI developed technology Lockheed Martin - Rockwell Collins Model Simplification

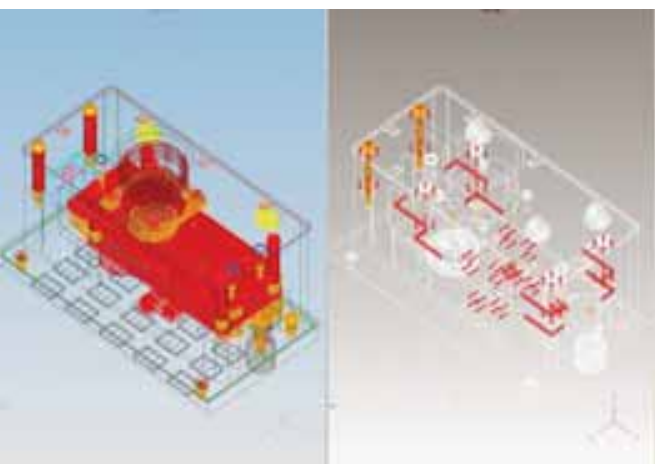

Simplification Demonstration Scenario

$$
\text { Gequires Human Interaction } \& \text { = Automated by CSI }
$$

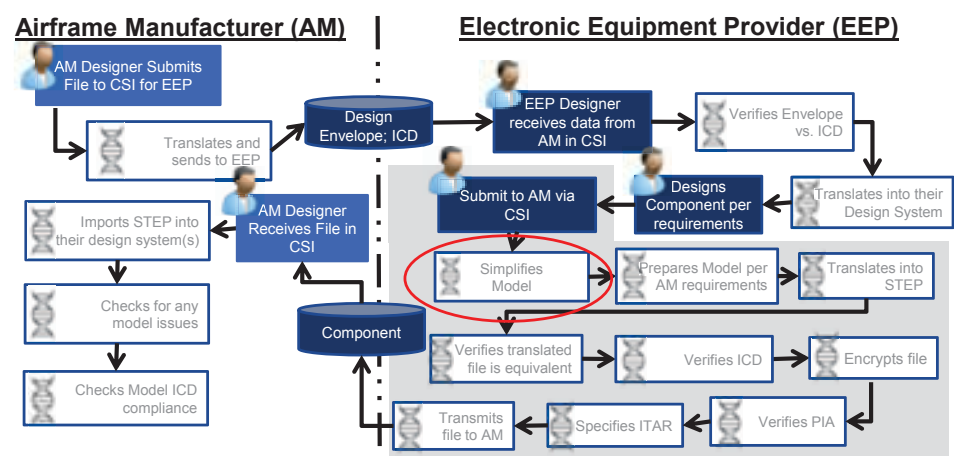

\section{CSI Demonstrated Savings - Phase 1 Results}

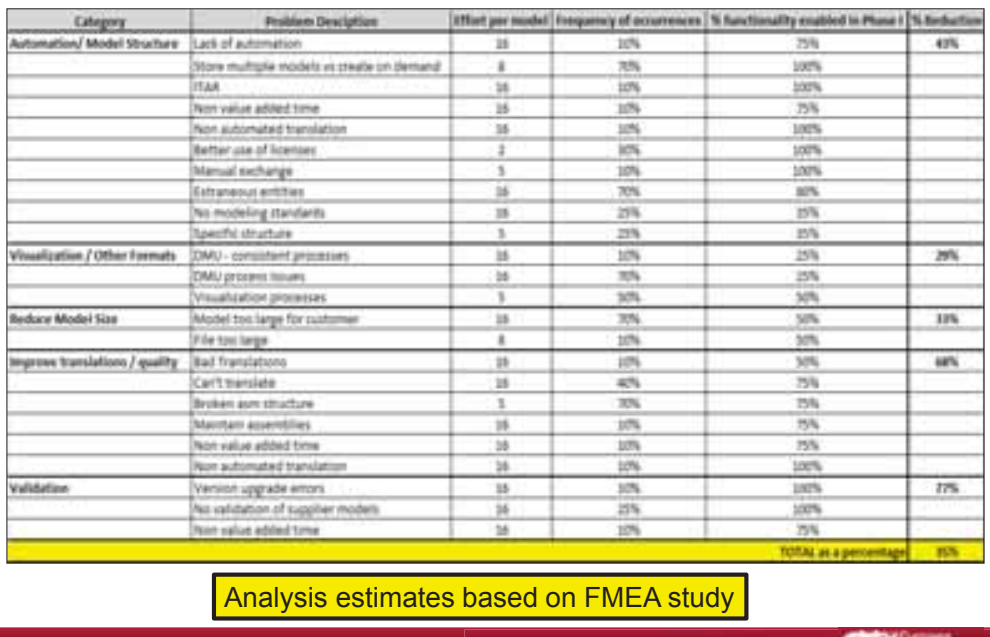


Basis for ITI estimated savings on F-35 program

- Program phases

- Initial design

- Detail design

- Support

- Number of file exchanges per month from prime to tier 1 suppliers based on phase

- Initial design - 250

Detail design - 2500-4000

- Production - 2500

- Support-625

- Categories of Tier 1 suppliers

- Suppliers with design responsibility

- Suppliers with manufacturing responsibility (build to print or build to spec)

Transactions per file based on type of supplier:

- Design responsibility (6 transactions)

- 1 exchange from prime

1 exchange to prime

1 exchange from (2) tier-2 suppliers

Manufacturing responsibility (4 transactions)

- 1 exchange from prime

1 exchange to (1) tier-2 supplier

- 1 exchange from (1) tier-2 supplier

Savings per file per transaction .35 hours from CSI demonstration

$\$ 100$ per hour labor rate

\title{
Other benefits
}

- Delivering systems to field quicker (\$??)

- Improved reliability through a controlled, repeatable process (\$??)

CSI Team Brain Storming Concept Synthesis - MBE Model

Generation, Maintenance and Interoperability

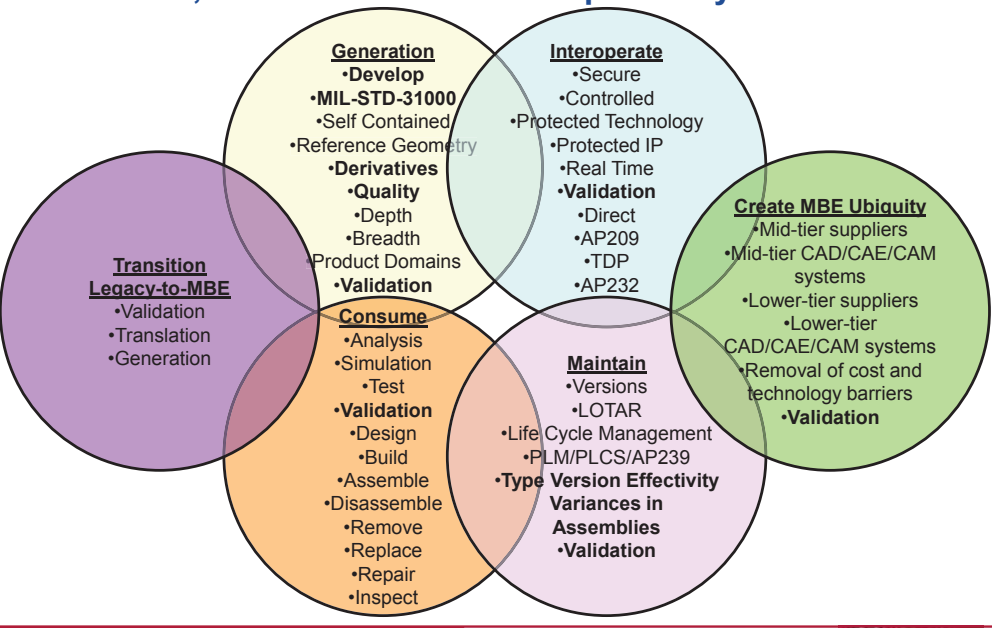

CSI Demonstrated Savings (ITI generated analysis)

CSI Demonstrated Savings Applied Over Life of Program (Based on F-35 Estimated Exchanges)

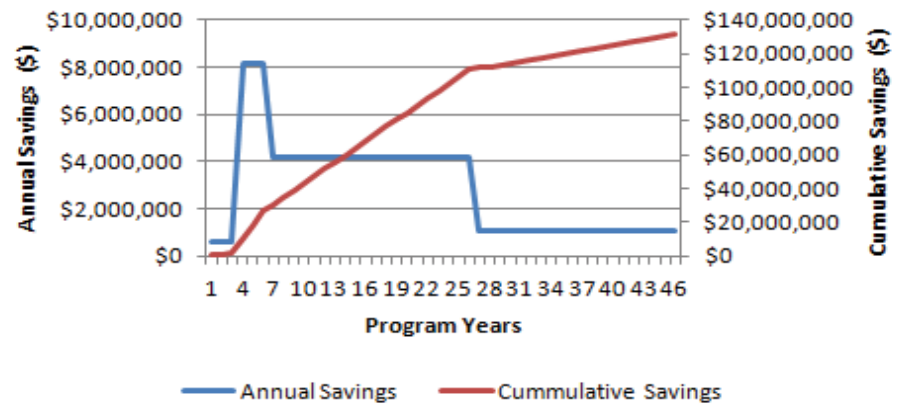

Savings based on functions developed in Phase 1, integrated into CSI platform and deployed throughout supply chain

27 | "DISTRIBUTION STATEMENT A. Approved for public release; distribution is unlimited. Case Number 88ABW-2011-5822"

Q6ers:
Accelerating MBE deployment - CSI contract addendums
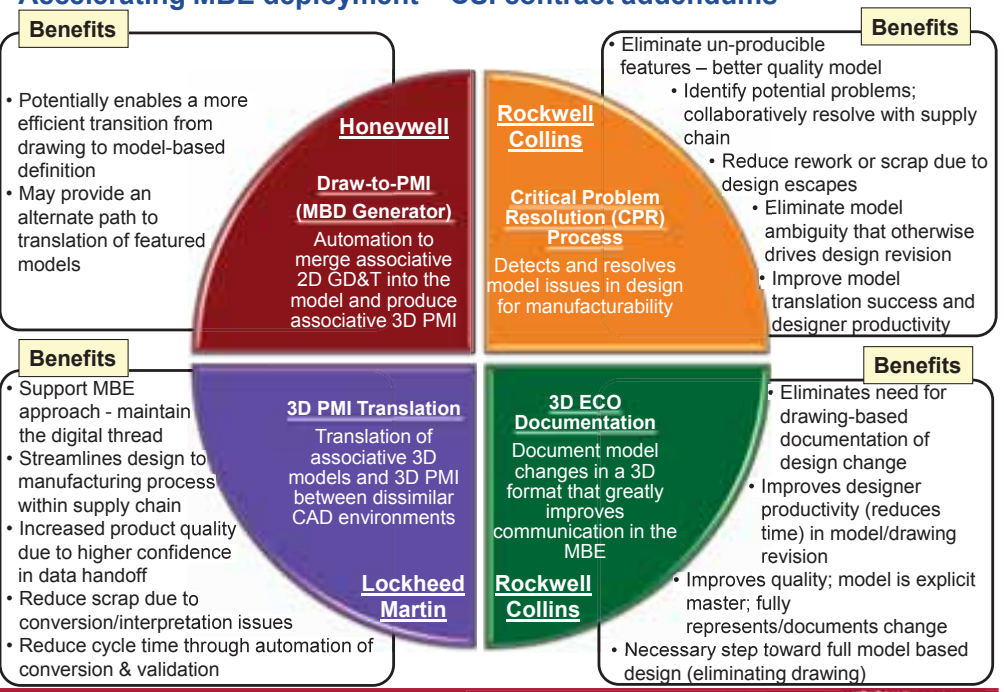

(e)ters:

\section{Questions?}

\author{
For More Information: \\ - http://www.transcendata.com \\ - john.gray@transcendata.com
}

